\author{
UNIVERSIDADE DE SÃO PAULO \\ ESCOLA DE ENGENHARIA DE SÃO CARLOS
}

Ellon Bernardes de Assis

\title{
ANÁLISE NUMÉRICA DA FIXAÇÃO DE ESCADAS PRÉ-MOLDADAS LEVES EM ALVENARIA ESTRUTURAL SOB INCÊNDIO
}

São Carlos 

Ellon Bernardes de Assis

\title{
ANÁLISE NUMÉRICA DA FIXAÇÃO DE ESCADAS PRÉ-MOLDADAS LEVES EM ALVENARIA ESTRUTURAL SOB INCÊNDIO
}

Dissertação apresentada à Escola de Engenharia de São Carlos da Universidade de São Paulo, para obtenção do título de Mestre em Ciências - Programa de Pós-Graduação em Engenharia Civil (Engenharia de Estruturas).

Área de concentração: Estruturas

Orientador: Prof. Dr. Jorge Munaiar Neto

\section{VERSÃO CORRIGIDA}

\author{
São Carlos
}


AUTORIZO A REPRODUÇÃO TOTAL OU PARCIAL DESTE TRABALHO, POR QUALQUER MEIO CONVENCIONAL OU ELETRÔNICO, PARA FINS DE ESTUDO E PESQUISA, DESDE QUE CITADA A FONTE.

Ficha catalográfica elaborada pela Biblioteca Prof. Dr. Sérgio Rodrigues Fontes da EESC/USP com os dados inseridos pelo(a) autor(a).

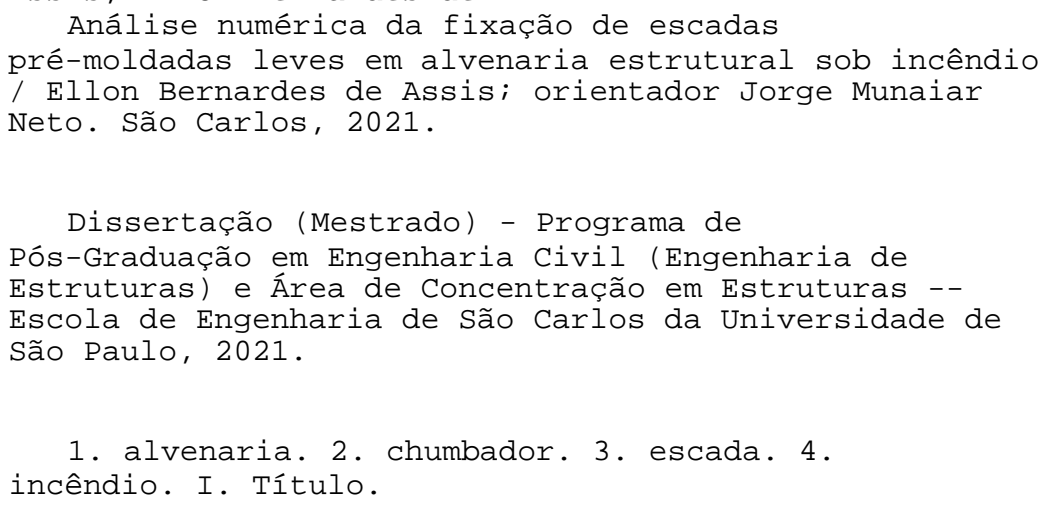

1. alvenaria. 2. chumbador. 3. escada. 4. incêndio. I. Título.

Eduardo Graziosi Silva - CRB - 8/8907 


\section{FOLHA DE JULGAMENTO}

Candidato: Engenheiro ELLON BERNARDES DE ASSIS.

Título da dissertação: " Análise numérica da fixação de escadas prémoldadas leves em alvenaria estrutural sob incêndio".

Data da defesa: 11/05/2021.

\section{Comissão Julgadora}

Prof. Associado Jorge Munaiar Neto

(Orientador)

(Escola de Engenharia de São Carlos - EESC/USP)

Prof. Dr. Roberto Marcio da Silva

(Universidade Federal de Minas Gerais/UFMG)

Prof. Dr. Douglas Barreto

(Universidade Federal de São Carlos/UFSCar)
Resultado

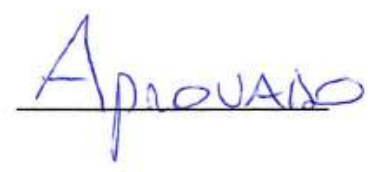

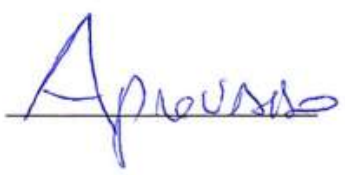

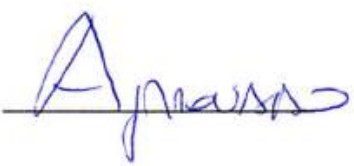

Coordenador do Programa de Pós-Graduação em Engenharia Civil (Engenharia de Estruturas):

Prof. Associado Vladimir Guilherme Haach

Presidente da Comissão de Pós-Graduação:

Prof. Titular Murilo Araujo Romero 

Dedico a todos aqueles inconformados

com respostas simplórias mas encantados com a beleza das respostas simples. 



\section{AGRADECIMENTOS}

A Deus que a todo momento me sustenta e me dá as forças que não tenho.

À Jéssica Ribeiro, por ter sonhado junto comigo e ajudado a tornar esse projeto uma realidade. Obrigado por me dar forças nas horas difíceis através do seu carinho, inteligência e companheirismo.

Aos meus pais, Eliseu e Maria Neusa, agradeço pela confiança e por me apoiar sempre. Agradeço pelo valor que deram para minha educação. São um exemplo de força a ser seguido.

Ao meu querido irmão, Eliseu Henrique, sua amizade renova as minhas energias e me deixa muito mais feliz.

Ao meu orientador, Jorge Munaiar Neto, agradeço pela disposição na orientação, preocupação sincera e confiança depositada em mim.

Aos professores Vladimir Haach, Márcio Corrêa, Roberto Marcio e Douglas Barreto pelas contribuições durante o exame de qualificação e na defesa da dissertação.

Aos professores e funcionários do Departamento de Engenharia de Estruturas da EESC-USP, pelo carinho e apoio excepcionais direcionados aos alunos.

Ao Conselho Nacional de Desenvolvimento Científico e Tecnológico pelo auxílio financeiro.

Ao Roberto Cyrino, pela ajuda extremamente carinhosa na chegada em São Carlos.

Aos amigos conquistados até aqui pelo apoio e companheirismo, especialmente em momentos difíceis.

Aos parceiros de mestrado pela amizade, trabalhar com vocês me inspira a ser cada vez melhor. 

"Ces recherches ont été jusqu'à présent plus utiles aux progrès des mathématiques qu'au perfectionnement de l'art des constructions. La plupart des constructeurs déterminent les dimensions des parties des édifices ou des machines d'après les usages établis, et l'exemple des ouvrages existans; ils se rendent compte rarement des efforts que ces parties supportent, et des résistances qu'elles opposent. Cela présent peu d'inconvéniens lorsque les ouvrages que l'on exécute ressemblent à ceux que l'on a fait de tout temps, et ne s'écartent pas, dans les dimensions et dans les poids, des limites accoutumées. Mais on ne peut plus en user de lat mème manière lorsque les circonstances obligent à sortir de ces limites, ou lorsqu'il s'agit d'édifices d'un genre nouveau, et sur lesquels l'expérience n'a rien appris. L'objet des ces Résumés est d'exposer les conditions de l'établissement des constructions queles ingénieurs dirigent, et de mettre à mème de vérifier le degré de résistance de chacune de leurs parties." 



\title{
RESUMO
}

\author{
ASSIS, E. B. de ANÁLISE NUMÉRICA DA FIXAÇÃO DE ESCADAS \\ PRÉ-MOLDADAS LEVES EM ALVENARIA ESTRUTURAL SOB \\ INCÊNDIO. 2021. 149p. Dissertação (Mestrado em Engenharia Civil (Engenharia de \\ Estruturas)) - Escola de Engenharia de São Carlos, Universidade de São Paulo, São \\ Carlos, 2021.
}

As escadas pré-moldadas leves de concreto são compostas de degraus e vigas denteadas pré-moldadas com peso adequado para manuseio manual. O seu uso é difundido como um meio de racionalização da construção. Por outro lado, há uma preocupação acerca do desempenho da alvenaria estrutural em situação de incêndio o que vem motivando uma série de estudos com objetivo de subsidiar uma futura normalização brasileira. Nesse contexto, surge a preocupação sobre a segurança estrutural em situação de incêndio desse tipo de escada em conjunto com a alvenaria estrutural. As vigas pré-moldadas são fixadas à alvenaria através de chumbadores de aço, no entanto, existem poucos trabalhos acerca do comportamento de chumbadores em elementos de alvenaria estrutural. Ainda mais, são poucos os trabalhos que tratam do comportamento de chumbadores em situação de incêndio seja em concreto ou em alvenaria. Assim, esse trabalho contribui para o tema apresentando um conjunto de simulações utilizando o Método dos Elementos Finitos para avaliar o desempenho do sistema de fixação de escadas pré-moldadas em situação de incêndio. Foram realizadas simulações estruturais, térmicas e termoestruturais do sistema quando exposto ao incêndio padrão ISO 834-1:1999 na face da alvenaria oposta à escada. Os resultados obtidos indicam que o uso de grauteamento no bloco em que o chumbador se ancora limita significativamente a elevação de temperatura. Além disso, não há elevação de temperatura significativa na viga denteada. No exemplo estudado não foi possível constatar um modo de ruptura do chumbador em si antes da ruptura da alvenaria. Os resultados apresentados são um ponto de partida para novas simulações que estudem outros exemplos bem como trabalhos experimentais no tema.

Palavras-chave: alvenaria; chumbador; escada; incêndio. 

ASSIS, E. B. de NUMERICAL ANALYSIS OF LIGHTWEIGHT PRECAST STAIRS FASTENING IN STRUCTURAL MASONRY ON FIRE. 2021. 149p. Dissertation (M. Sc. in Civil Engineering (Structural Engineering)) - São Carlos School of Engineering, University of São Paulo, São Carlos, 2021.

Lightweight precast concrete stairs are build of precast stair steps and indented beams which have appropriate weight for manual working. Its usage is a widespread practice as a way of rationalization of construction. On the other hand, there is a concern about the performance of structural masonry on fire situation, which has motivated a series of studies aiming a future Brazilian standardization. In this context, there is some concern about the structural fire safety of this type of stair applied to structural masonry. These indented beams are fastened to the masonry using steel anchors, however, there is little work on the behavior of fasteners in structural masonry elements. Furthermore, there are few works that deal with the behavior of fasteners in fire situations, whether in concrete or masonry. Thus, this work contributes to the topic by carrying out a set of simulations using the Finite Element Method to evaluate the performance of the fastening system of lightweight precast stairs under fire situation. Structural, thermal and thermo-structural simulations of the system were performed when exposed to the ISO 834-1:1999 standard fire in the face of the wall opposite to the stairs. Results indicate that grouting in the block's cavity which the fastener is anchored limits the temperature rise in the fastener. Besides, there is no significant temperature rise in the indented beam. In the example of the study, it was not possible to see a failure mechanism of the fastener itself before the masonry failure. The results shown are a start point for new simulations that tackle new examples as well as experimental studies.

Keywords: masonry; fastener; stairs; fire. 



\section{LISTA DE SÍMBOLOS}

\begin{tabular}{|c|c|}
\hline$D_{n o m}$ & Diâmetro nominal de chumbador \\
\hline$D_{e f}$ & Diâmetro efetivo de chumbador \\
\hline$f_{y}$ & Tensão de escoamento do aço \\
\hline$f_{u}$ & Tensão de ruptura aço \\
\hline$\varepsilon_{u}$ & Deformação na ruptura \\
\hline$f_{c}$ & Tensão de ruptura à compressão do concreto \\
\hline$\sigma_{N}$ & Tensão nominal \\
\hline$\varepsilon_{N}$ & Deformação nominal \\
\hline$\sigma_{T}$ & Tensão verdadeira \\
\hline$\varepsilon_{T}$ & Deformação verdadeira \\
\hline$\varepsilon_{T}^{\text {plastic }}$ & Parcela plástica da deformação verdadeira \\
\hline$\psi$ & Ângulo de dilatância no modelo Concrete Damaged Plasticity \\
\hline$\epsilon$ & Excentricidade no modelo Concrete Damaged Plasticity \\
\hline$K$ & $\begin{array}{l}\text { Parâmetro que controla a forma da superfície plastificação no modelo } \\
\text { Concrete Damaged Plasticity }\end{array}$ \\
\hline$\mu$ & $\begin{array}{l}\text { Viscosidade para regularização viscoplástica no modelo Concrete Da- } \\
\text { maged Plasticity }\end{array}$ \\
\hline$f_{b 0}$ & Resistência a compressão inicial em estado de compressão biaxial \\
\hline$f_{c 0}$ & Resistência a compressão inicial em estado uniaxial \\
\hline$f_{c t m}$ & Tensão de ruptura à tração do concreto \\
\hline$E_{c}$ & Módulo de Young do concreto \\
\hline$G_{f}$ & Energia de fratura do concreto \\
\hline$f_{c i l}$ & $\begin{array}{l}\text { Resistência à compressão do concreto a partir de ensaios em corpos de } \\
\text { prova cilíndrico }\end{array}$ \\
\hline
\end{tabular}




\begin{tabular}{|c|c|}
\hline$f_{\text {cubo }}$ & $\begin{array}{l}\text { Resistência à compressão do concreto a partir de ensaios em corpos de } \\
\text { prova cúbico }\end{array}$ \\
\hline$D_{a g}$ & Diâmetro máximo do agregado graúdo no concreto \\
\hline$d_{t}$ & Dano à tração \\
\hline$d_{c}$ & Dano à compressão \\
\hline$\sigma_{c}$ & Tensão de compressão \\
\hline$\sigma_{t}$ & Tensão de tração \\
\hline$w_{\text {fis }}$ & Abertura de fissura no concreto em ensaio de tração \\
\hline$\mu$ & Coeficiente de atrito de Coulomb \\
\hline$E_{s}$ & Módulo de Young do aço \\
\hline$\nu$ & Coeficiente de Poisson \\
\hline$u_{z}$ & Deslocamento na direção Z \\
\hline$\theta_{x}$ & Rotação em torno do eixo X \\
\hline$\theta_{y}$ & Rotação em torno do eixo Y \\
\hline$\theta_{z}$ & Rotação em torno do eixo Z \\
\hline$\varepsilon_{z}$ & Deformação na direção Z \\
\hline$\Delta t_{\text {est }}$ & Incremento de tempo estável na análise explícita no tempo \\
\hline$f_{b k}$ & Resistência característica à compressão do bloco em sua área bruta \\
\hline$f_{b}$ & Resistência à compressão do bloco em sua área bruta \\
\hline$\varepsilon_{c 1}$ & $\begin{array}{l}\text { Deformação à compressão no pico da curva tensão-deformação segundo } \\
\text { EN 1992-1-1:2004 }\end{array}$ \\
\hline$\varepsilon_{c u 1}$ & Deformação última à compressão segundo EN 1992-1-2:2004 \\
\hline$F_{z}$ & Força na direção Z aplicada pela chapa de carregamento \\
\hline$F_{r}^{c h u m b}$ & Força cortante de ruptura do chumbador \\
\hline$F_{s}$ & Força cortante solicitante no chumbador \\
\hline$\alpha$ & Coeficiente de expansão térmica \\
\hline$\alpha_{c}$ & Coeficiente de transferência de calor por convecção \\
\hline
\end{tabular}


Emissividade da superfície

$\rho_{a} \quad$ Massa específica do aço

$\sigma_{\text {rup }}^{\text {painel }} \quad$ Tensão de ruptura na área bruta do painel de alvenaria

$\sigma_{s}^{\text {painel }}$ Tensão solicitante na área bruta do painel de alvenaria na ocasião de incêndio

$\sigma_{z} \quad$ Tensão na direção Z

$\alpha_{a c ̧ o} \quad$ Coeficiente de expansão térmica do aço

$\alpha_{\text {conc }} \quad$ Coeficiente de expansão térmica do concreto

$M_{x} \quad$ Momento em torno do eixo X

$\sigma_{x} \quad$ Tensão na direção $\mathrm{X}$

$M_{z} \quad$ Momento em torno do eixo Z 



\section{SUMÁRIO}

INTRODUÇÃO $\ldots \ldots \ldots \ldots \ldots \ldots \ldots \ldots \ldots \ldots$

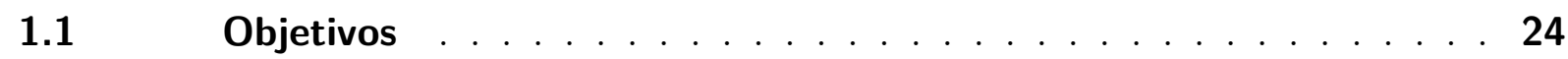

$1.1 .1 \quad$ Objetivo geral . . . . . . . . . . . . . . . . . . . . 24

$1.1 .2 \quad$ Objetivos específicos . . . . . . . . . . . . . . . . . 24

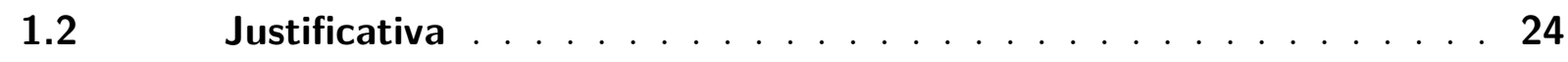

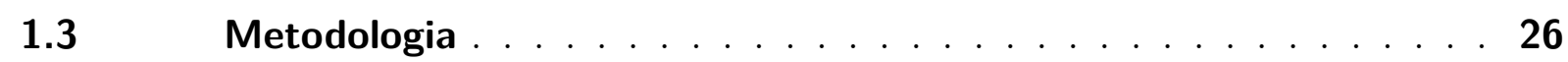

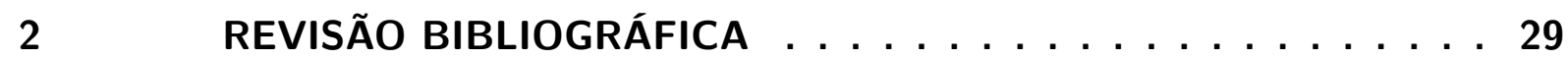

2.1 Segurança das estruturas em situação de incêndio . . . . . . . . 29

$2.2 \quad$ Alvenaria estrutural em situação de incêndio . . . . . . . . . . 32

2.3 Sistemas de fixação em concreto e alvenaria . . . . . . . . . . . . 34

2.4 Escadas pré-moldadas leves em edifícios de alvenaria estrutural . . . 38

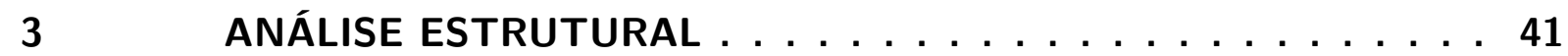

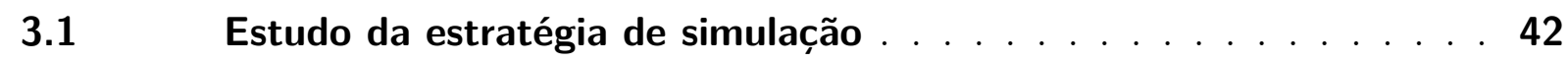

$3.1 .1 \quad$ Modelos constitutivos . . . . . . . . . . . . . . . 43

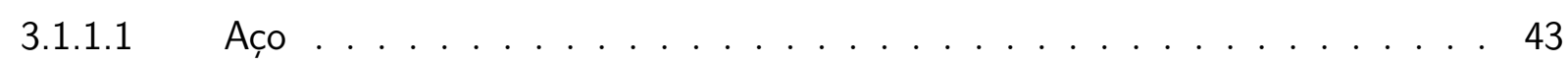

3.1.1.2 Concreto . . . . . . . . . . . . . . . . . . 44

3.1.2 Características geométricas e de análise . . . . . . . . . . . 47

3.1.3 Resultados e Análise . . . . . . . . . . . . . . . . . . . 51

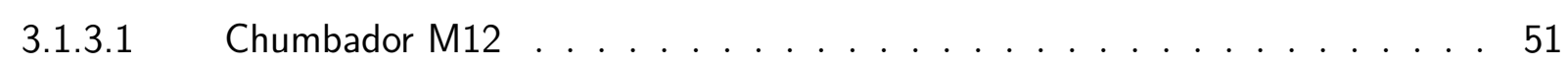

3.1.3.2 Chumbador M16 . . . . . . . . . . . . . . . . . 57

3.1.3.3 Análise da estratégia dinâmica explícita . . . . . . . . . . . 60

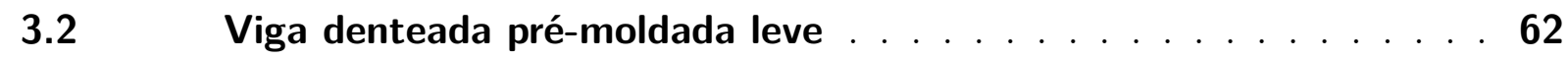

3.2.1 Resultados e Análise . . . . . . . . . . . . . . . . . . 67

3.3 Chumbador em painel de alvenaria de concreto . . . . . . . 71

3.3.1 Características geométricas e de análise . . . . . . . . . . . 71

3.3.2 Propriedades dos materiais . . . . . . . . . . . . . . . 75

3.3.3 Resultados e Análise . . . . . . . . . . . . . . . . . . . . . 79

4 ANÁLISE TÉRMICA $\ldots \ldots \ldots \ldots \ldots \ldots$

$4.1 \quad$ Estudo da estratégia de simulação $\ldots \ldots \ldots \ldots \ldots$

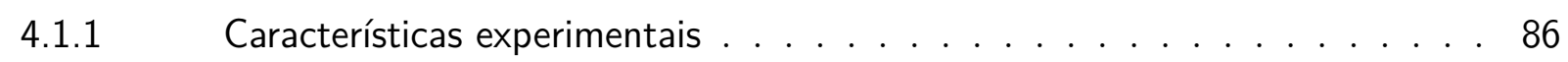

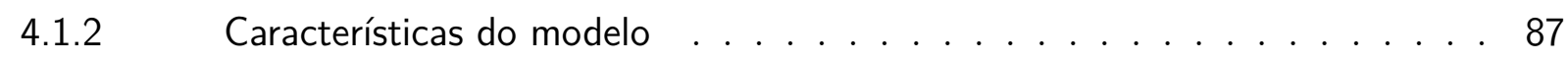

$4.1 .3 \quad$ Resultados e Análise . . . . . . . . . . . . . . . . . . . . 91

4.1.3.1 Bloco sob fogo em todas as faces laterais . . . . . . . . . . . . 92 
4.1.3.2 Bloco sob fogo em uma face . . . . . . . . . . . . . . . . . . . . 98

$4.2 \quad$ Chumbador em painel de alvenaria de concreto . . . . . . . . 103

$4.2 .1 \quad$ Resultados e Análise . . . . . . . . . . . . . . . . . . . . 104

5 ANÁlISE TERMOESTRUTURAL . . . . . . . . . . . 109

$5.1 \quad$ Características geométricas e de análise . . . . . . . . . . . 109

5.2 Modelos Constitutivos . . . . . . . . . . . . . . . 111

$5.3 \quad$ Resultados e Análise . . . . . . . . . . . . . . . . . . 114

6 CONSIDERAÇÕES FINAIS . . . . . . . . . . . . . 119

6.1 Sugestões para trabalhos futuros . . . . . . . . . . 121

REFERÊNCIAS . . . . . . . . . . . . . . . 123

APÊNDICES

APÊNDICE A - GRÁFICOS DE ENERGIA . . . . . . . . . . 131

A.1 Balanço de energia . . . . . . . . . . . . . . . . 131

A.2 Análise Estrutural . . . . . . . . . . . . . . . . . . 132

A.3 Análise Termoestrutural . . . . . . . . . . . . . . . . . . 133

APÊNDICE B - BANCO DE RESULTADOS - ANÁLISE TERMOESTRUTURAL . . . . . . . . . . . . . . 135

B.1 Caso 1 - Faces $+\mathbf{X}$ e -X livres . . . . . . . . . . . . . 135

B.2 Caso 2 - Faces $+\mathrm{X}$ e $-\mathrm{X}$ restritas $\ldots \ldots \ldots \ldots$

B.3 Caso 3 - Face $+\mathrm{X}$ restrita e Face $-\mathrm{X}$ livre $\ldots \ldots 142$

APÊNDICE C - CUSTO COMPUTACIONAL DAS SIMULAÇÕES 147 


\section{INTRODUÇÃO}

O uso da alvenaria estrutural como método construtivo traz um conjunto de vantagens as quais vem motivando o seu uso em edifícios de vários pavimentos. Esse sistema construtivo proporciona uma maior racionalização e industrialização da construção, fatores que tem impacto direto no custo da obra (PARSEKIAN; MEDEIROS; SIPP, 2018). Por outro lado, o uso de elementos pré-moldados de concreto em conjunto com a alvenaria estrutural potencializa a sua característica de obra com maior grau de racionalização. Entre os elementos pré-moldados utilizados em conjunto com a alvenaria estrutural pode-se citar escadas, vergas, lajes entre outros.

Nesse contexto, a Figura 1.1 mostra o uso de escada pré-moldada formada de peças leves conhecida como escada "jacaré". Essa escada é composta de peças leves de argamassa armada, as quais são dimensionadas de forma que seja possível sua montagem sem uso de equipamentos de içamento. A escada é composta de vigas denteadas conhecidas como vigas "jacaré" as quais são fixadas na parede de alvenaria através de chumbadores metálicos. As vigas denteadas por sua vez servem de suporte para os degraus que são assentados sobre ela (MAMEDE, 2001; ANDRADE; MAMEDE, 2012).

Figura 1.1 - Exemplo de fixação de escada leve pré-moldada

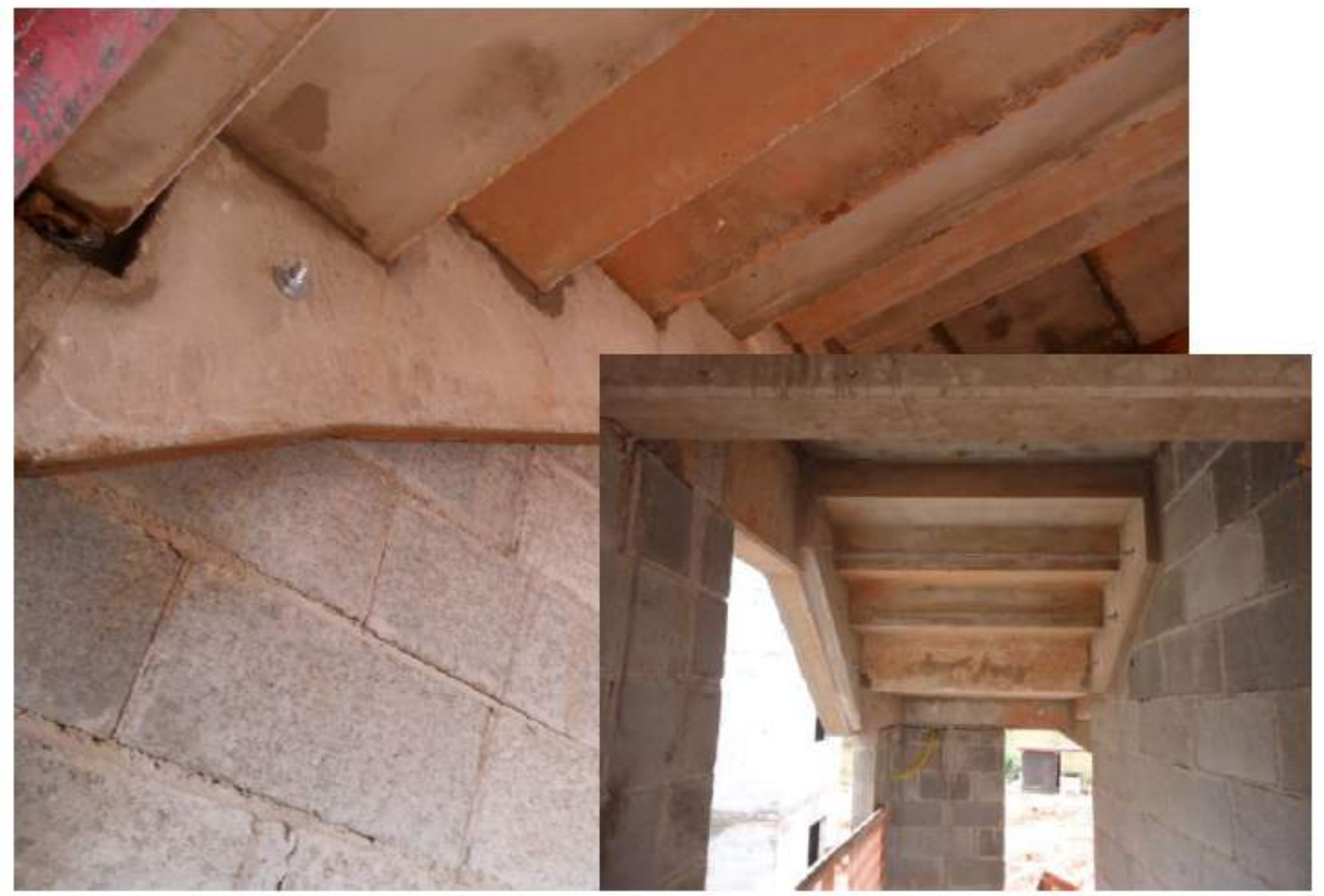

Fonte: Porto Ferraz Construtora (2012) 
Percebe-se que nesse exemplo da escada "jacaré", o chumbador desempenha função estrutural crítica para a segurança da escada. Recomenda-se que os blocos de alvenaria que recebem os chumbadores sejam grauteados e devem haver indicações claras de suas posições no projeto de alvenaria (MAMEDE, 2001; NETTO, 2016).

Assim como na escada leve pré-moldada, os sistemas de fixação são amplamente utilizados na engenharia. No Brasil, costuma-se denominar elementos de fixação discretos em base de concreto ou alvenaria como chumbadores. Chumbadores metálicos são os mais utilizados, de forma geral eles podem ser classificados como pré-instalados ou pós-instalados. Os chumbadores pré-instalados são posicionados no elemento antes da concretagem, desenvolvendo assim o seu mecanismo de ancoragem após a cura do concreto. Já os pósinstalados são posicionados após a concretagem através de um furo sendo que diferentes meios de ancoragem podem ser desenvolvidos a depender do tipo de chumbador. Esses sistemas são utilizados em conexões entre estruturas de aço e concreto, fixação de elementos acessórios na estrutura tais como curtain-walls, entre outros.

Percebe-se então que na análise da escada leve pré-moldada de concreto o seu sistema de fixação em si é um tema transversal de importância na engenharia de estruturas. Cabe destacar ainda que na aplicação estrutural de sistemas de fixação, inúmeras vezes esses pontos de fixação são críticos para estabilidade, como no caso da escada leve prémoldada, podendo levar a rupturas frágeis. Apesar disso, há falta de trabalhos na literatura que tratem de desempenho desse sistema nas escadas ancoradas em alvenaria.

Por outro lado, o desempenho de edificações em situação de incêndio é um tema de relevância em segurança estrutural. Incêndios importantes na história mundial e brasileira mostram que a desconsideração de efeitos térmicos na estrutura pode levar a rupturas prematuras e consequentemente perdas econômicas e humanas. Existe uma preocupação sobre o desempenho da alvenaria estrutural em situação de incêndio, pesquisas recentes mostram que pode haver grande redução de resistência da alvenaria pós-fogo (DUPIM, 2019). Deve-se levar em conta também o uso crescente da alvenaria estrutural em edifícios altos, situação na qual há grande necessidade de avaliação do desempenho estrutural em incêndio. A ausência de normas de projeto brasileiras que contemplem a ação do fogo nas estruturas de alvenaria estrutural evidencia a lacuna existente nessa linha de pesquisa.

Dentre os vários casos de incêndios em edifícios, destaca-se uma explosão seguida de incêndio devido a vazamento de gás em um Conjunto do CDHU na Zona Leste de São Paulo em 2008. Esse sinistro provocou dano especialmente na escada do edifício dificultando a desocupação do mesmo. A escada era constituída de elementos pré-moldados de concreto semelhante a que será estudada nesse trabalho (informação pessoal) ${ }^{1}$. Perceba na Figura 1.2 que o acidente provocou a ruptura e/ou deslocamento dos degraus da escada. Tal acidente demonstra a importância do objeto de estudo do presente trabalho.

$\overline{1}$ BARRETO, Douglas. Relato oral durante banca de exame do presente trabalho em 11/05/2021 
Figura 1.2 - Escada pré-moldada leve após explosão seguida de incêndio

(a) Vista superior

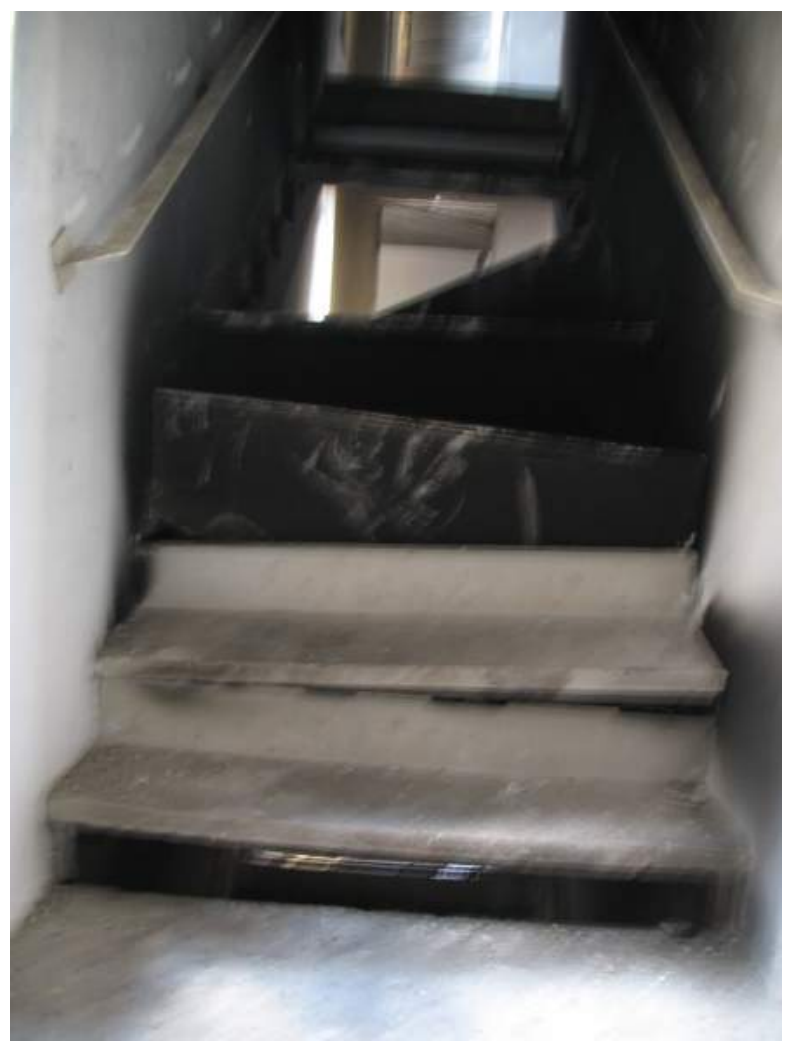

(b) Vista inferior

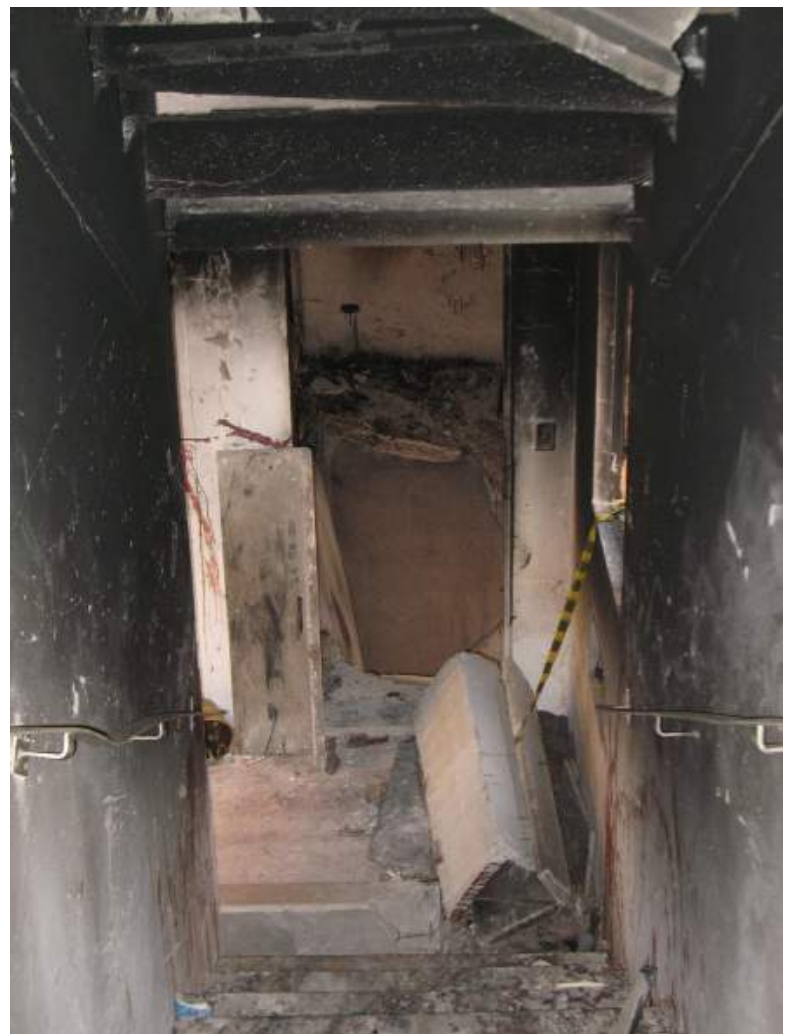

Fonte: Acervo pessoal de Douglas Barreto ${ }^{1}$

Quando se olha especificamente para sistemas de fixação em concreto e alvenaria também há uma lacuna de recomendações normativas brasileiras. Mesmo no contexto internacional apenas recentemente houve a oficialização de uma normativa europeia, a EN 1992-4:2018 (CEN, 2018). No Brasil, há um movimento para a normalização do tema, onde um manual de recomendações já foi publicado (ABECE, 2019). No entanto, ainda há um número limitado de trabalhos no tema, especialmente em alvenaria. Também há uma preocupação quanto ao desempenho em incêndio dos sistemas de fixação que vem motivando trabalhos recentes no tema (TIAN et al., 2018a, 2018a; LAHOUAR et al., 2018). Além da segurança estrutural, a avaliação da segurança de edificações em situação de incêndio é composta por várias disciplinas, entre elas: medidas de proteção passiva e ativa, estudo do comportamento humano, compartimentação de ambientes, planejamento de rotas de fuga, entre outras. Nesse contexto, a escada se constitui como um importante elemento das rotas de fuga dos edifícios. Esses elementos normalmente são protegidos de forma a atender um TRRF (Tempo Requerido de Resistência ao Fogo) de acordo com o porte e uso da edificação. Assim, a caixa de escada precisa que suas paredes e portas corta-fogo tenham resistência estrutural e além disso garantam estanqueidade e isolamento térmico para que não haja comprometimento da rota de fuga (SEITO et al., 2008).

Assim, sucintamente foram abordados os principais temas no qual este trabalho 
está inserido, maiores detalhes podem ser encontrados no Capítulo 2. Considera-se a importância da segurança estrutural em situação de incêndio, a importância de escadas como rota de fuga, bem como a necessidade de estudo da alvenaria estrutural e sistemas de fixação em temperaturas elevadas. Nesse contexto, elenca-se o sistema de fixação da escada como objeto principal de estudo tendo em vista que a estabilidade da escada é dependente deste. O estudo é realizado através de inúmeras simulações computacionais para avaliar o comportamento do sistema de fixação e viga denteada tanto em temperatura ambiente quanto em temperaturas elevadas.

\subsection{Objetivos}

\subsubsection{Objetivo geral}

Avaliar o desempenho em situação de incêndio de chumbadores utilizados na fixação de escadas pré-moldadas leves em alvenaria estrutural de blocos de concreto através do uso de simulações numéricas por meio do Método dos Elementos Finitos.

\subsubsection{Objetivos específicos}

- Validar uma estratégia de simulação numérica que permita análise não-linear mecânica, térmica e termomecânica do problema, permitindo uma adequada caracterização da geometria, materiais, interação entre componentes e condições de contorno;

- Analisar o comportamento estrutural de um chumbador submetido a cisalhamento e inserido em um típico elemento de alvenaria estrutural de blocos de concreto em temperatura ambiente;

- Analisar o comportamento estrutural da viga denteada pré-moldada leve da escada em temperatura ambiente;

- Estimar a evolução de temperatura na alvenaria e chumbador quando há exposição ao incêndio padrão ISO 834-1:1999 na face da alvenaria oposta à escada;

- Analisar a resposta estrutural do sistema de fixação durante a exposição ao incêndio padrão ISO 834-1:1999;

\subsection{Justificativa}

O uso de escada pré-moldada leve de concreto em edifícios de alvenaria estrutural apresenta boas vantagens quando se leva em conta o processo construtivo e racionalização da construção. Devido a essa vantagem esse sistema vem sendo utilizado em projetos e está presente em inúmeros edifícios já construídos. Por outro lado, nesse tipo de escada o 
sistema de fixação da peça na alvenaria tem um papel crítico na estabilidade, podendo levar a rupturas frágeis. Assim, torna-se um objeto de relevância para estudo, o qual pode fornecer subsídios técnicos para avaliar seu desempenho estrutural de forma adequada.

Nesse contexto, o desempenho estrutural é composto de uma importante disciplina: a segurança das estruturas em situação de incêndio. Inúmeros incêndios na história mostraram que essa condição pode levar a rupturas prematuras causando perdas de vidas e prejuízos materiais. Devido aos acidentes, vários avanços foram feitos acerca do comportamento de materiais e componentes estruturais em altas temperaturas. Esses estudos permitiram a criação de normas com recomendações gerais para projeto de estruturas em situação de incêndio. No entanto, a mudança dos materiais e o surgimento de novos sistemas estruturais demanda novas pesquisas e constante atualização das normas. Por outro lado, estudos experimentais em escala real são caros, fato que limita a velocidade do avanço da pesquisa na área.

No Brasil, ainda não há prescrição normativa acerca de alvenaria estrutural em situação de incêndio. Tal ausência motiva os trabalhos na área de forma a avaliar corretamente o desempenho de edifícios de alvenaria estrutural e fornecer subsídios técnicos para os projetos. Esse trabalho está inserido nesse contexto, onde se pretende avaliar um importante elemento acessório nos edifícios de alvenaria que são as escadas leves pré-moldadas de concreto, principalmente seu sistema de fixação. Cabe destacar também que não há prescrição normativa brasileira para projeto de sistemas de fixação, seja em concreto ou alvenaria. Portanto, estudos nessa área são bem-vindos para subsidiar o avanço do conhecimento considerando o contexto brasileiro.

Idealmente o estudo de estruturas em situação de incêndio deve ser feito de modo experimental de forma a avaliar a degradação dos materiais e a perda de resistência do sistema estrutural. Métodos experimentais mais tradicionais consistem em submeter o elemento estrutural a uma curva de elevação de temperatura padronizada em um forno apropriado. Assim, dependo dos recursos disponíveis, avalia-se o desempenho durante ou após o incêndio padronizado. No entanto, tal método experimental tem alto custo por isso é desejável que seja utilizado com critério.

Considerando isso, nesse trabalho adota-se o uso de simulação numérica dos processos mecânicos e térmicos relevantes para o entendimento do problema. Os métodos de análise numérica de estruturas como o Método dos Elementos Finitos são um importante aliado para diminuição de custos e avanço racional da pesquisa. O uso de simulações fornece flexibilidade e velocidade permitindo a análise de um maior número de variáveis que os modelos físicos. Apesar de as simulações tratarem de modelos simplificados da realidade, seus resultados permitem ao analista entender melhor o comportamento de um sistema estrutural e quais parâmetros tem mais influência na resposta. Assim, o uso de simulações é um grande aliado no planejamento de programas experimentais racionais que 
priorizem a avaliação de parâmetros importantes para o sistema.

Esse trabalho trata da intersecção entre três grandes áreas de estudo: alvenaria estrutural, sistemas de fixação e segurança estrutural em situação de incêndio. Nesse contexto trata-se de um tópico com número de pesquisas ainda limitado e que há espaço para novas análises. Assim, justifica-se a investigação do tema a fim de fornecer melhor entendimento do comportamento de escadas pré-moldadas leves de concreto bem como contribuir no desenvolvimento de métodos de dimensionamento de sistemas de fixação que considerem as especificidades da alvenaria e a segurança em situação de incêndio.

\subsection{Metodologia}

O trabalho consiste em uma série de simulações utilizando o Método dos Elementos Finitos. O software ABAQUS v6.14 foi utilizado como ferramenta para as simulações. São realizadas 3 tipos de simulações: simulação estrutural, simulação térmica e simulação termoestrutural. A abordagem é feita em dois modelos. No modelo local é avaliada a resposta do chumbador ancorado em alvenaria de blocos de concreto e sujeito a cisalhamento. Já no modelo global é analisado o comportamento da viga denteada que é fixada por meio desses chumbadores.

A simulação estrutural consiste em avaliar a resposta mecânica do sistema de fixação da escada leve pré-moldada de concreto em temperatura ambiente. Tanto no modelo local quanto no global considera-se as não-linearidades dos materiais adotando plasticidade de Von Mises para o aço e plasticidade com dano para o concreto. Tal simulação permite entender o comportamento do sistema e estimar modos de ruptura para determinada combinação de parâmetros.

A simulação térmica consiste na análise de transferência de calor considerando exposição ao incêndio padrão ISO 834-1:1999 na face da alvenaria oposta à escada. O objetivo dessa simulação é obter o campo de temperatura ao longo do tempo no interior dos elementos. Nas análises são consideradas as propriedades térmicas dos materiais variáveis com a temperatura bem como é feito um estudo adequado sobre os mecanismos de troca de calor nas cavidades dos blocos de alvenaria.

Por fim, realiza-se a simulação termoestrutural. Nesse caso considera-se uma simulação não-acoplada, isto é, supõe-se por hipótese que o campo de temperatura calculado na simulação térmica não é afetado pelos efeitos mecânicos que este gera como, por exemplo, deslocamentos da estrutura. Essa hipótese é razoável para pequenos deslocamentos e ausência de fissuras significativas que levem a uma distribuição de calor diferente daquela assumida. Assim, na análise termoestrutural utiliza-se a evolução temporal do campo de temperaturas calculado na simulação térmica para avaliar a resposta estrutural em termos de deslocamentos, tensões e deformações ao longo do tempo. Dessa forma é possível 
estimar a perda de resistência do elemento devido a exposição ao incêndio.

Os modelos buscam representar adequadamente as características geométricas do sistema, representando adequadamente os blocos, argamassa de assentamento e suas interfaces através de modelos tridimensionais. Tal metodologia é conhecida na literatura como micromodelagem detalhada. De modo similar, o chumbador é modelado considerando as devidas interfaces com a alvenaria. Essa metodologia permite uma análise detalhada do campo de tensões oriundo do chumbador sob cisalhamento bem como o modo de falha do sistema.

A ausência de ensaios experimentais de cisalhamento de chumbador imerso em alvenaria de blocos de concreto impede uma validação direta dos modelos. No entanto, escolhe-se realizar uma validação indireta aplicando os mesmos princípios de modelagem para o problema de cisalhamento de chumbador imerso em uma peça de concreto simples. Tendo validado a estratégia, esta é aplicada no modelo de chumbador ancorado em painel de alvenaria de bloco de concreto.

A Figura 1.3 ilustra os principais passos da metodologia adotada no trabalho em forma de fluxograma. 
Figura 1.3 - Fluxograma dos principais tópicos da metodologia

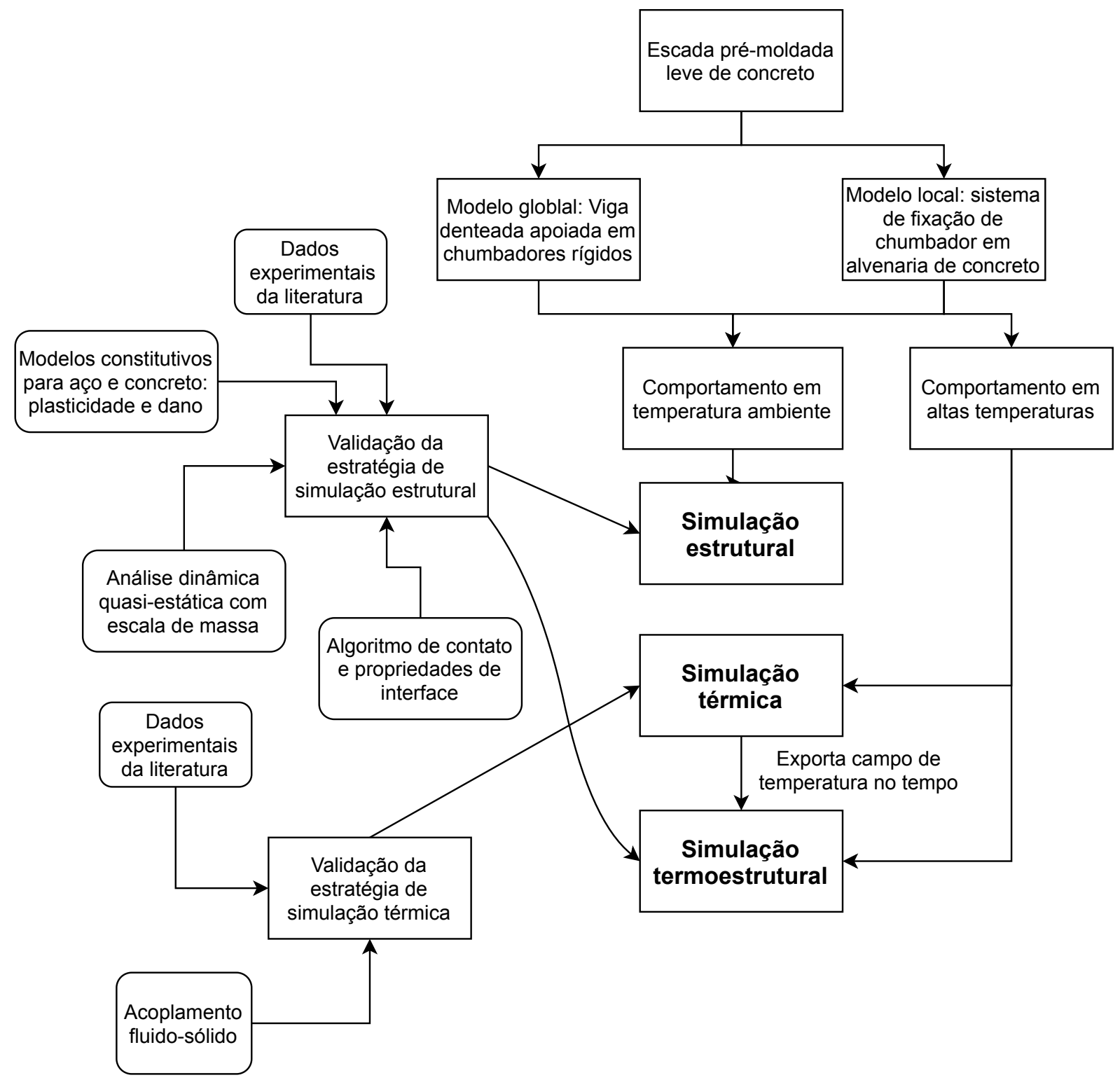




\section{REVISÃO BIBLIOGRÁFICA}

A seguir apresenta-se uma série de informações básicas e sobre o estado de pesquisa atual dos vários tópicos que envolvem o desenvolvimento desse trabalho. Essa seção tem como objetivo situar o leitor no contexto da pesquisa desenvolvida nesse trabalho, maiores detalhes podem ser encontrados nas referências citadas ao longo do texto.

\subsection{Segurança das estruturas em situação de incêndio}

Os principais objetivos da segurança contra incêndio são proteger a vida e reduzir as perdas patrimoniais. Nesse contexto, está inserida a segurança das estruturas como uma das disciplinas que devem ser consideradas na segurança contra incêndio. Na ocorrência de um incêndio é fundamental evitar o colapso precoce da estrutura, seja parcial ou total, de forma a permitir a desocupação da edificação ou o acesso da equipe de resgate. Silva et al. (2008) e Purkiss e Li (2013) fazem uma revisão sobre a filosofia da segurança estrutural em situação de incêndio bem como as características dos materiais de estruturas civis em altas temperaturas. A seguir, com base em Silva et al. (2008) e Purkiss e Li (2013), é feita uma breve explicação sobre a filosofia do estudo de estruturas em situação de incêndio. Sabe-se que os materiais usualmente utilizados nas estruturas civis sofrem grande redução de sua resistência e perda de rigidez quando expostos a altas temperaturas. Assim, cabe ao projetista considerar a ação do fogo no momento de dimensionamento da estrutura de forma a garantir a estabilidade da estrutura em face do incêndio.

Analisar a segurança estrutural na condição de incêndio passa pelo estudo das seguintes questões:

1. Como o incêndio evolui no ambiente ao longo do tempo?

2. Qual o campo de temperatura na estrutura?

3. Qual a resposta dos materiais frente a temperatura?

4. Qual a resposta do elemento estrutural?

5. Qual a resposta global da estrutura?

A resposta para cada uma dessas perguntas leva a simplificações que norteiam a análise de segurança estrutural atualmente.

A resposta à questão 1) é estudo de uma disciplina comumente chamada de Dinâmica do Incêndio. A forma de evolução de um incêndio em um edifício depende de uma série de fatores, entre eles destaca-se o tipo e quantidade de material combustível presente e as 
condições de ventilação do ambiente. Na verificação corrente de estruturas considera-se a condição de incêndio conhecida como pós inflamação generalizada ou pós flash-over. Nessa situação, considera-se que após o início do foco de incêndio em um compartimento, o fluxo de calor por convecção e radiação aquece os materiais combustíveis adjacentes e eventualmente todos os materiais chegam a sua temperatura de ignição num súbito evento chamado flash-over, onde todo o ambiente é tomado em chamas. Nesse momento chega-se as máximas temperaturas no ambiente e considera-se a distribuição de temperatura dos gases praticamente uniforme. Assim, define-se as curvas "Temperatura versus Tempo de incêndio". A curva real é de difícil determinação, no entanto, existem curvas analíticas chamadas de curvas de incêndio natural onde se estima a curva de evolução de temperatura no tempo a partir da carga de incêndio, grau de ventilação e da inércia térmica dos elementos de compartimentação. As curvas de incêndio natural são similares ao incêndio real onde há um aumento de temperatura seguido de uma fase de resfriamento que ocorre após o esgotamento do material combustível. No entanto, para análise experimental e dimensionamento de estruturas utiliza-se as curvas de incêndio padrão, entre elas a curva recomendada pelo ISO 834-1:1999 (ISO, 1999) é a mais difundida. Uma das características dessa curva é o fato de a temperatura ser sempre ascendente e não apresentar a fase de resfriamento.

Nesse ponto, cabe refletir sobre a questão 2). Sabendo os diferentes modelos de aumento de temperatura no ambiente, qual é a temperatura no elemento estrutural? Considerando o regime após o flash-over considera-se que toda a face do elemento que se encontra no ambiente estará exposto a gases com uma temperatura uniforme. Além disso é possível estimar valores para os coeficientes de troca de calor por convecção e radiação nas superfícies envolvidas. Assim, é possível realizar uma análise de transferência de calor para estimar o campo de temperaturas no interior do elemento ao longo do tempo, a qual pode ser realizada através do Método dos Elementos Finitos. No entanto, cabe lembrar que no incêndio natural a temperatura dos gases passa por um máximo e consequentemente o elemento estrutural também. No entanto, utiliza-se comumente uma curva de incêndio padrão para análise de segurança contra incêndio. Como essa curva não apresenta temperatura máxima se faz necessário definir um Tempo Requerido de Resistência ao Fogo (TRRF) onde as temperaturas nos elementos estruturais são avaliadas com base na curva de incêndio padrão, sendo portanto um tempo fictício. Esse TRRF pode ser definido como um consenso em uma determinada sociedade de acordo com os riscos de diferentes tipos de edificação. Ou pode ser definido de uma forma mais rigorosa onde se escolhe o TRRF como um tempo equivalente no qual as temperaturas nos elementos estruturais teriam a mesma temperatura da máxima temperatura atingida num incêndio natural de características compatíveis a edificação. A Figura 2.1 ilustra o formato das curvas de incêndio natural e padrão bem como o conceito de tempo equivalente. Repare como o tempo equivalente ou TRRF não necessariamente é o tempo real que a estrutura 
vai passar pelas máximas temperaturas.

Figura 2.1 - TRRF e Tempo Equivalente

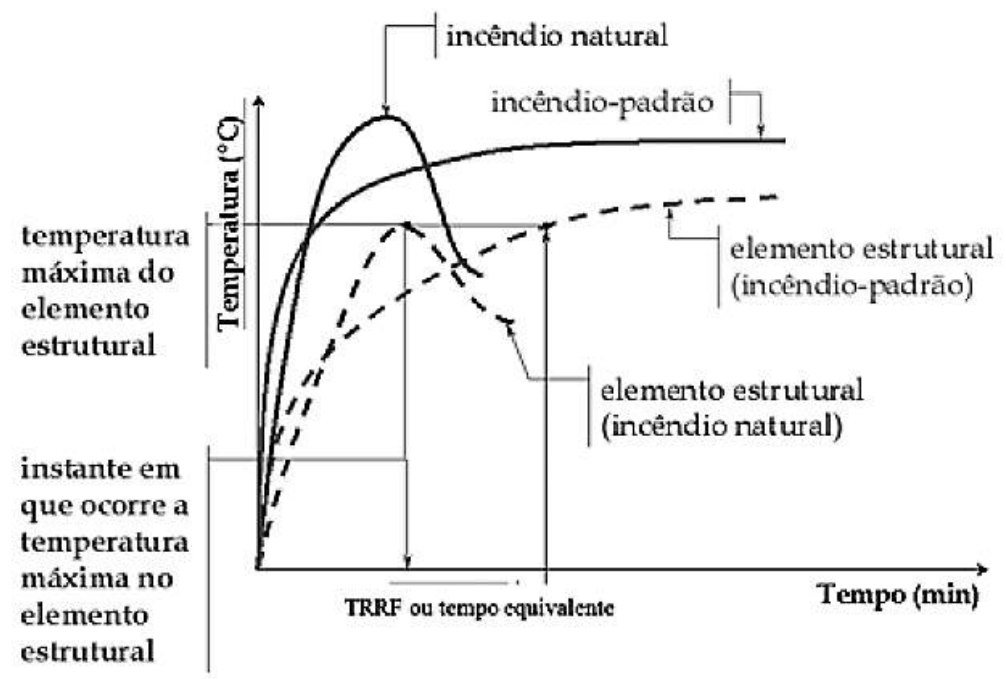

Fonte: (SILVA et al., 2008)

Os conceitos acima tratam de uma simplificação do comportamento do incêndio de forma que se possa estudar os elementos estruturais de forma experimental e numérica de forma mais simples. Com base neles, é preciso partir para a questão 3). As propriedades dos materiais sofrem grande variação com a mudança de temperatura, assim é preciso estimálas para que se estime o comportamento do elemento estrutural. Entre as propriedades de interesse estão a condutividade térmica, calor específico, dilatação térmica, resistência a compressão, resistência a tração e módulo de elasticidade. Idealmente essas propriedades devem ser avaliadas com ensaios específicos em várias temperaturas. No entanto, são poucos os laboratórios capazes de realizar ensaios em altas temperaturas e por isso é comum utilizar correlações presentes em normas de dimensionamento estrutural as quais são frutos de anos de pesquisa na área.

A pergunta 4) é a principal questão que vem sendo respondida pelas pesquisas e em boa parte já incorporada às normas de projeto. Devido ao alto custo, não há grande quantidade de ensaios de estruturas em escala natural, priorizando assim o estudo de elementos estruturais isolados. Comumente se utiliza uma abordagem prescritiva para a análise da segurança de estruturas contra o incêndio. Isso significa que se prescreve uma série de recomendações normativas de projeto para que seja atingido um tempo mínimo (TRRF) de acordo com a classe da edificação. Essas recomendações são elaboradas a partir de ensaios em fornos que podem reproduzir a curva de incêndio padrão e são utilizados para avaliar o desempenho de vigas, pilares, lajes, etc. Simulações numéricas são realizadas em conjunto com os ensaios para melhor entender o comportamento dos elementos e, uma vez validados os modelos, propor possíveis extrapolações. Esses ensaios e simulações são a base das referências normativas para dimensionamento de estruturas considerando a ação 
do fogo.

Já a resposta da questão 5) nem sempre é avaliada. A análise do desempenho global de uma edificação ainda é considerada uma tarefa difícil. Essa questão é a base para a análise de segurança contra incêndio com base em desempenho. No entanto, o uso e desenvolvimento dessa abordagem depende de ensaios de grandes proporções em estruturas de tamanho natural e com condições representativas de incêndio. Dessa forma, seria possível calibrar modelos que retratem o desempenho global da estrutura. Apesar de ser uma linha de pesquisa aberta, existem uma série de mecanismos já identificados em ensaios de grandes proporções ou em perícias de incêndios reais. Por exemplo, cita-se o arqueamento que é formado em vigas mistas de aço e concreto em que ativa o efeito membrana na laje e leva a resistências superiores comparadas aos métodos clássicos de análise (VASSART et al., 2014).

O estudo de estruturas em situação de incêndio necessariamente passa por todas as reflexões explicitadas acima. As simplificações em cada etapa merecem atenção e sempre deve-se refletir acerca do comportamento na situação de um incêndio natural.

\subsection{Alvenaria estrutural em situação de incêndio}

Os primórdios da alvenaria estrutural remonta a antiguidade através do empilhamento de blocos de pedra. No entanto, foi no século XX que se desenvolveu a alvenaria estrutural moderna. A alvenaria estrutural moderna é caracterizada pelo uso de blocos de concreto ou cerâmicos os quais são coordenados através de juntas de argamassa de forma a constituir uma estrutura monolítica. Além disso, na alvenaria com blocos vazados é possível utilizar o preenchimento de graute das cavidades bem como inserção de armaduras.

Cabe destacar as diferenças da alvenaria estrutural em relação a alvenaria de vedação. No Brasil se adota amplamente a alvenaria de vedação em blocos cerâmicos ou blocos de concreto em várias edificações. Esse tipo de alvenaria tem o objetivo de atingir requisitos de uso tais como estanqueidade, conforto térmico e conforto acústico. Nesse caso, não se considera as paredes de alvenaria como elementos capazes de suportar as cargas de utilização. Assim utiliza-se pórtico estrutural de aço ou concreto armado o qual além de suportar as cargas de utilização também deve suportar o peso da alvenaria. Por outro lado, a alvenaria estrutural é caracterizada pelo uso de paredes portantes, as quais são dimensionadas para suportar as solicitações de uso da edificação bem como o seu peso próprio. Por isso, o rigor na produção e qualidade dos blocos e na execução da alvenaria é essencial, bem como um projeto adequado.

Parsekian, Medeiros e Sipp (2018) destacam a importância e as características da adoção da alvenaria estrutural no Brasil. O uso desse sistema construtivo em edifícios vem aumentando a medida que a disseminação do conhecimento em alvenaria estrutural 
tem maior alcance na comunidade técnica. A racionalização da construção que o sistema proporciona é um fator primordial para o aumento da produtividade na indústria da construção civil.

A alvenaria não-armada de blocos vazados de concreto tem boa receptividade da comunidade técnica no projeto de edificações residenciais de padrão baixo ou médio com até 12 pavimentos. Nesse tipo de projeto costuma-se utilizar paredes com espessura de 14 $\mathrm{cm}$ e a resistência do bloco igual a $1 \mathrm{MPa}$ vezes o número de pavimentos acima do nível considerado (RAMALHO; CORRÊA, 2003).

A pesquisa nacional acerca do comportamento da alvenaria estrutural proporcionou o desenvolvimento de normas de projeto, execução e métodos de ensaio. No entanto, ainda há uma lacuna acerca do projeto considerando a situação de incêndio. Lacuna essa que vem sendo abordada pela comunidade técnica com objetivo de preenchê-la (LEITE; MORENO Jr.; TORRES, 2016).

Nesse contexto, uma série de ensaios em pequenas paredes de alvenaria estrutural vem sendo desenvolvidos no SET-EESC-USP. Dupim (2019) realizou ensaios em blocos, primas e pequenas paredes de concreto em situação de incêndio com foco na avaliação da resistência pós-fogo. Foram utilizados blocos de $14 \mathrm{~cm}$ de espessura e os valores de resistência residual pós-fogo foram inferiores à 50\%. Sendo que a resistência residual foi de $14 \%$ para a parede com fogo em ambos as faces submetida ao incêndio-padrão por 70 min. Além dos ensaios, foram realizados uma série de simulações em elementos finitos para estudar o comportamento térmico e termoestrutural de elementos de alvenaria quando submetidos a ação térmica do incêndio (RODOVALHO, 2018; RODOVALHO; CORRÊA, 2019; CARVAlHO, 2019; RODOVALHO; CORRÊA; MUNAIAR NETO, 2020).

Cabe destacar que uma das dificuldades desses ensaios é realizar o carregamento da parede durante a exposição ao incêndio bem como definir condições de contorno representativas do uso real da alvenaria estrutural. Essa abordagem é utilizada nos ensaios de Lopes (2017) em que é possível carregar o corpo-de-prova durante um ensaio que simula um incêndio compartimentado. O autor utiliza blocos de alvenaria em concreto com 3 células em escala reduzida (1:2) iguais aos utilizados por Haach (2009) em seus ensaios em temperatura ambiente.

Portanto, o presente trabalho se encaixa no contexto das pesquisas sobre segurança em situação de incêndio em edifícios de alvenaria estrutural que foram citadas. No entanto, o foco aqui é a escada pré-moldada leve e seu sistema de fixação considerando adequadamente as características da alvenaria no desempenho.

Considerando o tema do presente trabalho é interessante o estudo do comportamento bloco-graute uma vez que normalmente os chumbadores são inseridos em blocos grauteados. Izquierdo (2015) e Izquierdo, Corrêa e Soto (2017) tratam da interação entre graute-bloco 
em alvenaria estrutural em temperatura ambiente. Foi constatado que a aderência entre graute e bloco é um fator limitante em blocos cerâmicos sendo evidenciado escorregamento nessa interface em ensaios de push-out. Por outro lado, não foi verificado escorregamento nos blocos de concreto, sendo a ruptura das paredes do bloco o fator limitante em ensaios de push-out. No entanto, fica o questionamento acerca do desempenho do sistema em situação de incêndio uma vez que o gradiente de temperatura leva a deformações diferenciais que podem levar à falha na interface.

\subsection{Sistemas de fixação em concreto e alvenaria}

Os sistemas de fixação para uso em concreto e alvenaria podem ser classificados em pós-instalados e pré-instalados. Os sistemas pré-instalados são caracterizados pela imersão de um chumbador no concreto fresco, tais como o chumbador de pino com cabeça (stud-bolt) e o chumbador L ou J. Já os sistemas pós-instalados se caracterizam por serem instalados no concreto ou alvenaria após a sua construção, no estado endurecido. Nesse caso, a ancoragem do chumbador é garantida por meios mecânicos que promovem atrito ou por adesivos químicos (ELIGEHAUSEN; MALLÉE; SILVA, 2006).

Existem uma série de normas sobre ensaios de desempenho em chumbadores aplicados em concreto e alvenaria. No entanto, existem poucas previsões normativas para projeto de sistemas de fixação. Dentro dessa filosofia, cabe ao fabricante ensaiar e certificar seus produtos dentro de determinadas condições que devem ser representativas ao uso que será dado ao sistema de fixação. Por outro lado, existe um movimento recente de normatizar o projeto de sistemas de fixação, cita-se como exemplo a publicação da norma europeia EN 1992-4:2018 (CEN, 2018) e a recomendação brasileira da Associação Brasileira de Engenharia e Consultoria Estrutural (ABECE, 2019). As normas permitem estimar a carga de ruptura de um sistema de fixação submetido a cisalhamento, tração e solicitações combinadas a partir de informações básicas como tipo de ancoragem, propriedades geométricas e mecânicas do chumbador e do material base. A carga de ruptura estimada é calculada para diferentes modos de ruptura para que assim encontre-se o modo de ruptura crítico para o sistema.

Muitos dos trabalhos disponíveis na literatura são sobre fixação em elementos de concreto armado ou blocos de concreto simples. Há uma pequena quantidade de referências acerca do comportamento de chumbadores aplicados em alvenaria. Com base na revisão bibliográfica não se encontrou trabalhos experimentais ou numéricos acerca do desempenho frente a incêndio de sistemas de fixação aplicados em alvenaria. Por outro lado, existe um conjunto de trabalhos que trata do comportamento de chumbadores em alvenaria grauteada de blocos de concreto em temperatura ambiente.

Brown e Whitlock (1983) ensaiaram 45 chumbadores tipo L instalados em alvenaria 
de blocos de concreto grauteados. Os blocos utilizados apresentam espessura de 8"(20,32 $\mathrm{cm}$ ), a profundidade de embutimento foi de $162 \mathrm{~mm}$ e os diâmetros ensaiados foram 3/8", 1/2", 3/4", 1" e 1-1/4" . Foram realizados ensaios de arrancamento, cisalhamento e carregamento combinado dos chumbadores. Os resultados mostraram que há um incremento na carga de ruptura ao arrancamento até o diâmetro de 3/4"(19 mm), para diâmetros maiores a carga de ruptura é menor. Em diâmetros maiores a falha ocorre por ruptura do concreto enquanto diâmetro menores ocorre por arrancamento devido ao estiramento do chumbador L. Já para carregamento cisalhante a falha ocorre por corte do aço até o diâmetro de 3/4"(19 mm) e para diâmetros maiores há esmagamento do concreto.

McGinley (2006) faz uma revisão de uma série de recomendações normativas aplicadas a alvenaria e compara essas prescrições com uma ampla série experimental realizada em blocos de concreto grauteados (MCGINLEY et al., 2004). A Figura 2.2 mostra a geometria dos corpos de provas e um resultado típico de ruptura para chumbador sobre cisalhamento. As cavidades dos blocos foram completamente grauteadas. O autor relata que a única norma que traz um método de cálculo para estimativa da resistência do sistema de fixação é a americana TMS 402/602-16 (TMS, 2016). As normas canadense, europeia, australiana e nova zelandense trazem apenas recomendações prescritivas e delegam aos fabricantes a responsabilidade de realizar ensaios para prever a capacidade resistente em condições representativas as usadas em campo. O autor faz uma comparação das estimativas calculadas com os resultados experimentais e chega-se a conclusão de que as expressões normativas tem limitações no caso de chumbadores de diâmetros superiores a $19 \mathrm{~mm}$ sujeitos a esforço cortante.

Figura 2.2 - Modo de ruptura (a) e esquema de carregamento (b)

(a)

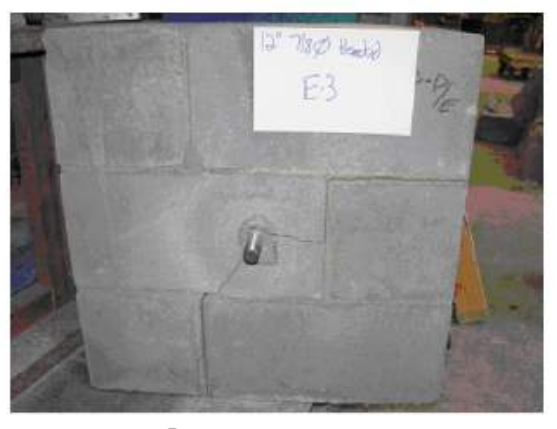

(b)

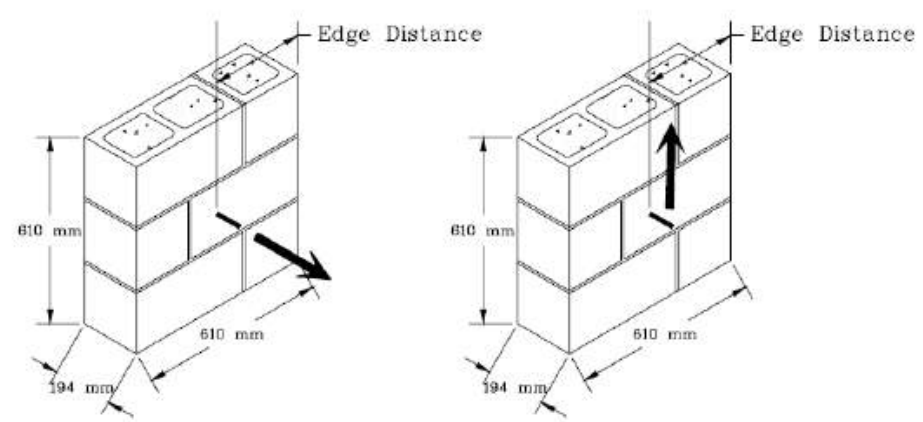

Fonte: (MCGINLEY et al., 2004)

Apesar de existir recomendações e normas para chumbadores em elementos de concreto, poucas são as referências para dimensionamento especificamente em alvenaria. Um exemplo é o manual TEK12-3C (NCMA, 2013). Esse manual é baseado na norma de alvenaria americana TMS 402-2013. No entanto, ele se limita a chumbadores pré-instalados tipo pino com cabeça e tipo L. 
O Instituto de Materiais de Construção da Universidade de Stuttgart na Alemanha é um polo de pesquisa na área de fixações e ancoragem em concreto e alvenaria desde a década de 1970. Inúmeros trabalhos nessa área foram produzidos desde então, muitos dos quais são base para normas atuais acerca de ancoragem em concreto (ELIGEHAUSEN; MALLÉE; SILVA, 2006). Assim, é natural que as pesquisas desenvolvidas nesse instituto forneçam informações relevantes para este trabalho. Dentre as linhas de pesquisa recentes ressalta-se as pesquisas sobre fixações em condições extremas como sismos e incêndio.

Para o presente trabalho, o comportamento do sistema de fixação ao cisalhamento é o que tem maior importância. Nesse contexto, Hofmann (2004) e Grosser (2012) estudam o comportamento ao cisalhamento de chumbadores e grupos de chumbadores especialmente aqueles ancorados próximos as bordas de elementos de concreto. Ambos autores fazem uma extensa campanha experimental e também simulações bem-sucedidas através do Método dos Elementos Finitos.

Tian (2019) estende os estudos sobre cisalhamento de chumbadores em borda de elementos de concreto através de uma campanha experimental e simulações de chumbadores em situação de incêndio. Os resultados da pesquisa são condensados em Tian et al. (2018a) e Tian et al. (2018b). A Figura 2.3 mostra as condições de contorno utilizadas, bem como a geometria dos corpos de prova. Os corpos de prova consistem em vigas de formato $\mathrm{T}$ com entalhes entre a mesa e alma para gerar uma borda na direção da qual os chumbadores são ensaiados. A mesa do corpo-de-prova é utilizada como parte da tampa do forno como pode ser visto na Figura 2.4. São realizados dois tipos de ensaios: no estado quente e no estado frio. Os ensaios no estado quente são realizados imediatamente após 90 min de exposição ao incêndio-padrão ISO 834-1:1999. Já os ensaios no estado frio são realizados após o resfriamento natural dos corpos-de-prova.

Figura 2.3 - Carregamento aplicado e condições de incêndio para: a) Fogo em um lado da borda de concreto, b) fogo nos dois lados da borda de concreto, c) corpo-deprova

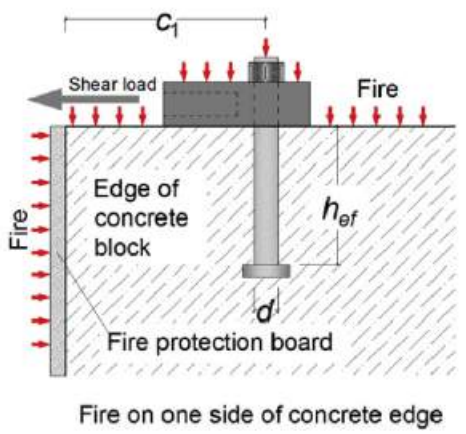

(a)

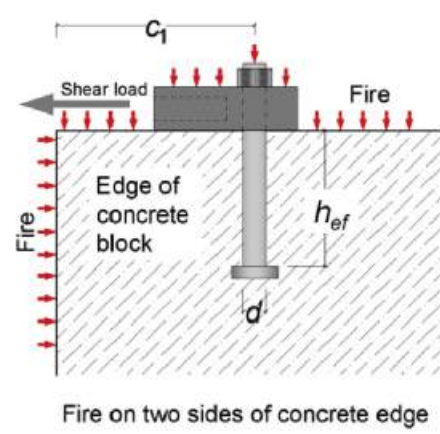

(b)

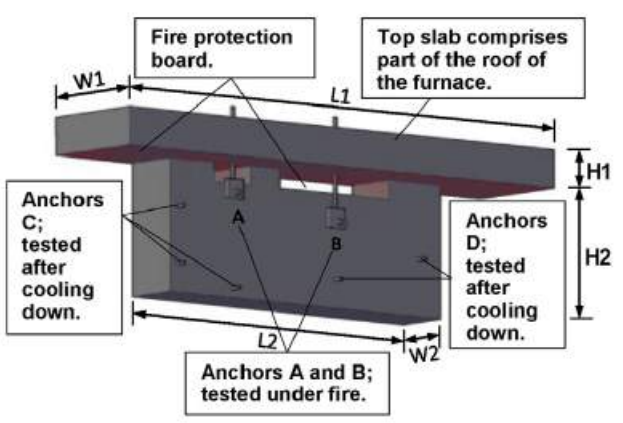

(c)

Fonte: (TIAN et al., 2018a) 
Figura 2.4 - Layout experimental no forno horizontal

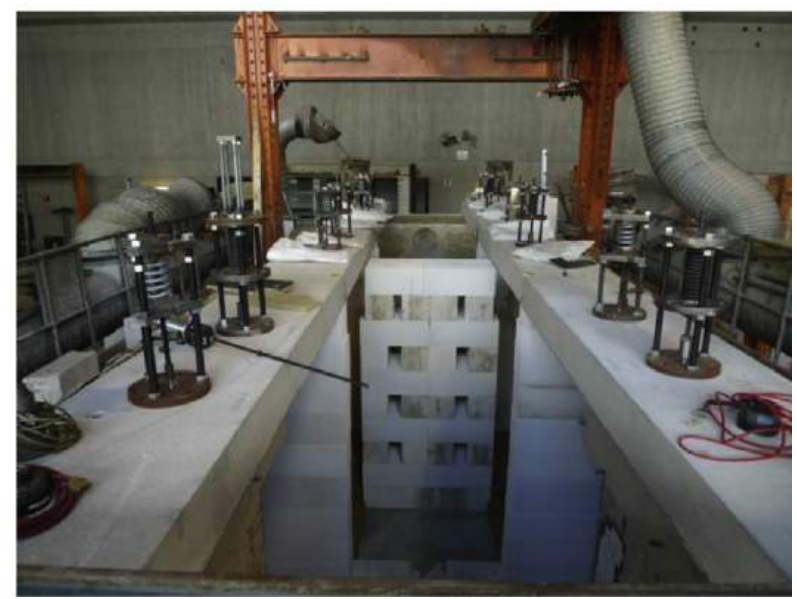

Fonte: (TIAN et al., 2018a)

Através do uso de simulações (ver Figura 2.5) e análise dos resultados experimentais as principais conclusões foram: as simulações puderam replicar satisfatoriamente a carga de ruptura, modo de falha e distribuição de temperatura; a carga de ruptura dos corpos-deprova de referência à temperatura ambiente tiveram boa concordância com as expressões do EN 1992-4 (CEN, 2018); a expansão térmica devido ao incêndio pode gerar confinamento indesejado dependendo da geometria e condições de contorno do corpo-de-prova, fato que merece atenção no planejamento de ensaios; os resultados mostram que é mais provável que ocorra falha da borda do concreto após o resfriamento enquanto a falha do aço é mais provável que ocorra no estado quente; as fórmulas de dimensionamento do EN 1992-4 subestimam a resistência no estado quente mas superestimam a resistência no estado frio (pós-fogo).

Figura 2.5 - Dano no concreto numérico e experimental em chumbador submetido à incêndio-padrão por 90 min

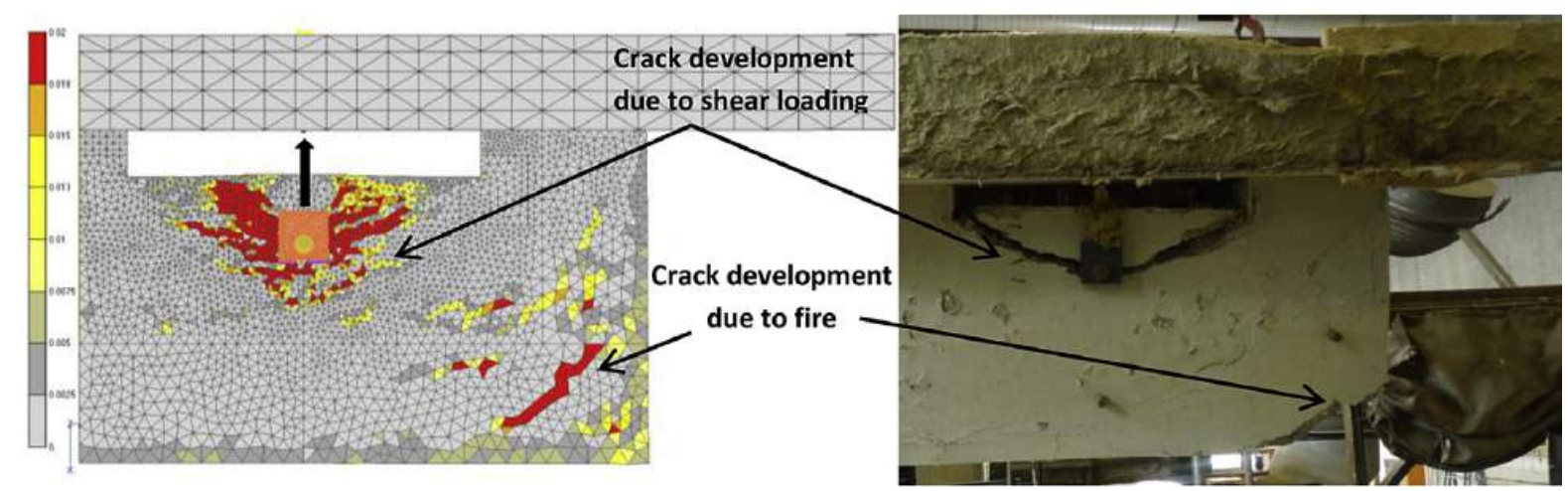

Fonte: (TIAN et al., 2018a)

Pesquisadores de outros institutos também tem se preocupado sobre o desempenho de fixações em situação de incêndio, especialmente fixações pós-instaladas por adesão química sob tração. Al-Mansouri et al. (2019) realiza ensaios de chumbadores por adesão 
química submetidos à tração e expostos ao incêndio-padrão ISO 834-1:1999. O autor analisa a influência dos métodos experimentais na distribuição de temperatura e na resistência ao arrancamento. Já Lahouar et al. (2018) realiza um ensaio de uma laje de concreto armado em balanço sendo que as armaduras negativas do engaste são ancoradas através de um adesivo químico. A laje é exposta ao incêndio-padrão ISO 834-1:1999 na sua face inferior.

No âmbito brasileiro não foi possível encontrar publicações que tratem do desempenho de sistemas de fixação em alvenaria. Percebe-se que, no que se refere à sistemas de fixação ou ancoragem de barras, há uma prevalência de estudos focados em concreto armado ou pré-moldado bem como estruturas mistas de aço e concreto. Os trabalhos desse tema no contexto da alvenaria ainda são escassos. E a análise desses sistemas em situação de incêndio é ainda mais escassa.

\subsection{Escadas pré-moldadas leves em edifícios de alvenaria estrutural}

O uso de elementos pré-moldados de concreto na construção de edifícios de alvenaria estrutural contribui para a racionalização da produção. Escadas, vergas e contramarcos são alguns exemplos de elementos que podem ser pré-fabricados e utilizados em conjunto com a alvenaria estrutural.

As escadas pré-moldadas de concreto podem ser divididas em dois tipos principais: escadas de peças com grandes dimensões e escadas com peças de pequenas dimensões. As escadas compostas por peças de grandes dimensões são aquelas em que uma peça constitui o lance completo da escada com ou sem patamar. Essas peças necessitam de equipamento de içamento para o seu posicionamento na obra. Já as escadas compostas de peças de pequenas dimensões são projetadas levando em conta a possibilidade de montagem manual pelos operários. Assim, o peso das peças é limitado considerando o manuseio manual das peças. Nesse trabalho esse tipo de escada é denominado "escada leve pré-moldada de concreto".

O modelo de escada leve pré-moldada de concreto conhecido como "escada jacaré" é apresentado na Figura 2.6. Essa escada é constituída de peças leves de concreto sendo seus elementos principais os degraus, o patamar e a viga denteada (também chamada de "viga jacaré") que serve de apoio aos degraus. Já a viga denteada é ancorada na alvenaria através de chumbadores metálicos.

Mamede (2001), Mamede, Corrêa e Ramalho (2006) ressaltam os benefícios da utilização de pré-moldados em conjunto com a alvenaria estrutural, entre eles, as escadas pré-moldadas em concreto. Em especial, Mamede (2001) faz a concepção e dimensionamento completo de uma escada pré-moldada leve para uso em edificações de alvenaria estrutural a qual é ilustrada na Figura 2.8.

Cabe destacar também a importância da indicação em projeto da posição dos 
Figura 2.6 - Escada pré-moldada leve de concreto
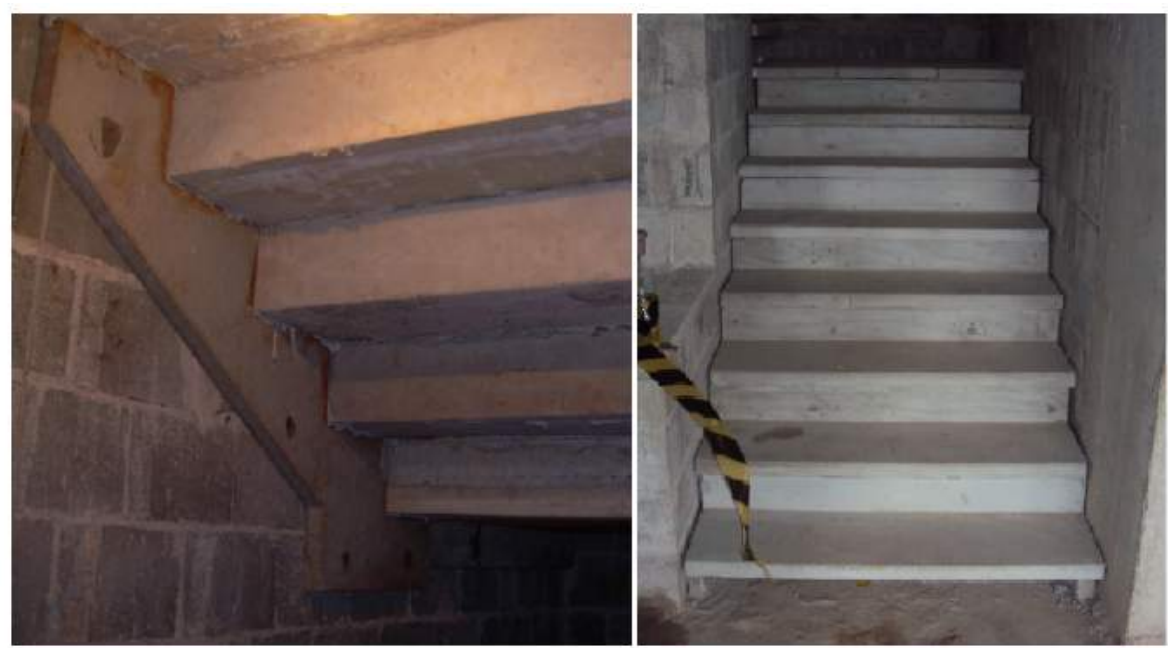

Fonte: (NETTO, 2016)

chumbadores uma vez que se recomenda que os blocos onde se ancora a viga sejam grauteados (MAMEDE, 2001; NETTO, 2016). Veja a Figura 2.7 para a recomendação de grauteamento de Netto (2016).

Figura 2.7 - Pontos de grauteamento sugeridos

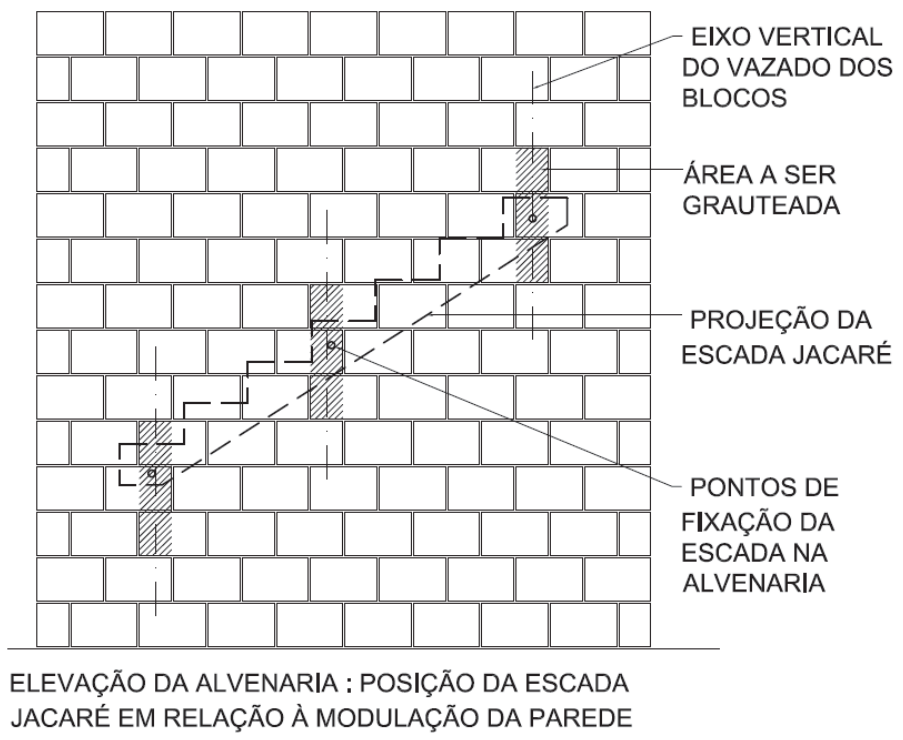

Fonte: (NETTO, 2016)

Alguns aspectos de dimensionamento que Mamede (2001) destaca estão relacionados com a pequena espessura das peças que nesse caso foi de $4 \mathrm{~cm}$ para as vigas denteadas. A pequena espessura dos elementos limita o uso de concreto com diâmetros de agregados grandes, sendo assim, a autora caracteriza o sistema como argamassa armada. Também devido às pequenas espessuras limita-se o diâmetro da armadura à 6,3 mm e adotase cobrimento de $1 \mathrm{~cm}$. Devido aos pequenos cobrimentos característicos de peças de argamassa armada, adota-se 0,15 $\mathrm{mm}$ como limite de abertura de fissura. 
Figura 2.8 - Plantas e cortes da escada
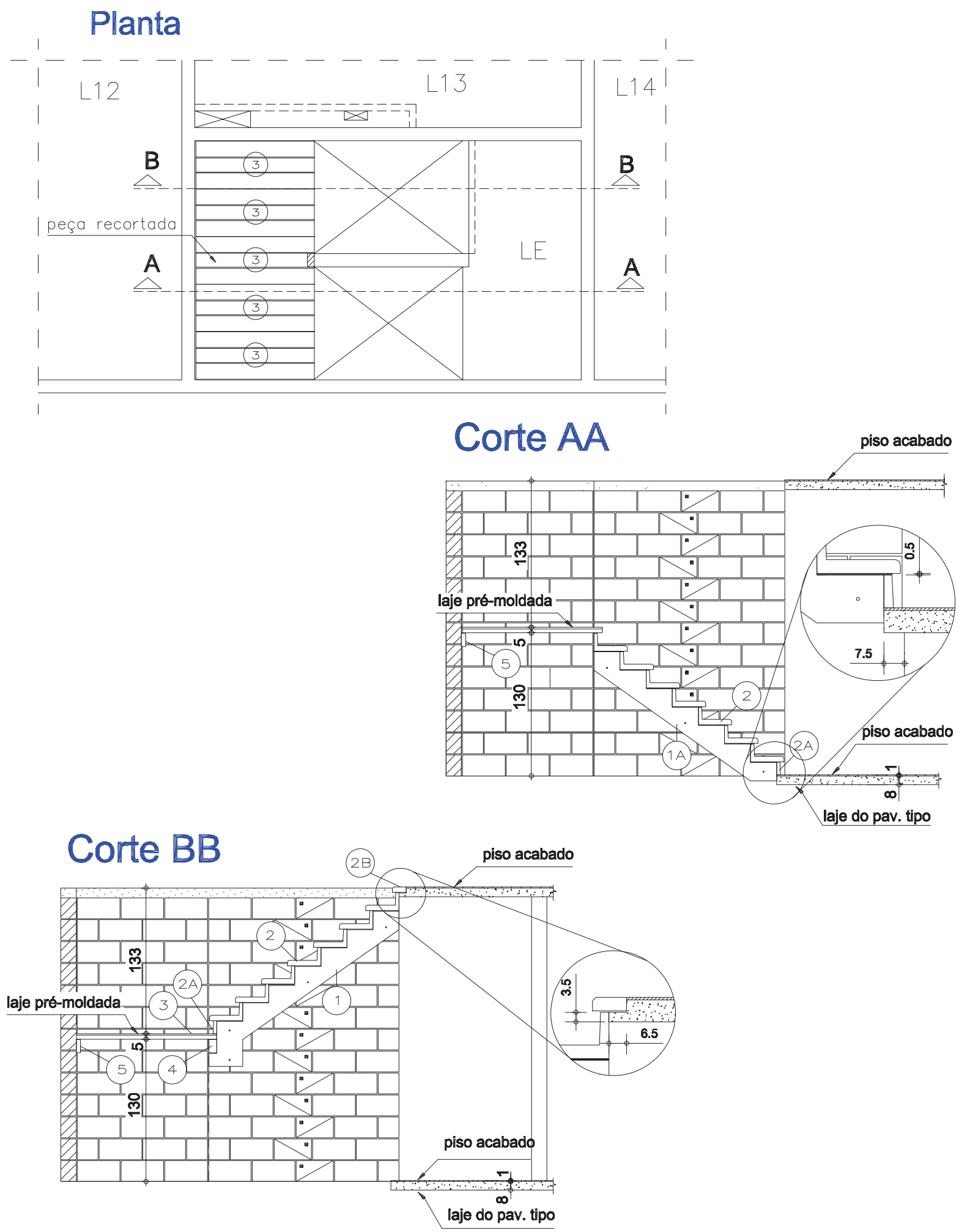

Fonte: Cortesia da TecSof Engenharia de Estruturas S/C Ltda apud (MAMEDE, 2001) 


\section{ANÁLISE ESTRUTURAL}

Esse capítulo documenta as análises utilizadas para avaliar estratégias de simulação no que concerne o desempenho estrutural do sistema de fixação entre alvenaria e escada leve pré-moldada. Ao fim das análises estruturais espera-se obter informações acerca do comportamento e modo de ruptura do sistema a temperatura ambiente.

Em primeiro lugar, cabe destacar que a viga denteada é suportada por apoios discretos sob efeito de cisalhamento, logo, o sistema de fixação e a própria viga são fundamentais para a estabilidade da escada como um todo. Por esse motivo opta-se por dividir a análise em dois aspectos principais.

O primeiro aspecto a se estudar é o comportamento do sistema de fixação em si, isto é, o mecanismo de transferência de carga do objeto fixado para o material base. No caso em questão trata-se de chumbadores metálicos de aderência química ancorados em alvenaria estrutural de blocos de concreto os quais são submetidos a cisalhamento devido a uma peça pré-moldada de concreto. O objetivo dessa análise é avaliar a carga última estimada e entender os mecanismos de deformação e ruptura da fixação bem como possíveis influências das características da alvenaria.

Definidos o escopo da simulação esbarra-se em um problema. Este trabalho apresenta caráter exploratório no sentido de que não foram encontrados dados experimentais na literatura acerca de cisalhamento de chumbadores imersos em alvenaria de concreto em condições semelhantes a fixação da escada. Assim, em princípio não há trabalhos experimentais para validar os modelos numéricos propostos. No entanto, escolhe-se realizar uma validação indireta das estratégias utilizadas. O problema de chumbadores imersos em peças de concreto simples é um tópico que há disponibilidade de dados experimentais. Nesse caso, há semelhança entre esse problema e o problema dos chumbadores imersos em alvenaria de blocos de concreto com as cavidades grauteadas. Assim, opta-se por realizar simulações de fixação por chumbadores metálicos de aderência química ancorados em concreto simples. Nessas simulações o carregamento é cisalhante assim como espera-se no caso da viga denteada. Assim, validando a estratégia de simulação nesse caso esperase obter resultados aceitáveis na utilização da mesma estratégia para a ancoragem em alvenaria.

O segundo aspecto a se estudar é o comportamento da viga denteada pré-moldada em si. Isto é, existe a possibilidade de que a ruptura do sistema seja causada pela ruptura da viga, sendo este caso explorado nessas simulações. Assim, considera-se a geometria da viga denteada sob carregamento bem como as devidos apoios discretos representando os chumbadores. O objetivo dessa análise é avaliar a carga última estimada e modo de 
ruptura da viga tais como a ruptura por flexão e a ruptura de bordo devido o chumbador.

\subsection{Estudo da estratégia de simulação}

A validação da estratégia de modelagem será feita utilizando os dados experimentais de Grosser (2012) o qual realizou uma série de ensaios em sistemas de fixação imersos em concreto e submetidos a cisalhamento. Utilizou-se a série de ensaios de chumbador por adesão química com adesivo polimérico imerso em concreto e longe das bordas do corpo de prova. A Figura 3.1 mostra a configuração de ensaio utilizada. Repare que também foram realizados ensaios de cisalhamento em bloco de aço para comparação.

Figura 3.1 - Configuração de ensaio ao cisalhamento de chumbador isolado

(a) Imerso em concreto

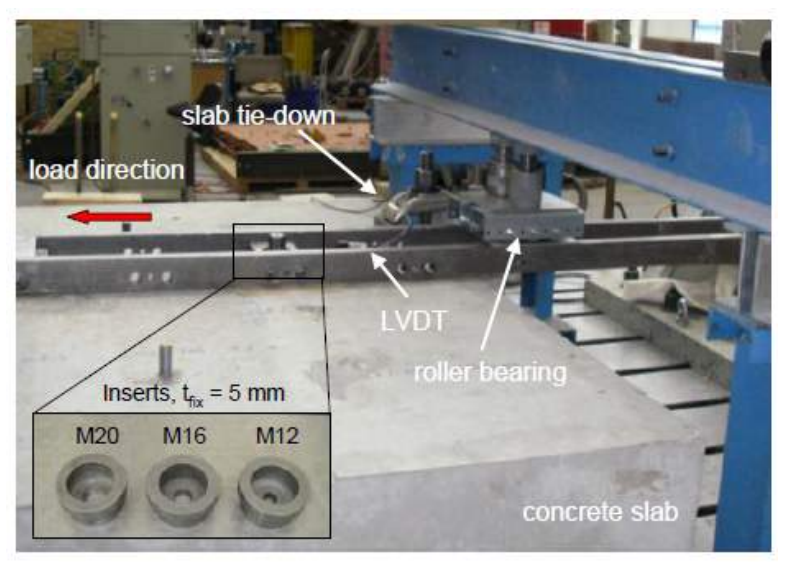

(b) Imerso em bloco de aço

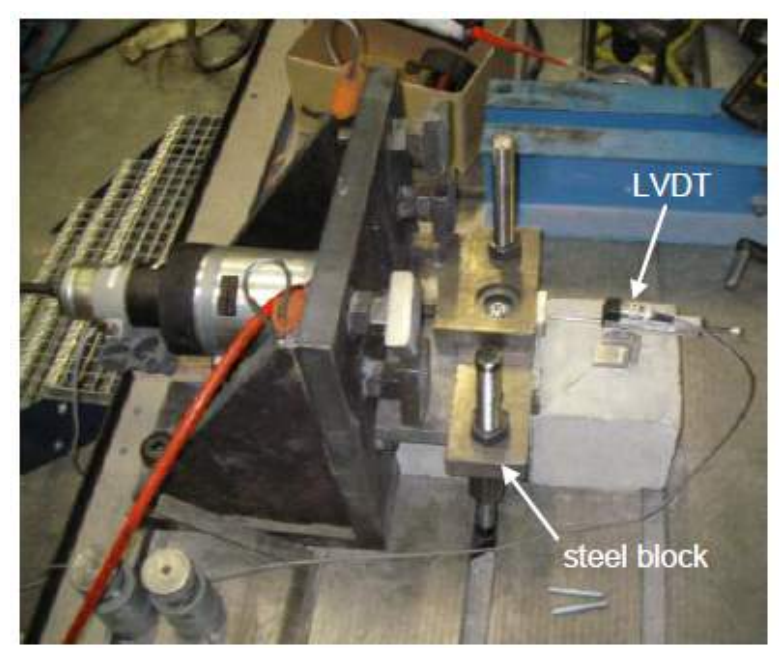

Fonte: (GROSSER, 2012)

Grosser (2012) utilizou chumbadores M12, M16 e M20 nesses ensaios. Para validação utiliza-se aqui os resultados para os chumbadores M12 e M16. Foram consideradas três classes de resistência para os chumbadores e duas resistências à compressão para o concreto. A Tabela 3.1 descreve as características principais das 18 simulações realizadas na validação da estratégia utilizada na modelagem. 
Tabela 3.1 - Características básicas dos modelos simulados

\begin{tabular}{|c|c|c|c|c|c|c|c|c|}
\hline \multirow[b]{2}{*}{ Modelo } & \multicolumn{6}{|c|}{ Chumbador } & \multicolumn{2}{|c|}{ Material base } \\
\hline & $\begin{array}{l}D_{\text {nom }} \\
(\mathrm{mm})\end{array}$ & $\begin{array}{c}D_{e f}^{1} \\
(\mathrm{~mm})\end{array}$ & Classe & $\begin{array}{c}f_{y}{ }^{2} \\
(\mathrm{MPa})\end{array}$ & $\begin{array}{c}f_{u}^{2} \\
(\mathrm{MPa})\end{array}$ & $\begin{array}{l}\varepsilon_{u}^{2} \\
(\%)\end{array}$ & Tipo & $\begin{array}{c}f_{c}^{3} \\
(\mathrm{MPa})\end{array}$ \\
\hline m12-8_8-aco & 12 & 10,36 & 8.8 & 640 & 800 & 12 & Aço & - \\
\hline m12-10_9-асо & 12 & 10,36 & 10.9 & 940 & 1040 & 9 & Aço & - \\
\hline m12-12_9-асо & 12 & 10,36 & 12.9 & 1100 & 1220 & 8 & Aço & - \\
\hline m12-8_8-low & 12 & 10,36 & 8.8 & 640 & 800 & 12 & Concreto & 27,115 \\
\hline m12-10_9-low & 12 & 10,36 & 10.9 & 940 & 1040 & 9 & Concreto & 27,115 \\
\hline m12-12_9-low & 12 & 10,36 & 12.9 & 1100 & 1220 & 8 & Concreto & 27,115 \\
\hline m12-8_8-high & 12 & 10,36 & 8.8 & 640 & 800 & 12 & Concreto & 56,695 \\
\hline m12-10_9-high & 12 & 10,36 & 10.9 & 940 & 1040 & 9 & Concreto & 56,695 \\
\hline m12-12_9-high & 12 & 10,36 & 12.9 & 1100 & 1220 & 8 & Concreto & 56,695 \\
\hline m16-8_8-aco & 16 & 14,14 & 8.8 & 640 & 800 & 12 & Aço & - \\
\hline m16-10_9-асо & 16 & 14,14 & 10.9 & 940 & 1040 & 9 & Aço & - \\
\hline m16-12_9-асо & 16 & 14,14 & 12.9 & 1100 & 1220 & 8 & Aço & - \\
\hline m16-8_8-low & 16 & 14,14 & 8.8 & 640 & 800 & 12 & Concreto & 27,115 \\
\hline m16-10_9-low & 16 & 14,14 & 10.9 & 940 & 1040 & 9 & Concreto & 27,115 \\
\hline m16-12_9-low & 16 & 14,14 & 12.9 & 1100 & 1220 & 8 & Concreto & 27,115 \\
\hline m16-8_8-high & 16 & 14,14 & 8.8 & 640 & 800 & 12 & Concreto & 56,695 \\
\hline m16-10_9-high & 16 & 14,14 & 10.9 & 940 & 1040 & 9 & Concreto & 56,695 \\
\hline m16-12_9-high & 16 & 14,14 & 12.9 & 1100 & 1220 & 8 & Concreto & 56,695 \\
\hline
\end{tabular}

${ }^{1}$ Calculado com base na área efetiva de tensão de acordo com EN ISO 898-1:2013 (CEN, 2013)

${ }^{2}$ Valores correspondentes a classe do chumbador de acordo com EN ISO 898-1:2013 (CEN, 2013)

${ }^{3}$ Resistência no cilindro estimada com base na resistência à compressão no cubo

Nota: Tensões e deformações nominais.

\subsubsection{Modelos constitutivos}

\subsubsection{Aço}

O modelo de plasticidade de Von Mises é adequado para modelar o comportamento de metais de uma forma geral. Nesse modelo considera-se a máxima energia de distorção do material como critério de plastificação, assim sendo, a plastificação do material é dependente da parcela desviadora do tensor de tensões e independente da parcela hidrostática. $\mathrm{O}$ 
único parâmetro de material necessário para esse critério de plastificação é a tensão de escoamento unidimensional $f_{y}$ obtida através de um ensaio de tração. Além disso é possível definir uma lei de evolução das deformações plásticas ou lei de encruamento, sendo o encruamento isotrópico uma opção possível para carregamentos monotônicos em metais. O encruamento do material permite que haja aumento da tensão dentro do regime plástico.

Neste trabalho adota-se o modelo de plasticidade de Von Mises com encruamento isotrópico. Os parâmetros de entrada são calculados a partir da curva tensão-deformação nominal $\left(\sigma_{N}\right.$ e $\left.\varepsilon_{N}\right)$ onde se chega a tensão e deformação verdadeiras $\left(\sigma_{T}\right.$ e $\varepsilon_{T}$ respectivamente), isto é, tensões calculadas com base na área deformada da seção transversal e não na área inicial. A relação entre essas variáveis é dada pela Equação 3.1.

$$
\begin{aligned}
& \sigma_{T}=\sigma_{N} \cdot\left(1+\varepsilon_{N}\right) \\
& \varepsilon_{T}=\ln \left(1+\varepsilon_{N}\right)
\end{aligned}
$$

Assim pode-se calcular os pares tensão e deformação plástica $\left(\sigma_{T} v s \varepsilon_{T}^{\text {plastic }}\right)$ que definem os trechos lineares de comportamento plástico com encruamento isotrópico. A Tabela 3.2 mostra os dados de entrada do modelo constitutivo das diferentes classes de resistência dos chumbadores. Já a Figura 3.2 mostra a curva tensão-deformação das diferentes classes. Repare que após o alongamento máximo o material apresenta comportamento perfeitamente plástico.

Tabela 3.2 - Pontos para definição da curva tensão-deformação do aço

\begin{tabular}{cccccc}
\hline $\begin{array}{c}\text { Classe de } \\
\text { Resistência }\end{array}$ & $\varepsilon_{N}$ & $\begin{array}{c}\sigma_{N} \\
(\mathrm{MPa})\end{array}$ & $\varepsilon_{T}$ & $\begin{array}{c}\sigma_{T} \\
(\mathrm{MPa})\end{array}$ & $\varepsilon_{T}^{\text {plastic }}$ \\
\hline 8.8 & 0 & 0 & 0 & 0 & 0 \\
& 0,0032 & 640 & 0,003194891 & 642,048 & 0 \\
& 0,12 & 800 & 0,113328685 & 896 & 0,108848685 \\
10.9 & 0 & 0 & 0 & 0 & 0 \\
& 0,0047 & 940 & 0,004688989 & 944,418 & 0 \\
12.9 & 0,09 & 1040 & 0,086177696 & 1133,6 & 0,080509696 \\
& 0,0055 & 0 & 0 & 0 & 0 \\
& 0,08 & 1100 & 0,00548493 & 1106,05 & 0 \\
\hline
\end{tabular}

Nota: $E_{S}=200 \mathrm{GPa}$

\subsubsection{Concreto}

O ABAQUS tem em sua biblioteca de materiais o modelo constitutivo Concrete Damaged Plasticity (CDP) o qual é um modelo de plasticidade e dano aplicável a materiais 
Figura 3.2 - Gráfico tensão-deformação adotado para as classes de resistência

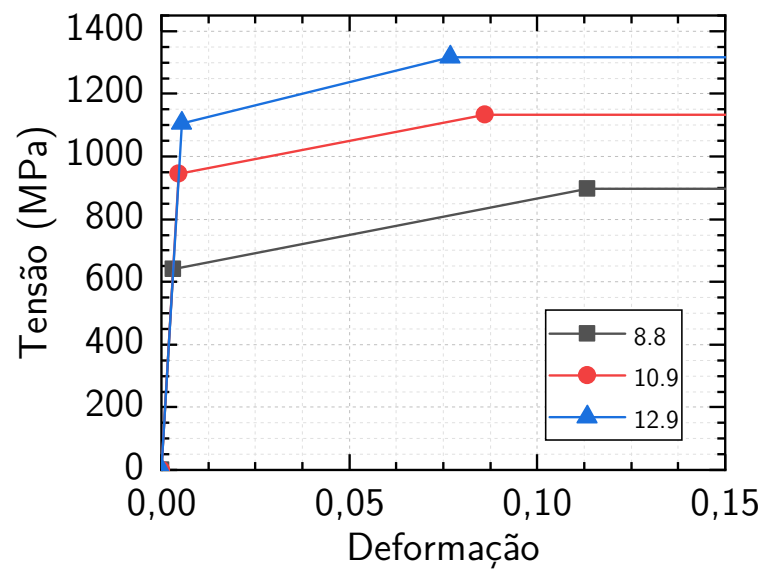

Fonte: O autor

frágeis baseado nos modelos propostos por Lubliner et al. (1989) e Lee e Fenves (1998). Esse modelo permite a consideração de um comportamento elastoplástico para o material considerando comportamentos distintos a tração e a compressão, inclusive com consideração de amolecimento (Strain-Softening). Além disso é possível definir uma curva de evolução de dano que penaliza o módulo de elasticidade do material, tal característica torna o modelo especialmente adequado para simulações com carregamento cíclico.

Para utilizar o CDP deve-se fornecer uma série de parâmetros os quais definem a superfície de plastificação. Define-se $\psi$ como o ângulo de dilatância do material, $\epsilon$ como uma excentricidade aplicada a lei de plastificação, $f_{b 0} / f_{c 0}$ é a relação entre a resistência a compressão inicial em estado de compressão biaxial e a resistência a compressão inicial em estado uniaxial, $K$ é um parâmetro que afeta a forma da superfície de plastificação e $\mu$ é a viscosidade para a regularização viscoplástica do modelo. Os parâmetros utilizados na simulação são dados na Tabela 3.3. Os parâmetros $\epsilon, f_{b 0} / f_{c 0}$ e $K$ foram adotados de acordo com os valores padrão do ABAQUS que obedecem os intervalos sugeridos por Lubliner et al. (1989) e tipicamente são utilizados em trabalhos que utilizam o CDP. Já a viscosidade é um parâmetro da regularização viscoplástica que permite melhorar a convergência na zona de amolecimento do modelo constitutivo. Para escolha da viscosidade considerou-se pequenos valores comparados ao valor típico do incremento o que leva a uma melhor convergência sem afetar significativamente os resultados. Por fim, a escolha do ângulo de dilatância via de regra deve ser calibrado. Como estimativa inicial pode-se adotar $25^{\circ}<\psi<35^{\circ}$ o qual é um intervalo na qual vários autores adotam em suas simulações (WOSATKO et al., 2019).

Tabela 3.3 - Parâmetros adotados no modelo CDP

\begin{tabular}{ccccc}
\hline$\psi$ & $\epsilon$ & $f_{b 0} / f_{c 0}$ & $\mathrm{~K}$ & $\mu$ \\
\hline $30^{\circ}$ & 0,1 & 1,16 & $2 / 3$ & $10^{-5}$ \\
\hline
\end{tabular}


Além dos parâmetros de plasticidade deve-se conhecer o comportamento uniaxial do concreto à compressão e à tração. No entanto, o único dado experimental dado por Grosser (2012) é a resistência à compressão do concreto. Assim, há a necessidade de estimar outras propriedades do material com base em normas. A Tabela 3.4 mostra os valores estimados da resistência à tração $\left(f_{c t m}\right)$, módulo de Young $\left(E_{c}\right)$ e energia de fratura $\left(G_{f}\right)$ para os dois concretos utilizados.

Tabela 3.4 - Propriedades do concreto

\begin{tabular}{cccc}
\hline & $\begin{array}{c}\text { Baixa } \\
\text { resistência }\end{array}$ & $\begin{array}{c}\text { Alta } \\
\text { resistência }\end{array}$ & Referência \\
\hline $\begin{array}{c}f_{c m} \\
(\mathrm{MPa})\end{array}$ & 27,115 & 56,695 & Grosser $(2012)$ considerando $f_{c i l}=0,85 \cdot f_{\text {cubo }}$ \\
$f_{c t m}$ & 2,145 & 4,001 & EN 1992-1-1:2004 e MC2010 \\
$\left(\begin{array}{c}\mathrm{MPa}) \\
E_{c}\end{array}\right.$ & 23248,9 & 32048,6 & MC2010 considerando agregado calcário \\
$\left(\begin{array}{c}\mathrm{MPa}) \\
G_{f}\end{array}\right.$ & 0,05443 & 0,09122 & MC1990 considerando $D_{a g}=12,5 \mathrm{~mm}$ \\
$(\mathrm{~N} / \mathrm{mm})$ & & \\
\hline
\end{tabular}

Para utilizar o modelo CDP é necessário definir a curva de compressão uniaxial incluindo a região de amolecimento (strain-softening). Para cálculo da curva de compressão considerou-se comportamento elástico linear até $0,4 f_{c}$ e após considerou-se o modelo nãolinear de Carreira e Chu (1985) o qual permite estimar a curva no regime de amolecimento. A Figura 3.3a mostra a curva calculada para os dois concretos considerados.

Já comportamento a tração do concreto é dependente da resistência à tração e da energia de fratura. A energia de fratura define a área abaixo do gráfico tensão vs abertura da fissura. Nesse trabalho optou-se por utilizar a curva tensão vs abertura de fissura bilinear proposta no Model Code 2010 (MC2010) (FIB, 2013). A curva calculada é apresentada na Figura 3.3b para os dois concretos.

O ABAQUS permite se definir o comportamento a tração de 3 maneiras: curva tensão vs deformação plástica, curva tensão vs abertura de fissura e determinação de uma energia de fratura. O uso de curvas tensão-deformação introduz uma forte dependência da malha uma vez que se deve converter a curva tensão-abertura de fissura em uma relação tensão-deformação e para isso deve-se utilizar o tamanho característico de um elemento da malha onde se supõe que a fratura se distribuiu. Dessa forma, todos os elementos do modelo devem ter o mesmo tamanho, ou cada elemento deve ter sua própria curva. Por outro lado, o ABAQUS oferece um método de regularização onde o usuário pode inserir a relação tensão-abertura de fissura. Essa formulação parte do conceito de que um corpo tracionado irá fraturar em alguma seção, após esse corpo ser suficientemente tracionado o seu alongamento será governado pela abertura da fissura independentemente do tamanho 
Figura 3.3 - Comportamento uniaxial do concreto

(a) Compressão

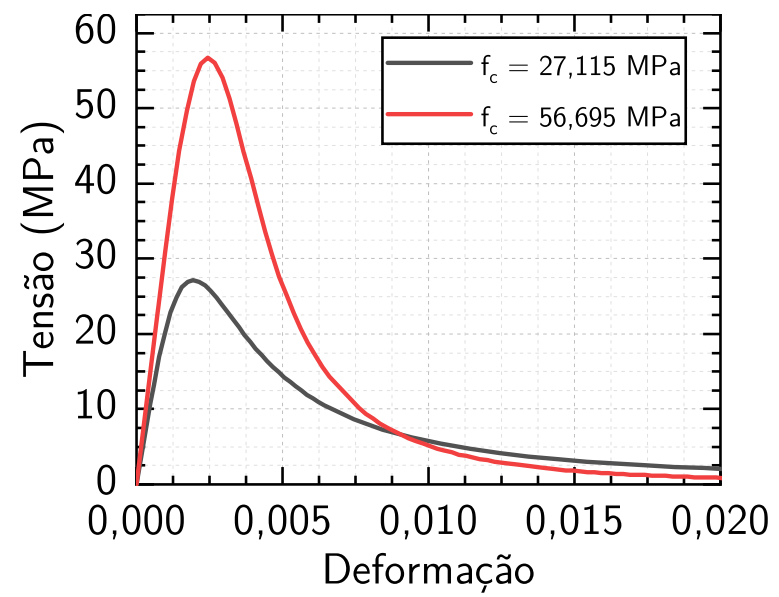

(b) Tração

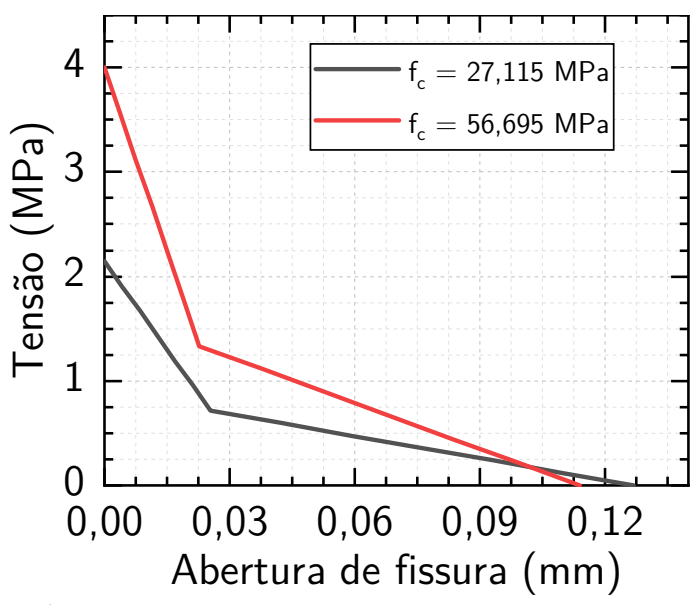

do corpo. A implementação desse modelo de tensão-abertura de fissura depende da definição de um comprimento característico associado a um ponto de integração. O ABAQUS calcula internamente esse comprimento característico como o comprimento típico de uma linha que cruza um elemento de primeira ordem e metade desse comprimento para elementos de segunda ordem (Dassault Systèmes Simulia Corp., 2014). Optou-se por adotar o modelo tensão-abertura de fissura uma vez que no modelo há elementos com tamanhos diferentes, além disso adota-se comportamento elástico linear no regime pré-ruptura $\left(\sigma<f_{c t m}\right)$.

O último dado de entrada necessário é a curva de evolução do dano em função das deformações plásticas. A atribuição de uma curva de evolução do dano implica numa penalização do módulo de elasticidade do material a medida que esse se danifica. Dessa forma, o descarregamento de um material acontece não mais com a rigidez inicial como em modelos de plasticidade mas com uma rigidez reduzida. Nesse trabalho optou-se por utilizar a lei de evolução do dano descrita na Equação 3.2 onde $d_{c}$ é o dano à compressão, $d_{t}$ é o dano a tração, $\sigma_{c}$ é a tensão de compressão, $\sigma_{t}$ é a tensão de tração e $w_{f i s}$ é a abertura de fissura. Assim, define-se a evolução do dano de acordo com a tensão e através da curva tensão-deformação obtém-se os pares dano e deformação plástica.

$$
\begin{aligned}
& d_{c}=1-\frac{\sigma_{c}}{f_{c m}} \leq 0,9 \text { se } \varepsilon\left(\sigma_{c}\right)>\varepsilon\left(f_{c m}\right) \\
& d_{t}=1-\frac{\sigma_{t}}{f_{c t m}} \leq 0,9 \text { se } w_{f i s}>0
\end{aligned}
$$

\subsubsection{Características geométricas e de análise}

Escolhe-se um modelo tridimensional para estudar o problema pelo entendimento de que o estado de tensão gerado pelo chumbador sob cisalhamento no bloco de concreto é tridimensional sendo tal fato fundamental para o seu estudo, especialmente na ruptura. A 
geometria e malha do modelo para o chumbador M12 estão apresentadas na Figura 3.4. O modelo consiste em um bloco de concreto suficientemente grande (320 x 320 x $320 \mathrm{~mm}$ ) para evitar efeitos de borda no comportamento do chumbador e comprimento de embutimento suficientemente grande $\left(8 D_{\text {nom }}=96 \mathrm{~mm}\right)$ para evitar ruptura por efeito alavanca (pry-out). Desconsiderou-se a rosca do chumbador adotando geometria cilíndrica com o diâmetro efetivo de acordo com a Tabela 3.1. Além disso, considerou-se continuidade na interface porca/chumbador com isso tornando-se uma única peça. A chapa de carregamento tem dimensões $50 \times 50 \times 5 \mathrm{~mm}$ onde se atribui o mesmo material do chumbador considerado. Foi utilizada a condição de simetria do problema em relação ao plano YZ, assim apenas metade da geometria é modelada.

Optou-se por utilizar uma malha de elementos finitos tetraédricos lineares de 4 nós (C3D4 na nomenclatura do ABAQUS) para o bloco de concreto e a chapa de carregamento. Esse tipo de elemento já foi usado com sucesso em simulações similares por Grosser (2012) e Tian et al. (2018a). Com os elementos tetraédricos foi utilizado o algoritmo de malhamento livre o qual permite um aumento da densidade de malha em áreas de interesse de forma simples. Assim, utilizou-se uma densidade de malha consideravelmente maior na zona próxima ao chumbador. Essa estratégia permite o adequado balanço entre acurácia e custo computacional. Já para o chumbador optou-se por utilizar elementos hexaédricos lineares de 8 nós com integração reduzida (C3D8R na nomenclatura do ABAQUS). Optou-se por essa alternativa pois os elementos hexaédricos permitem uma melhor acurácia na simulação da flexão quando comparados aos elementos elementos tetraédricos. Ao total foram necessários 8848 elementos to tipo C3D8R e 150750 elementos do tipo C3D4 os quais totalizaram 38975 nós.

Figura 3.4 - Geometria e malha - Chumbador M12
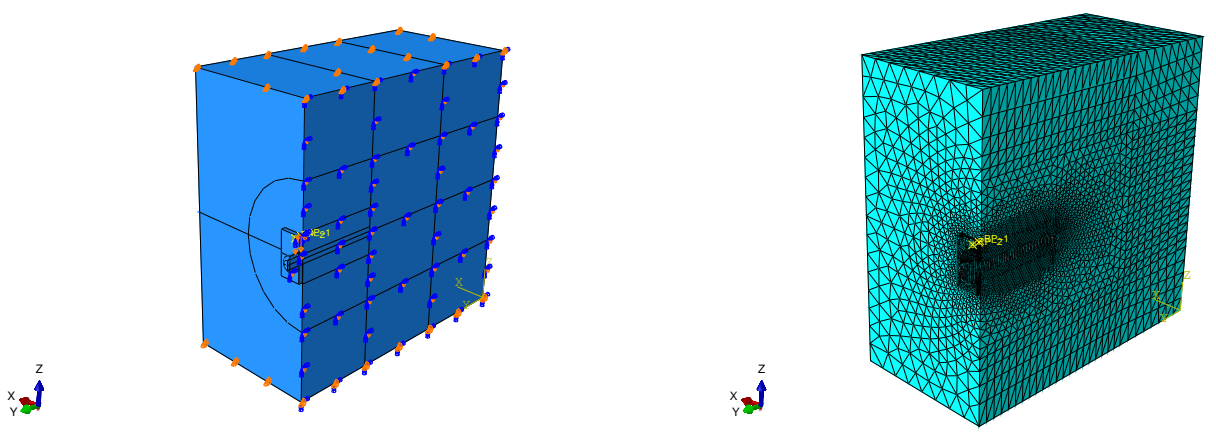

Fonte: $\mathrm{O}$ autor

O modelo para o chumbador M16 foi modificado para utilizar uma chapa maior pois foi verificado a partir das primeiras simulações que o tamanho da chapa utilizado no modelo com chumbador M12 seria muito pequeno nesse caso. Grosser (2012) não traz os dados geométricos da chapa utilizada, no entanto, através de uma inspeção visual nas imagens percebe-se as dimensões da chapa do modelo com chumbador M12 estava pequena. 
Quando o tamanho da chapa foi aumentado percebeu-se que ainda assim ela não oferecia o confinamento necessário pois era muito flexível, assim sua espessura foi aumentada. A Figura 3.5 mostra a geometria e para o modelo do Chumbador M16 que se aproxima mais do ensaio o qual tem uma chapa espessa com inserts específicos para cada chumbador (ver Figura 3.1).

Figura 3.5 - Malha - Chumbador M16

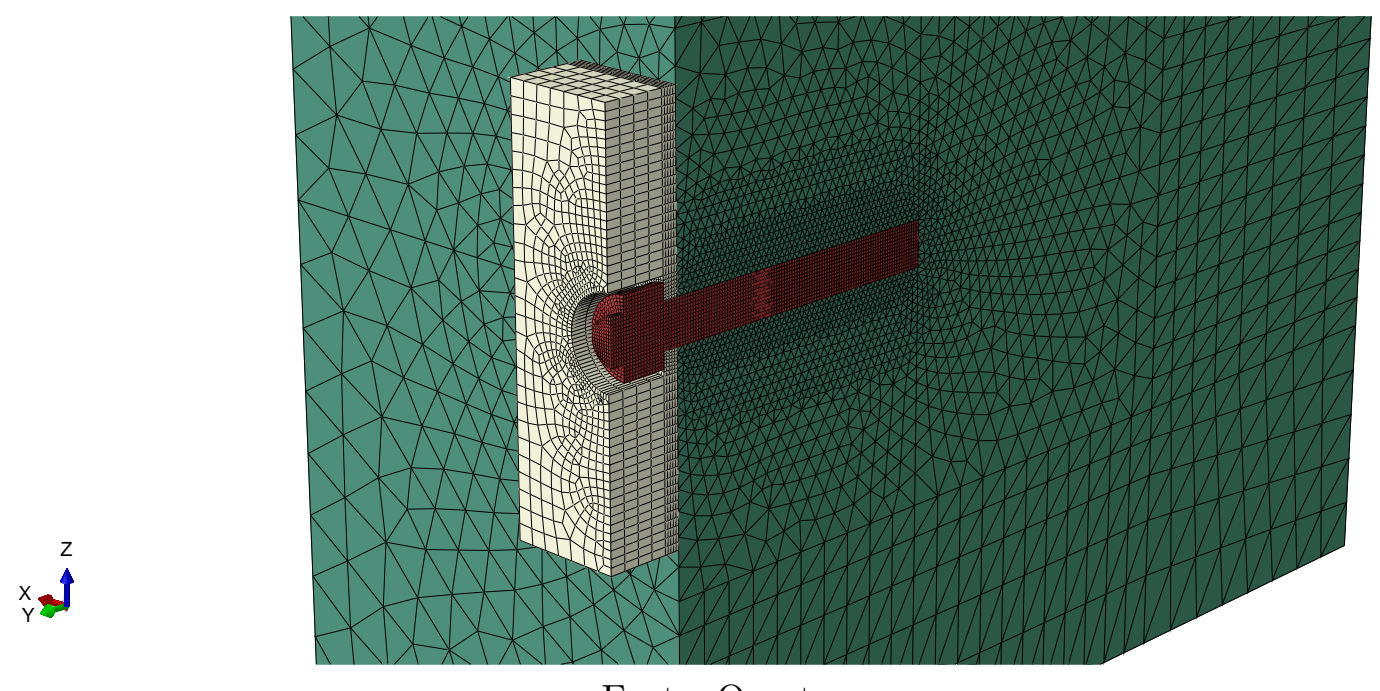

Fonte: $\mathrm{O}$ autor

Adota-se interação do tipo contato entre a chapa de carregamento, chumbador e bloco de concreto. Esse tipo de interação permite a separação das superfícies assim como se espera em ensaio. Foi utilizado contato por penalização com discretização do tipo superfície à superfície. Esse tipo de contato prescreve que um conjunto de nós vizinhos na superfície escrava não interseccione a superfície mestre num sentido médio entre esses nós, desta forma as forças de contato são suavizadas para levar em conta as imperfeições geométricas presentes devido a discretização em malha de elementos finitos.

No contato entre chapa e chumbador e entre chapa e face do bloco foi adotado contato com condição de não-penetração (hard contact) e ausência de atrito. Já no contato entre chumbador e o bloco de concreto foi adotado contato com condição de não-penetração e coeficiente de atrito de Coulomb $\mu=0,8$ de modo similar as simulações realizadas por Grosser (2012) para chumbador por adesão química.

As condições de contorno são impostas em deslocamento. Para o topo e base do bloco de concreto adota-se restrição total de deslocamentos. Já para o plano de simetria YZ que passa pelo centro do chumbador é adotada condição de deslocamento nulo na direção X.

A Figura 3.6 mostra como é realizado o controle de deslocamento na chapa sendo análoga para o modelo do chumbador M16. Toda a lateral da chapa está acoplada a um nó mestre mantendo um deslocamento de corpo rígido em relação a aquele. Assim, foi imposto 
deslocamento controlado no nó mestre na direção Z que reflete em deslocamento na chapa. Todas as rotações da chapa são impedidas através de condições de contorno apropriadas no nó mestre. Por outro lado, durante as análises verificou-se que seria interessante controlar como a chapa se move na direção Y. Assim, utilizando um elemento de conexão não-linear foi implementado uma conexão entre o nó mestre da chapa e um nó fixo auxiliar. Foi utilizado um elemento conector com propriedade stop que permite que a chapa se mova inicialmente sem nenhuma restrição na direção Y e após um deslocamento crítico de 0,05 mm há restrição total. A possibilidade desse deslocamento é importante pois afetam o estado de confinamento do concreto e tem grande impacto na resposta inicial do sistema.

Figura 3.6 - Detalhe do acoplamento na chapa

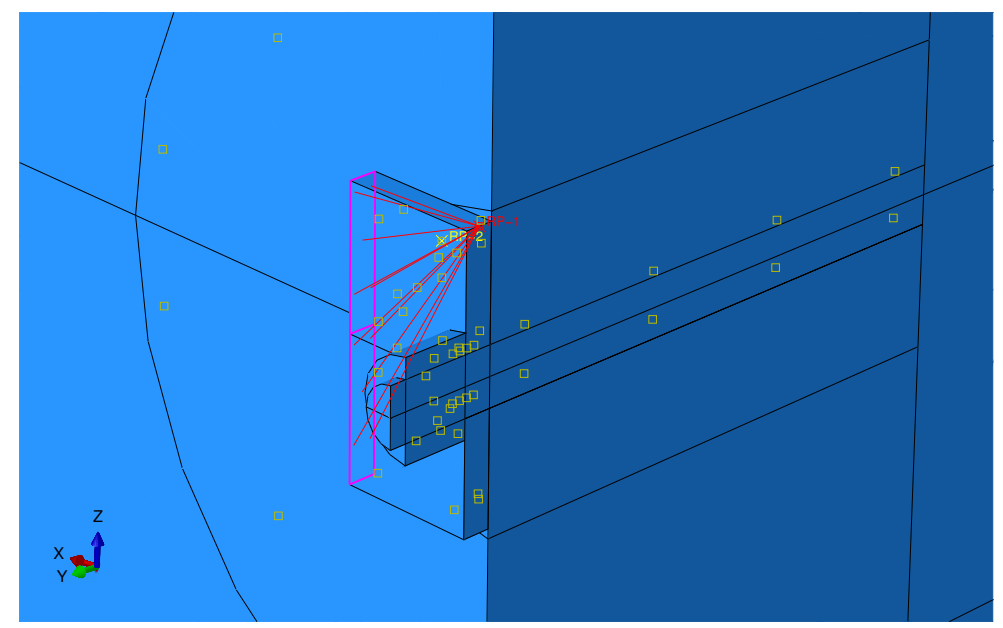

Fonte: O autor

Nas simulações foi utilizado carregamento por controle de deslocamento na chapa onde se escolheu um deslocamento alvo compatível com o deslocamento último experimental. Foi utilizada análise dinâmica explicíta quasi-estática utilizando a estratégia de escala da massa para aumentar o incremento de tempo estável e assim reduzir o custo computacional. O uso de algoritmos explícitos para análises quasi-estáticas é utilizado principalmente para problemas que envolvam situações complexas de contato, plasticidade e dano. A presença dessas características no modelo frequentemente leva a instabilidades locais as quais a análise estática e implícita apresenta dificuldade de encontrar uma resposta convergente. Na literatura é possível encontrar situações onde essa estratégia é utilizada com sucesso inclusive na análise de conexões aço-concreto (PAVLOVIČ; VELJKOVIČ, 2017; THAI et al., 2017; KIRANE; BAŽANT; ZI, 2014).

O ABAQUS permite a escala da massa de forma variável ao longo da análise de forma que seja satisfeito um incremento de tempo estável alvo. Dessa forma, apenas a quantidade necessária de massa é adicionada em cada elemento para satisfazer o tempo estável alvo. Dessa forma, menos massa é adicionada ao sistema se comparado a uma escala global ajudando a controlar os efeitos inerciais. O tempo de simulação nessas análises pode 
ser arbitrário uma vez que não se está simulando o ensaio na escala de tempo real. O que se deseja é encontrar uma combinação entre taxa de carregamento e escala da massa que produza uma resposta quasi-estática a um custo computacional razoável. Em todas as simulações utiliza-se tempo total de simulação de $30 \mathrm{~s}$, sendo que o deslocamento imposto na chapa aumenta de forma gradual durante esse tempo seguindo uma amplitude em forma de S (opção Smooth no ABAQUS). O uso de uma amplitude suave ao longo do tempo ajuda a minimizar os efeitos inerciais que o carregamento provoca. Após alguns testes chegou-se a conclusão que o incremento estável alvo de 0,0005 s foi suficiente para os resultados desejados.

\subsubsection{Resultados e Análise}

Nessa seção apresenta-se os resultados das simulações descritas na seção anterior. O Apêndice $\mathrm{C}$ traz um resumo do custo computacional demandado em todas as simulações.

\subsubsection{Chumbador M12}

A Figura 3.7 mostra a curva carga vs deslocamento experimental e numérica obtida para o chumbador M12 considerando material base aço. Analisando-a percebe-se que há uma boa concordância com a carga última mas uma diferença significativa na rigidez inicial. Uma hipótese para essa diferença é na possível acomodação inicial do sistema de ensaio especialmente na interface entre chapa e chumbador. Cabe lembrar que no modelo de elementos finitos não foi considerada a rosca da barra explicitamente mas utilizado um diâmetro equivalente da área útil da barra. Por outro lado, destaca-se que passado a fase inicial, a rigidez do modelo numérico e dos ensaios tem boa aproximação. Cabe lembrar também que no modelo numérico o aço é elasto-plástico com encruamento, no entanto, não apresenta dano. Assim, as curvas apresentadas aqui ainda precisam ser avaliadas quanto ao seu intervalo de validade, isto é, antes que o deslocamento alcance $2 \mathrm{~mm}$ o aço já está com deformações excessivas que na prática o teriam levado a ruptura. As oscilações presentes na resposta numérica acontecem principalmente após o escoamento do chumbador o qual faz com que a condição geométrica no contato entre chapa e chumbador se torne mais complicada provocando oscilações na força de contato. No entanto, ressalta-se que é preciso avaliar o intervalo de validade e a maior parte dessas oscilações fica fora dele.

Os resultados com base em concreto são apresentados na Figura 3.8 e Figura 3.9. Aqui também vale reflexões similares quanto a rigidez inicial e o intervalo de validade dos gráficos. 
Figura 3.7 - Curva carga vs deslocamento - Chumbador M12 classes 8.8, 10.9 e 12.9 sob cisalhamento em bloco de aço

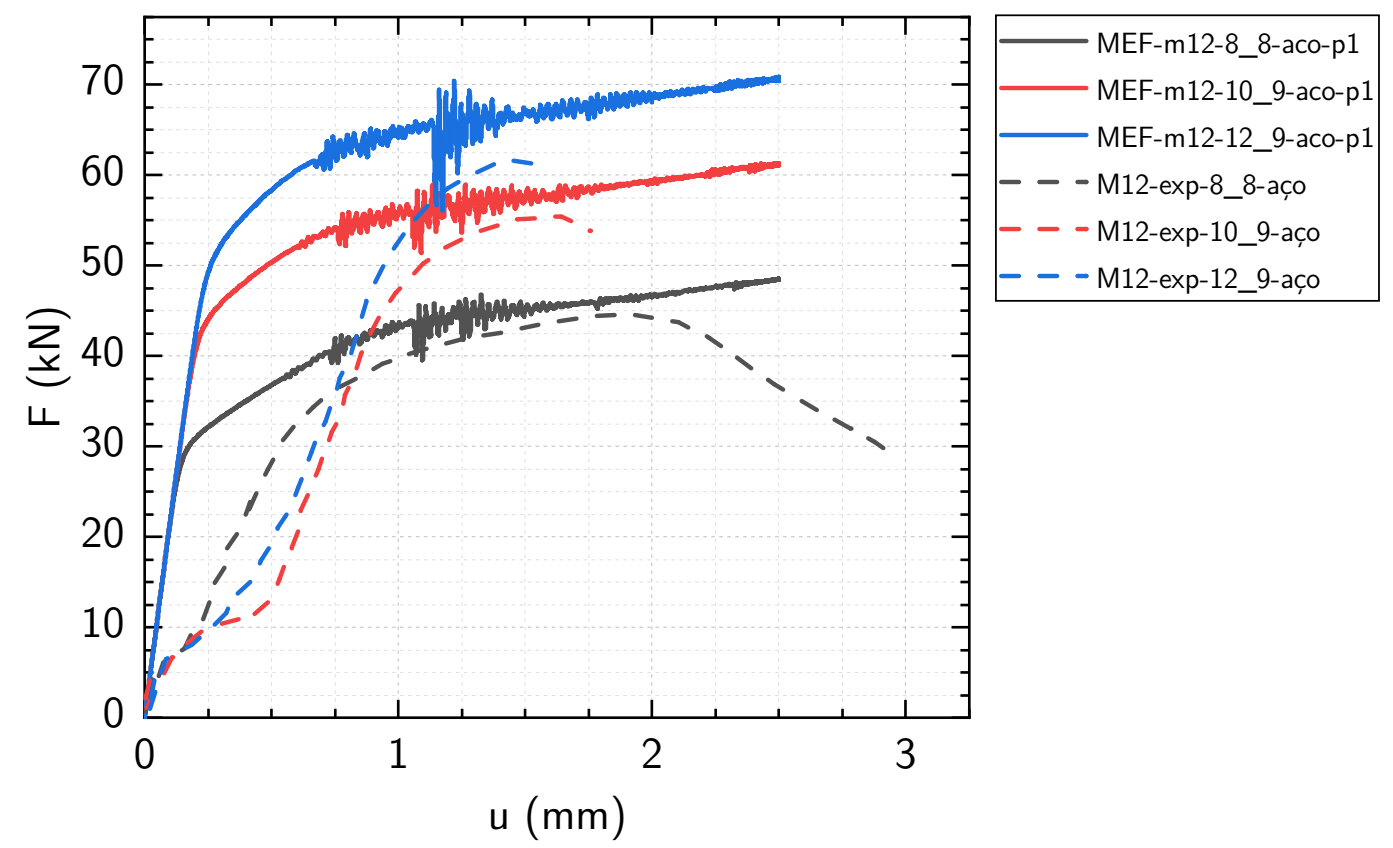

Fonte: O autor. Dados experimentais de Grosser (2012)

Figura 3.9 - Curva carga vs deslocamento - Chumbador M12 classes 8.8, 10.9 e 12.9 sob cisalhamento em concreto $f_{c}=56,695 \mathrm{MPa}$

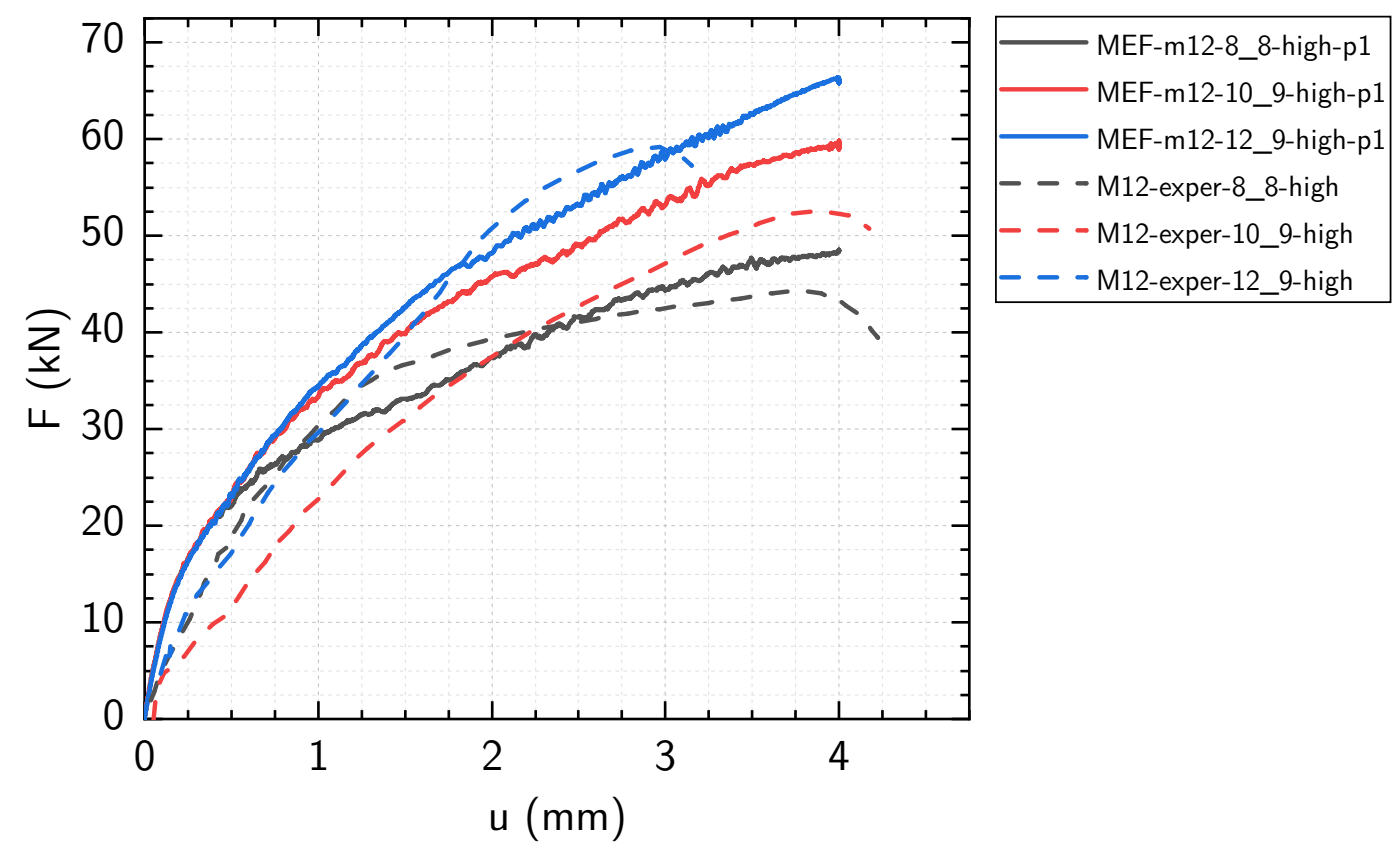

Fonte: O autor. Dados experimentais de Grosser (2012) 
Figura 3.8 - Curva carga vs deslocamento - Chumbador M12 classes 8.8, 10.9 e 12.9 sob cisalhamento em concreto $f_{c}=27,115 \mathrm{MPa}$

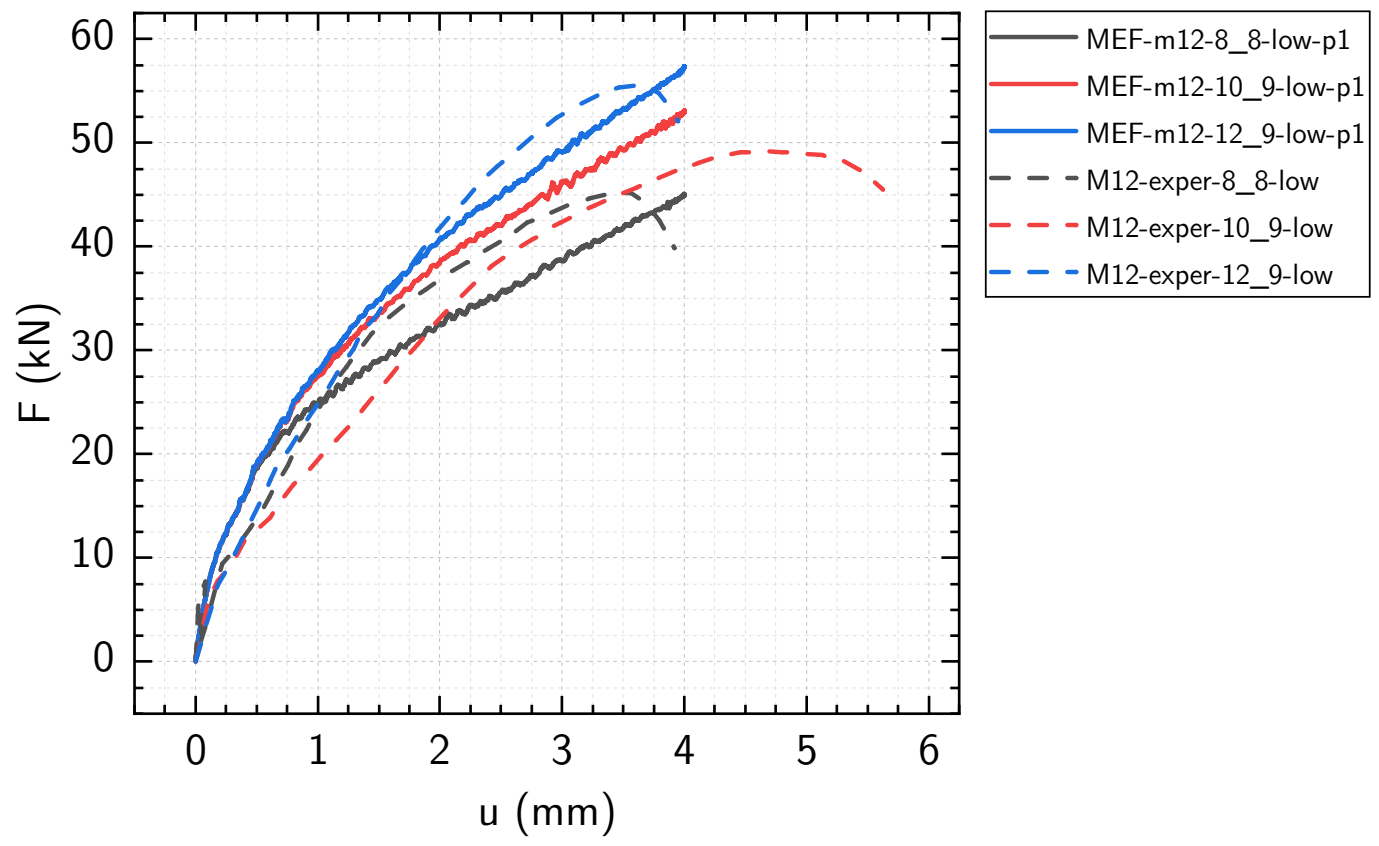

Fonte: O autor. Dados experimentais de Grosser (2012)

As Figuras 3.10, 3.11, 3.12, 3.13, 3.14 e 3.15 mostram alguns gráficos de contorno para o caso m12-8_8-low, ou seja, chumbador M12 classe de resistência 8.8 ancorado em concreto com $f_{c}=27,115 \mathrm{MPa}$. Destaca-se a Figura 3.14 que traz a informação de deformação que pode ser utilizada para definir o intervalo de validade das curvas Força vs deslocamento já que o modelo constitutivo do aço não contempla dano. Isto é, pode-se avaliar em qual ponto da história de carregamento as deformações no chumbador estão além do intervalo de validade da curva tensão-deformação uniaxial do aço, estabelecendo assim uma deformação de ruptura. 
Figura 3.10 - Tensão de Von Mises para chumbador M12 Classe 8.8 imerso em concreto $f_{c}=27,115 \mathrm{MPa}$

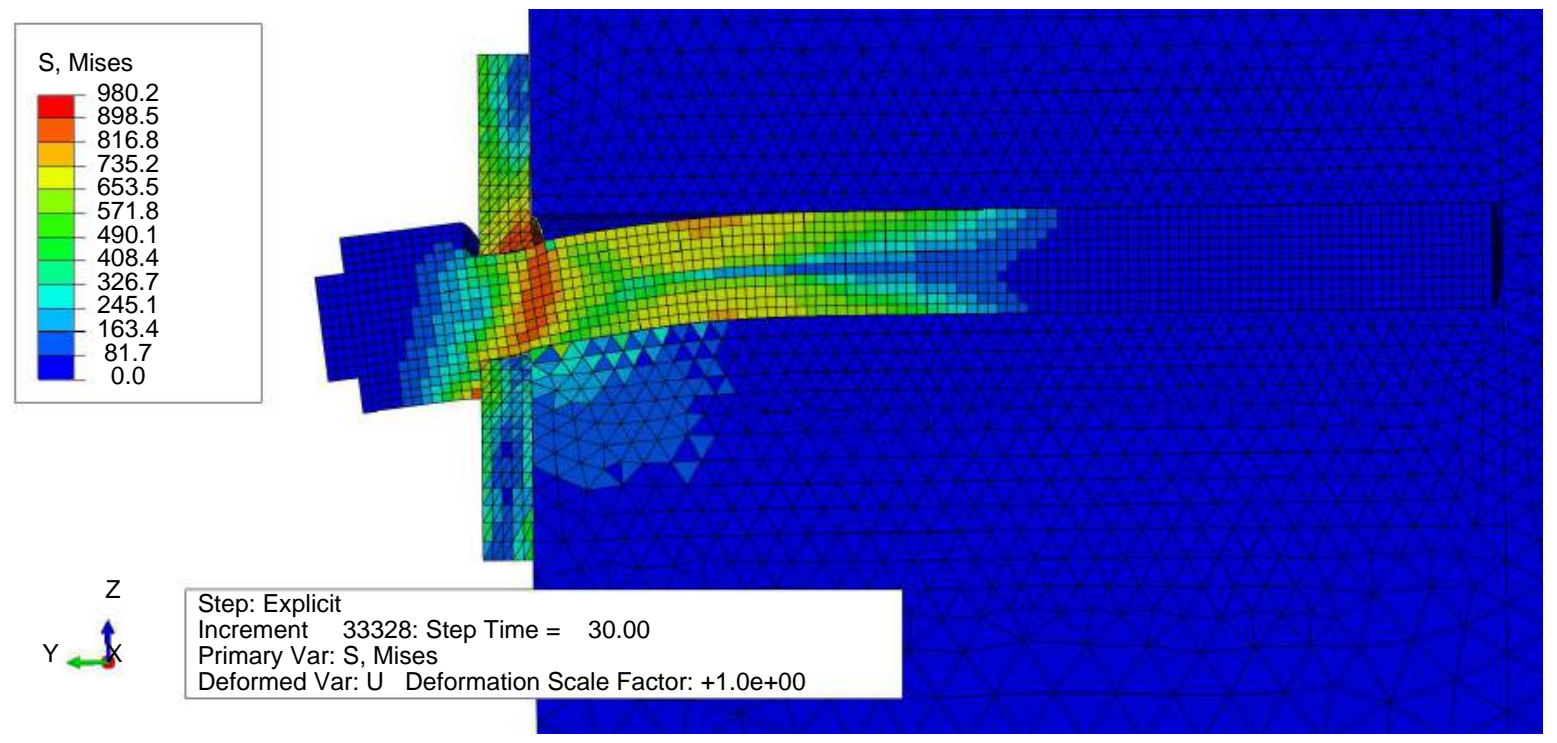

Fonte: $\mathrm{O}$ autor

Figura 3.11 - Dano a tração para chumbador M12 Classe 8.8 imerso em concreto $f_{c}=$ $27,115 \mathrm{MPa}$
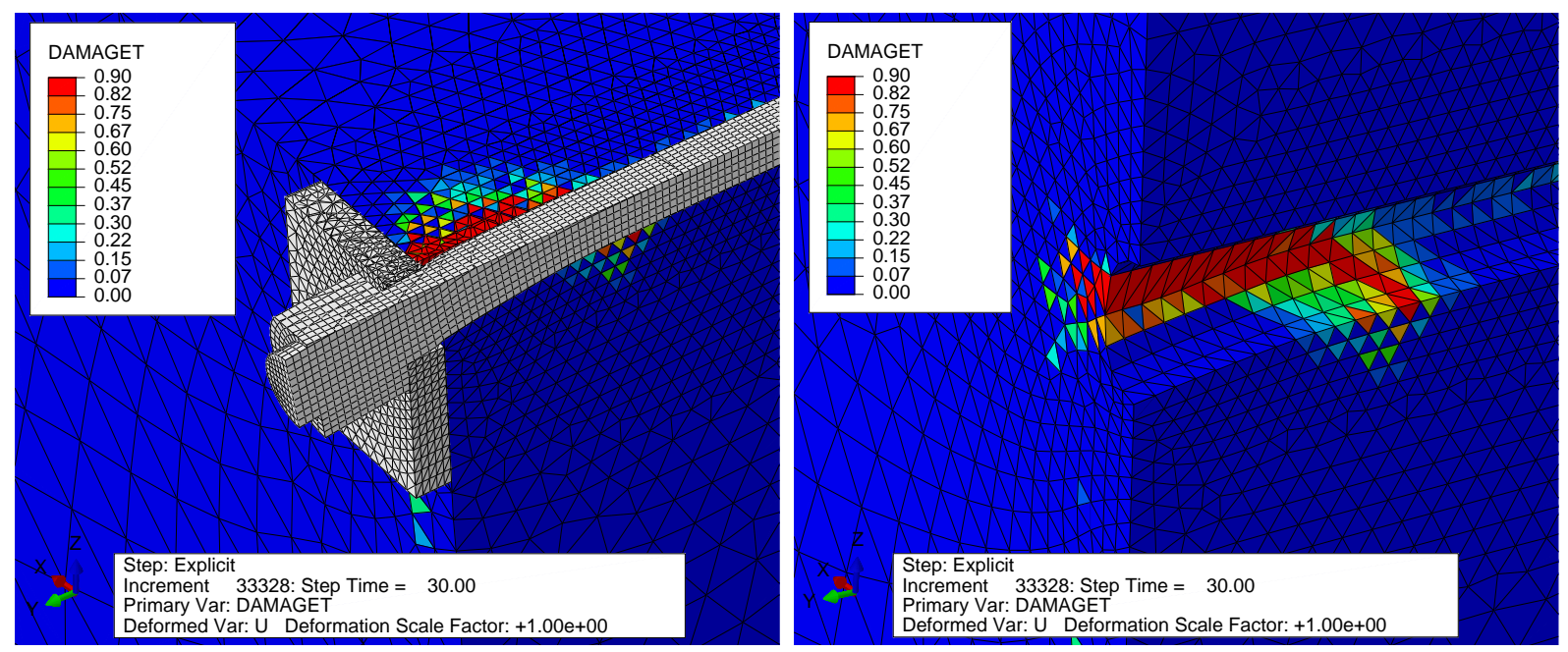

Fonte: $\mathrm{O}$ autor 
Figura 3.12 - Dano a compressão para chumbador M12 Classe 8.8 imerso em concreto $f_{c}=27,115 \mathrm{MPa}$

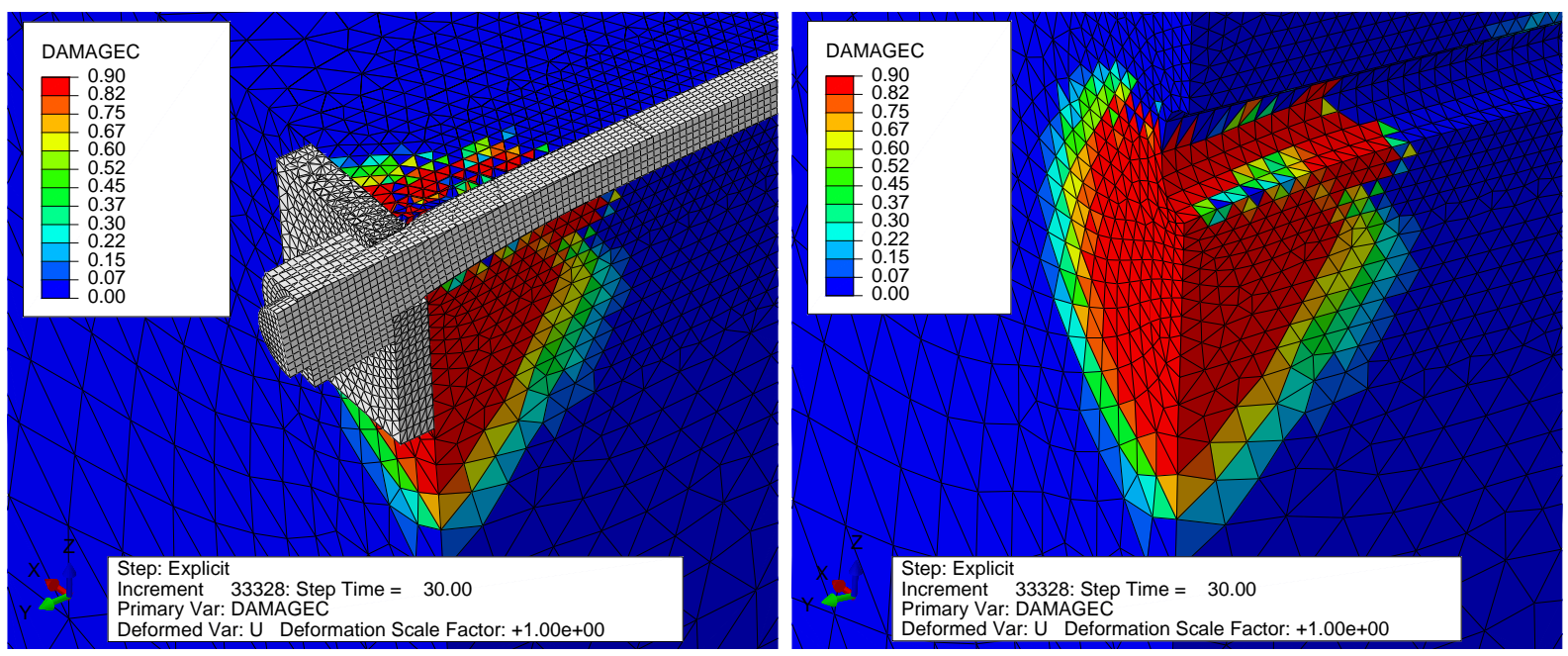

Fonte: $\mathrm{O}$ autor

Figura 3.13 - Deformação plástica equivalente à tração e à compressão no concreto para M12 Classe 8.8 imerso em concreto $f_{c}=27,115 \mathrm{MPa}$
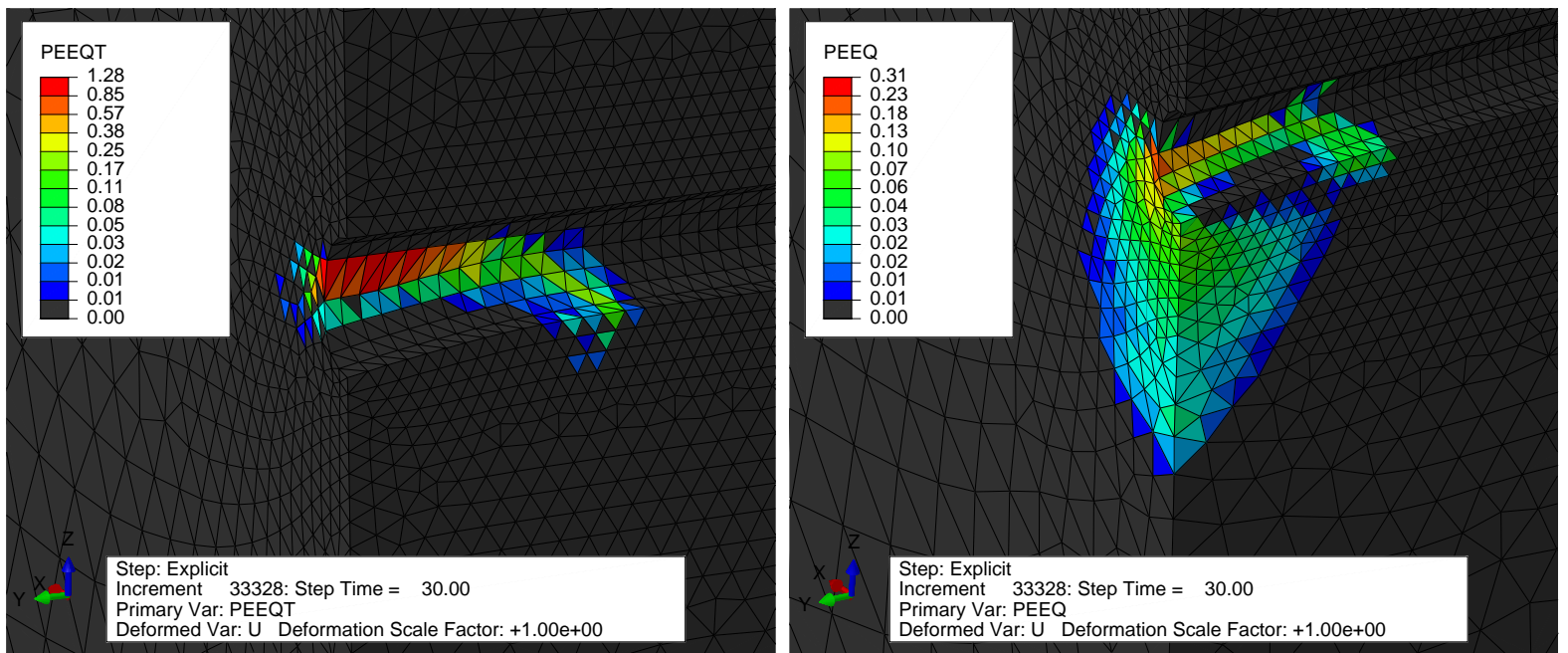

Fonte: O autor 
Figura 3.14 - Deformação plástica equivalente no aço para M12 Classe 8.8 imerso em concreto $f_{c}=27,115 \mathrm{MPa}$

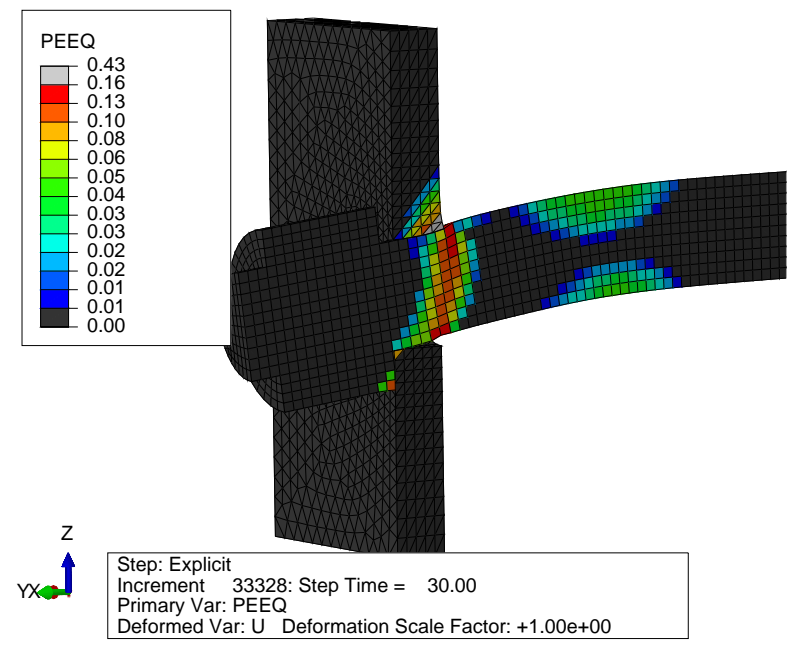

Fonte: $\mathrm{O}$ autor

Figura 3.15 - Campo de deslocamentos U3 e U2 para M12 Classe 8.8 imerso em concreto $f_{c}=27,115 \mathrm{MPa}$
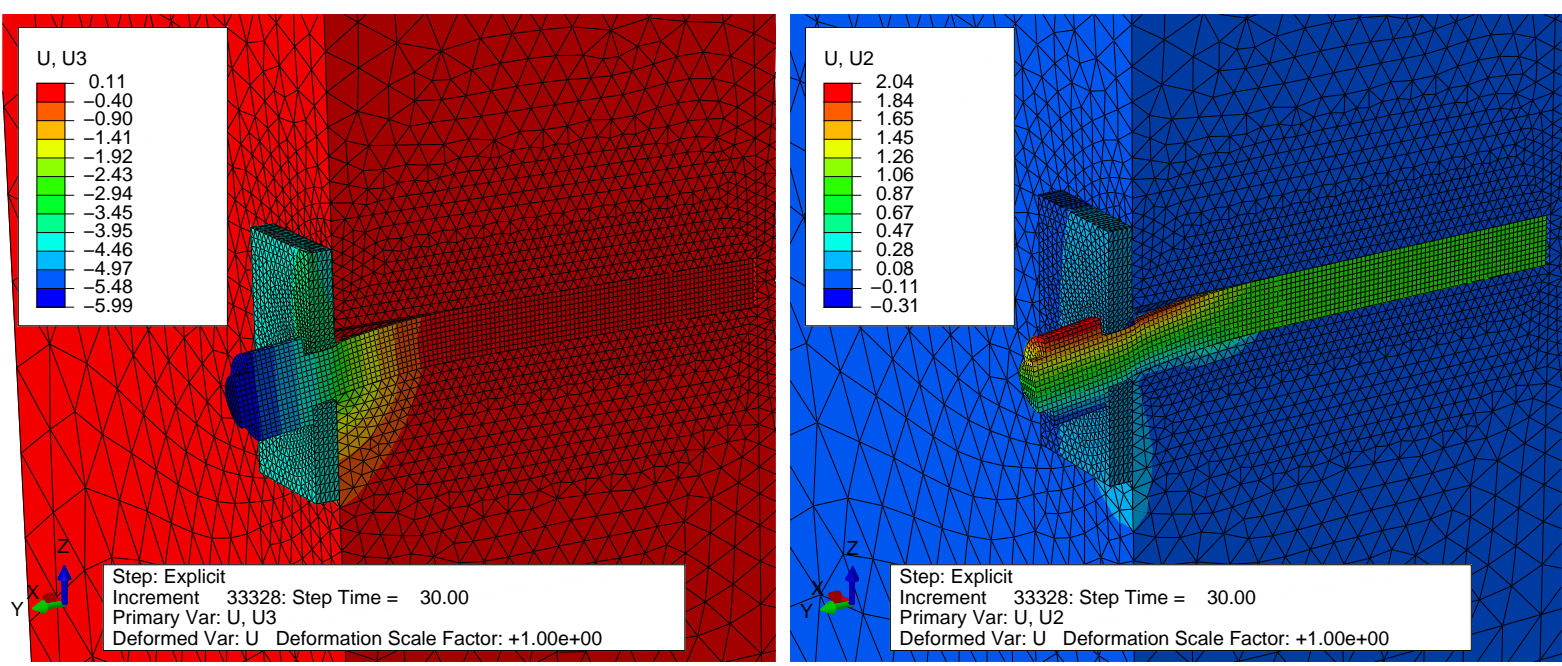

Fonte: $\mathrm{O}$ autor 


\subsubsection{Chumbador M16}

Os resultados das curvas Força vs deslocamento são apresentados nas Figuras 3.16, 3.17 e 3.18. Os gráficos mostram boa concordância com os resultados experimentais. Aqui também análises similares as do modelo com chumbador M12 podem ser aplicadas quanto a rigidez inicial. Já as Figuras 3.19, 3.20 e 3.21 mostram alguns resultados para o caso m16-8_8-low, isto é, chumbador M16 classe de resistência 8.8 ancorado em concreto com $f_{c}=27,115 \mathrm{MPa}$.

Figura 3.16 - Curva carga vs deslocamento - Chumbador M16 classes 8.8, 10.9 e 12.9 sob cisalhamento em bloco de aço

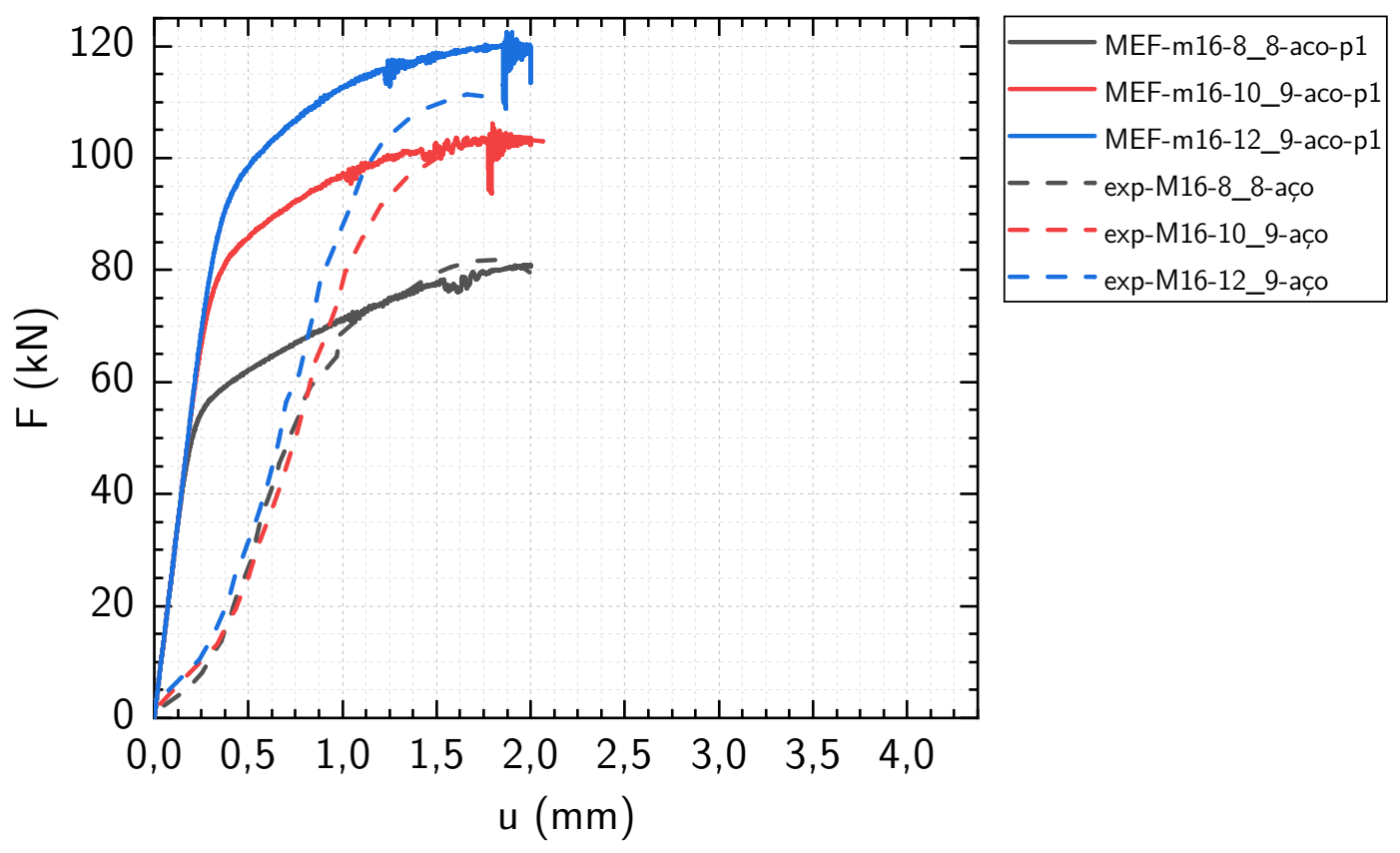

Fonte: O autor. Dados experimentais de Grosser (2012) 
Figura 3.17 - Curva carga vs deslocamento - Chumbador M16 classes 8.8, 10.9 e 12.9 sob cisalhamento em concreto $f_{c}=27,115 \mathrm{MPa}$

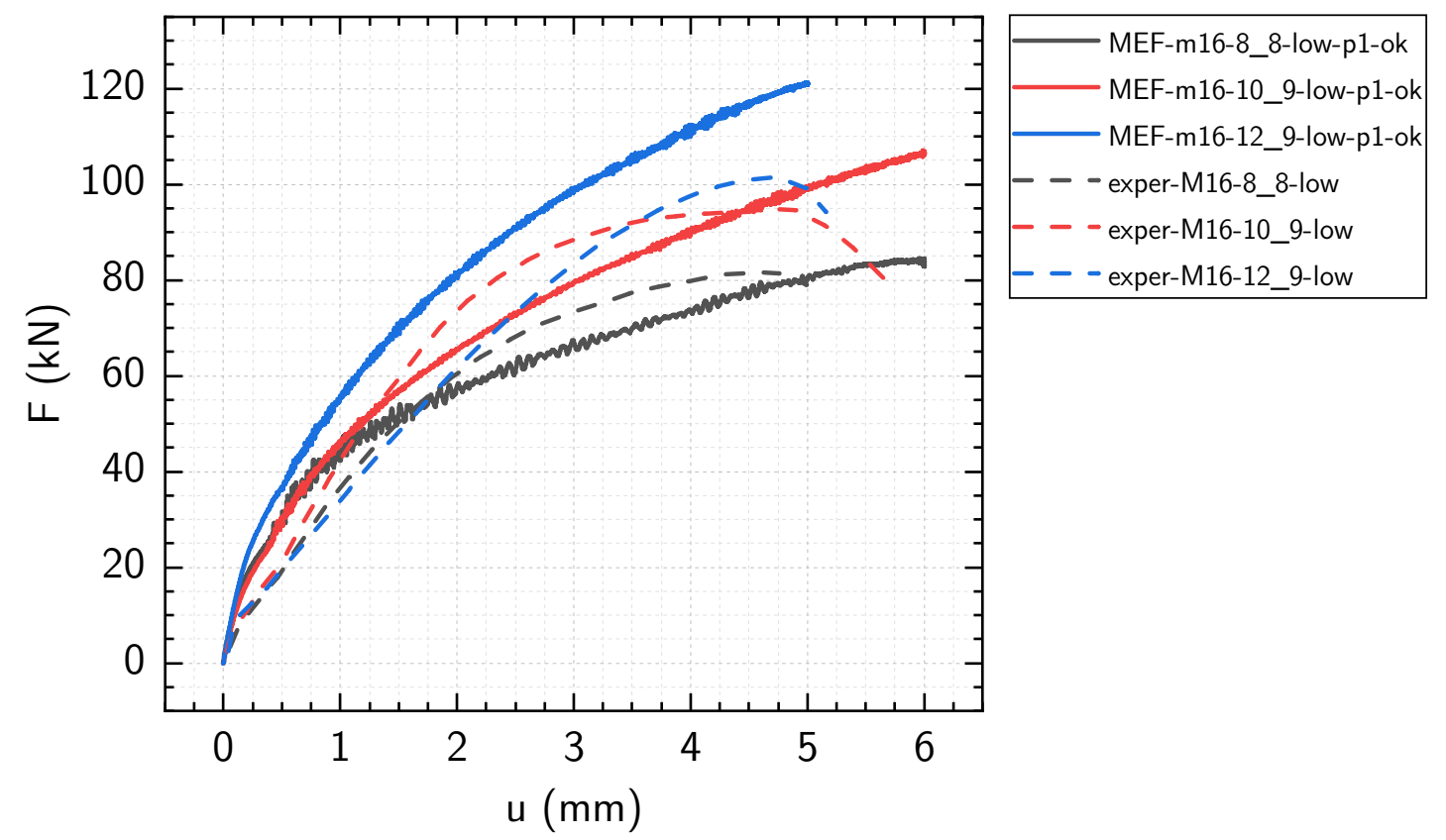

Fonte: O autor. Dados experimentais de Grosser (2012)

Figura 3.18 - Curva carga vs deslocamento - Chumbador M16 classes 8.8, 10.9 e 12.9 sob cisalhamento em concreto $f_{c}=56,695 \mathrm{MPa}$

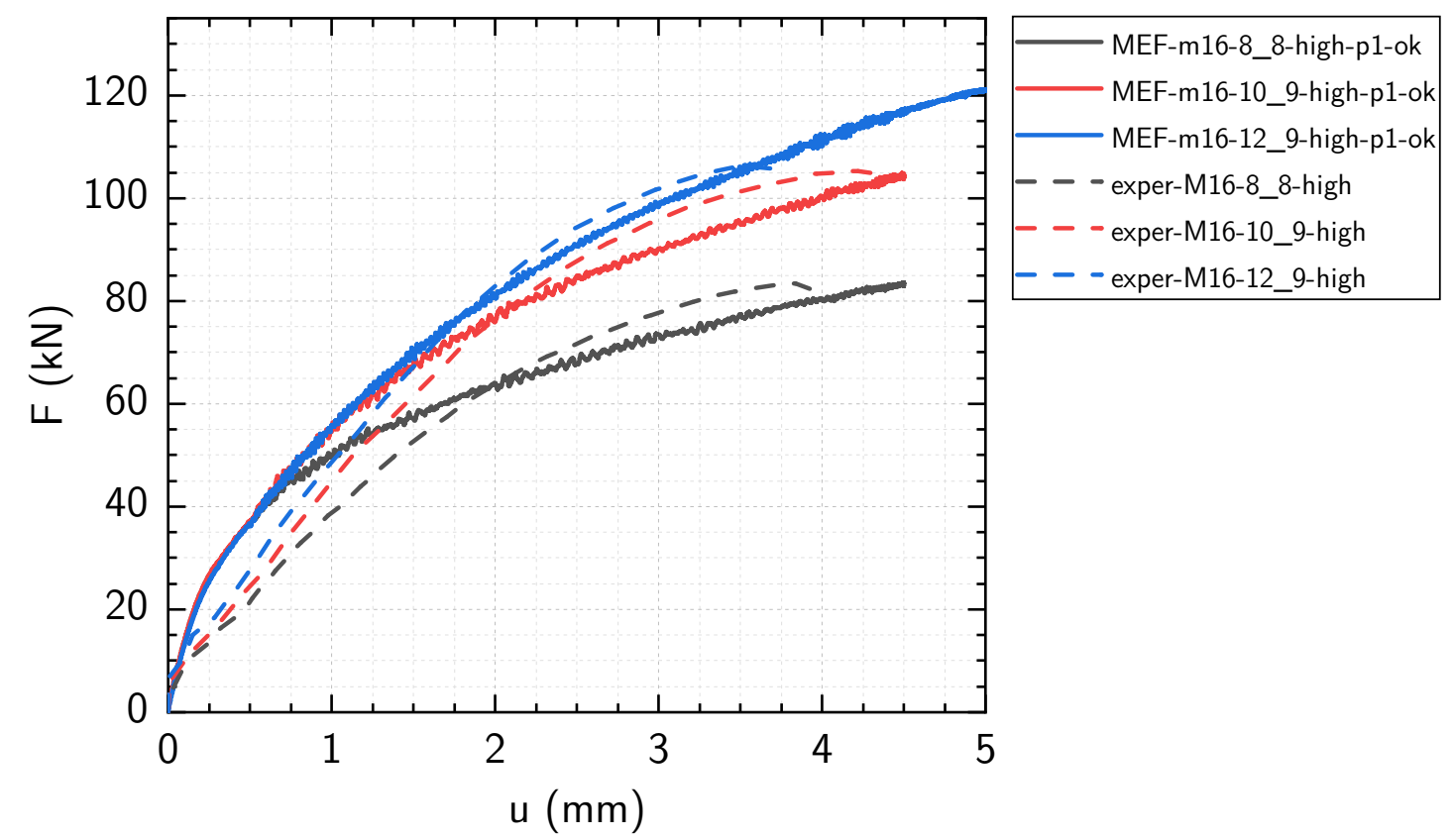

Fonte: O autor. Dados experimentais de Grosser (2012) 
Figura 3.19 - Tensão de Von Mises e deformação plástica equivalente para M16 Classe 8.8 imerso em concreto $f_{c}=27,115 \mathrm{MPa}$

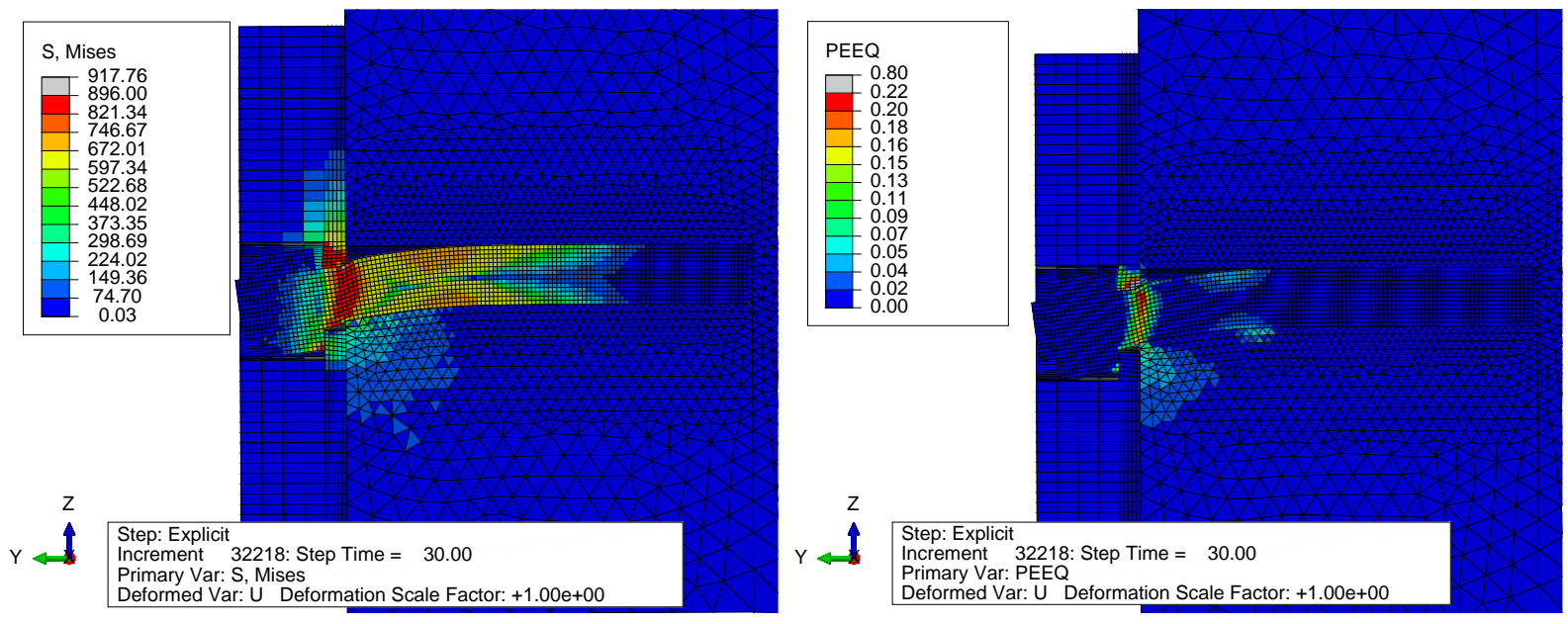

Fonte: O autor

Figura 3.20 - Dano à compressão e à tração para M16 Classe 8.8 imerso em concreto $f_{c}=27,115 \mathrm{MPa}$
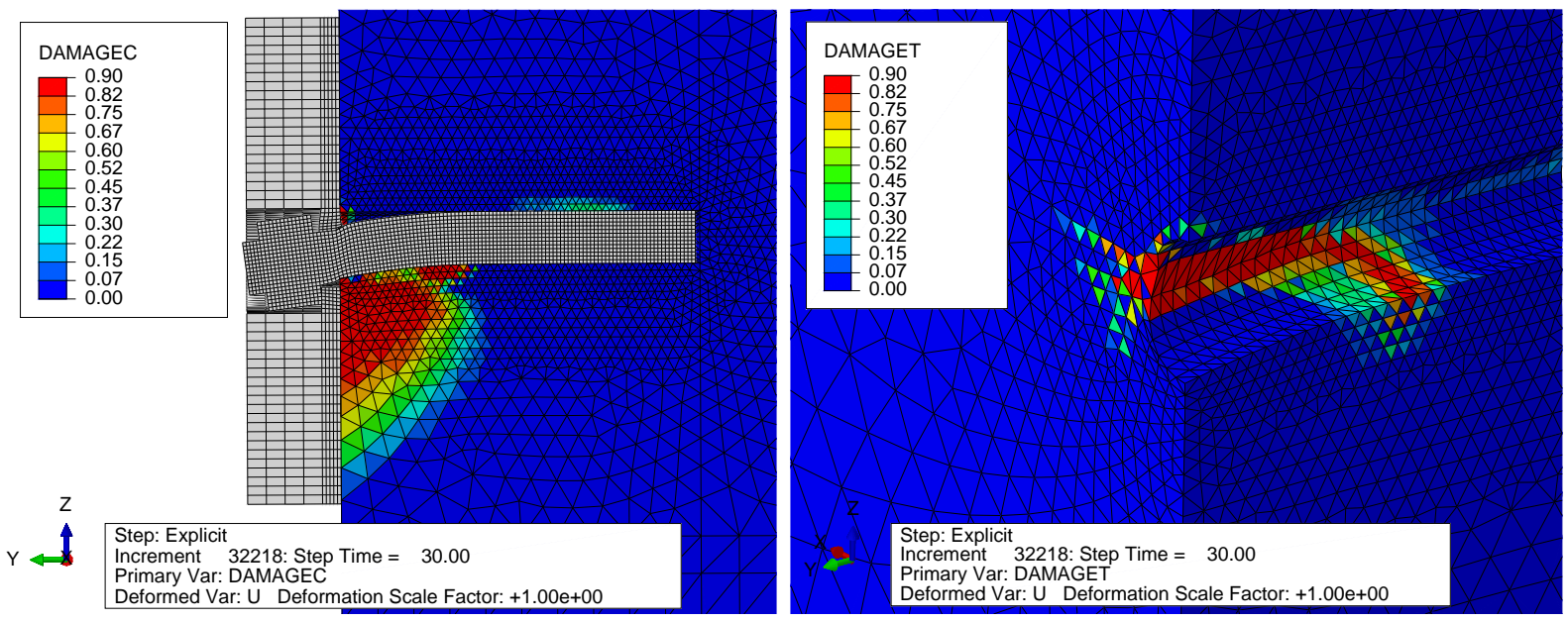

Fonte: O autor 
Figura 3.21 - Campo de deslocamentos U3 e U2 para M16 Classe 8.8 imerso em concreto $f_{c}=27,115 \mathrm{MPa}$
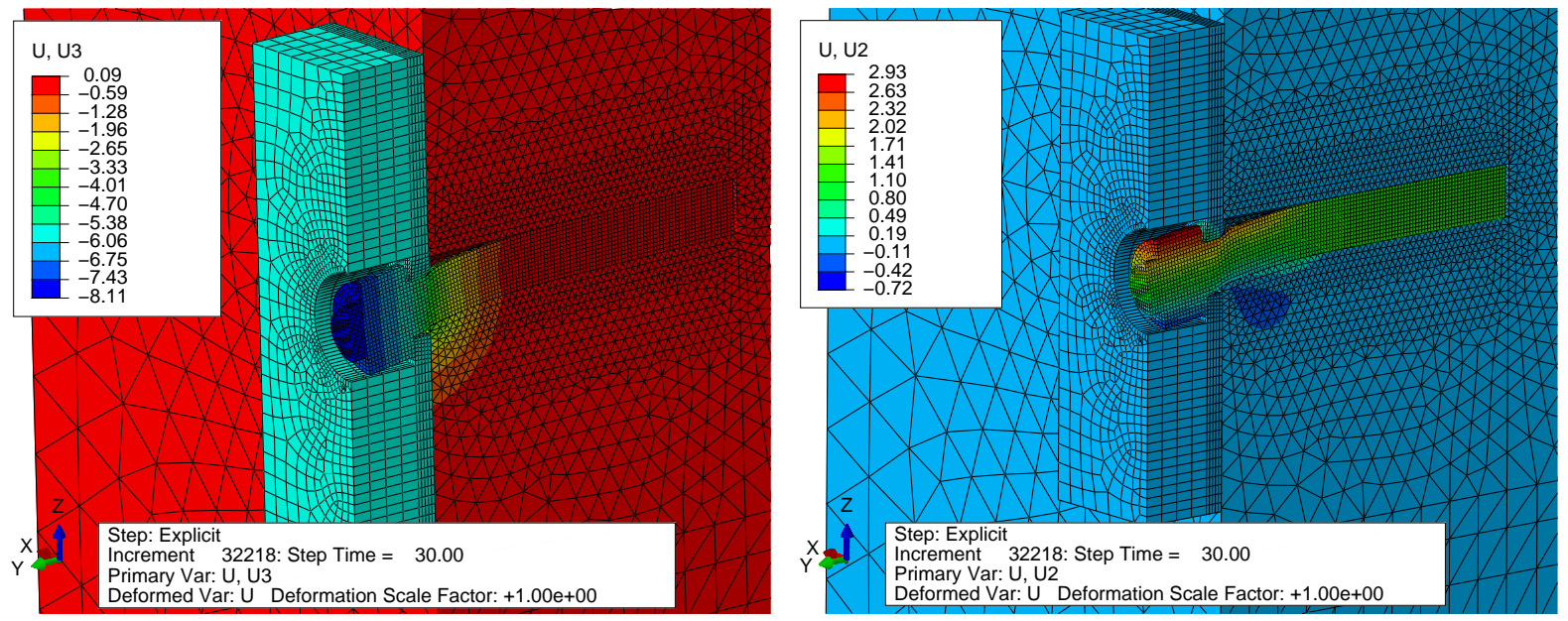

Fonte: $\mathrm{O}$ autor

\subsubsection{Análise da estratégia dinâmica explícita}

Uma das formas de se avaliar se a solução não está comprometida devido as forças inerciais derivadas da massa artificial adicionada é avaliar a proporção entre a energia cinética do modelo e o trabalho realizado pelas forças externas. A Figura 3.22 mostra essa relação para os modelos m12-8_8-low, m12-10_9-low e m12-12_9-low. Percebe-se que na maior parte do intervalo de carregamento essa relação fica abaixo de $10 \%$, assim pode-se assumir uma reposta quasi-estática do problema. Como comparação adicional os mesmos modelos foram analisados utilizando uma análise estática implícita através do algoritmo de Newton-Raphson. Os resultados são apresentados na Figura 3.23 onde as curvas do modelo implícito são apresentadas até o ponto onde houve convergência. Percebe-se que no intervalo onde houve convergência há boa concordância. Dependendo do modelo o algoritmo implicíto tem melhor ou pior desempenho sendo que nesse caso há dificuldade na presença de grandes perdas de rigidez devido o dano o qual pode levar a possíveis instabilidades em certos elementos da malha. No modelo m12-12_9-low, por exemplo, a análise estática não converge para deslocamentos acima de aproximadamente $1 \mathrm{~mm}$. 
Figura 3.22 - Proporção entre energia cinética do modelo e o trabalho das forças externas ao longo do deslocamento imposto
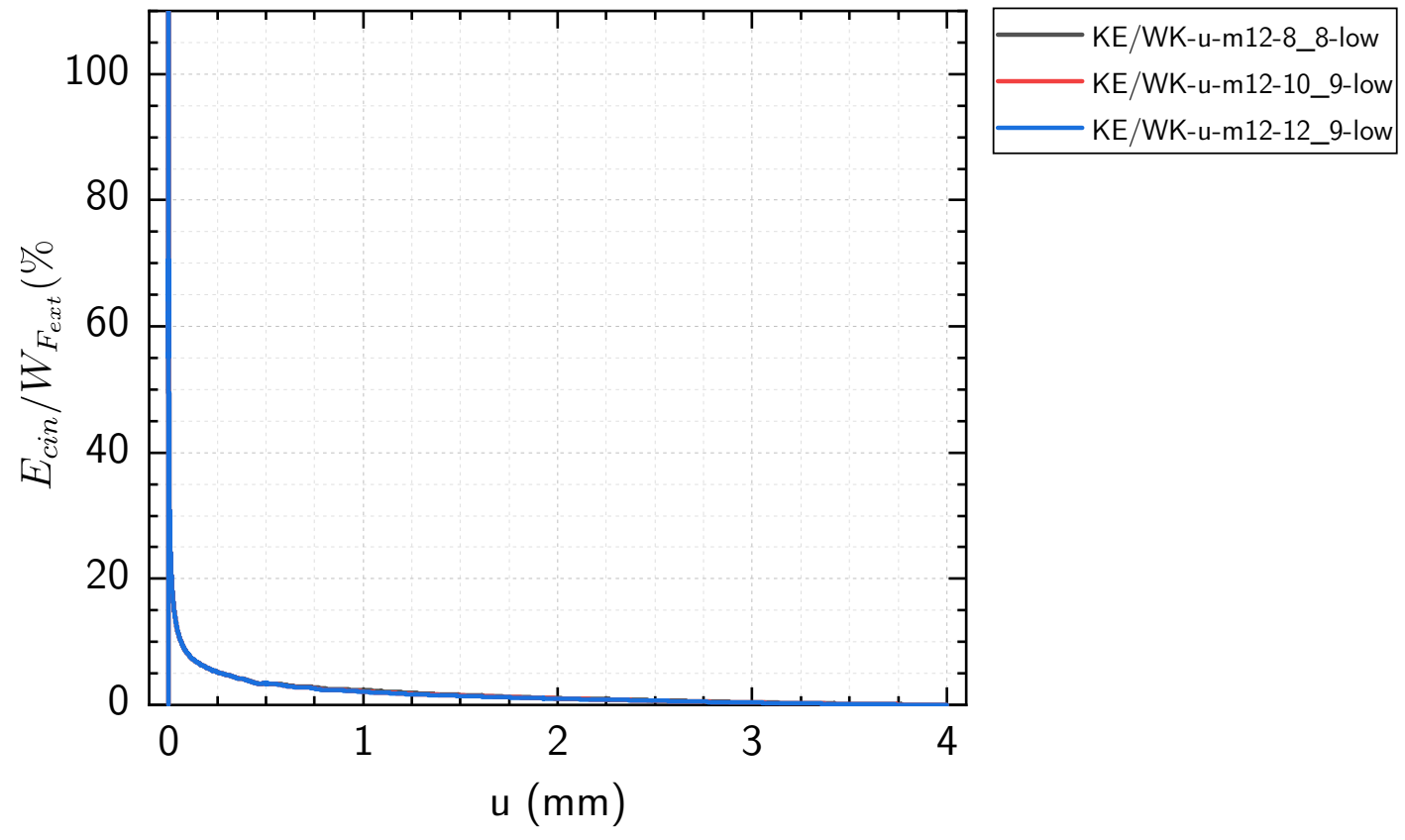

Fonte: $\mathrm{O}$ autor

Figura 3.23 - Comparação entre simulações explícita quasi-estática e estática implicíta

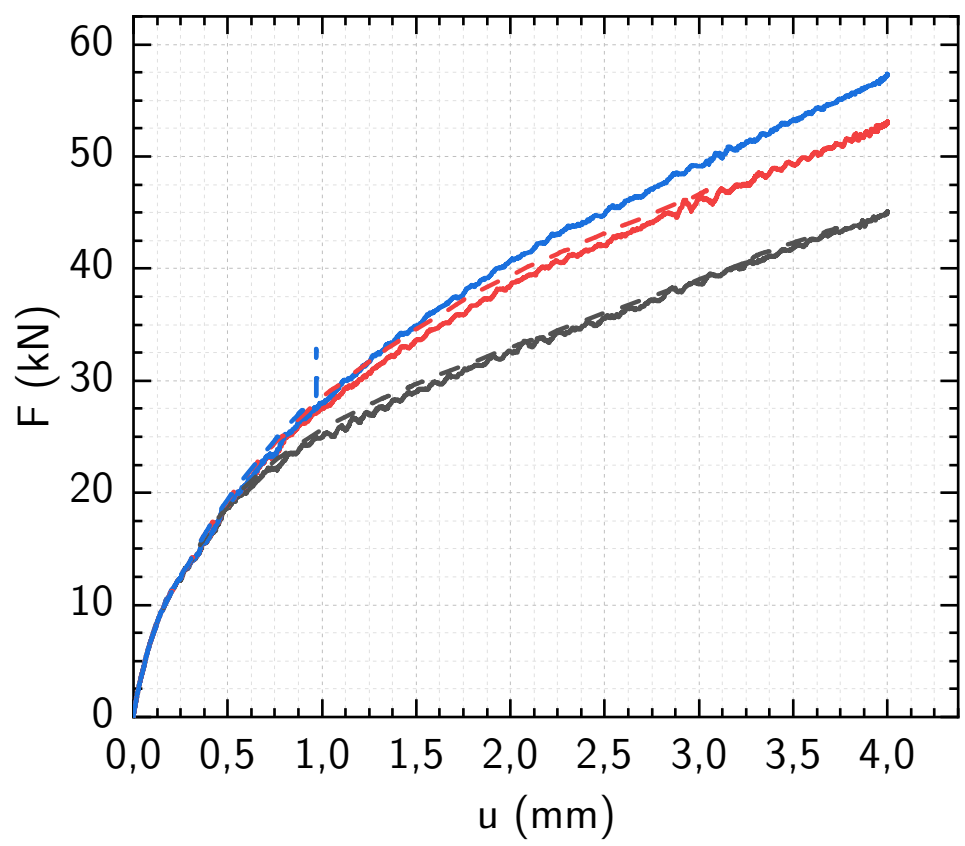

Dinâmico explícito com escalonamento

da massa: Quasi-estático

— MEF-m12-8_8-low-p1

MEF-m12-10_9-low-p1

MEF-m12-12_9-low-p1

Estático implícito

- - - MEF-m12-8_8-low-p2-imp

- - MEF-m12-10_9-low-p2-imp

- - - MEF-m12-12_9-low-p2-imp

Fonte: O autor 
Com essas comparações espera-se mostrar a adequabilidade da análise dinâmica explícita com escala de massa para análises quasi-estáticas. Essa estratégia se mostra robusta desde que associada com bom pós-processamento dos dados, especialmente as parcelas de energia, para avaliar a qualidade da resposta. A ausência de necessidade de inversões de matrizes e o uso de aumento da massa para reduzir o tempo de processamento traz algumas vantagens entre elas, o menor uso de memória, melhor escalabilidade e maior robustez ao tratar instabilidades geradas por dano e contato quando comparado a análise estática implícita.

\subsection{Viga denteada pré-moldada leve}

Mamede (2001) faz o dimensionamento de uma escada pré-moldada para uso em edifícios de alvenaria estrutural. Essa escada é composta por peças leves pré-moldadas de argamassa armada. Ou seja, as peças são de pequena espessura e concreto com ausência de agregados graúdos. Os degraus são peças em L que vencem um vão de $120 \mathrm{~cm}$ e se apoiam em vigas denteadas. As vigas por sua vez são conectadas a parede através de chumbadores metálicos. O dimensionamento foi realizado utilizando as premissas de segurança estrutural e também considerando o critério de massa máxima das peças para permitir a construção sem o uso de equipamentos de içamento. A Figura 3.24 mostra o esquema estático da viga de acordo com as cargas características calculadas por Mamede (2001). Já a Figura 3.25 mostra os momentos e reações de apoio devido a essa carga característica.

Figura 3.24 - Esquema estático da viga

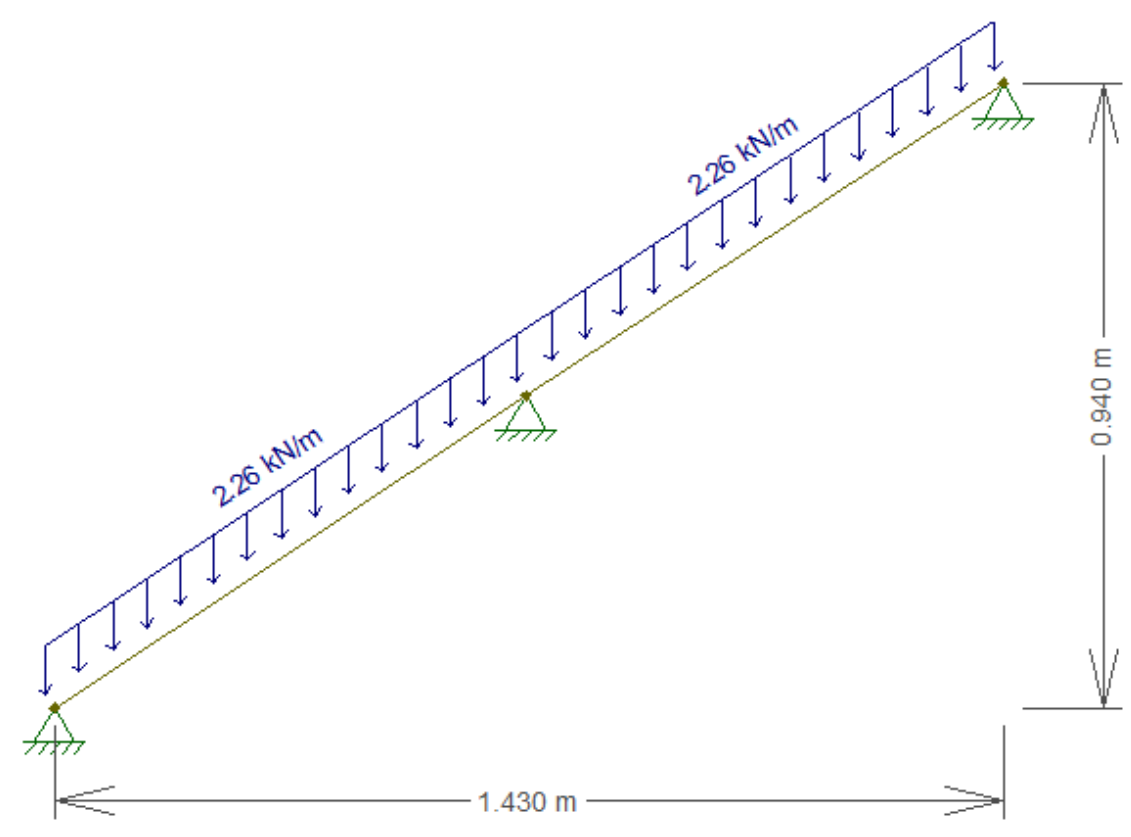

Fonte: O autor. Nota: Carga permanente característica + carga variável característica 
Figura 3.25 - Diagrama de momentos fletores e reações na viga

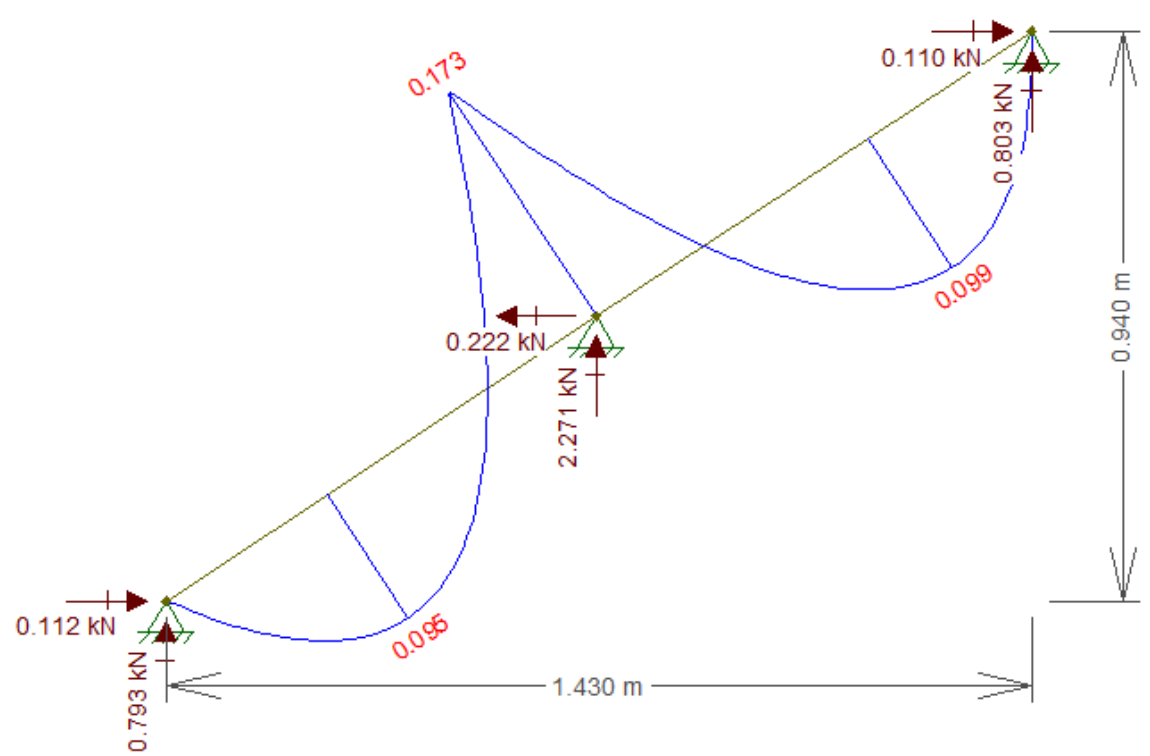

Fonte: (MAMEDE, 2001). Nota: Carga permanente característica + carga variável característica

A viga utilizada apresenta espessura de $4 \mathrm{~cm}$ apoiada discretamente em 3 chumbadores de 12,5 mm de diâmetro. A Figura 3.26 mostra a armadura da viga de acordo com o dimensionamento realizado pela autora. Ressalta-se que a armadura de flexão necessária é apenas a armadura mínima normativa devido ao baixo momento fletor para a seção da viga adotada. No entanto, foi considerado o regime transiente de transporte no qual a viga sofre flexão devido ao seu peso próprio no sentido de sua menor inércia (espessura), aumentando assim a armadura de flexão necessária. Maiores detalhes quanto ao dimensionamento podem ser encontrados em Mamede (2001).

Figura 3.26 - Armadura da viga

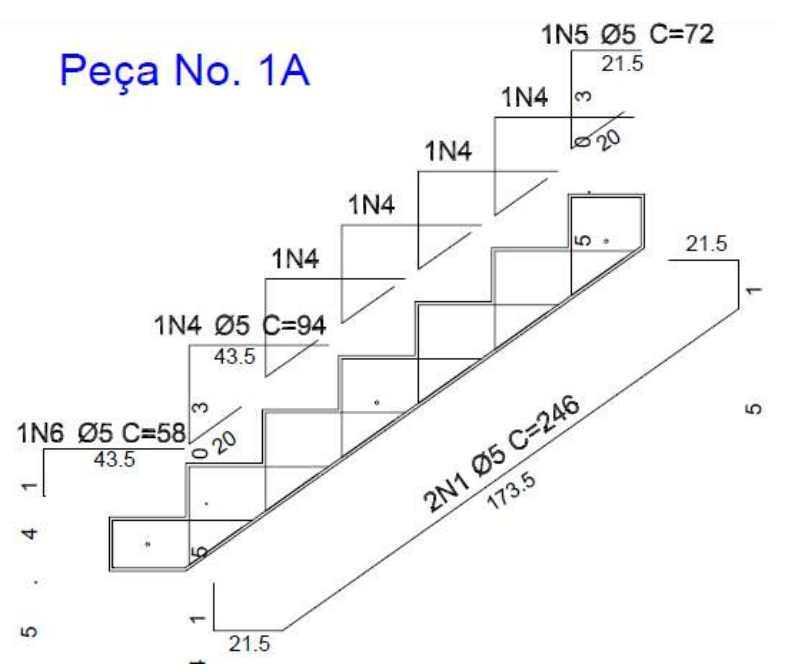

Fonte: (MAMEDE, 2001)

Foi criado um modelo tridimensional para a viga denteada. Apesar da possibilidade 
do problema ser modelado por elementos bidimensionais de chapa escolheu-se utilizar elementos tridimensionais pois posteriormente pretende-se utilizar esse modelo para análise térmica e termoestrutural. Dessa forma, será possível considerar o gradiente de temperatura e degradação ao longo da espessura da viga. A viga consiste numa peça de $4 \mathrm{~cm}$ de espessura que é apoiada em três chumbadores de 12,5 mm de diâmetro. Os apoios são modelados como cilindros rígidos inseridos em furos de mesmo diâmetro na viga.

A Figura 3.27 mostra a malha de elementos finitos. Foram utilizados elementos finitos tetraédricos lineares de 4 nós (C3D4 na nomenclatura do ABAQUS), totalizando 225663 elementos e 45181 nós. Já a Figura 3.28 mostra os elementos finitos da armadura, os quais são definidos como elementos lineares do tipo viga (B31 na nomenclatura do ABAQUS). Um total de 1103 elementos com 1106 nós foram utilizados. Os elementos de viga são considerados imersos na malha de elementos de concreto, isso significa que os nós da armadura que estejam no interior de um elemento de concreto tem seus graus de liberdade conectados aos nós do elemento de concreto de modo que eles se movam em conjunto.

Figura 3.27 - Malha de elementos finitos

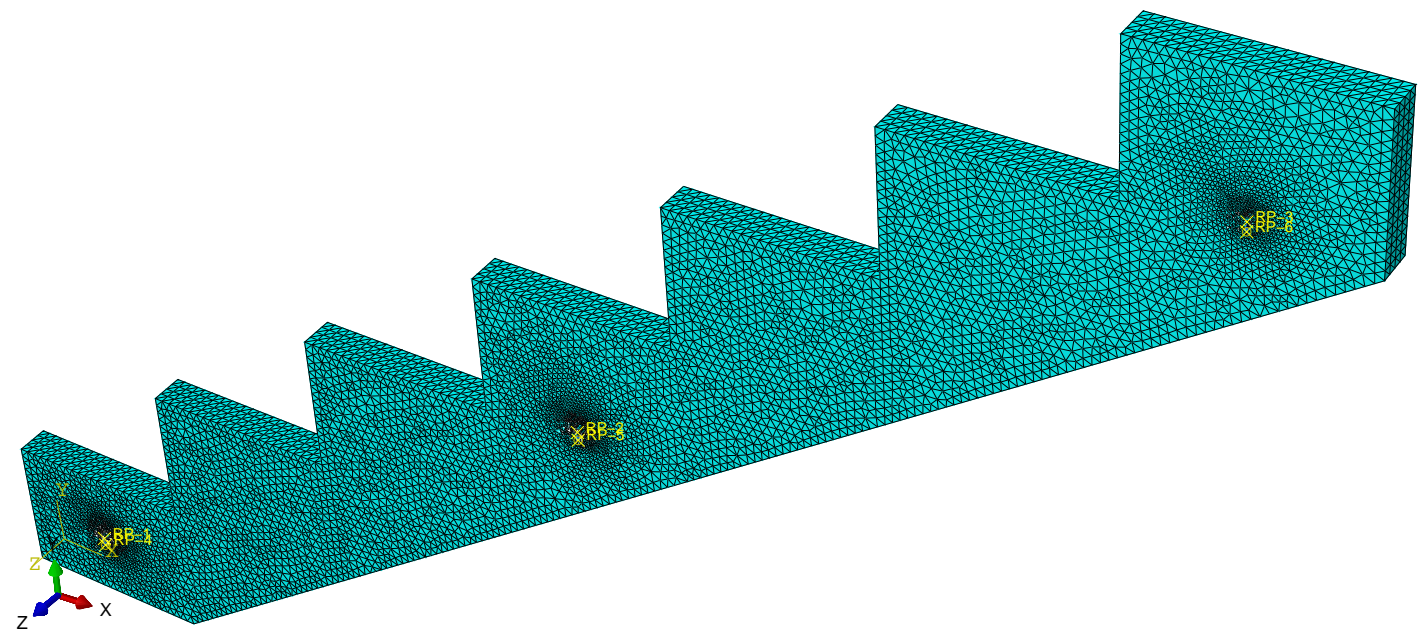

Fonte: $\mathrm{O}$ autor

A viga é apoiada nos chumbadores rígidos através de uma interação de contato entre a superfície interna do furo e a superfície do chumbador. Utilizou-se o algoritmo de contato por penalização com a propriedade de não-penetração (hard-contact) e atrito de Coulomb com $\mu=0,6$.

Os chumbadores rígidos são restritos aos movimentos através da utilização de um elemento de conexão que o liga a um nó fixo. Esse elemento de conexão pode englobar comportamentos não-lineares como plasticidade, dano, amortecimento, entre outros. A Figura 3.29 mostra o detalhe do elemento de conexão. Nessas simulações foi adotado um comportamento elástico para o conector na direção $\mathrm{Y}$ onde foi adotada uma alta rigidez 
Figura 3.28 - Armadura e apoios

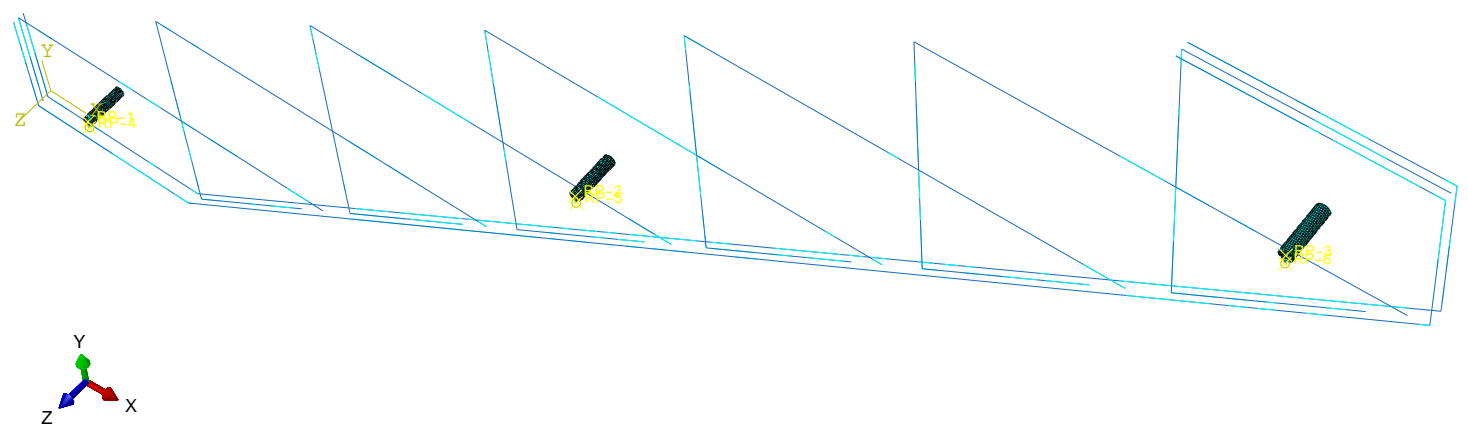

Fonte: O autor

para simular um apoio quase indeslocável.

Por fim, a Figura 3.30 mostra as condições de contorno adotadas no modelo. Considerou-se que uma das faces da viga (face na direção -Z) está totalmente apoiada na parede. O carregamento é aplicado de forma distribuída nas faces que recebem os degraus (faces na direção $+Y$ ). A carga distribuída total equivale a $80 \mathrm{kN}$. Escolheu-se esse valor de modo a levar a viga a ruptura na simulação.

Figura 3.29 - Detalhe do apoio da viga - Pino rígido com seu movimento de corpo rígido restrito por conector elástico

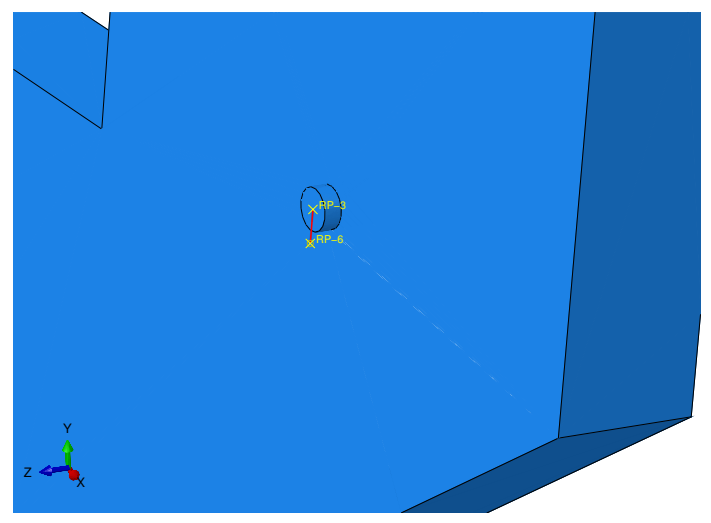

Fonte: $\mathrm{O}$ autor

Escolheu-se modelar os materiais com suas propriedades características assim como os carregamentos também são modelados com seus valores característicos. O aço das armaduras considerado no dimensionamento foi o CA50 o qual é caracterizado por $f_{y k}=500 \mathrm{MPa}$.Nesse caso considerou-se um modelo elasto-plástico perfeito de Von Mises com $E_{s}=210 \mathrm{GPa}, \nu=0,3$. e $f_{y}=500 \mathrm{MPa}$.

O concreto considerado no dimensionamento foi o C25 o qual é caracterizado por sua resistência à compressão $f_{c k}=25 \mathrm{MPa}$. Nesse caso, utilizou-se o modelo constitutivo 
Figura 3.30 - Condições de contorno do modelo

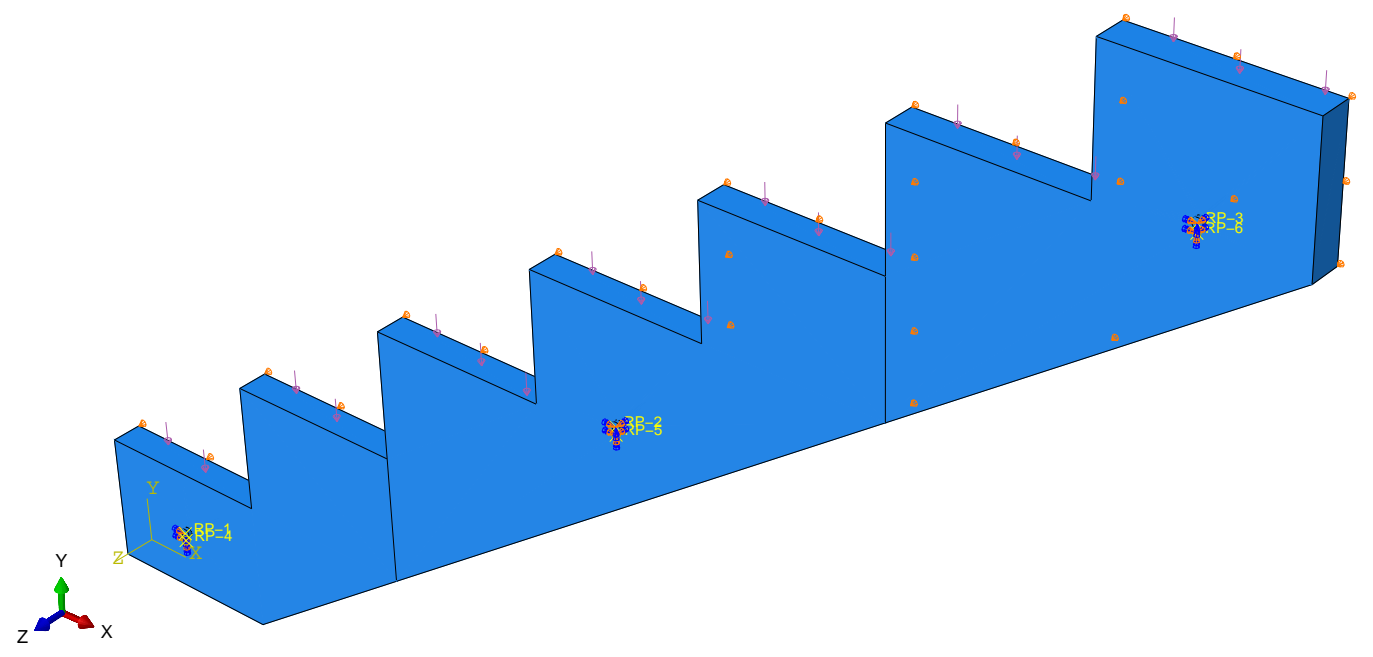

Fonte: $\mathrm{O}$ autor

Concrete Damaged Plasticity (CDP) o qual é um modelo de plasticidade e dano aplicável a materiais frágeis baseado nos modelos propostos por Lubliner et al. (1989) e Lee e Fenves (1998). A metodologia para cálculo dos parâmetros de entrada é similar àquela utilizada no estudo da estratégia de simulação, apresentada na Seção 3.1.1.2. As propriedades básicas do concreto foram estimadas como mostra a Tabela 3.5. De posse desses dados é possível estimar a curva tensão-deformação à compressão de acordo com Carreira e Chu (1985) e a curva tensão vs abertura de fissura de acordo com MC2010 (FIB, 2013) as quais são apresentadas na Figura 3.31. A atribuição de dano foi realizada como descrito na Seção 3.1.1.2.

Tabela 3.5 - Propriedades do concreto

\begin{tabular}{ccc}
\hline & Valor & Referência \\
\hline $\begin{array}{c}f_{c m} \\
(\mathrm{MPa})\end{array}$ & 25 & (MAMEDE, 2001) \\
$f_{c t m}$ & 1,983 & EN 1992-1-1:2004 e MC2010 \\
$\left(\begin{array}{l}\mathrm{MPa}) \\
E_{c}\end{array}\right.$ & 22501,75 & MC2010 considerando agregado calcário \\
$(\mathrm{MPa})$ & & \\
$G_{f}$ & 0,05143 & MC1990 considerando $D_{a g}=12,5 \mathrm{~mm}$ \\
$(\mathrm{~N} / \mathrm{mm})$ & & \\
\hline
\end{tabular}

A simulação foi realizada através de análise dinâmica quasi-estática com escala da massa. Nesse caso utilizou-se a estratégia de carga controlada para aumento incremental da carga distribuída durante a análise. Uma das alternativas para diminuir os efeitos inerciais é realizar o incremento de carga de forma suave através de uma variação progressiva e suave da taxa de carregamento. Isso foi obtido através de uma curva de carregamento em 
Figura 3.31 - Comportamento uniaxial do concreto - Viga denteada

(a) Compressão

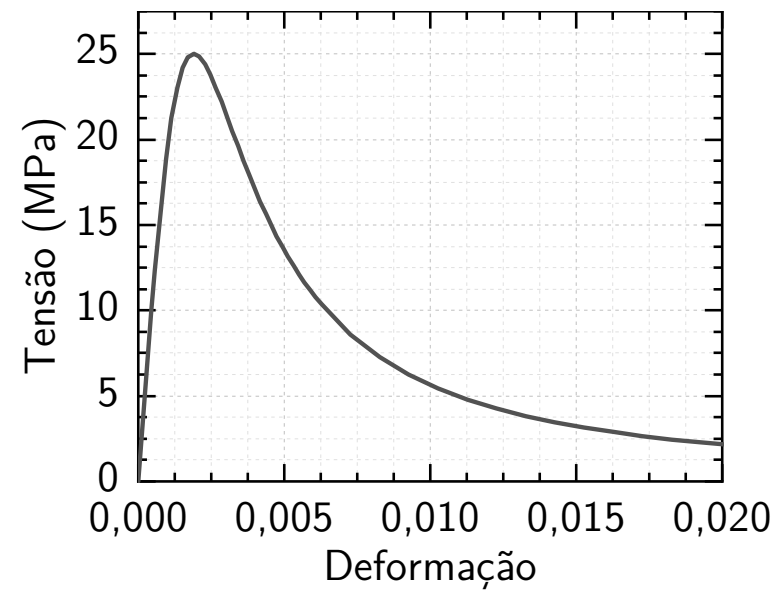

(b) Tração

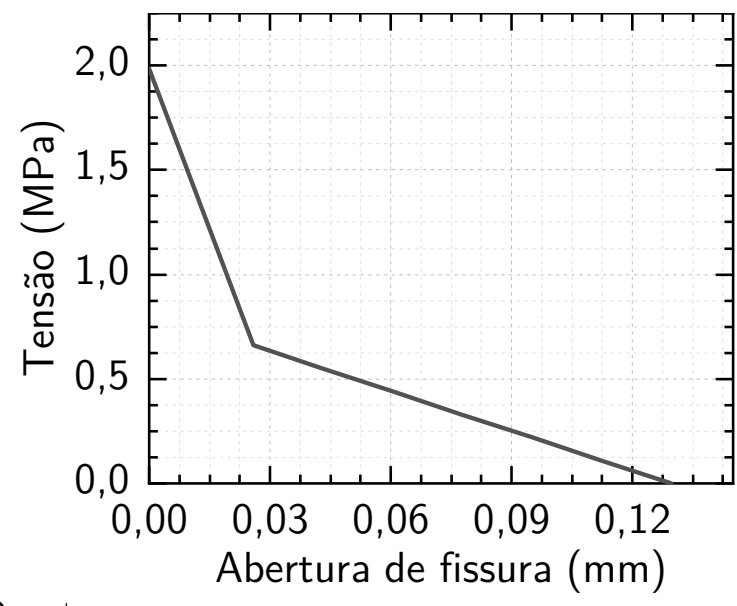

formato de S o qual é chamada de Smooth Amplitude no ABAQUS. O tempo de simulação nessas análises pode ser arbitrário uma vez que não se está simulando o ensaio na escala de tempo real. Assim optou-se por utilizar um tempo total de análise de 30 s. O ABAQUS permite a escala da massa de forma variável ao longo da análise de forma que seja satisfeito um incremento de tempo estável alvo. Nessa simulação foi utilizado incremento estável alvo de $0,0001 \mathrm{~s}$.

\subsubsection{Resultados e Análise}

O leitor pode encontrar no Apêndice C um resumo do custo computacional demandado em todas as simulações. Para verificar se o resultado se aproxima da resposta quasi-estática, na Figura 3.32a apresenta-se a razão entre a energia cinética e o trabalho das forças externas e na Figura 3.32b é apresentada a reação vertical nos apoios. Percebe-se que a energia cinética permanece em valores baixos até um certo momento em que ela apresenta aumento brusco. Por outro lado, a força de reação também apresenta boa concordância com a carga aplicada até que por volta dos 18s há uma certa oscilação e queda abrupta. Aos 18,74 s a simulação foi interrompida com o aviso que a taxa de deformação em um elemento era maior que a velocidade de onda elástica nele. Isso acontece quando o elemento se deforma muito rapidamente e nem mesmo a escala automática da massa que modifica a velocidade de onda é capaz de compensar o efeito. Essa condição foi atingida em elementos muito danificados em processo de abertura de uma fissura crítica para o equilíbrio global. O uso de carga controlada também dificulta a mitigação desse problema pois não há possibilidade de diminuição do carregamento no momento da ruptura.

Por fim, foi realizada a simulação estática do problema através do algoritmo de Newton-Raphson com restrição ao arco de acordo com a estratégia de Riks. A curva carga vs deslocamento de ambas as simulações são apresentadas na Figura 3.33. Percebe-se boa 
Figura 3.32 - Resultados modelo viga denteada

(a) Razão entre energia cinética e trabalho rea-(b) Comparação entre força total aplicada e a lizado pelas forças externas força de reação nos apoios
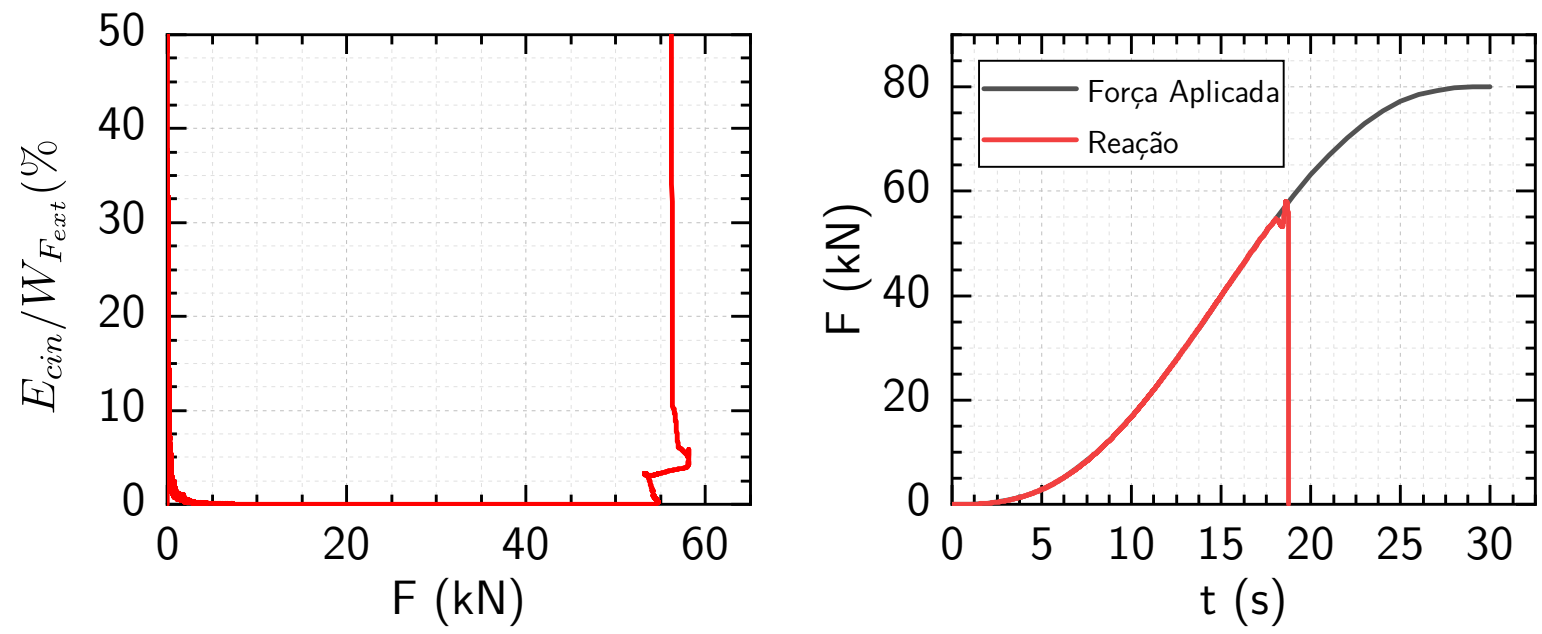

Fonte: $\mathrm{O}$ autor

concordância das duas respostas no intervalo em que houve convergência na análise estática.

Figura 3.33 - Curva Carga vs Deslocamento no meio do vão inferior

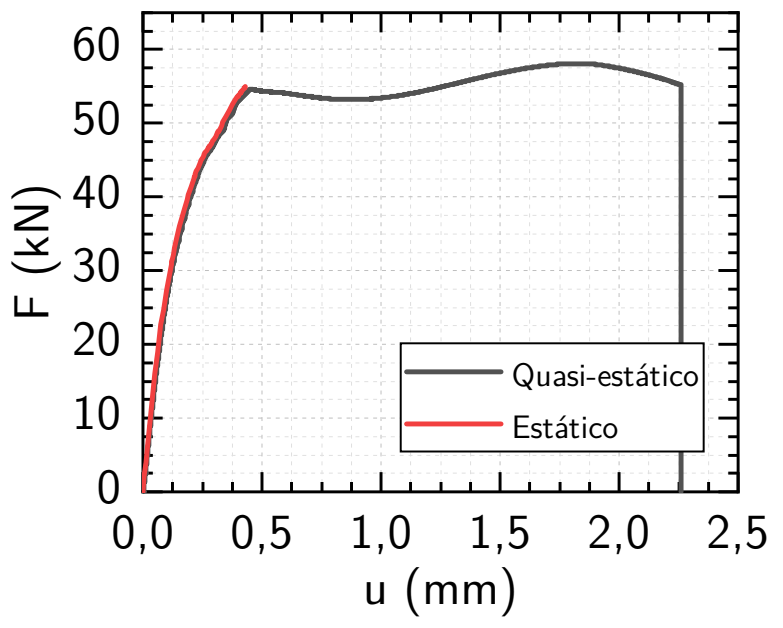

Fonte: $\mathrm{O}$ autor

O patamar presente na resposta quasi-estática é originado após os 18 s quando há um aumento da energia cinética devido a abertura de fissura no apoio intermediário. Essa abertura leva a um rápido escoamento da armadura nessa região a qual eventualmente chegaria a ruptura. A ruptura da armadura nessa região levaria a perda de apoio intermediário uma vez que ela funciona como armadura de suspensão. Pode-se avaliar que a perda de apoio intermediário por sua vez levaria ao colapso completo da estrutura. Essa interpretação pode ser apoiada na análise do dano a tração e dos esforços nas armaduras.

A Figura 3.34 mostra o dano a tração na viga aos $18 \mathrm{~s}$, pouco antes do aumento 
subto de energia cinética presente nos gráficos, portanto, podemos considerar a resposta nesse instante como quasi-estática. Percebe-se a abertura de uma fissura proeminente a esquerda do apoio intermediário. Nessa região está localizada a armadura que combate ao momento negativo e também serve como armadura de suspensão para o esforço cortante que deve ser transferido ao chumbador. A análise estática deixa de convergir em situação semelhante a essa.

Figura 3.34 - Dano a tração na viga no momento antes da ruptura

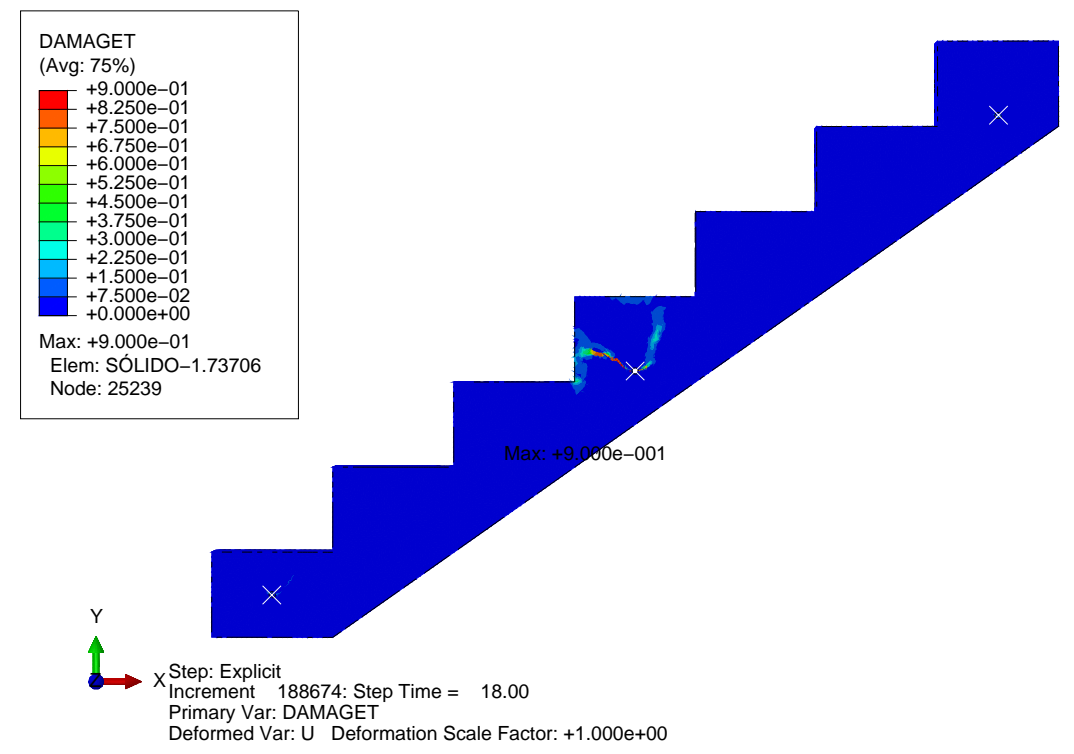

Fonte: $\mathrm{O}$ autor

Já a Figura 3.35 mostra o dano a tração no último incremento da análise, o incremento em que houve taxa de deformação excessiva em um elemento. Esse gráfico de contorno em si não pode ser interpretado como quasi-estático pois como vemos nos gráficos anteriores há um grande aumento de energia cinética nesse intervalo. Não foram salvos gráficos de contorno entre 18 s e 18,74 s. Por outro lado, esse gráfico serve para interpretar o mecanismo de ruptura que é formado cuja resposta é refletida na Figura 3.33. Percebe-se que há ruptura no apoio intermediário e posteriormente fissuras nos outros dois apoios bem como fissuras de flexão. Já na Figura 3.36a e Figura 3.36b pode-se perceber que há grande deformação na armadura próxima ao apoio intermediário.

Por fim, apresenta-se o esforço cisalhante nos apoios em função do deslocamento no meio do vão na Figura 3.37. Percebe-se que o primeiro a diminuir a carga é o apoio 2 (intermediário), seguido rapidamente pelo apoio 1 (inferior) e por outro lado o apoio 3 (superior) recebe mais carga. Os picos no final desse gráfico são consequência do aumento abrupto da energia cinética, bem como da taxa de deformação excessiva nos elementos, assim não deve ser levados em conta na análise.

A análise com carga controlada cria uma dificuldade em determinar o instante de 
Figura 3.35 - Dano a tração no último incremento

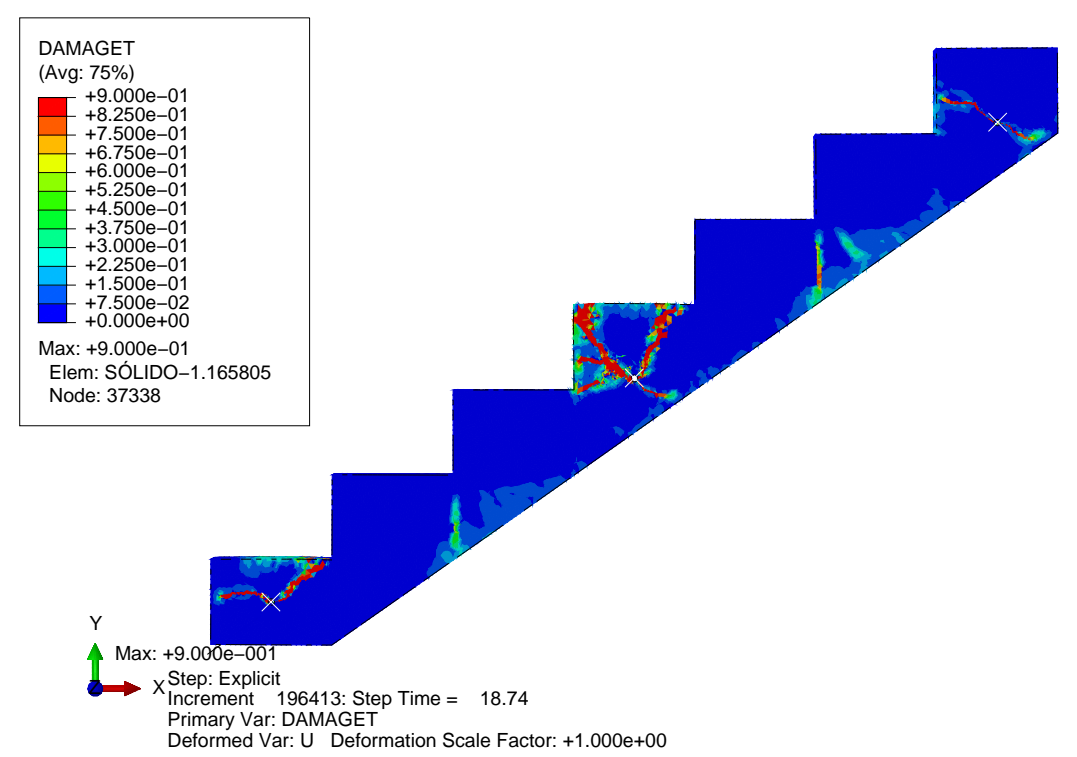

Fonte: $\mathrm{O}$ autor

Figura 3.36 - Resultados para armadura no último incremento salvo

(a) Tensão de Von Mises

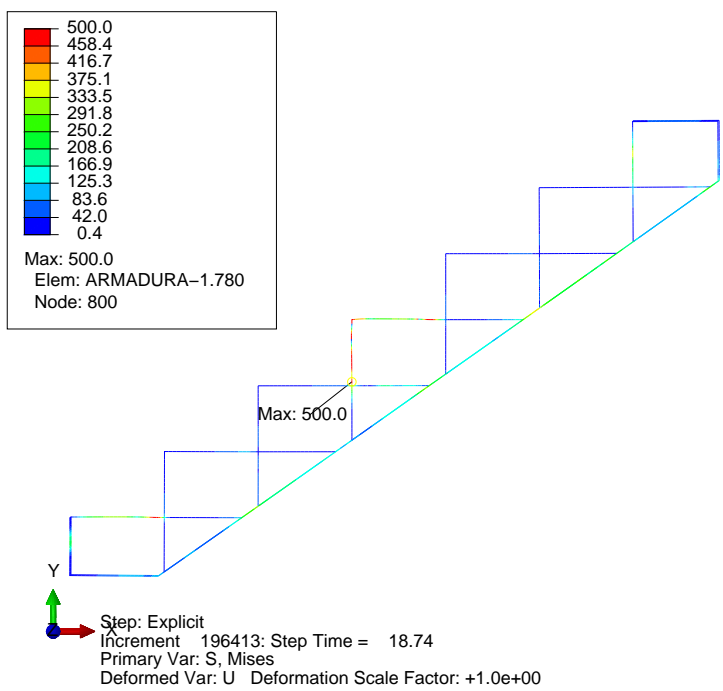

(b) Deformação plástica equivalente

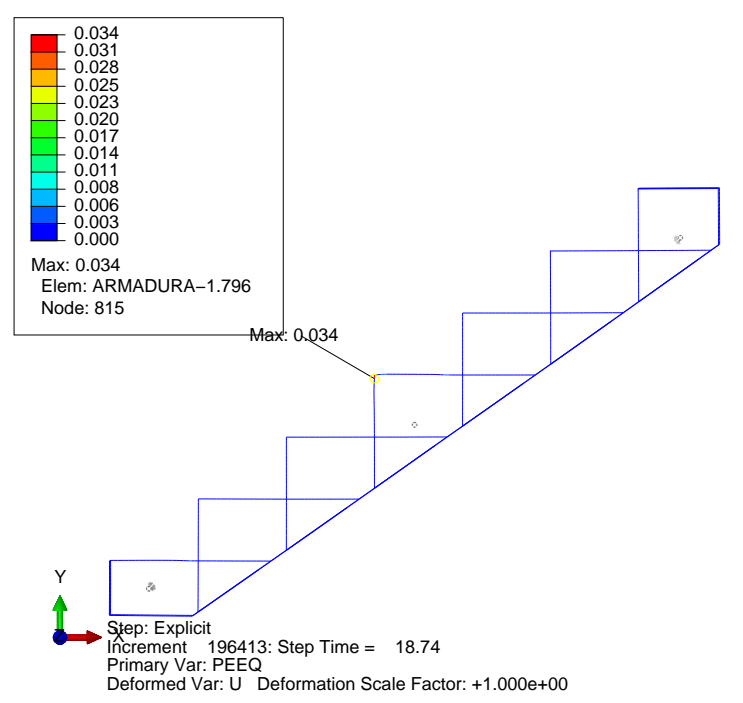

Fonte: $\mathrm{O}$ autor

ruptura pois nesse momento a energia cinética aumentará rapidamente e o carregamento continuará aumentando. Assim é preciso utilizar os gráficos de evolução da energia cinética e julgar o comportamento do modelo para definir um ponto de ruptura. Outra opção seria analisar a viga utilizando deslocamento controlado no meio vão, sendo assim sujeita a cargas pontuais. No entanto ficaria a dúvida sobre a influência da carga distribuída diretamente em cima do chumbador a qual pode levar a ruptura de borda e/ou esmagamento.

Percebe-se que a carga característica vertical total de dimensionamento foi de 3,87 $\mathrm{kN}$ de acordo com o dimensionamento de Mamede (2001) enquanto a carga de ruptura na simulação, onde foram consideradas propriedades características dos materiais, foi de 
aproximadamente $55 \mathrm{kN}$. Cabe lembrar que essa é uma análise apenas da viga, considerando apoios indeslocáveis. Assim, é necessário a análise dos chumbadores para avaliar se a carga resistente é compatível com as solicitações da Figura 3.37. Tal fato será analisado nos modelos locais do chumbador ancorado em alvenaria.

Figura 3.37 - Cisalhamento nos apoios em função do deslocamento no vão inferior
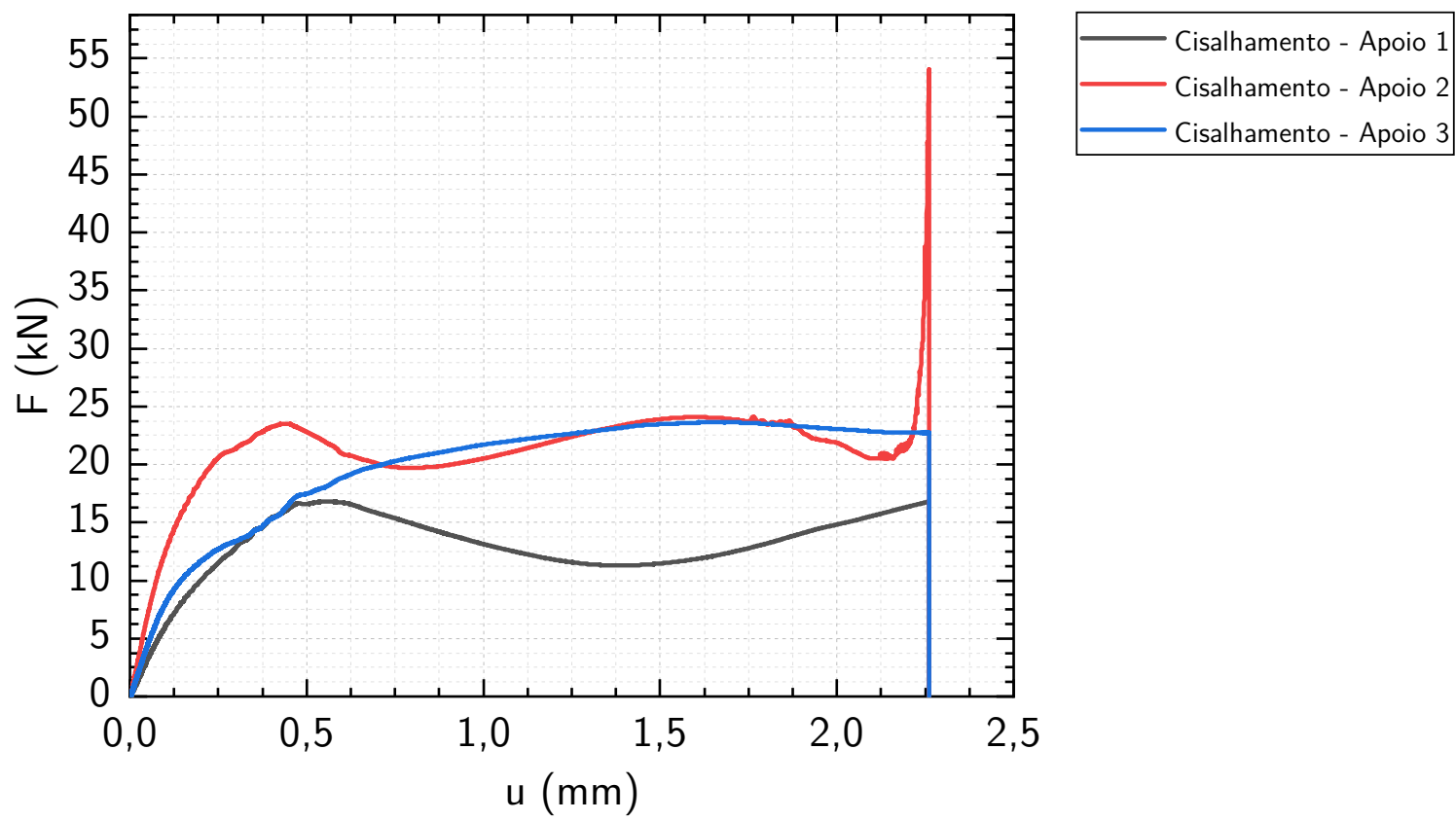

Fonte: $\mathrm{O}$ autor

\subsection{Chumbador em painel de alvenaria de concreto}

O objetivo dessa seção é analisar o comportamento de um chumbador utilizado em alvenaria de blocos de concreto. Para isso optou-se por construir um modelo tridimensional da alvenaria, abordagem conhecida como micromodelagem detalhada. A carga de ruptura da alvenaria e do chumbador são determinadas e confrontadas com as solicitações da viga denteada apresentadas na seção 3.2.

\subsubsection{Características geométricas e de análise}

O modelo utilizado nas simulações é similar ao modelo utilizado nos ensaios de (MCGINLEY et al., 2004) e ilustrado na Figura 2.2. No entanto, ao contrário dos ensaios do autor, o modelo estudado aqui apresenta grauteamento apenas no vazio em que o chumbador está ancorado. O modelo consiste em um painel mínimo para caracterizar a alvenaria, o qual é constituído por 3 blocos e 3 meios-blocos. Com esse modelo, espera-se avaliar o comportamento do chumbador, considerando que esse tem efeito localizado na parede de alvenaria. 
A Figura 3.38 ilustra a geometria do modelo, bem como, o detalhe da malha do chumbador no bloco grauteado. Foi utilizado um chumbador composto de barra roscada com $D_{\text {nom }}=1 / 2$ ", o mesmo diâmetro utilizado por Mamede (2001). Considerando a área efetiva do chumbador, utilizou-se $D_{e f}=10,796 \mathrm{~mm}$ no modelo. O comprimento de embutimento do chumbador foi de $100 \mathrm{~mm}$. Para realizar o carregamento do chumbador foi criada uma chapa de carregamento com $4 \mathrm{~cm}$ de espessura, a qual representa a viga denteada. Além disso, nas faces do painel foram criadas chapa rígidas as quais são utilizadas para restringir a alvenaria e aplicar carregamento.

Figura 3.38 - Modelo de chumbador em painel de alvenaria de concreto

(a) Geometria do modelo - Caso 1

(b) Detalhe da malha
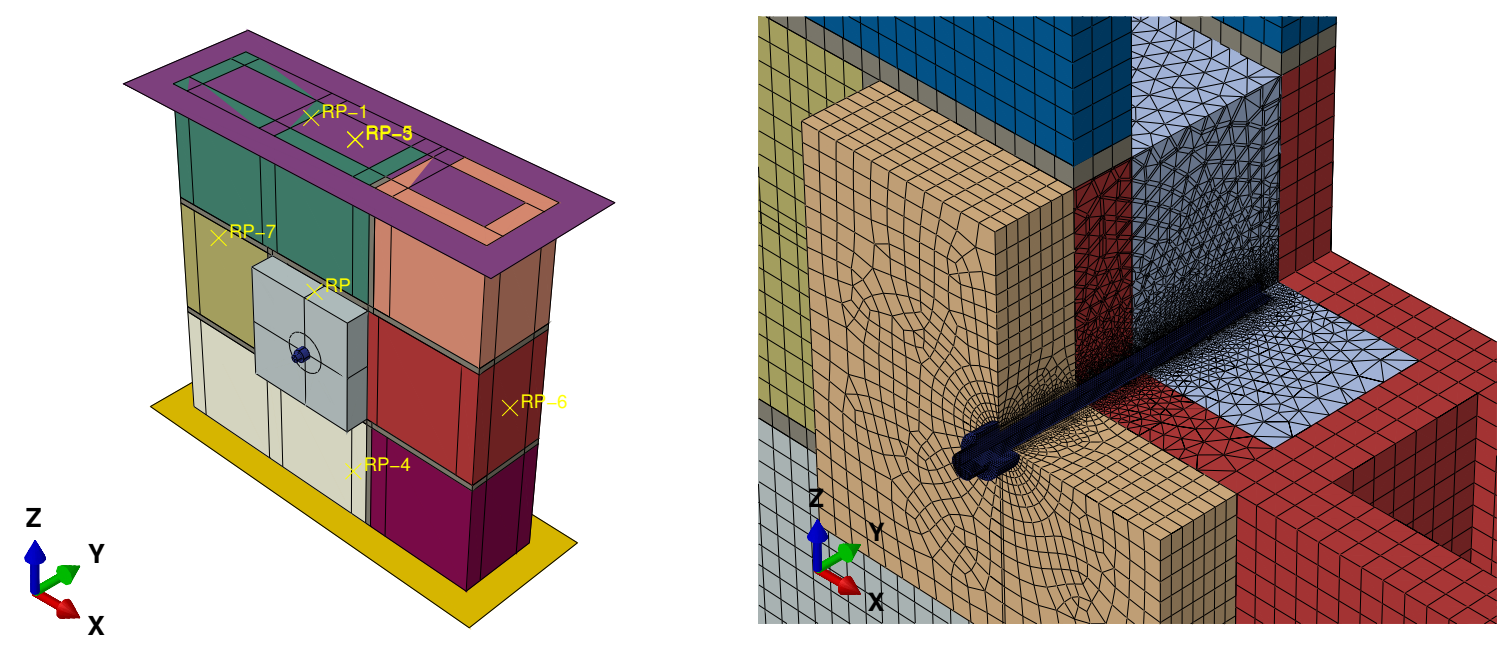

Fonte: $\mathrm{O}$ autor.

Foi utilizado bloco vazado de concreto da família 15 x 40, assim o painel apresenta dimensões de 590 mm x 590 mm. Carvalho (2019) modelou os ensaios de Dupim (2019) e adotou uma simplificação da geometria do bloco a qual também é adotada aqui. O bloco de alvenaria de concreto apresenta vazados verticais com formato tronco-cônico e mísulas nos septos, no entanto, adota-se aqui vazados prismáticos e ausência da mísula. Essa simplificação é baseada na igualdade de áreas das seções transversais, maiores detalhes podem ser encontrados em Carvalho (2019). A Figura 3.39 mostra as dimensões adotadas para o bloco.

A malha de elementos finitos utilizadas está descrita na Tabela 3.6. No bloco grauteado utilizou-se malha livre com elementos tetraédricos para uma melhor aproximação da geometria e das tensões na região de apoio do chumbador. Para os blocos e argamassa foi utilizada malha estruturada hexaédrica idêntica a malha obtida no estudo de malha realizado por Carvalho (2019).

A interação entre os diversos componentes do modelo se deu através de contato por penalização, as diferentes propriedades adotadas são listadas a seguir. 
Figura 3.39 - Dimensões adotadas para o bloco $(\mathrm{mm})$
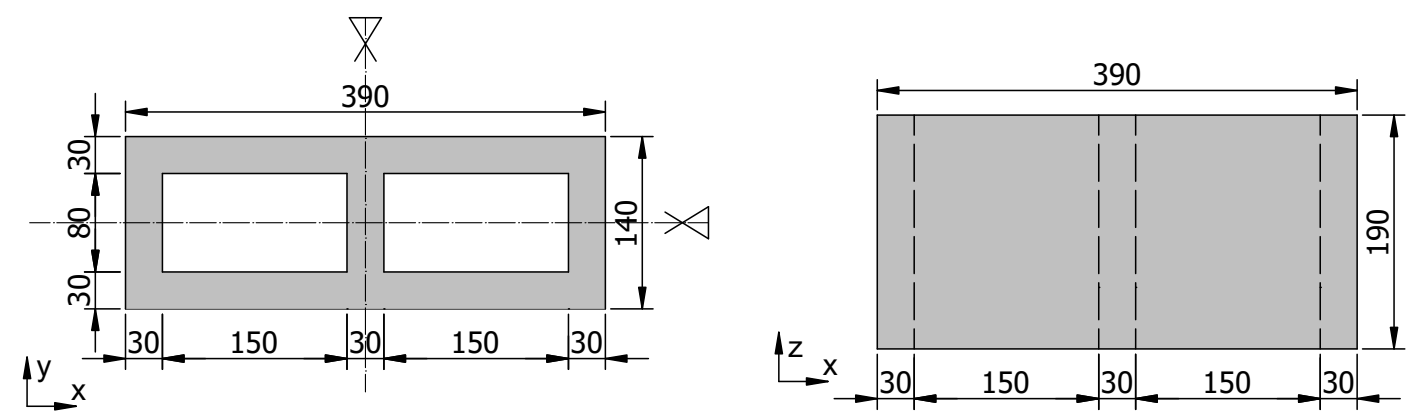

Fonte: $\mathrm{O}$ autor

Tabela 3.6 - Características da malha

\begin{tabular}{ccc}
\hline & Características da malha & Tamanho Aproximado \\
\hline Blocos & 21714 elementos C3D8R & C3D8R: $10 \mathrm{~mm}$ \\
Argamassa & 1202 elementos C3D8R & $10 \mathrm{~mm}$ \\
Graute & 105896 elementos C3D4 & $1 \mathrm{~mm} \mathrm{a} 10 \mathrm{~mm}$ \\
Chumbador & 23520 elementos C3D8R & $1 \mathrm{~mm}$ \\
Chapa de & 11614 elementos C3D8R & $1 \mathrm{~mm} \mathrm{a} 10 \mathrm{~mm}$ \\
Carregamento & 220 elementos C3D6 & \\
\hline
\end{tabular}

Nota: C3D8R: elemento hexaédrico de 8 nós com integração reduzida. C3D4: elemento tetraédrico com 4 nós. C3D6: elemento cunha com 6 nós. Nos blocos, o elemento C3D4 só foi utilizado próximo ao furo do chumbador. Total de nós do modelo: 101913

- Interação 1: Condição de não-penetração (Hard contact) e não-deslizamento (Rough contact). Superfícies: Bloco e Chumbador, Graute e Chumbador

- Interação 2: Condição de não-penetração (Hard contact) e deslizamento livre (sem atrito). Superfícies: Chapa de carregamento e Chumbador, Chapa de carregamento e Bloco, Chapa Face +X e Blocos, Chapa Face -X e Blocos

- Interação 3: Condição de não-penetração (Hard contact) e atrito de Coulomb com $\mu=0,6$. Superfícies: Chapa Face $+\mathrm{Z}$ e Blocos, Chapa Face $-\mathrm{Z}$ e Blocos

- Interação 4: Contato coesivo com dano. Tensão coesiva máxima à tração e ao cisalhamento na interface: 0,15 MPa. Deslocamento máximo para danificação total: 0,001 mm. Após danificação: Condição de não-penetração (Hard contact) e atrito de Coulomb com $\mu=0,6$. Superfícies: Blocos e Junta de argamassa

Para análise da resistência do painel de alvenaria foram consideradas diferentes condições de contorno. Elas foram determinadas a partir da presença ou ausência de chapas rígidas no contorno e dos seus movimentos permitidos. A Tabela 3.7 mostra os 3 casos considerados nas simulações para verificar a resistência do painel de alvenaria. Esses casos 
buscam ilustrar o efeito do confinamento na resistência do painel. É importante notar que esses casos representam situações limite, uma parede de alvenaria em um edifício terá um comportamento intermediário entre esses casos limites. Também cabe destacar que mesmo no Caso 1 ainda existe um certo confinamento na direção X devido ao atrito entre as Chapas $+\mathrm{Z}$ e $-\mathrm{Z}$ com a alvenaria.

Tabela 3.7 - Condições de contorno da parede estudadas

\begin{tabular}{cccc}
\hline & Caso 1 & Caso 2 & Caso 3 \\
\hline Face $+\mathrm{X}$ & Livre & Chapa fixa & Chapa fixa \\
Face $-\mathrm{X}$ & Livre & Chapa fixa & Livre \\
Face $-\mathrm{Z}$ & Chapa fixa & Chapa fixa & Chapa fixa \\
Face $+\mathrm{Z}$ & $\begin{array}{c}\text { Chapa fixa, } \\
\text { exceto } u_{z} \text { e } \theta_{x}\end{array}$ & $\begin{array}{c}\text { Chapa fixa, } \\
\text { exceto } u_{z} \text { e } \theta_{x}\end{array}$ & $\begin{array}{c}\text { Chapa fixa, } \\
\text { exceto } u_{z} \text { e } \theta_{x}\end{array}$ \\
\hline
\end{tabular}

Nota: $u_{z}$ e $\theta_{x}$ na Face $+\mathrm{Z}$ varia de acordo com a simulação realizada. Para verificação da resistência última $\theta_{x}=0$ e $u_{z}$ é calculado para aplicação de um ciclo de carregamento e descarregamento de $\varepsilon_{z}=0$ a $\varepsilon_{z}=-0,002$.

Já para realizar o carregamento do chumbador foi utilizado acoplamento cinemático entre um nó de referência e o nós do topo da chapa de carregamento do chumbador como ilustra a Figura 3.40. Através dessa propriedade, os nós da superfície superior da chapa obedecem as condições de contorno do nó de referência. Nesse caso, adotou-se $\theta_{y}=0$ e $\theta_{z}=0$ para o nó de referência, impedindo assim esses giros na chapa. Todos os outros giros e deslocamentos são livres, exceto $u_{z}$, o qual foi prescrito para levar o chumbador até a ruptura.

Figura 3.40 - Acoplamento cinemático na chapa de carregamento do chumbador

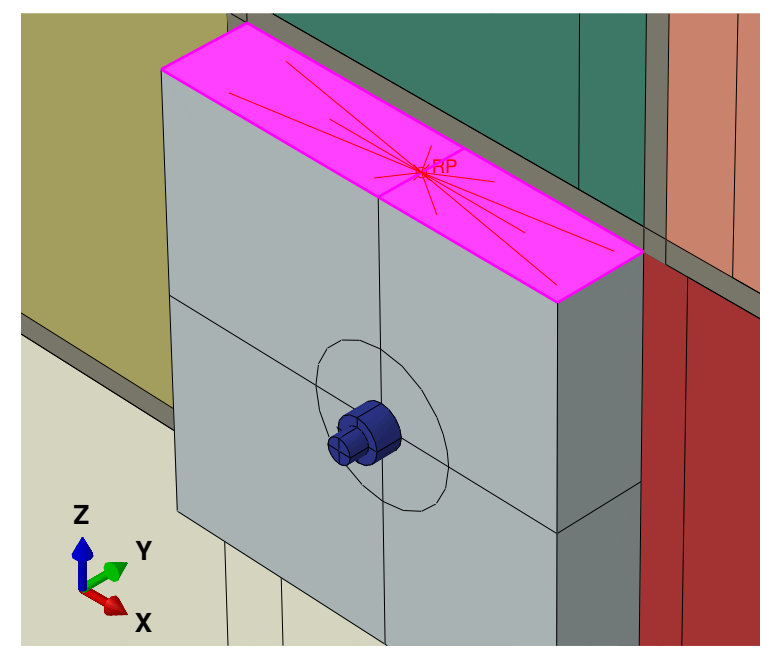

Fonte: $\mathrm{O}$ autor.

As simulações foram realizadas utilizando a mesma estratégia apresentada na Seção 
3.1.2. Para analisar a carga de ruptura optou-se por utilizar deslocamento controlado para que dessa forma fosse possível determinar o trecho pós-ruptura da curva cargadeslocamento. A Tabela 3.8 traz as características de análise utilizada para avaliação da resistência da alvenaria e do chumbador.

Tabela 3.8 - Características da análise de resistência

\begin{tabular}{|c|c|c|}
\hline & $\begin{array}{l}\text { Resistência da } \\
\text { alvenaria }\end{array}$ & $\begin{array}{l}\text { Resistência do } \\
\text { chumbador }\end{array}$ \\
\hline Carregamento & $\begin{array}{c}u_{z}^{\text {Face }+\mathrm{Z}}(t=0)=0 \\
u_{z}^{\text {Face }+\mathrm{Z}}(t=1800)=-1,2 \mathrm{~mm} \\
u_{z}^{\text {Face }+\mathrm{Z}}(t=3600)=0\end{array}$ & $\begin{array}{c}u_{z}^{\text {Chapa }}(t=0)=0 \\
u_{z}^{\text {Chapa }}(t=3600)=-6,25 \mathrm{~mm}\end{array}$ \\
\hline $\begin{array}{l}\text { Tempo total da } \\
\text { análise }(\mathrm{s})\end{array}$ & \multicolumn{2}{|l|}{3600} \\
\hline Tipo de análise & \multicolumn{2}{|c|}{ Dinâmica explícita quasi-estática } \\
\hline$\Delta t_{\text {est }}(\mathrm{s})$ & \multicolumn{2}{|c|}{0,12} \\
\hline $\begin{array}{c}\text { Escala } \\
\text { de massa }\end{array}$ & \multicolumn{2}{|c|}{ Variável durante análise para satisfazer $\Delta t_{e s t}$} \\
\hline $\begin{array}{l}\text { Nota: O tempo } \\
\Delta t_{\text {est }} \text { é o increm }\end{array}$ & $\begin{array}{l}\text { l de análise não tem significado } \\
\text { de tempo estável da análise e } \\
\text { scritos são aplicados através de }\end{array}$ & $\begin{array}{l}\text { sico nessa análise quasi-estática. } \\
\text { ícita no tempo. Os incrementos }\end{array}$ \\
\hline
\end{tabular}

\subsubsection{Propriedades dos materiais}

As propriedades dos materiais da alvenaria e chumbador foram escolhidas de forma a criar um exemplo representativo do problema. Dessa forma, arbitrou-se resistências que foram julgadas plausíveis para o problema de estudo desse trabalho. Com isso, espera-se obter resultados em uma faixa de resistências relevante para o problema. Cabe destacar, que pesquisas futuras complementares podem endereçar o problema por meio de ensaios. Nesse caso, as propriedades do materiais seriam obtidas diretamente para o caso específico do ensaio.

O modelo local tem como objetivo analisar o comportamento do chumbador, por isso, a chapa de carregamento foi considerada com comportamento elástico linear com $E=25 \mathrm{GPa}$ e $\nu=0,2$. Ou seja, toma-se como hipótese que a viga denteada não sofrerá grandes danos no decorrer do carregamento do chumbador. A validade dessa hipótese depende do nível de carregamento e da resistência da viga denteada.

O chumbador por adesão química, ou mesmo chumbadores mecânicos, são constituídos por uma barra roscada. É comum que os fabricantes de chumbadores divulguem em seus manuais as resistências últimas de seus produtos. No entanto, normalmente não há uma caracterização suficiente do aço utilizado, algumas vezes há apenas a designação 
das propriedades químicas do aço, como por exemplo SAE 1010/1020 o que indica um aço de baixo carbono. Mamede (2001) considera chumbador com aço SAE 1010/1020 e $f_{u}=330 \mathrm{MPa}$ em seu dimensionamento do sistema de fixação. Por outro lado, existe uma série de normas que fazem uma classificação das propriedades mecânicas de aço para uso em parafusos, barras roscadas e chumbadores. A Tabela 3.9 traz algumas classificações mecânicas de aço que são aproximadamente equivalentes entre si e se referem a menor classe de resistência das referidas normas. Nesse trabalho optou-se por adotar as propriedades do aço SAE J429 Grau 1 como representativas de um chumbador que usualmente seria utilizado no problema em questão.

Tabela 3.9 - Diferentes especificações mecânicas para aço de baixo carbono para uso em chumbadores ou parafusos

\begin{tabular}{cccc}
\hline & $f_{y}(\mathrm{MPa})$ & $f_{u}(\mathrm{MPa})$ & $\begin{array}{c}\text { Alongamento } \\
\text { na ruptura (\%) }\end{array}$ \\
\hline SAE J429 Grau 1 & 250 & 415 & 22 \\
EN ISO 898-1 Classe 4.6 & 240 & 400 & 22 \\
ASTM F1554 Grau 36 & 248 & 558 & 20 \\
ASTM A307 Grau A & - & 414 & 18 \\
\hline
\end{tabular}

Ligações e sistemas de fixação são comumente analisados até a tensão de ruptura $\left(f_{u}\right)$ do aço. Logo, nesse caso, é preciso definir uma curva de tensão-deformação que considere o encruamento do aço. Optou-se por utilizar o modelo de encruamento disponível no EN 1993-1-2:2005 (CEN, 2005), ilustrado na Figura 3.41. Além disso, o modelo constitutivo adotado para o aço foi o de plastificação pelo critério de Von Mises.

Figura 3.41 - Gráfico tensão-deformação adotado para o aço do chumbador

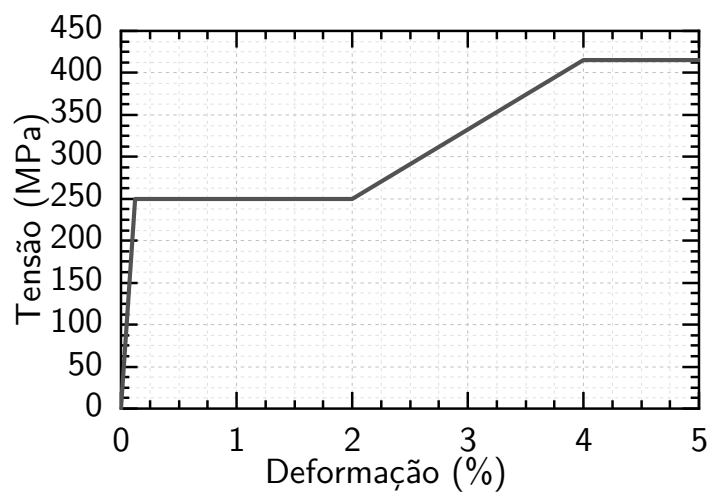

Fonte: $\mathrm{O}$ autor

De forma similar, as propriedades do concreto do bloco, graute e argamassa foram definidos com base em normas e em trabalhos experimentais prévios. A NBR 6136:2016 (ABNT, 2016) define requisitos para os blocos de concreto. Para as classes estruturais são definidos requisitos de resistência característica à compressão do bloco em sua área 
bruta $\left(f_{b k}\right)$. A Classe B requer $4 \mathrm{MPa} \leq f_{b k} \leq 8 \mathrm{MPa}$ e a Classe A requer $f_{b k} \geq 8 \mathrm{MPa}$. Analisando resultados experimentais da literatura foi possível avaliar a resistência de blocos disponíveis no mercado. Dupim (2019) ensaiou blocos de $14 \mathrm{~cm}$ e $19 \mathrm{~cm}$ no qual o fabricante especificava $f_{b k}=4 \mathrm{MPa}$. Foi verificado uma variabilidade entre os blocos e meios-blocos bem como entre aqueles de diferentes espessuras. Esse fato evidencia a dependência do $f_{b}$ com a geometria do bloco, a qual influencia o confinamento entre as placas da prensa. Além disso os valores de $f_{b}$ foram sensivelmente maiores do que $f_{b k}=4 \mathrm{MPa}$, especificado pelo fabricante. A média entre todos os corpos de prova foi de $f_{b m}=8,09 \mathrm{MPa}$. Portanto, arbitrou-se $f_{b}=8 \mathrm{MPa}$ como a resistência à compressão na área bruta a ser adotada nas simulações desse trabalho. Considera-se tal valor como representativo e razoável para o problema, o que permitirá suas primeiras análises. A partir dos resultados, é importante avaliar a necessidade de simulações com diferentes valores de resistência.

Já para a argamassa utiliza-se a resistência a compressão do traço (ii) da BS 5628-3:2005 (BSI, 2005) o qual foi utilizada nos ensaios de Oliveira (2014) e Izquierdo (2015). Por fim, para o graute utiliza-se a resistência à compressão do traço G14 utilizado nos ensaios de Izquierdo (2015). As propriedades do concreto do bloco, argamassa e graute são apresentadas na Tabela 3.10, bem como as referências utilizadas para estimar as demais propriedades com base na resistência à compressão.

Tabela 3.10 - Propriedades do concreto

\begin{tabular}{|c|c|c|c|c|}
\hline & Bloco & Argamassa & Graute & Referência \\
\hline $\begin{array}{c}f_{c m} \\
(\mathrm{MPa})\end{array}$ & 14,276 & 6 & 14 & $\begin{array}{c}\text { Bloco: } f_{b}=8 \mathrm{MPa} \text { e } A_{l i q} / A_{b}=56,04 \% \\
\text { Argamassa: BS 5628-3:2005 } \\
\text { Graute: Izquierdo }(2015)\end{array}$ \\
\hline $\begin{array}{c}f_{c t m} \\
(\mathrm{MPa})\end{array}$ & 1,25 & 0,81 & 1,23 & Genikomsou e Polak (2015) \\
\hline $\begin{array}{c}E_{c} \\
(\mathrm{GPa})\end{array}$ & 19,38 & 13,94 & 19,24 & $\begin{array}{c}\text { Secante em } 0,4 f_{c} \text { da curva } \sigma \text { vs } \varepsilon \\
\text { EN 1992-1-1:2004 }\end{array}$ \\
\hline $\begin{array}{c}G_{f} \\
(\mathrm{~N} / \mathrm{mm})\end{array}$ & 0,0327 & 0,0178 & 0.0323 & MC 1990 considerando $D_{a g}=9,5 \mathrm{~mm}$ \\
\hline
\end{tabular}

O modelo constitutivo adotado para o concreto foi o Concrete Damaged Plasticity tal qual foi utilizado na Seção 3.1.1.2. Os parâmetros da superfície de plastificação foram mantidos iguais ao da Tabela 3.3 e o cálculo do dano seguiu a Equação 3.2. O cálculo da curva tensão-deformação do concreto à compressão foi calculada a partir da curva tensão-deformação presente na EN 1992-1-1:2004 (CEN, 2004a). No intervalo entre $\sigma_{c}=0$ e $\sigma_{c}=0,4 f_{c}$ adotou-se comportamento linear para o concreto, entre $\sigma_{c}=0,4 f_{c}$ e $\sigma_{c}=f_{c}$ adotou-se a curva não-linear descrita no EN 1992-1-1:2004 (CEN, 2004a). Para o trecho pós-pico adotou-se uma curva de amolecimento exponencial descrita pela Equação 3.3 
(GERNAY; MILLARD; FRANSSEN, 2013). A curva foi calibrada para que a tensão na deformação última $\left(\varepsilon_{c u 1}\right)$ seja igual a $1 \%$ da tensão de pico. A deformação de pico $\left(\varepsilon_{c 1}\right)$ foi obtida de acordo com a EN 1992-1-1:2004 (CEN, 2004a) e a deformação última $\left(\varepsilon_{c u 1}\right)$ de acordo com a EN 1992-1-2:2004 (CEN, 2004b).

$$
\begin{aligned}
& \sigma_{c}(\varepsilon)=f_{c}\left(1+b_{c}\left(\varepsilon-\varepsilon_{c 1}\right)\right) \exp \left(-b_{c}\left(\varepsilon-\varepsilon_{c 1}\right)\right), \quad \varepsilon_{c 1} \leq \varepsilon \\
& \sigma_{c}\left(\varepsilon_{c u 1}\right)=0,01 f_{c} \rightarrow b_{c}=6,63835 /\left(\varepsilon_{c u 1}-\varepsilon_{c 1}\right)
\end{aligned}
$$

Já para o comportamento a tração do concreto, optou-se por utilizar a curva tensão vs abertura de fissura bilinear proposta no Model Code 2010 (FIB, 2013) de forma similar ao descrito na Seção 3.1.1.2.

A Figura 3.42, Figura 3.43 e Figura 3.44 ilustram as curvas de comportamento uniaxial dos materiais calculadas de acordo com o exposto. No entanto, ao decorrer das simulações percebeu-se a necessidade de limitar a inclusão de valores excessivamente baixos de tensão na zona de amolecimento uma vez que esse fato levava a deformações excessivas e instabilidades nos elementos. Portanto, na zona de amolecimento foram desconsiderados aqueles pontos em que $\sigma \leq 0,1 f_{\text {pico }}$, tanto para tração como compressão.

Figura 3.42 - Blocos - Comportamento uniaxial do concreto

(a) Compressão

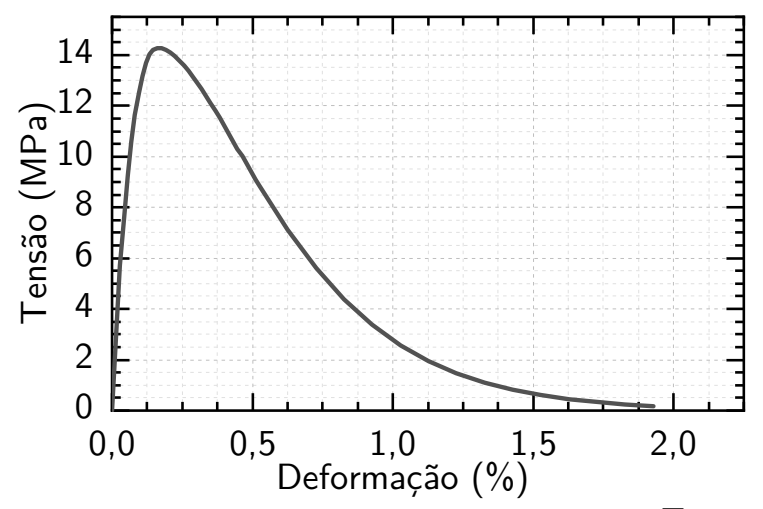

(b) Tração

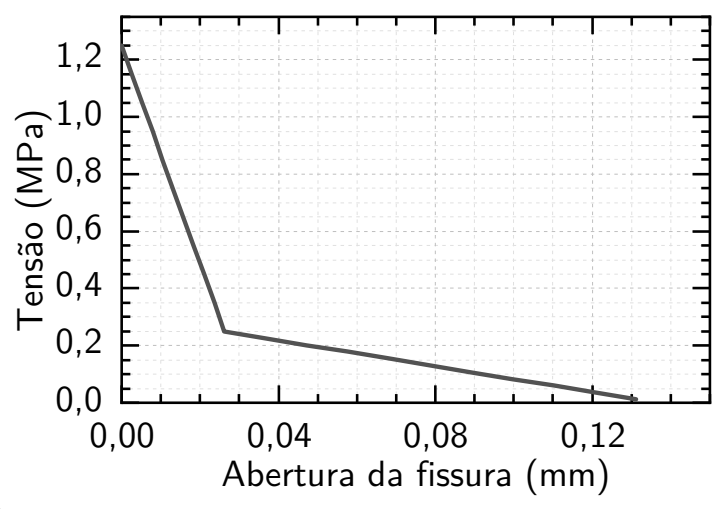

Fonte: O autor 
Figura 3.43 - Argamassa - Comportamento uniaxial do concreto

(a) Compressão

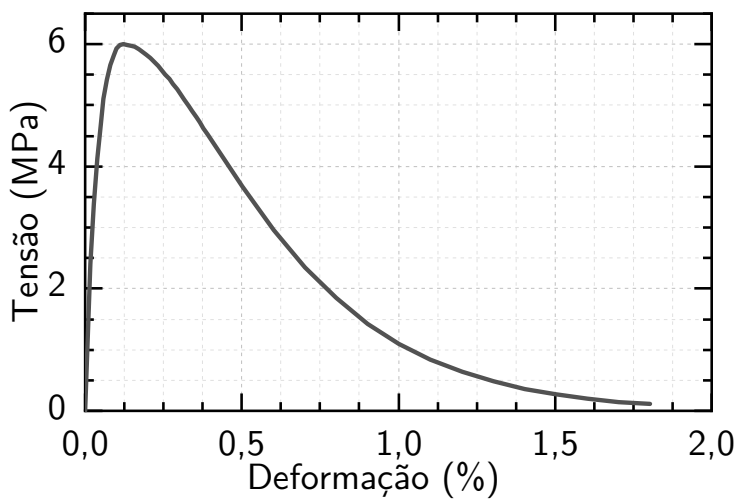

(b) Tração

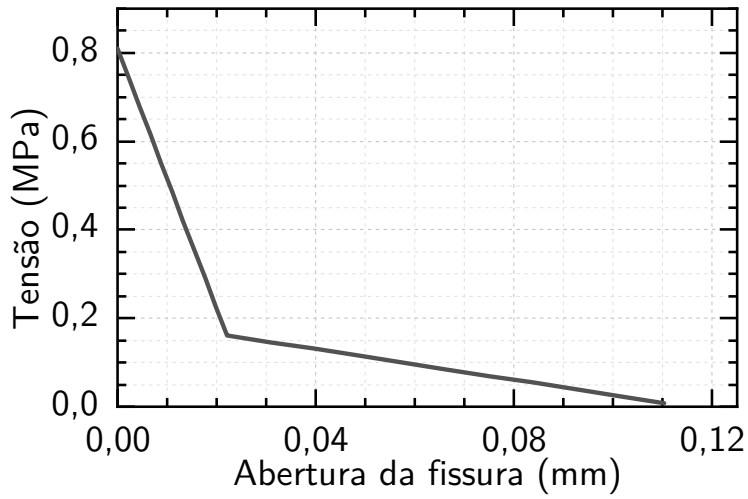

Figura 3.44 - Graute - Comportamento uniaxial do concreto

(a) Compressão

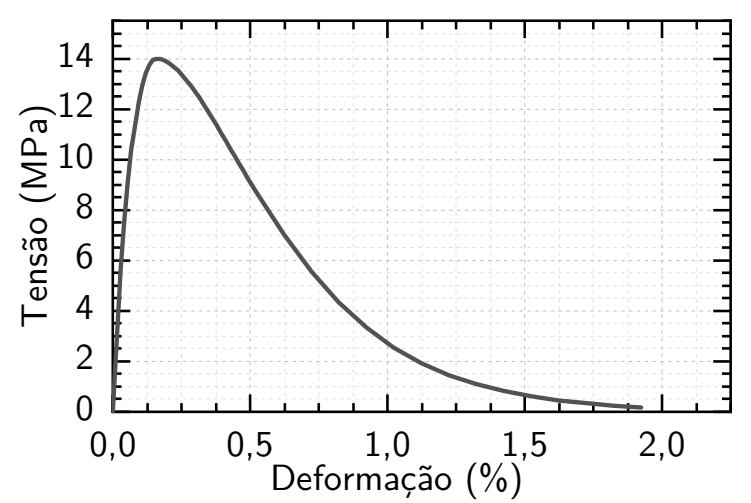

(b) Tração

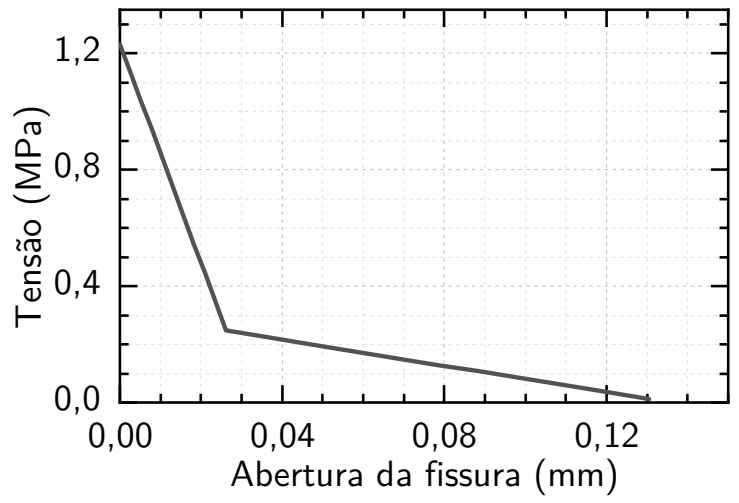

Fonte: $\mathrm{O}$ autor

\subsubsection{Resultados e Análise}

Em todas as simulações, para garantir que a análise é quasi-estática é preciso analisar os gráficos de energia de forma similar ao realizado na Seção 3.1. Os gráficos das simulações da presente seção estão inclusos no Apêndice A.2. Já o Apêndice C traz um resumo do custo computacional demandado em todas as simulações.

Para avaliar a resistência à compressão do painel de alvenaria utilizou-se a reação, $F_{z}$, da chapa na Face $+Z$ e seu deslocamento, $u_{z}$, para calcular a tensão na área bruta e a deformação média. Onde, $\sigma=F_{z} /(140 \cdot 590)$ e $\varepsilon=u_{z} / 590$. As curvas tensão-deformação para os 3 casos de condição de contorno são apresentadas na Figura 3.45.

Pode-se perceber que as diferentes condições de confinamento lateral tem pouca influência na rigidez inicial do painel e na sua deformação última. Por outro lado, há uma elevação da resistência quando se considera chapas rígidas confinando lateralmente o painel. A resistência no Caso 1 foi de, aproximadamente, 6,25 $\mathrm{MPa}$, o que corresponde a $78,13 \%$ da resistência à compressão na área bruta do bloco. Tal razão encontra-se dentro 
Figura 3.45 - Resistência à compressão do painel de alvenaria

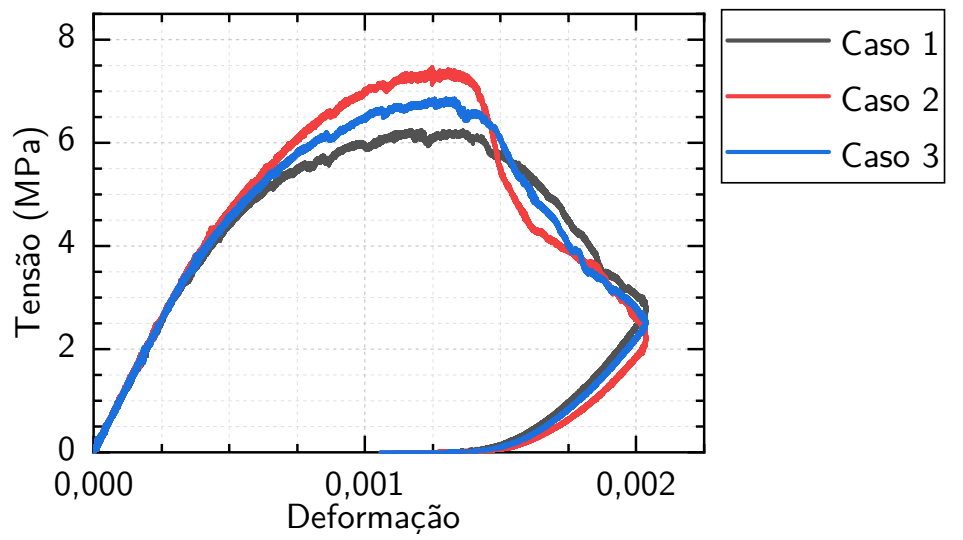

Nota: Tensão na área bruta e deformação média. Fonte: O autor

da faixa esperada e reflete a presença das juntas de argamassa.

A Figura 3.46 mostra o dano a tração após a ruptura para o Caso 1. É possível perceber que há a formação de fissuras nas Faces $+\mathrm{X}$ e -X do painel e também nas Faces -Y e +Y. Essa última é decorrente da expansão lateral que o painel sofre.

Figura 3.46 - Dano à tração após a tensão de pico - Caso 1

(a) Face $-\mathrm{Y}$

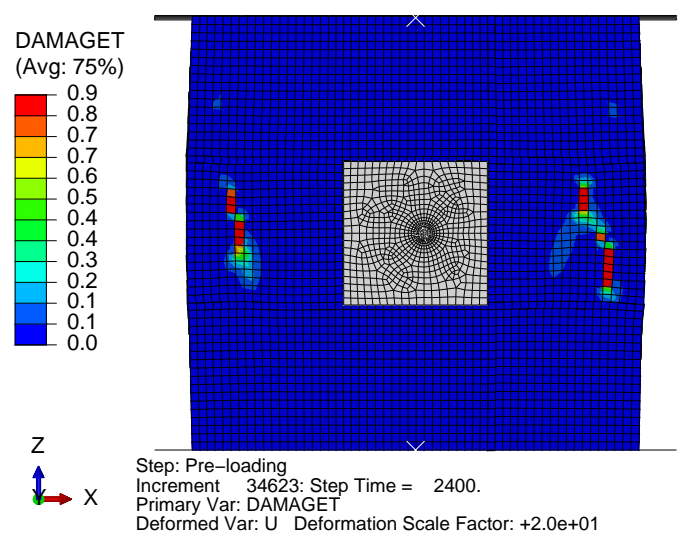

(c) Face $+\mathrm{X}$

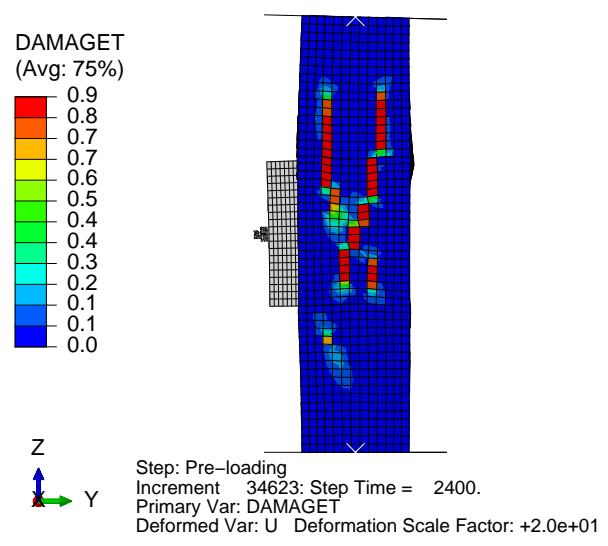

(b) Face $+Y$

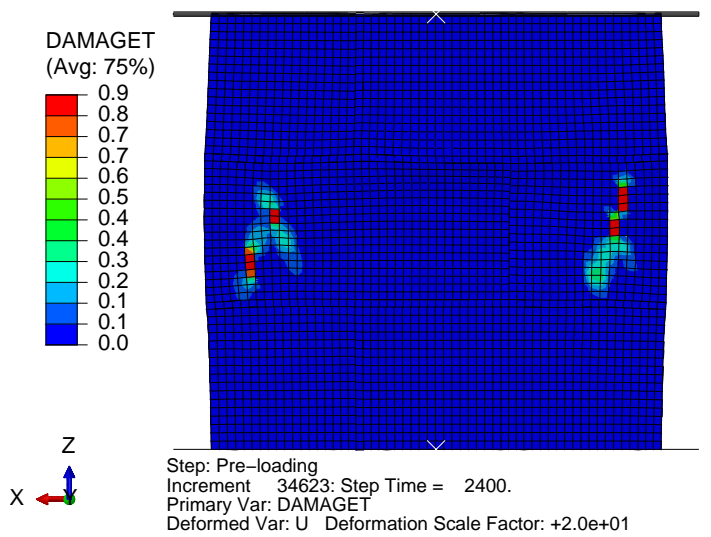

(d) Seção transversal central

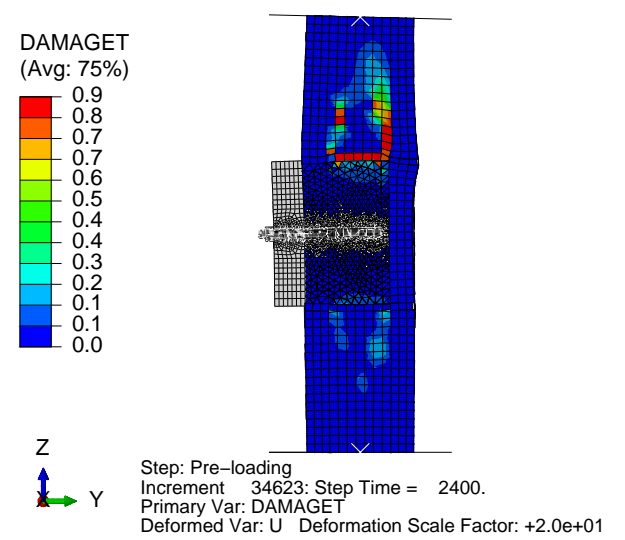

Nota: Caso 1: Faces +X e -X livres. Escala de deformação = 20. Fonte: $\mathrm{O}$ autor. 
Já a Figura 3.47 mostra o dano a compressão. Percebe-se que há um maior dano nas juntas horizontais o que pode ser justificado pela menor resistência da argamassa em comparação com o bloco.

Figura 3.47 - Dano à compressão após a tensão de pico - Caso 1

(a) Face $-Y$

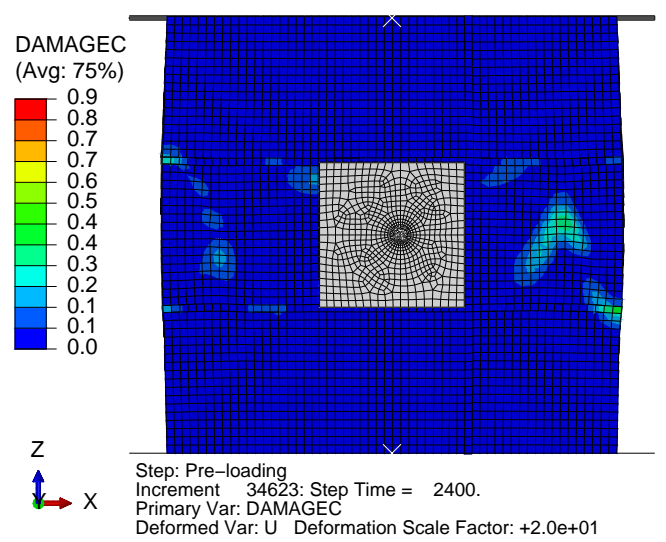

(c) Face $+\mathrm{X}$

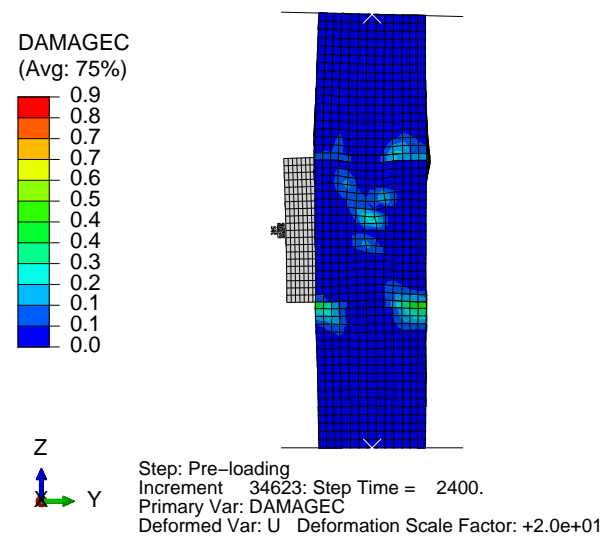

(b) Face $+Y$

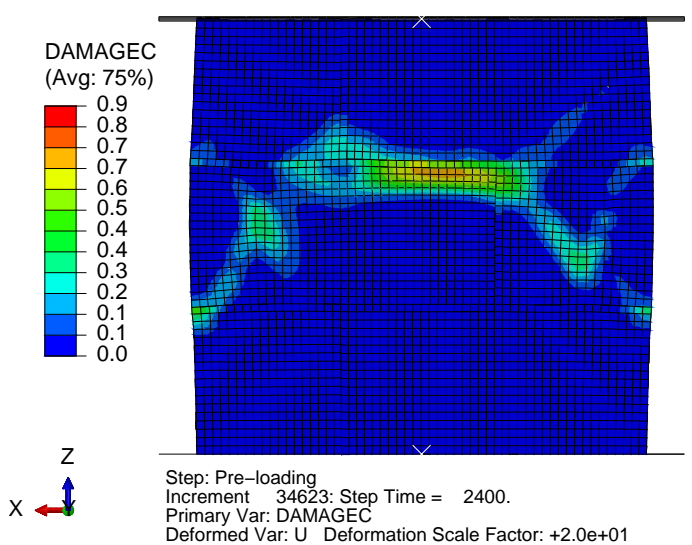

(d) Seção transversal central

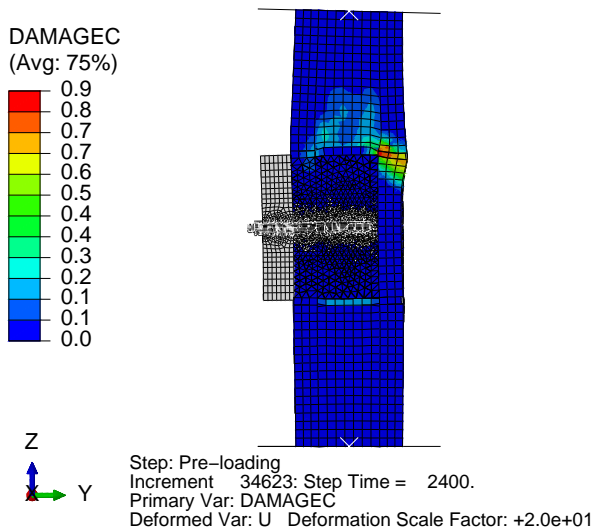

Nota: Caso 1: Faces +X e -X livres. Escala de deformação = 20. Fonte: O autor.

A segunda simulação avaliou a resistência do chumbador. A Figura 3.48 mostra relação entre a força cisalhante e o deslocamento na direção da força, avaliado no topo da chapa de aplicação da carga no chumbador. É possível perceber que as condições de contorno do painel tem pouca influência na resposta do chumbador. Por outro lado, não é possível definir claramente um ponto de ruptura. Isso ocorre pois o aço escoa indefinidamente assim que alcança $f_{u}$. Como mostram os ensaios de Grosser (2012), a resistência ao cisalhamento de chumbadores ancorados em concreto depende do alongamento do aço na ruptura. No gráfico marca-se o ponto em que a deformação plástica equivalente verdadeira de Von Mises alcança $19 \%$. Nesse trabalho, $F_{r}^{\text {chumb }}=21,1 \mathrm{kN}$ é a carga de ruptura assumida para um aço de baixo carbono e elevada ductilidade.

De acordo com o exposto na Figura 3.25, a força solicitante cisalhante característica 
Figura 3.48 - Resistência ao cisalhamento do chumbador ancorado em alvenaria

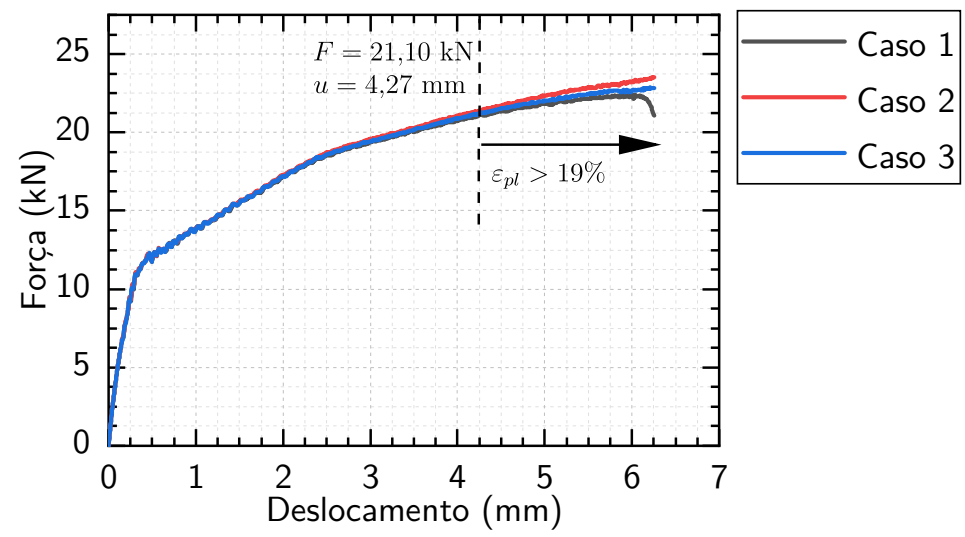

Fonte: $\mathrm{O}$ autor

no apoio da viga denteada é $F_{s}=2,28 \mathrm{kN}$. Além disso, de acordo com a Figura 3.37, a máxima força cisalhante que a viga denteada pode suportar é $F_{r}^{v i g a}=23,75 \mathrm{kN}$. Assim, considerando as características previamente descritas, $\mathrm{FS}=21,1 / 2,28=9,25$ para $\mathrm{o}$ sistema viga denteada + chumbador ancorado em alvenaria. É importante lembrar que os degraus estão fora do escopo da análise, ou seja, há a possibilidade dos degraus romperem antes do sistema de fixação. A análise específica dos degraus não é realizada nesse trabalho visto que o objetivo é analisar o sistema de fixação da escada e comparar seu desempenho em temperatura ambiente e em situação de incêndio.

Cabe destacar que essa análise reflete apenas o caso específico analisado, onde se considerou valores característicos para as ações e resistências dos materiais. Nesse sentido, ela se aproxima de um "ensaio virtual", onde a resposta é derivada de uma única entrada. A análise de segurança do sistema deve ser feita através de uma abordagem semi-probabilística de acordo com a filosofia adotada nas normas de dimensionamento. Somente com essa análise seria possível propor equações para dimensionamento apropriadas. No entanto, essa tarefa foge ao escopo desse trabalho. Ainda assim, os resultados são interessantes para o estudo de uma "equação de resistência", ou seja, o problema de estimar a resistência a partir de determinados parâmetros de entrada.

A Figura 3.49 ilustra a configuração deformada bem como a deformação plástica e tensão de Von Mises no chumbador na carga de ruptura. A ruptura foi caracterizada pela plastificação excessiva do aço no plano de cisalhamento do chumbador. É possível perceber que há um efeito combinado de cisalhamento e flexão do chumbador. Além disso, a flexão leva a plastificação numa profundidade de embutimento de aproximadamente $1,5 \mathrm{~cm}$. A tensão de Von Mises permanece abaixo de $200 \mathrm{MPa}$ na metade mais profunda do comprimento de embutimento do chumbador. 
Figura 3.49 - Deformação e tensão no chumbador na situação de ruptura

(a) Deformação plástica equivalente

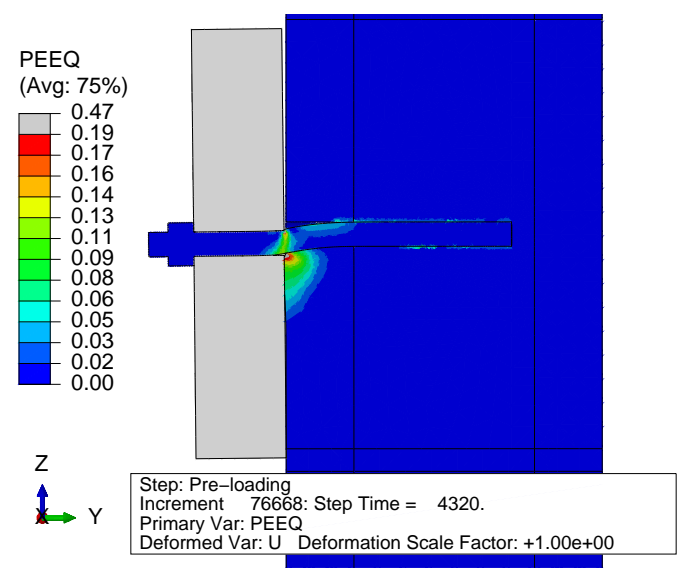

(b) Tensão de Von Mises

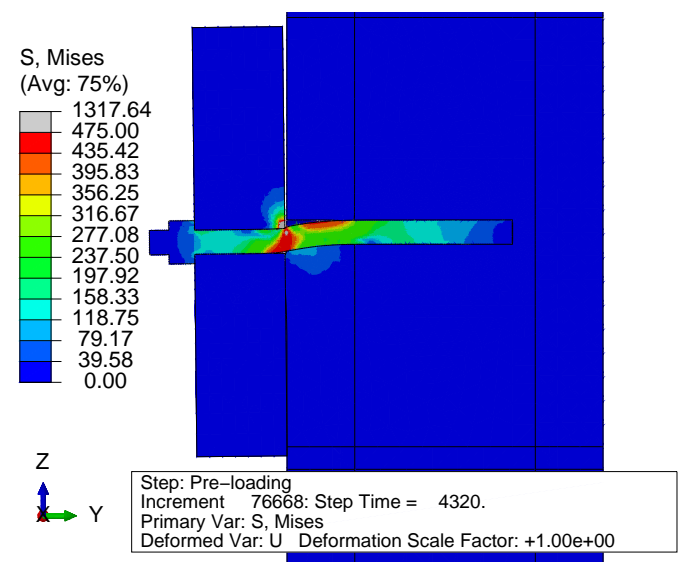

Fonte: O autor.

A Figura 3.50 mostra o dano no bloco e graute devido ao chumbador. É possível observar o surgimento de dano a tração no plano XY próximo a borda do furo indicando que o chumbador promove um alargamento do furo. Além disso, há dano a tração na face -Y indicando um possível desplacamento. Já o dano à compressão é preponderante na zona próxima a borda do furo onde o chumbador exerce maior pressão. Além disso, ao longo de toda a superfície do furo há dano a tração e compressão. Isso ocorre pois foi considerada condição de não-deslizamento entre a superfície do chumbador e do furo. Assim, quando o concreto acabou se danificando em alguns pontos por não resistir às tensões necessárias para garantir o não-deslizamento. A análise do bloco e graute não indica a formação de nenhum modo de ruptura controlado pelo concreto como, por exemplo, ruptura de cunha de concreto por braço de alavanca (Pry-out Failure).

Figura 3.50 - Dano no bloco e graute na situação de ruptura do chumbador

(a) Dano a tração

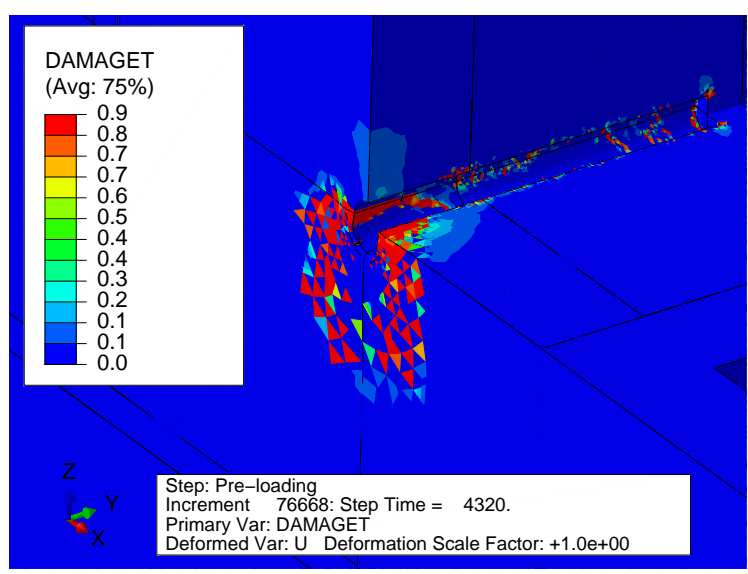

(b) Dano a compressão

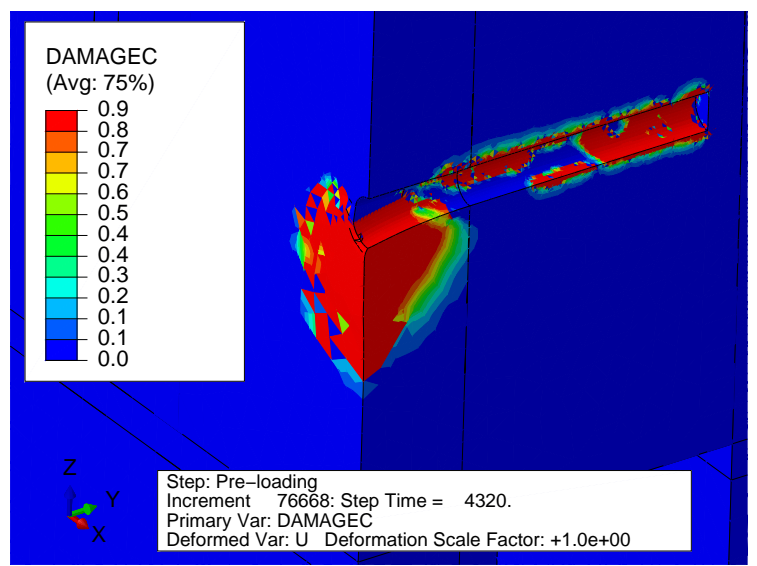

Nota: Seções transversais passando pelo chumbador. A chapa de carregamento e o chumbador são omitidos na figura. Fonte: $\mathrm{O}$ autor. 



\section{ANÁLISE TÉRMICA}

O estudo de elementos estruturais em situação de incêndio depende da evolução de temperatura que a estrutura sofre ao ser submetida à incêndio. Logo, esse é um problema de transferência de calor que aqui chamamos de análise térmica. O uso do Método dos Elementos Finitos para resolver as equações de transferência de calor é um dos métodos usados para estimar o campo de temperatura nos elementos.

O ambiente em chamas transfere calor para a estrutura principalmente por convecção e radiação enquanto o calor propaga internamente ao longo da estrutura principalmente por condução. No entanto, é comum que as alvenarias sejam constituídas de unidades que possuem cavidades, logo, há também transferência de calor por radiação e convecção nessas cavidades. Alguns autores consideram uma condutividade equivalente para o material da alvenaria de modo a encontrar um material fictício no qual as simulações apresentam boa concordância com os resultados experimentais (RUSSO; SCIARRETTA, 2016; CARVALHO, 2019). Uma das limitações dessa abordagem é que ela é dependente da geometria utilizada nos ensaios utilizados para calibrar os modelos. A convecção e radiação nas cavidades são fenômenos que dependem da geometria do bloco, logo, qualquer tentativa de calibração de um material equivalente deve levar isso em consideração. Rodovalho (2018) considera o ar nas cavidades do bloco, no entanto, considera-se uma condutividade do ar superior à real para compensar os efeitos da radiação que não é considerada nas cavidades. Além disso, os resultados parecem não capturar os efeitos de convecção livre nas cavidades do bloco.

\subsection{Estudo da estratégia de simulação}

O objetivo dessa seção é validar uma estratégia de simulação que considere adequadamente os mecanismos de transferência de calor nos vazados de um bloco de alvenaria estrutural em concreto. Para isso, a radiação entre as superfícies da cavidade e a convecção do ar são consideradas através de uma análise de transferência de calor transiente com acoplamento fluido-sólido. As simulações são validadas através dos resultados experimentais de Dupim (2019) e Oliveira e Berto (2015 apud RODOVALHO, 2018) com isso espera-se entender a importância de cada mecanismo de transferência nas cavidades e julgar as estratégias de simulação simplificada tais como a adoção de condutividade equivalente. Cabe ressaltar que parte dos resultados aqui apresentados também foram reportados em Assis e Munaiar Neto (2020). 


\subsubsection{Características experimentais}

Dupim (2019) fez uma série de ensaios em blocos, prismas e pequenas paredes de alvenaria estrutural em blocos de concreto em situação de incêndio. O forno horizontal à gás da Figura 4.1 foi utilizado nos ensaios. Este forno é capaz de aplicar a curva de elevação de temperatura padrão da ISO 834-1:1999.

Figura 4.1 - Forno horizontal à gás - LE-SET-EESC-USP

(b) Visão interna

(a) Visão externa
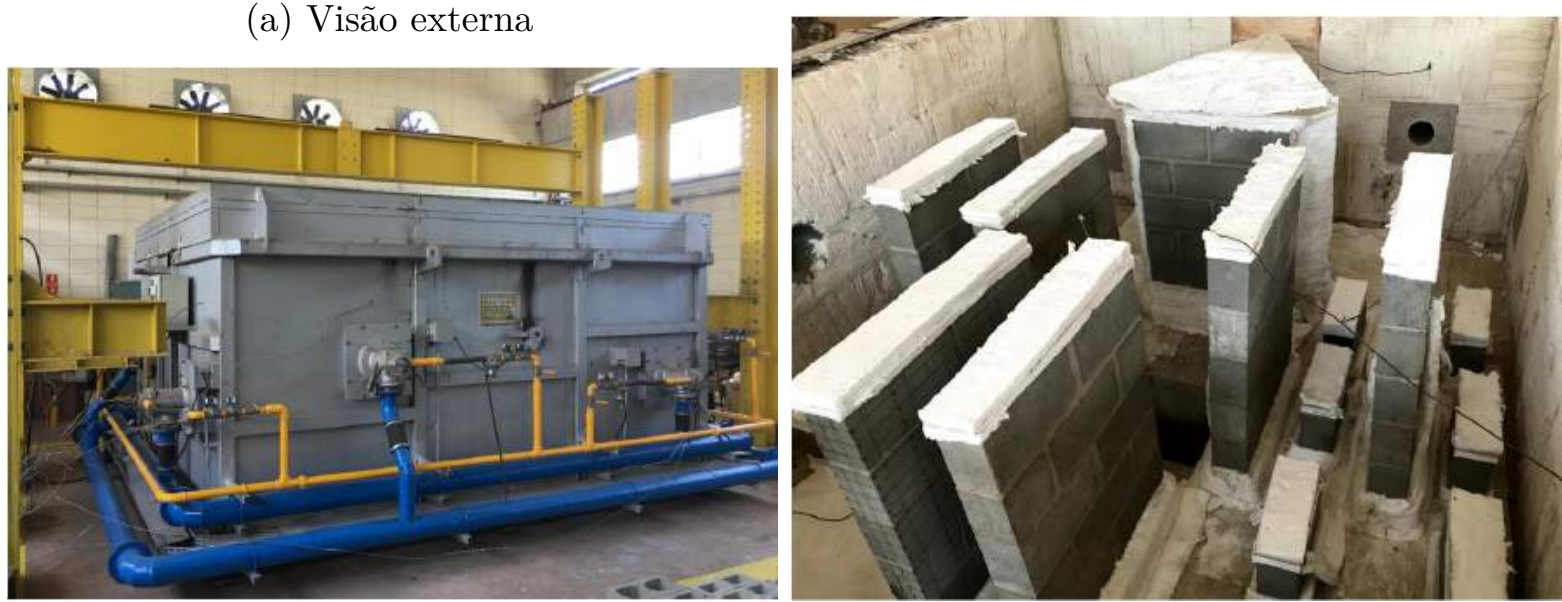

Fonte: (DUPIM, 2019)

Para validação foram utilizados os resultados experimentais de 2 fornadas: fornada "Teste Instrumentação"e "Fornada 1". No "Teste Instrumentação"foram ensaiados apenas blocos isolados considerando diferentes formas de fixação e posicionamento dos termopares (ver Figura 4.2). Já na "Fornada 1"foram utilizados blocos, prismas de 2 blocos e pequenas paredes de alvenaria. Em nenhum dos casos foi utilizado revestimento nos blocos. A curva de incêndio padrão da ISO 834-1:1999 foi utilizada sendo que o tempo total de ensaio foi de 43 minutos para a "Teste Instrumentação"e 70 minutos para a "Fornada 1". Foram utilizados blocos de $14 \mathrm{~cm}$ de espessura com resistências à compressão $f_{b k}=4 \mathrm{MPa} \mathrm{e}$ $f_{b k}=10 \mathrm{MPa}$. 
Figura 4.2 - Termopares no bloco
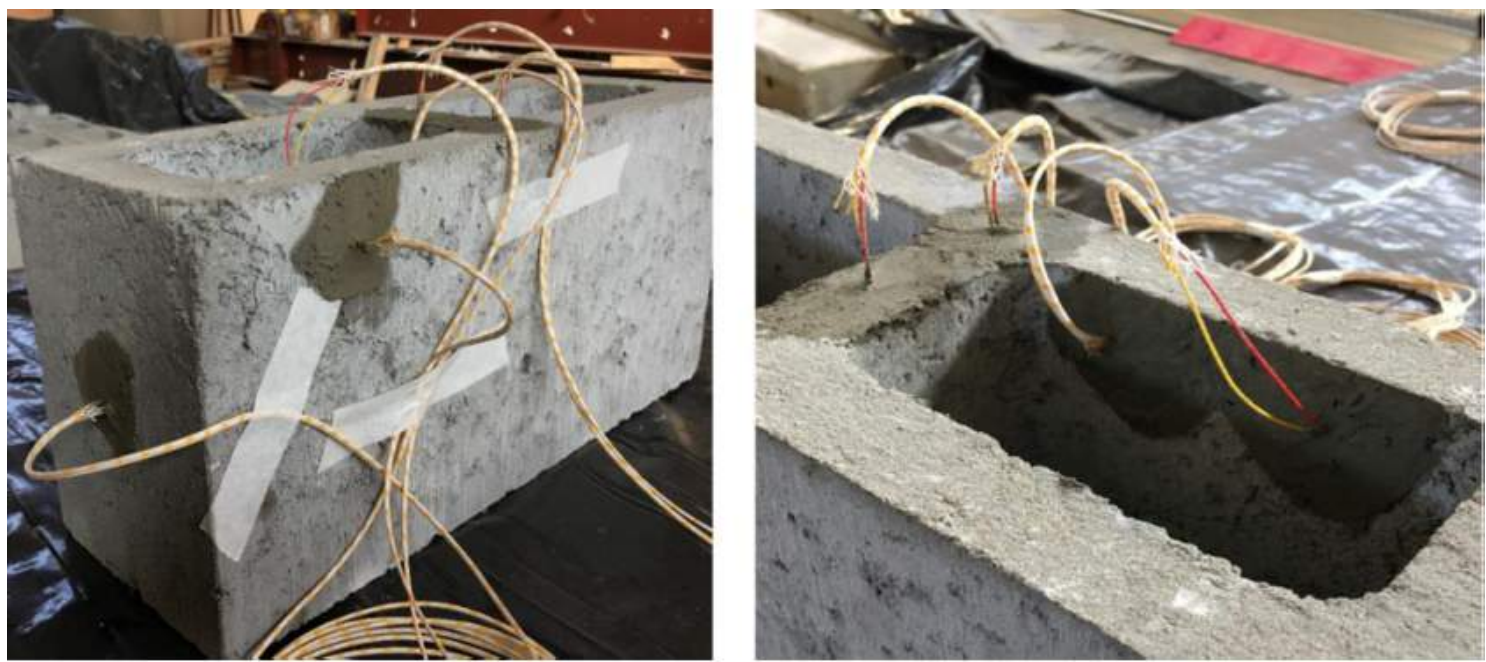

Fonte: (DUPIM, 2019)

\subsubsection{Características do modelo}

O modelo consiste num bloco vazado de concreto da família 15 x 40 idêntico ao ilustrado na Figura 3.39 e descrito em maiores detalhes na Seção 3.3. Como o bloco apresenta dupla simetria, apenas $1 / 4$ do deste é modelado para o caso de fogo em todos as faces perpendiculares aos eixos X e Y como mostra a Figura 4.3a. Já para fogo apenas em uma das faces perpendiculares ao eixo $\mathrm{Y}$, apenas metade do bloco é modelado como mostra a Figura 4.3b.

A Figura 4.3 mostra malha de elementos finitos utilizada nos blocos. Foram utilizados elementos hexaédricos quadráticos de 20 nós (D3D20 na nomenclatura do ABAQUS) com lado de $10 \mathrm{~mm}$. O uso de elementos quadráticos aqui fornece uma melhor interpolação das temperaturas no interior dos elementos, fato importante para avaliar a evolução de temperatura à uma profundidade de $5 \mathrm{~mm}$ da superfície do bloco. Para o modelo com dupla simetria foram utilizados 1520 elementos que totalizam 8188 nós. Já para o modelo com simetria simples foram utilizados 3040 elementos que totalizam 16003 nós. Por outro lado, a malha do domínio do fluido no interior das cavidades é constituída de elementos hexaédricos lineares com lado de $10 \mathrm{~mm}$ (FC3D8 na nomenclatura do ABAQUS). 
Figura 4.3 - Malha de elementos finitos do bloco

(a) Fogo em todas as faces laterais

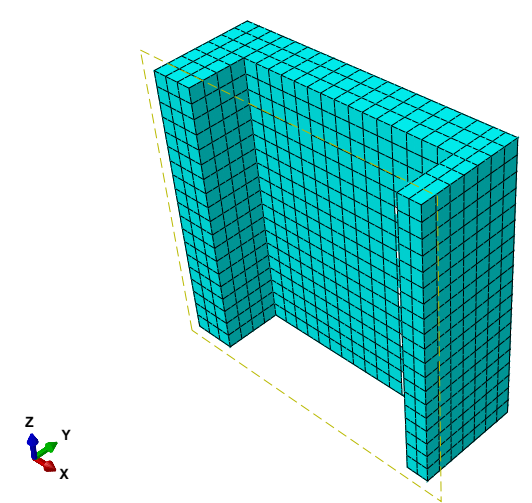

(b) Fogo em uma face

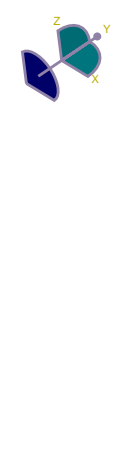

Fonte: $\mathrm{O}$ autor

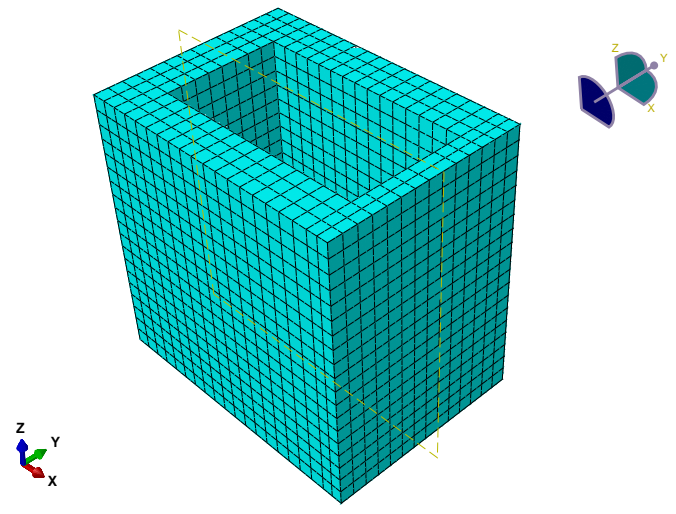

A condutividade térmica, massa específica e calor específico do concreto em função da temperatura foram calculadas de acordo com a EN 1992-1-2:2004 (CEN, 2004b). No caso do calor específico optou-se por calcular o calor latente de vaporização da água considerando umidade de $1,5 \%$ e a mudança de fase ocorrendo entre $100^{\circ} \mathrm{C}$ e $115^{\circ} \mathrm{C}$ (WICKSTRÖM, 2016). A Figura 4.4 mostra as curvas das propriedades.

As propriedades do ar dependem da temperatura e foram adotadas de acordo com Çengel e Cimbala (2018) as quais são apresentadas na Figura 4.5. O coeficiente de expansão (Figura 4.5c) pode ser calculado de acordo com a variação da densidade do ar com a temperatura. No entanto, a consideração do ar como um gás ideal fornece uma boa aproximação, logo, utilizou-se $\alpha=1 / T$ onde $T$ é a temperatura absoluta em Kelvin.

A temperatura dos gases foi adotada de acordo com a curva de elevação de temperatura da ISO 834-1:1999 a qual é mostrada na Figura 4.6. A transferência de calor do ambiente aquecido para o bloco ocorre através de convecção e radiação. Pode-se simular esse fenômeno de maneira simplificada através de condições de contorno que dependem de características do material e do fenômeno de transferência de calor em si. Para calcular o fluxo de calor convectivo através do contorno é necessário definir o coeficiente de transferência de calor por convecção $\left(\alpha_{c}\right)$. Adotou-se a recomendação da EN 1991-1-2:2002 (CEN, 2002) de $\alpha_{c}=25 \mathrm{~W} / \mathrm{m}^{2} \mathrm{~K}$ para superfícies expostas a curva de incêndio padrão e $\alpha_{c}=4 \mathrm{~W} / \mathrm{m}^{2} \mathrm{~K}$ para superfícies não-expostas. Já para cálculo do fluxo de calor no contorno devido a radiação é necessário definir a emissividade da superfície. Esse é um parâmetro que depende de inúmeros fatores tais como, as características da superfície, a temperatura da superfície e as características das ondas eletromagnéticas envolvidas na transferência de calor (ÇENGEL, 2008). Para as superfícies expostas ao incêndio adotou-se $\varepsilon=0,7$ constante para todas as temperaturas conforme recomendado pela EN 1992-1-2:2004 (CEN, 2004b).

No modelo com fogo em todas as faces do bloco (simetria dupla) adota-se condição 
Figura 4.4 - Propriedades do concreto

(a) Condutividade térmica

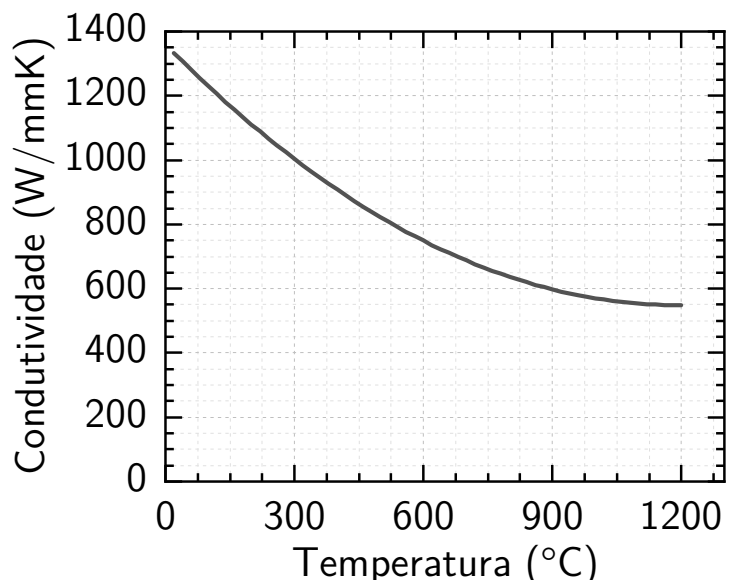

Fonte: Limite inferior do EN 1992-1-2:2004 (CEN, 2004b) (b) Massa específica

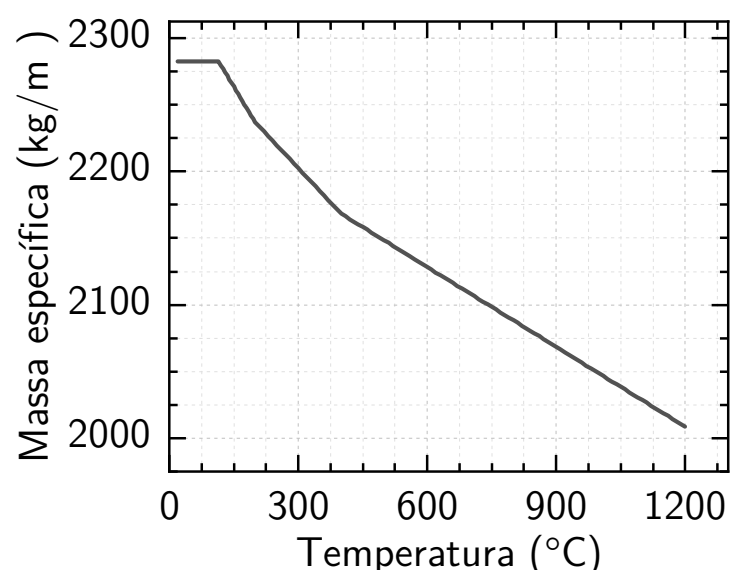

Fonte: (DUPIM, 2019) e EN 1992-1-2:2004

(CEN, 2004b)

(c) Calor específico e calor latente

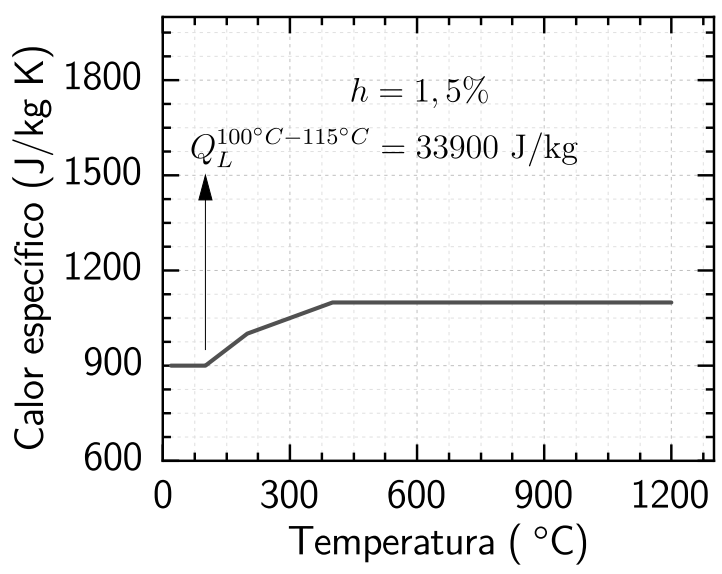

Fonte: EN 1992-1-2:2004 (CEN, 2004b) e

(WICKSTRÖM, 2016)

adiabática (fluxo de calor nulo) nas paredes do bloco que estão no plano de simetria. Já no modelo com fogo apenas em uma face do bloco (simetria simples) adota-se condição adiabática nas paredes no plano de simetria e também nas faces perpendiculares ao fogo, simulando assim a continuidade que existe numa parede de blocos.

Por outro lado, é preciso definir as condições de contorno na superfície dos vazados. No modelo de elementos sólidos é possível definir a transferência de calor por radiação entre as superfícies que compõem uma cavidade. O algoritmo calcula os fatores de configuração de cada elemento de superfície em relação aos demais, utiliza as emissividades e considera reflexão difusa para calcular o fluxo de calor por radiação entre as faces. Inicialmente adotou-se $\varepsilon=0,95$ para as superfícies da cavidade e posteriormente foi realizado um estudo para diferentes valores os quais são detalhados nos resultados das simulações. $\mathrm{Na}$ atribuição da cavidade considera-se o vazado do bloco totalmente fechado com as superfícies 
Figura 4.5 - Propriedades do ar

(a) Condutividade térmica

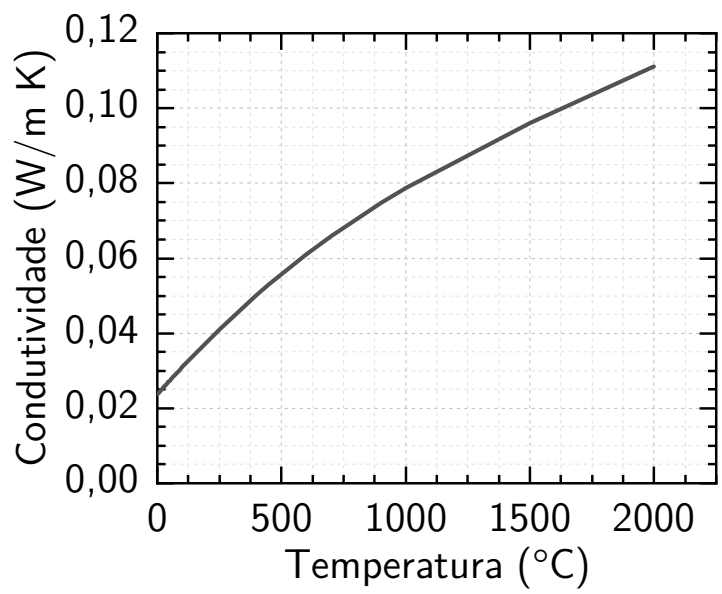

(c) Coeficiente de expansão

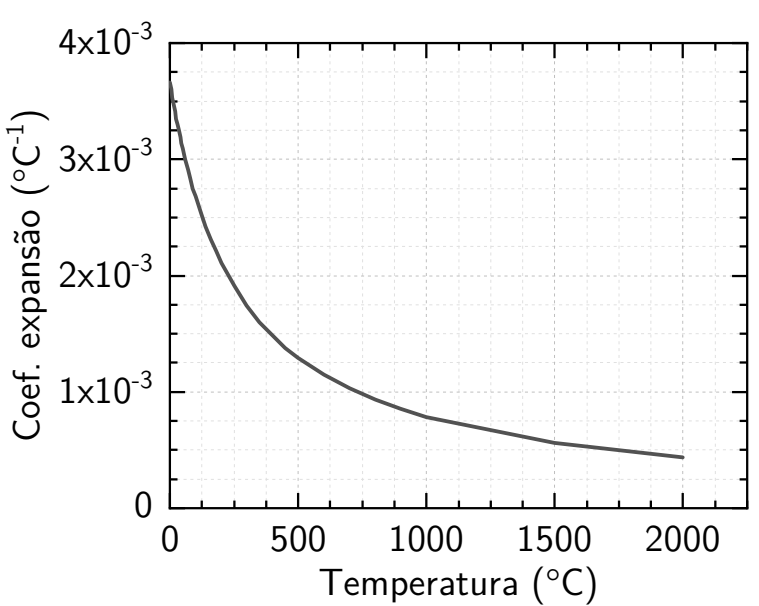

Fonte: (ÇENGEL; CIMBALA, 2018) (b) Calor específico

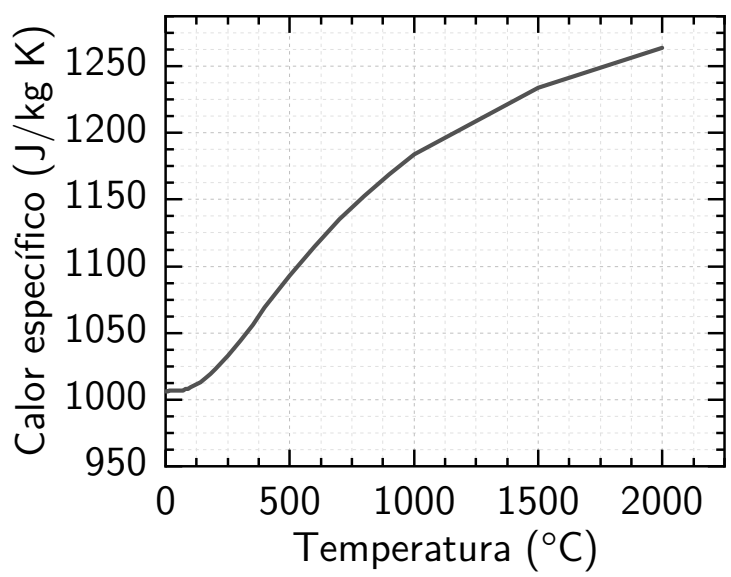

(d) Viscosidade dinâmica

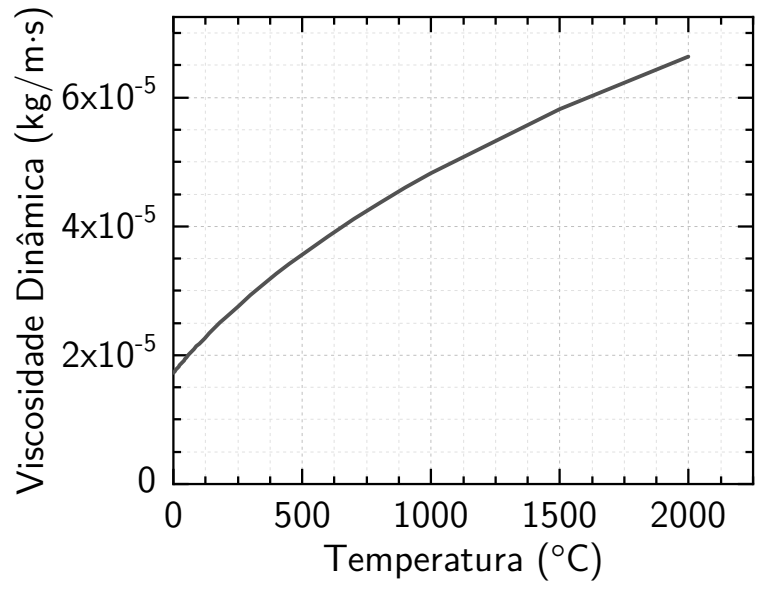

Figura 4.6 - Curva de elevação de temperatura

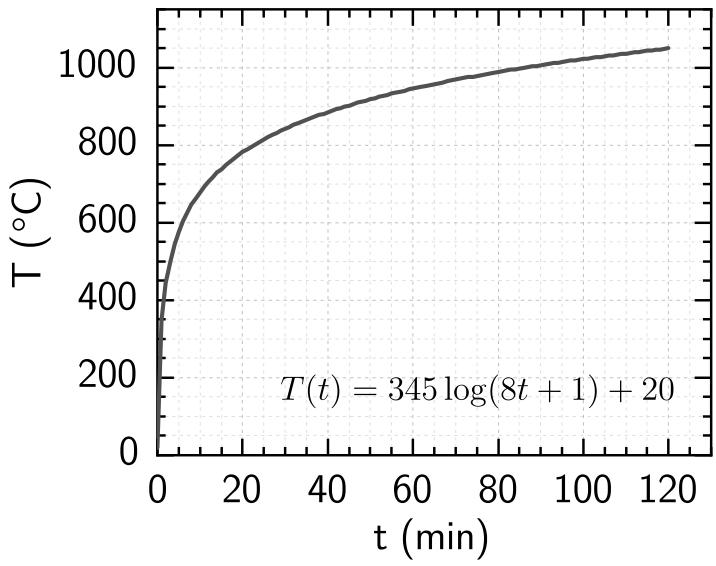

Fonte: ISO 834-1:1999 (ISO, 1999) 
inferior e superior com reflexão total $(\varepsilon=0)$ do calor. Essa condição é verdadeira para o ensaios de blocos isolados no forno os quais tem suas superfícies inferior e superior isoladas termicamente. Essa também é uma aproximação razoável para os ensaios de prismas e pequenas paredes devido a continuidade dos vazados e exposição uniforme na superfície externa.

A consideração do ar no interior dos vazados foi realizada através de uma análise térmica acoplada fluido-estrutura. O ar é considerado um fluido incompressível e suas condições de contorno em temperatura são acopladas a temperatura na superfície interna dos vazados. Adota-se ainda um ponto arbitrário como pressão de referência nula que é necessário para análises de fluidos incompreensíveis. Com auxílio da aproximação de Boussinesq é possível simular a situação de convecção livre no qual há movimentos convectivos devido a expansão do fluido quando este aumenta de temperatura. Por isso, define-se a direção da gravidade bem como sua aceleração.

Como condição de contorno mecânica do fluido considera-se não-escorregamento e não-penetração na interface entre ar e bloco, ou seja, velocidades nulas na interface. Cabe destacar que nessa simulação não estão incluídos os efeitos de expansão do bloco devido a elevação de temperatura.

O bloco foi simulado através de uma análise de transferência de calor transiente sendo o tempo total escolhido de acordo com o intervalo de tempo dos dados experimentais. As configurações de análise do fluido são atribuídas separadamente e o ABAQUS calcula os devidos incrementos de forma a obedecer análise acoplada. Para análise do fluido adotou-se integração implícita no tempo (Backward-Euler) a qual é incondicionalmente estável. Assim, é possível utilizar incrementação automática com valores que excedam a condição de estabilidade de Courant-Friedrichs-Lewy(CFL) a qual é aplicável para integração explícita. Nas simulações utilizadas nesse trabalho foi possível manter $C F L=10$ e manter a convergência da análise. Dessa forma foi possível alcançar intervalos de incrementos em torno de $1 \mathrm{~s}$ ou mais a medida que a análise avança.

\subsubsection{Resultados e Análise}

Nessa seção apresenta-se os resultados das simulações térmicas realizadas. Os resultados são divididos em duas partes de acordo com as características da simulação. No primeiro modelo os blocos estão sujeitos ao fogo em todas as suas faces laterais, já no segundo os blocos estão sujeitos ao fogo em apenas uma de suas faces. Por fim, o Apêndice C traz um resumo do custo computacional demandado em todas as simulações. 


\subsubsection{Bloco sob fogo em todas as faces laterais}

Nessa seção apresenta-se os resultados da simulação de blocos sob incêndio em todas as faces laterais e as faces superior e inferior isoladas termicamente. A simulação reproduz a condição de ensaio utilizada por Dupim (2019), cujos resultados são utilizados na validação do modelo. Os resultados de Dupim (2019) são apresentados para duas classes de resistência dos blocos, $f_{b k}=4 \mathrm{MPa}$ e $f_{b k}=4 \mathrm{MPa}$, e duas fornadas, "Teste Instrumentação", aqui chamada de "Fornada Teste", e "Fornada 1".

A Figura 4.7 e Figura 4.8 mostra os resultados para a "Fornada Teste". Nesses gráficos a curva experimental apresenta declínio a partir dos 43 minutos quando o forno é desligado, no entanto, não foi considerado esse fato na simulação, logo, a resposta em temperatura é ascendente.

O posicionamento dos termopares nessa fornada foi variável e estes estão agrupados com cores por sua semelhança quanto ao posicionamento na parede do bloco. Assim, curvas de mesma cor estão relacionadas com posições semelhantes, as quais podem ser verificadas no desenho esquemático no gráfico. Maiores detalhes quanto ao posicionamento podem ser encontrados em Dupim (2019). Já para as simulações, foram escolhidas algumas profundidades de avaliação da temperatura em relação a face externa as quais estão indicadas no gráfico.

Figura 4.7 - Temperatura ao longo do tempo - "Fornada Teste" Bloco $f_{b k}=4 \mathrm{MPa}$
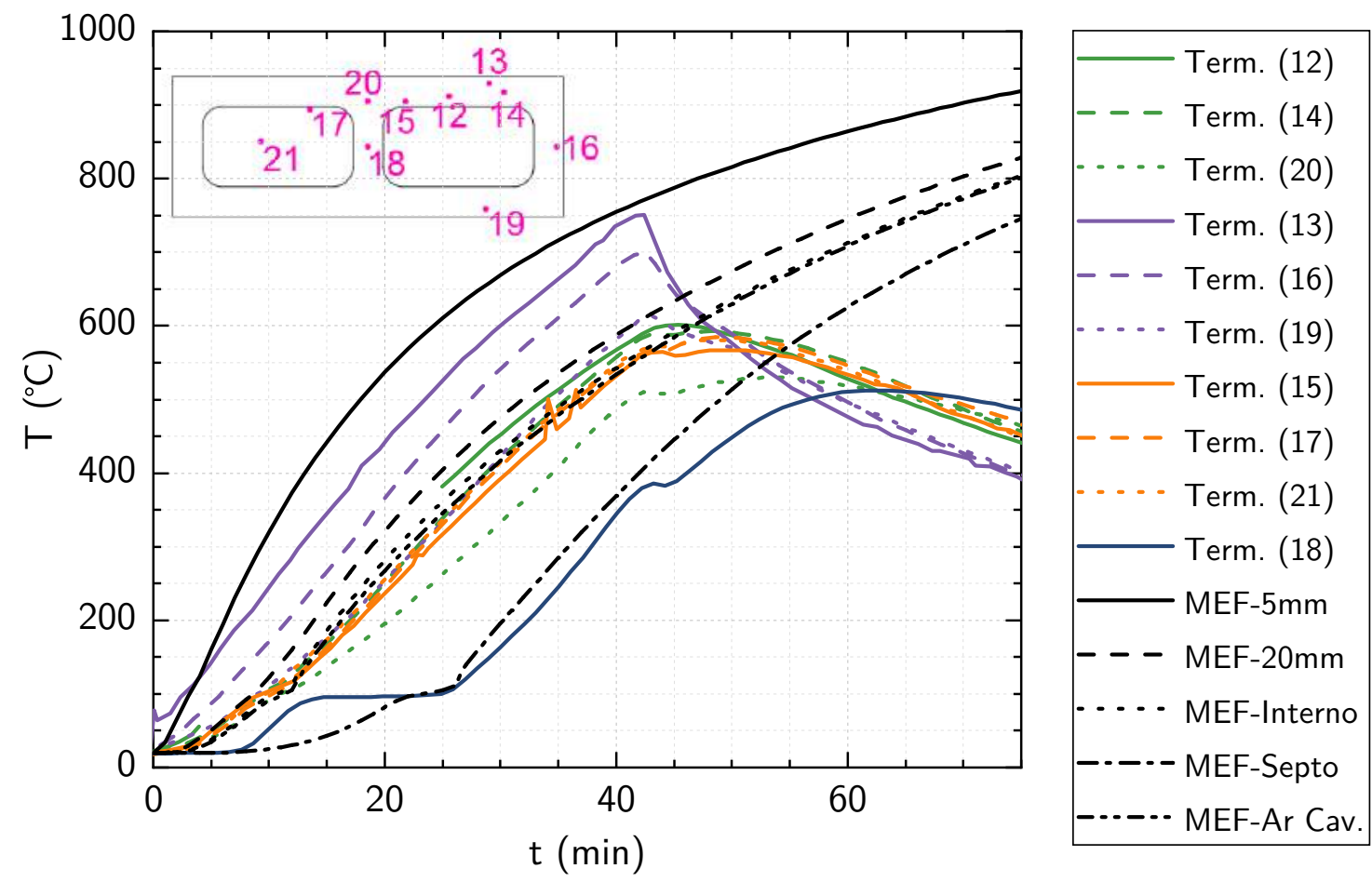

Nota: O forno é desligado aos 43 minutos mas a simulação considera aquecimento contínuo Fonte: O autor. Dados experimentais de Dupim (2019) 
Figura 4.8 - Temperatura ao longo do tempo - "Fornada Teste" Bloco $f_{b k}=10 \mathrm{MPa}$
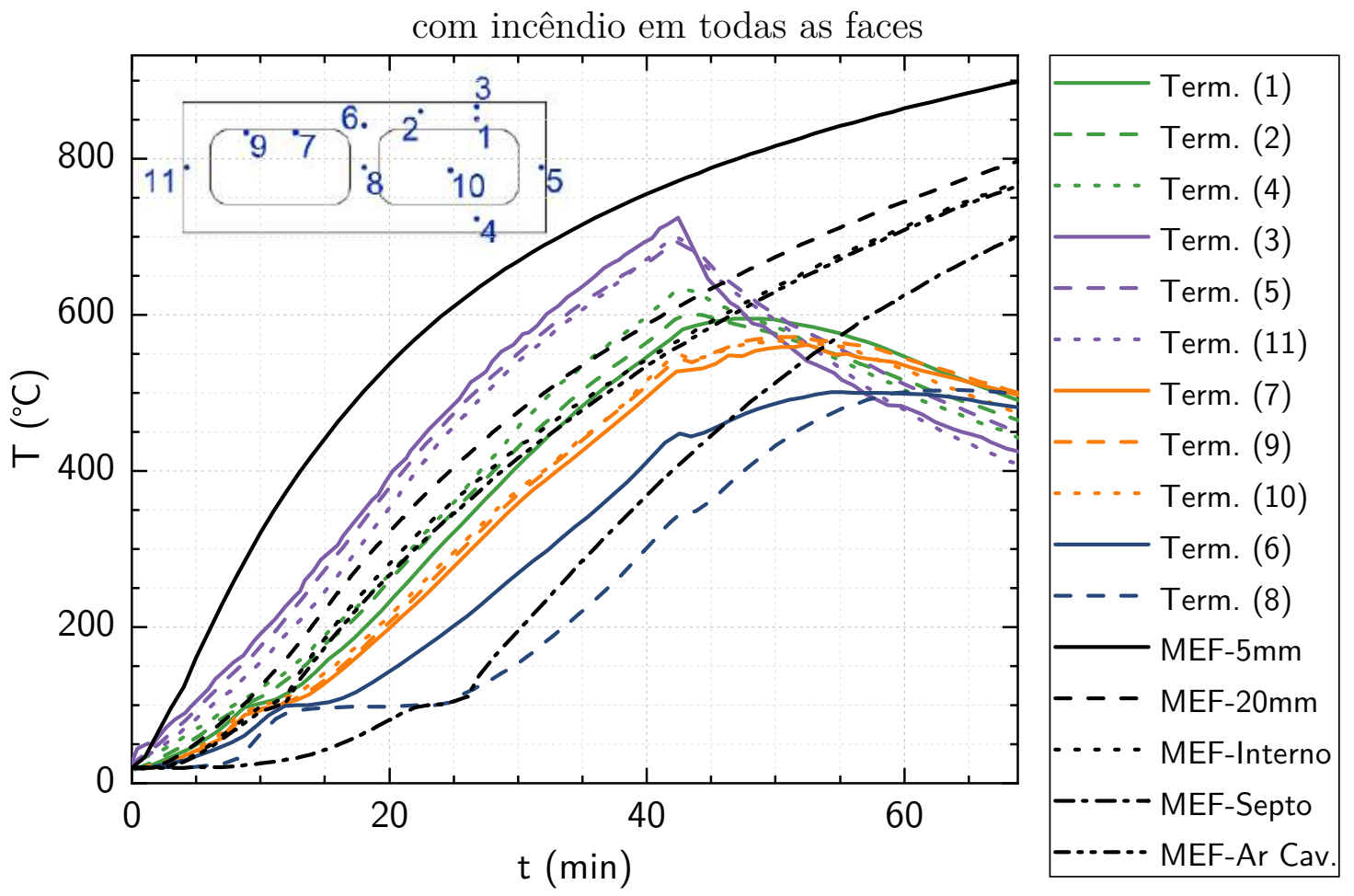

Nota: O forno é desligado aos 43 minutos mas a simulação considera aquecimento contínuo Fonte: O autor. Dados experimentais de Dupim (2019)

De modo geral, através da análise da "Fornada Teste", parece que os resultados das simulações tendem a superestimar as temperaturas. No entanto, cabe destacar que as posições dos termopares nessa fornada não são exatamente a posição avaliada nas simulações. Além disso, há erro experimental nesse posicionamento e cabe lembrar que a temperatura varia de forma quadrática ao longo da espessura do bloco o que pode levar a diferenças significativas. Um outro aspecto dos resultados diz respeito ao termopar inserido no septo do bloco. A curva temperatura vs tempo desse ponto experimental apresenta tendência diferente daquela obtida na simulação. É visível que o resultado experimental apresenta uma elevação de temperatura precoce seguida de extenso patamar em temperatura de $100^{\circ} \mathrm{C}$. Enquanto na simulação a elevação de temperatura é mais lenta e o patamar é mais curto. Chama a atenção essa diferença de comportamento especialmente porque após essa divergência inicial, a simulação apresenta resultados semelhantes ao ensaio.

A Figura 4.9 e Figura 4.10 mostram os resultados para a "Fornada 1". Nesse caso o forno foi desligado aos $70 \mathrm{~min}$, fato que não é considerado nas simulações. As posições dos termopares estão indicadas nos gráficos. Percebe-se uma boa concordância dos resultados experimentais e da simulação. É interessante notar também a variabilidade experimental das curvas de termopares localizados na mesma profundidade. Cabe destacar que as curvas de simulação das Figuras 4.7, 4.8,4.9 e 4.10 são as mesmas. Os diferentes gráficos são utilizados para comparar a mesma simulação com diferentes corpos-de-prova dos ensaios. 
Figura 4.9 - Temperatura ao longo do tempo - "Fornada 1" Bloco e Prisma $f_{b k}=4 \mathrm{MPa}$
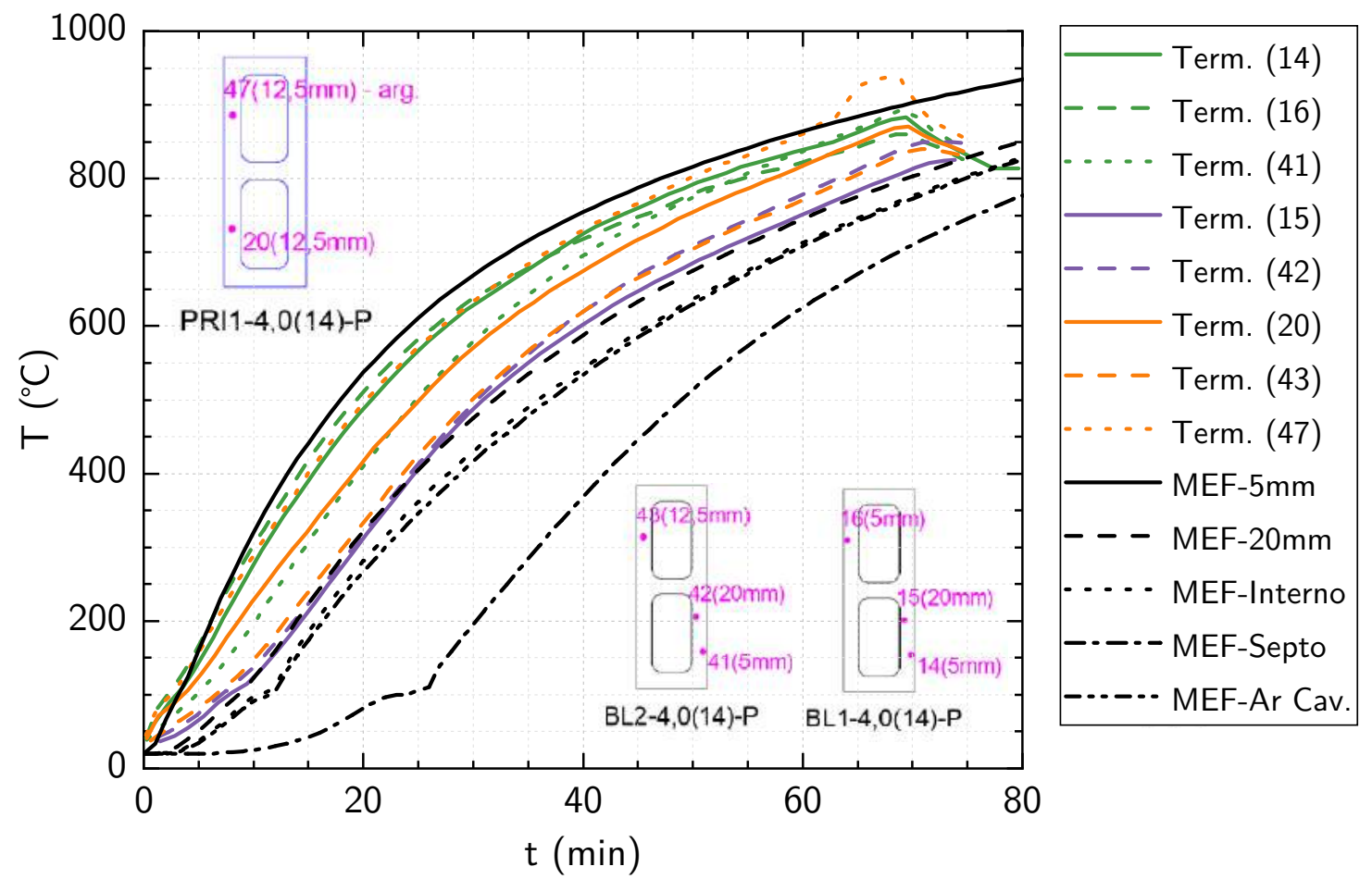

Fonte: O autor. Dados experimentais de Dupim (2019)

Figura 4.10 - Temperatura ao longo do tempo - "Fornada 1" Blocos $f_{b k}=10 \mathrm{MPa}$
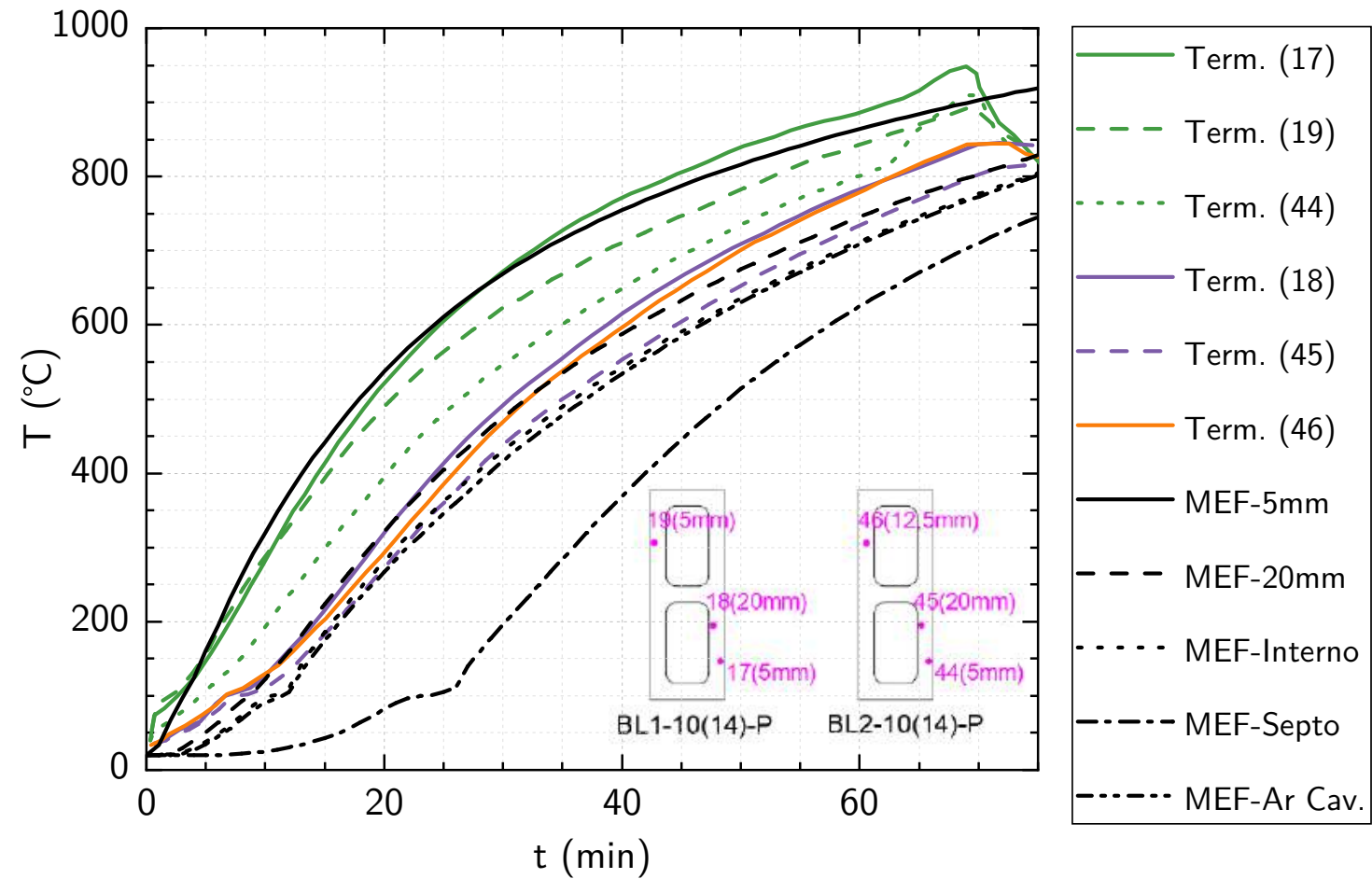

Fonte: O autor. Dados experimentais de Dupim (2019) 
Além das curvas temperatura vs tempo é interessante analisar os gráficos do campo de temperatura e fluxo de calor no bloco. A Figura 4.11 mostra o campo de temperatura em $t=40$ min. Já no campo de temperatura é possível perceber a influência da radiação no aquecimento da face do septo no interior da cavidade. Caso a transferência de calor se desse apenas por condução a temperatura no septo seria aproximadamente constante para determinada profundidade a partir da face exposta ao fogo. Tal fato é confirmado através do campo de fluxo de calor, Figura 4.12, e fluxo de calor por radiação na superfície da cavidade, Figura 4.13. Percebe-se que há um fluxo de calor significativo na superfície do septo derivada da transferência por radiação das outras paredes que estão sendo diretamente aquecidas.

Figura 4.11 - Temperatura $\left({ }^{\circ} \mathrm{C}\right)$ em $t=40 \mathrm{~min}$
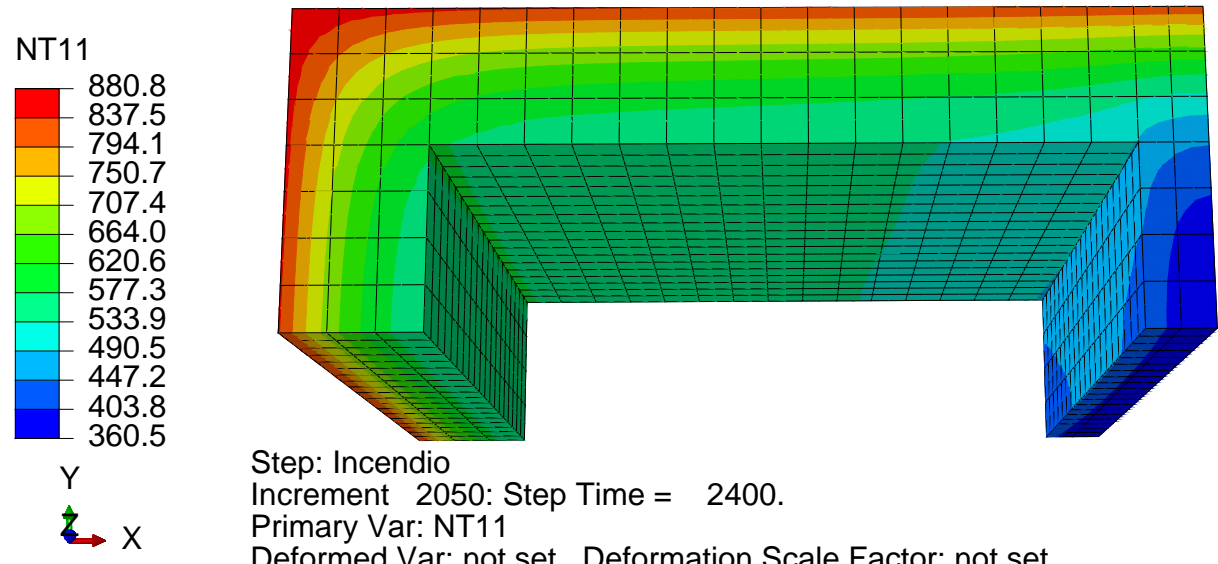

Step: Incendio Increment 2050: Step Time $=2400$.

Primary Var: NT11

Deformed Var: not set Deformation Scale Factor: not set

Fonte: $\mathrm{O}$ autor

Figura $4.12-$ Fluxo de calor no bloco em $t=40 \mathrm{~min}$
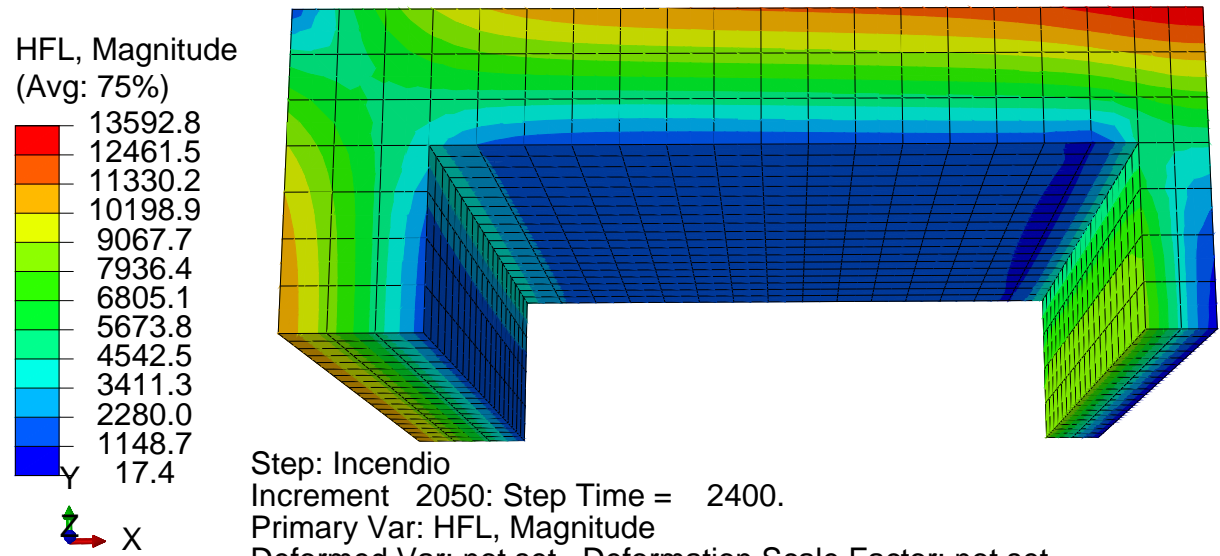

Step: Incendio

Increment 2050: Step Time $=2400$.

Primary Var: HFL, Magnitude

Deformed Var: not set Deformation Scale Factor: not set

Fonte: $\mathrm{O}$ autor

Também é de interesse a análise do campo de temperatura e velocidade do ar preso nas cavidades. A Figura 4.14 mostra o campo de temperaturas do ar em $t=40 \mathrm{~min}$. É possível perceber que há uma camada próxima as paredes que apresenta temperatura 
Figura 4.13 - Fluxo de calor por radiação na cavidade em $t=40 \mathrm{~min}$
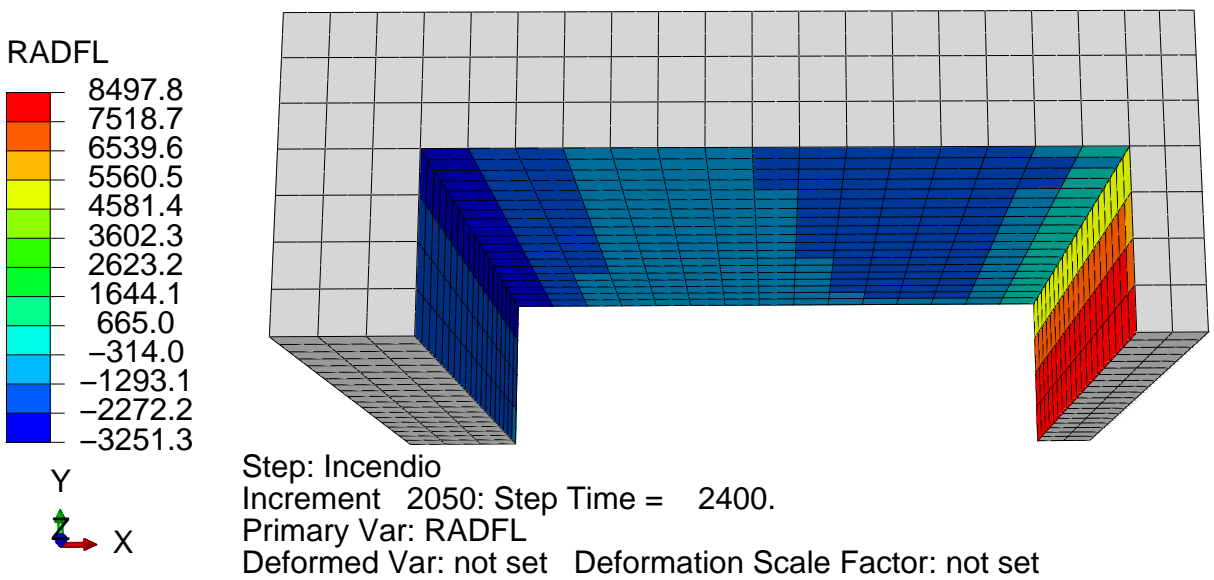

Fonte: $\mathrm{O}$ autor

próxima a esta. Logo, o ar próximo ao septo apresenta temperatura maior, já aquele próximo ao encontro entre paredes longitudinal e transversal apresenta as maiores temperaturas. Além disso, há uma estratificação vertical onde o ar com maiores temperaturas se localiza na parte superior. Por outro lado, a Figura 4.15 e Figura 4.16 mostram o campo de velocidades no ar da cavidade. Nessas figuras é possível perceber o fluxo convectivo que ocorre onde o ar quente próximo as paredes longitudinal e transversal apresenta fluxo ascendente e o ar mais frio próximo ao septo apresenta fluxo descendente criando assim um vórtice convectivo. Esse movimento de transferência de massa também contribui para a transferência de calor das paredes mais quentes para as mais frias.

Figura 4.14 - Temperatura $\left({ }^{\circ} \mathrm{C}\right)$ do ar na cavidade em $t=40 \mathrm{~min}$
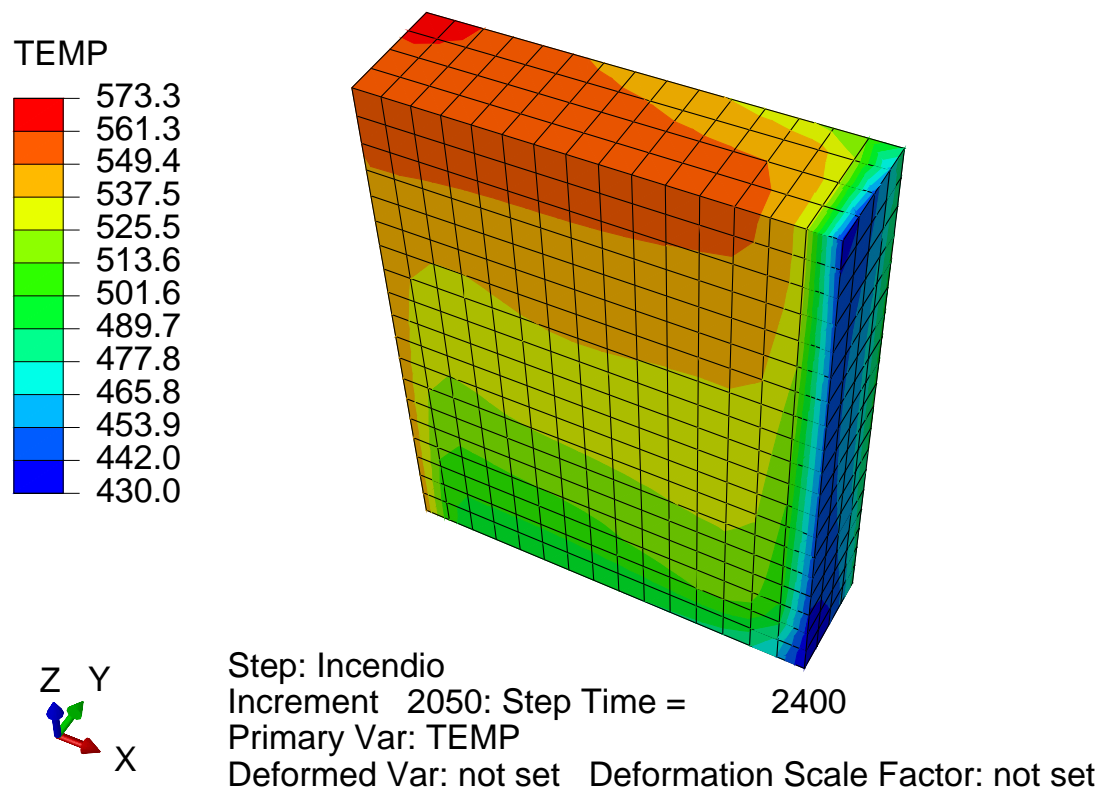

Fonte: O autor 
Figura 4.15 - Velocidade $(\mathrm{mm} / \mathrm{s})$ do ar na cavidade em $t=40 \mathrm{~min}$
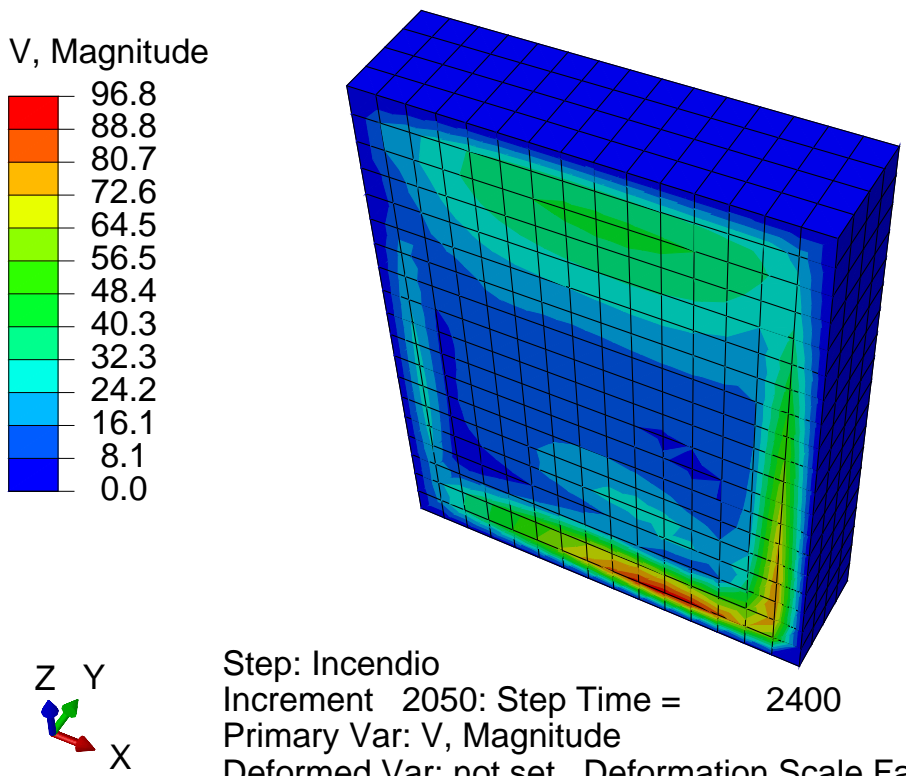

Primary Var: V, Magnitude

Deformed Var: not set Deformation Scale Factor: not set

Fonte: $\mathrm{O}$ autor

Figura 4.16 - Vetor velocidade $(\mathrm{mm} / \mathrm{s})$ do ar na cavidade em $t=40 \mathrm{~min}$
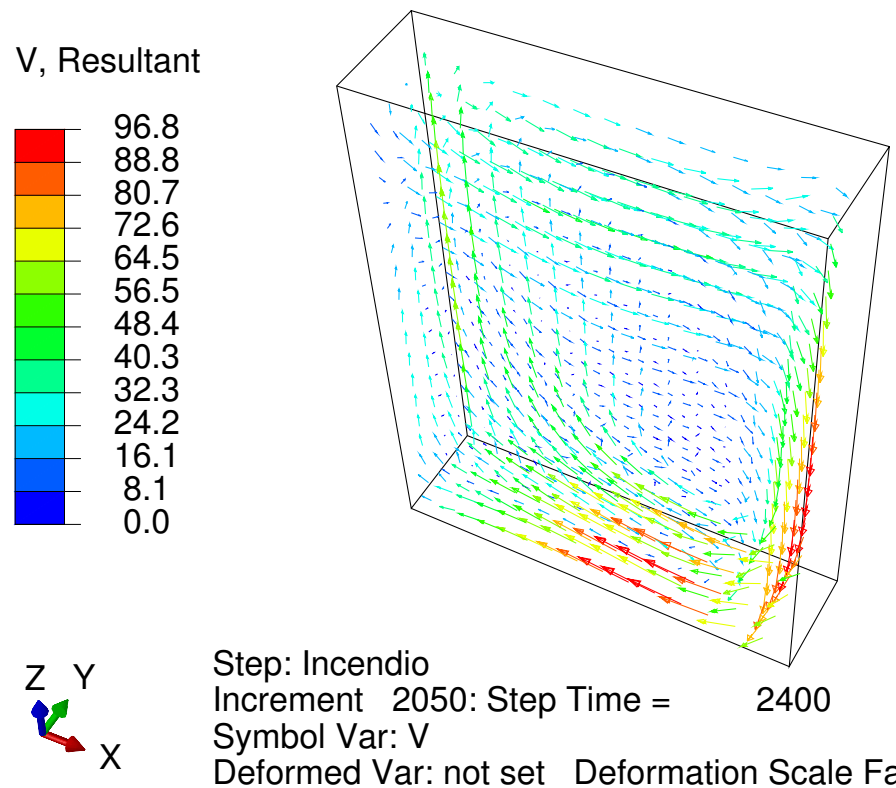

Step: Incendio Increment 2050: Step Time = Symbol Var: V Deformed Var: not set Deformation Scale Factor: not set

Fonte: $\mathrm{O}$ autor

Por fim, simulações adicionais foram realizadas pelo autor e apresentadas em Assis e Munaiar Neto (2020). O objetivo dessas simulações foi avaliar a importância da convecção e radiação dentro das cavidades na elevação de temperatura dos blocos durante o incêndio. Para isso, foram realizadas simulações onde se desconsidera o fluido dentro da cavidade, considerando apenas a parcela de radiação. Além disso, foram realizadas simulações para diferentes emissividades da superfície da cavidade. A Figura 4.17 mostra os resultados das simulações. As linhas preta e vermelha estão quase sobrepostas mostrando que a influência 
da convecção na cavidade é limitada quando a emissividade da superfície é 0,95. Simulações adicionais considerando apenas a radiação e utilizando $\varepsilon=0,7$ e $\varepsilon=0,5$ mostram que as mudanças nas temperaturas são moderadas e as maiores mudanças são verificadas no septo central. Já quando se desconsidera a transferência por radiação, considerando assim apenas a condução no sólido, as diferenças no septo central são significativas. Esses resultados mostram que a radiação na cavidade tem um papel importante no processo de transferência de calor no interior do bloco. Entretanto, para valores de emissividade superiores a 0,5 as diferenças nos resultados são pequenas. Além disso, para um valor alto de emissividade a contribuição da convecção no interior da cavidade é pequena.

Figura 4.17 - Influência da emissividade na superfície da cavidade na evolução de temperatura em diferentes pontos de bloco sujeito a incêndio ISO 834-1:1999 em todas as faces

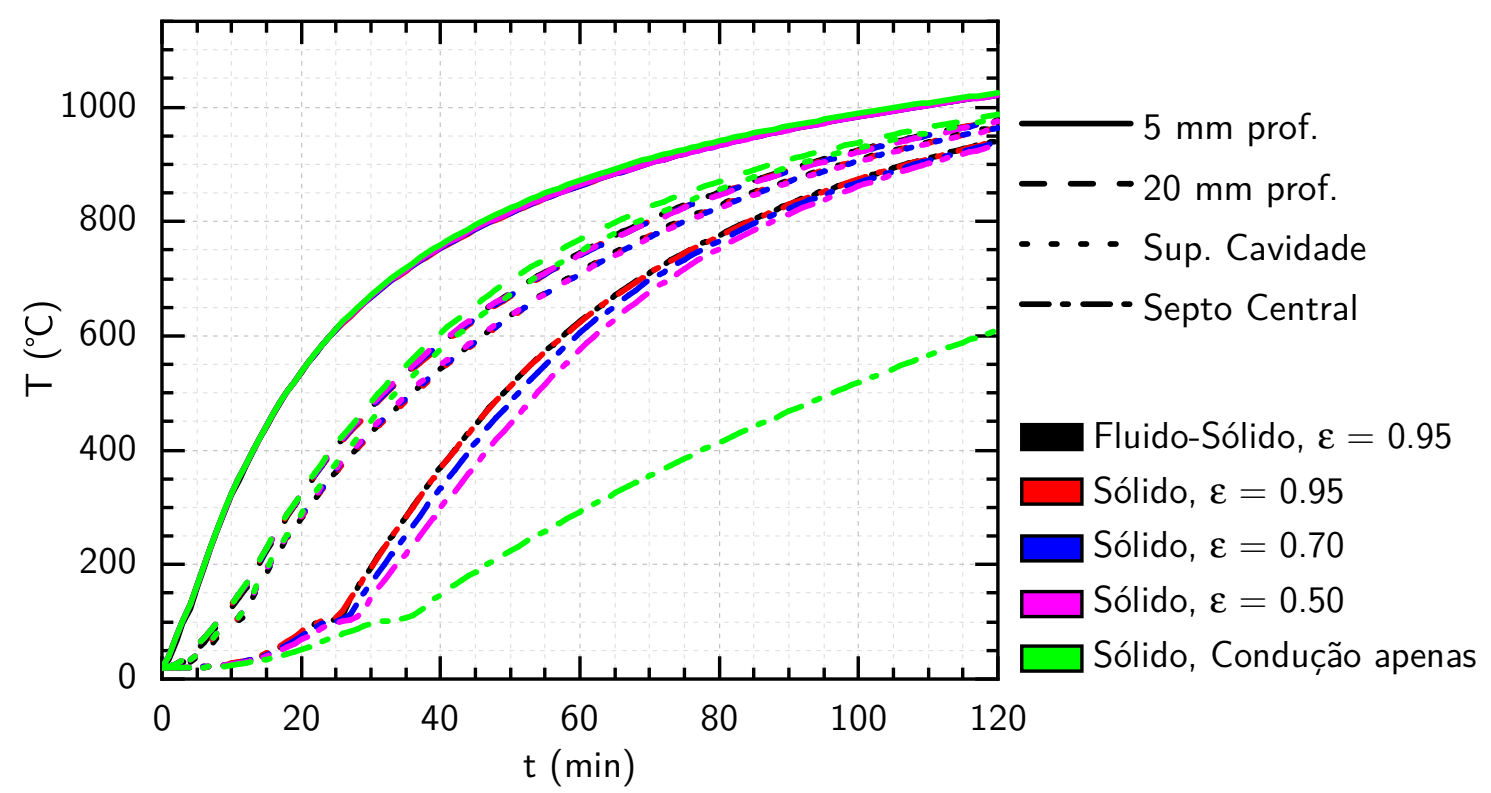

Fonte: (ASSIS; MUNAIAR NETO, 2020)

\subsubsection{Bloco sob fogo em uma face}

Nessa seção é a realizada a análise do bloco submetido a fogo em uma das faces simulando assim um bloco em alvenaria com objetivo de compartimentação do ambiente. Nesse caso, não há resultados experimentais de Dupim (2019) pois o autor realizou apenas ensaios onde há confinamento de gases através de um trio de pequenas paredes. Nesse caso, os gases elevam de temperatura como resultado do fluxo de calor na alvenaria. Nos modelos aqui considerados não foi possível modelar esse caso. Portanto, utilizou-se dados experimentais onde a alvenaria está sujeita ao incêndio-padrão em uma das faces e a temperatura ambiente na outra. Rodovalho (2018) apresenta os dados experimentais de Oliveira e Berto (2015) os quais são utilizados aqui. 
Inicialmente, foi realizado um estudo considerando a geometria da Figura 3.39 e simetria simples. O objetivo nesse caso é avaliar como os campos de temperatura e comportamento do ar na cavidade diferem daqueles do bloco sujeito ao fogo em todas as faces laterais.

A Figura 4.18 mostra o campo de temperatura no bloco em $t=40$ min. É possível perceber a influência da transferência de calor por radiação na cavidade. A superfície interna da parede longitudinal oposta ao fogo recebe a maior parte da radiação e sua temperatura é maior que a temperatura do septo para uma mesma distância da face exposta ao fogo.

Figura 4.18 - Temperatura $\left({ }^{\circ} \mathrm{C}\right)$ no bloco $-t=40 \mathrm{~min}$

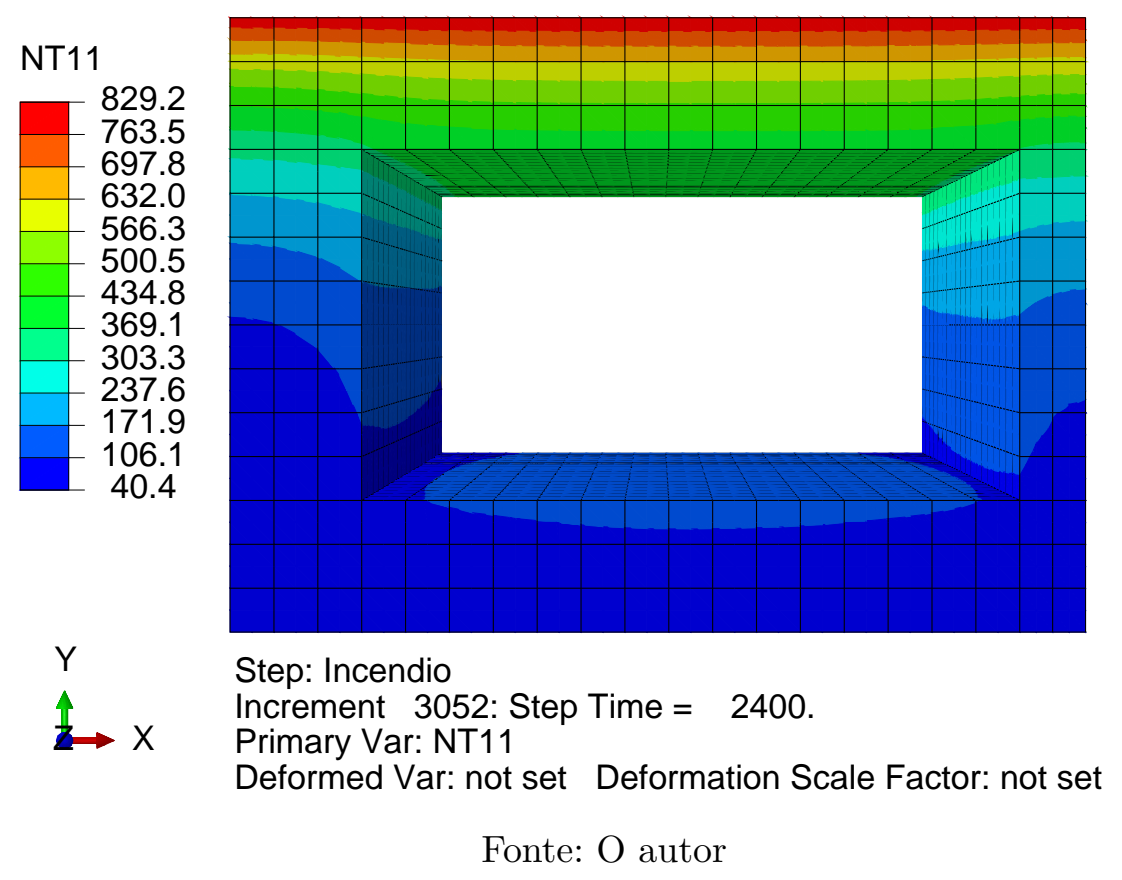

A Figura 4.19 mostra que o campo de temperaturas no ar é estratificado sendo que o ar mais quente concentra-se na parte superior. Além disso, uma pequena camada próxima as paredes tem a mesma temperatura delas, ou seja, extremamente aquecido nas parede longitudinal exposta ao fogo. Já a Figura 4.20 e Figura 4.21 mostra o campo de velocidades. Percebe-se que há a formação de um fluxo convectivo em que o ar quente próximo a parede longitudinal exposta ao fogo é transferido para a superfície da parede longitudinal oposta. Esse fluxo convectivo contribui para a transferência de calor entre as superfícies internas da cavidade.

De forma similar ao que foi realizado para o bloco com incêndio em todos os lados, foi realizada uma simulação no qual o ar nas cavidades é desconsiderado mantendo apenas a transferência de calor por radiação. A Figura 4.22 mostra o campo de temperaturas no bloco para $t=40$ min o qual é idêntico aquele da Figura 4.18 no qual foi realizada a análise acoplada com o ar nas cavidades. Assim, considerando ambos os resultados 
Figura 4.19 - Temperatura $\left({ }^{\circ} \mathrm{C}\right)$ do ar na cavidade $-t=40 \mathrm{~min}$
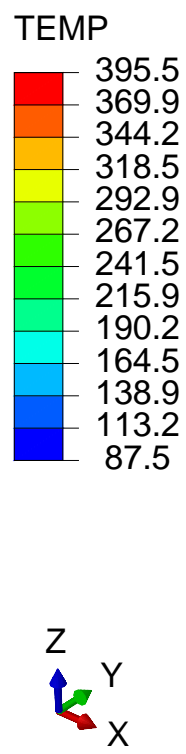

Step: Incendio

Increment 3052: Step Time $=2400$

Primary Var: TEMP

Deformed Var: not set Deformation Scale Factor: not set

Fonte: $\mathrm{O}$ autor

Figura 4.20 - Velocidade $(\mathrm{mm} / \mathrm{s})$ do ar na cavidade $-t=40 \mathrm{~min}$
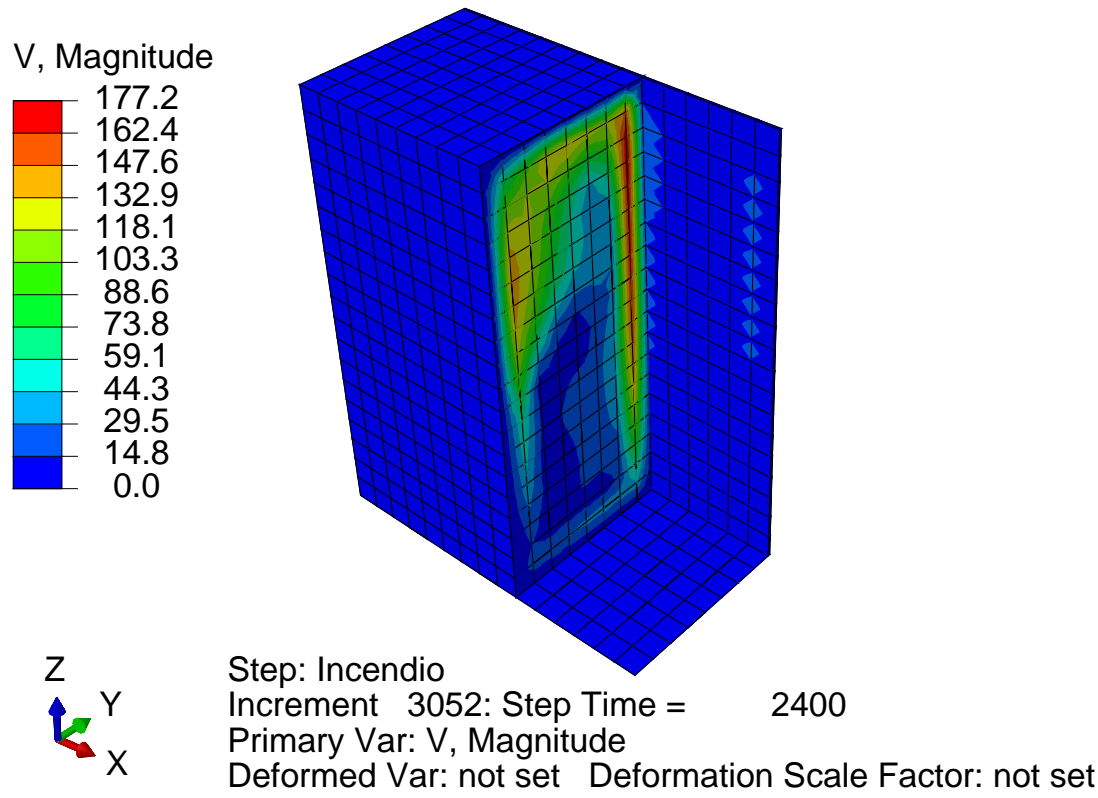

Fonte: $\mathrm{O}$ autor

apresentados chega-se a conclusão que a influência do ar é desprezável quando se considera uma alta emissividade na superfície da cavidade $(\varepsilon=0,95)$. No entanto, estudos futuros podem analisar essa parcela de contribuição do ar para diferentes valores de emissividade da superfície da cavidade.

Por fim, o modelo com fogo em apenas uma superfície é validado com os resultados experimentais de Oliveira e Berto (2015). Nesse caso, foi utilizado revestimento de $1,5 \mathrm{~cm}$ na face exposta ao fogo. As propriedades térmicas do revestimento foram adotadas iguais 
Figura 4.21 - Vetor velocidade $(\mathrm{mm} / \mathrm{s})$ do ar na cavidade $-t=40 \mathrm{~min}$
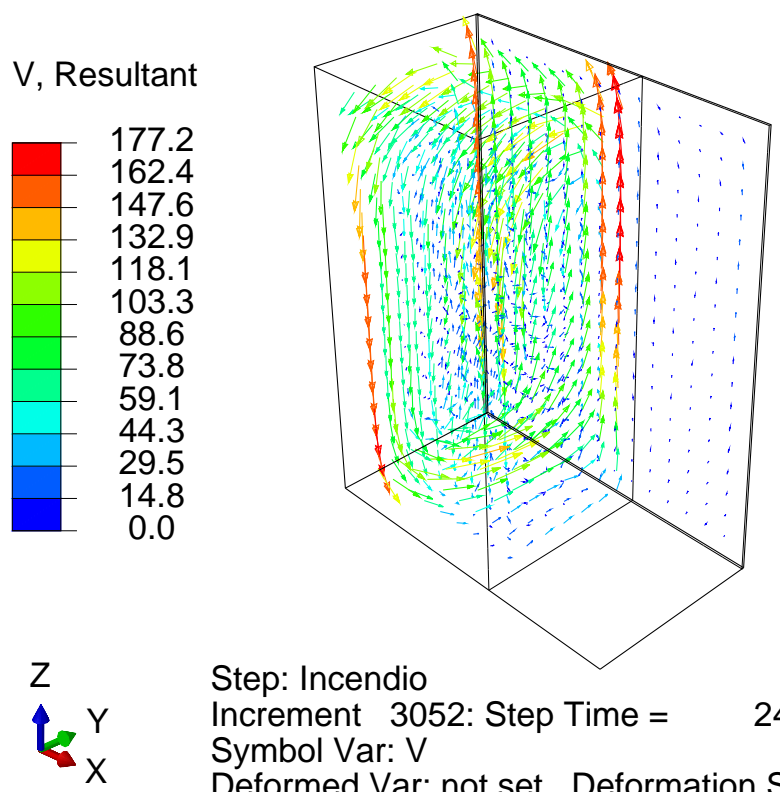

$$
\begin{aligned}
& \text { Step: Incendio } \\
& \text { Increment 3052: Step Time }=2400
\end{aligned}
$$

Symbol Var: V

Deformed Var: not set Deformation Scale Factor: not set

Fonte: $\mathrm{O}$ autor

Figura 4.22 - Temperatura $\left({ }^{\circ} \mathrm{C}\right)$ no bloco, apenas radiação na cavidade- $t=40 \mathrm{~min}$
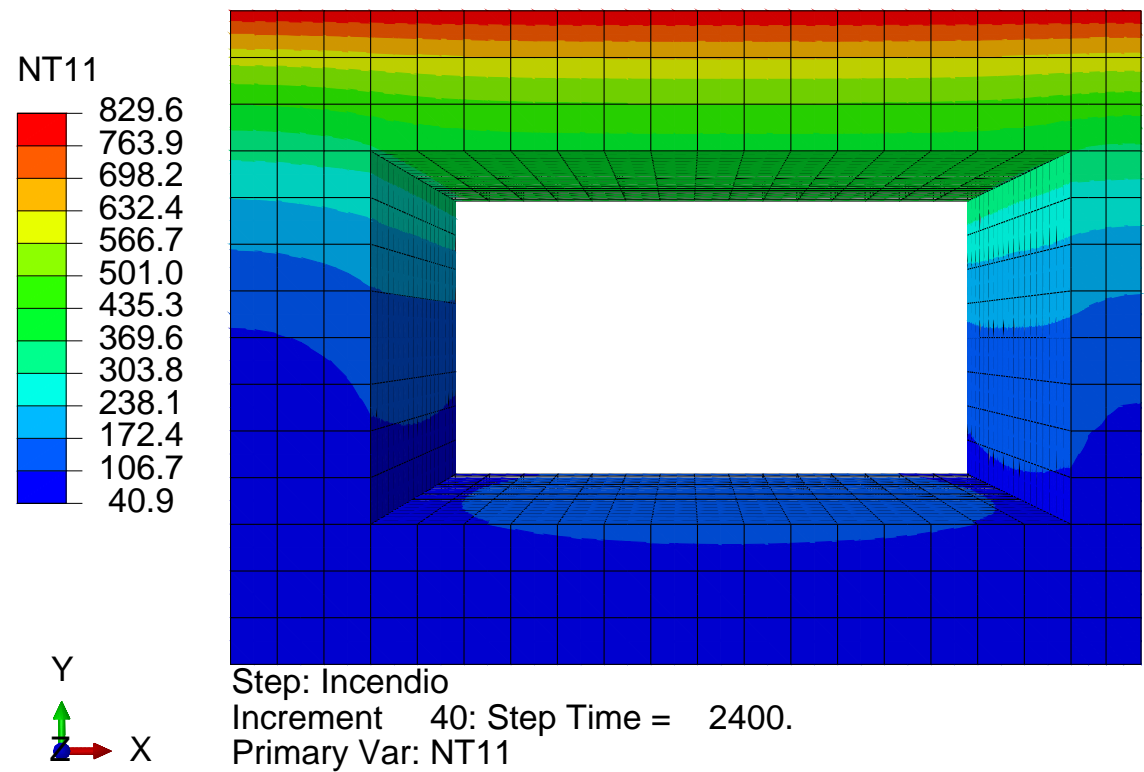

Step: Incendio

Increment 40: Step Time $=2400$.

Primary Var: NT11

Deformed Var: not set Deformation Scale Factor: not set

Fonte: O autor

ao do concreto do bloco já detalhadas anteriormente.

A Figura 4.23 mostra o campo de temperaturas para $t=40$ min e a Figura 4.24 mostra a curva de elevação de temperatura no tempo para diferentes pontos no bloco.

Através da análise do gráfico percebe-se que houve ótima concordância da simulação com os resultados experimentais para a temperatura na face oposta nos tempos finais de ensaio. No entanto, há uma grande diferença nos períodos iniciais do ensaio. Aqui o 
Figura 4.23 - Temperatura $\left({ }^{\circ} \mathrm{C}\right)$ no bloco, apenas radiação na cavidade - $t=40 \mathrm{~min}$
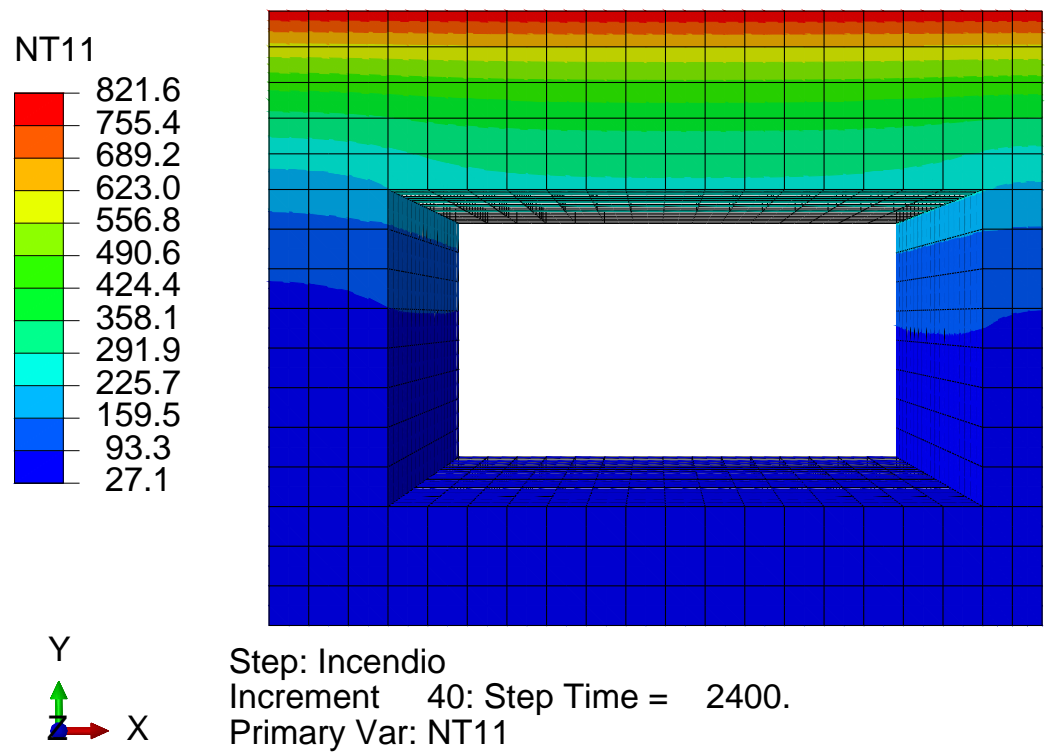

Step: Incendio

Increment 40: Step Time $=2400$.

Primary Var: NT11

Deformed Var: not set Deformation Scale Factor: not set

Nota: Considerando revestimento de 1,5 cm do mesmo material do bloco. Fonte: $\mathrm{O}$ autor.

Figura 4.24 - Temperatura ao longo do tempo para fogo em uma face

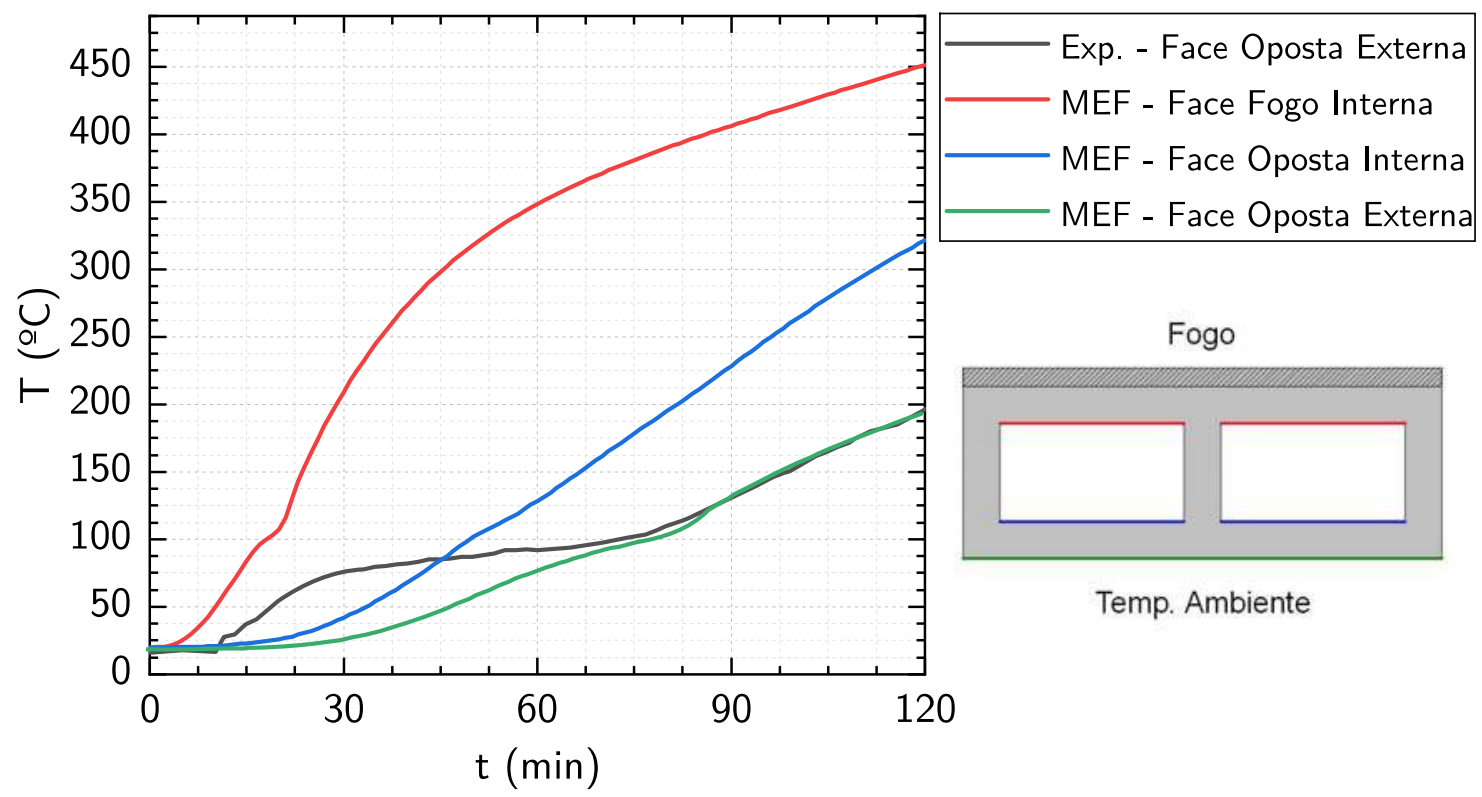

Fonte: O autor. Dados experimentais de Oliveira e Berto (2015 apud RODOVALHO, 2018)

comportamento obtido se assemelha bastante daquele mostrado Figura 4.7 e Figura 4.8 para a temperatura no septo. Em ambos os casos, a divergência ocorre no ponto com menor temperatura do bloco, ou seja, o septo para fogo em todas as faces, e a parede longitudinal oposta para fogo em uma face. Rodovalho (2018) em suas simulações, na qual as propriedades térmicas foram variadas, também não pôde reproduzir a elevação de temperatura precoce e longo patamar presente nos resultados experimentais.

Chama a atenção a semelhança desse tipo de resposta quando se avalia resultados 
experimentais independentes utilizando a mesma estratégia de simulação. Pesquisas futuras podem investigar esse comportamento, especialmente a influência da umidade, visto que os patamares presentes nos resultados experimentais são resultados do calor latente de vaporização da água.

\subsection{Chumbador em painel de alvenaria de concreto}

Nessa seção é realizada uma análise térmica do sistema de fixação em alvenaria de concreto. Utiliza-se o mesmo modelo de painel de alvenaria utilizado nas simulações estruturais da Seção 3.3. A malha de elementos finitos utilizada é ilustrada na Figura 4.25. Foram utilizados elementos hexaédricos lineares de 8 nós (DC3D8) e elementos de cunha lineares de 6 nós (DC3D6).

Figura 4.25 - Detalhe da malha de elementos finitos do modelo térmico

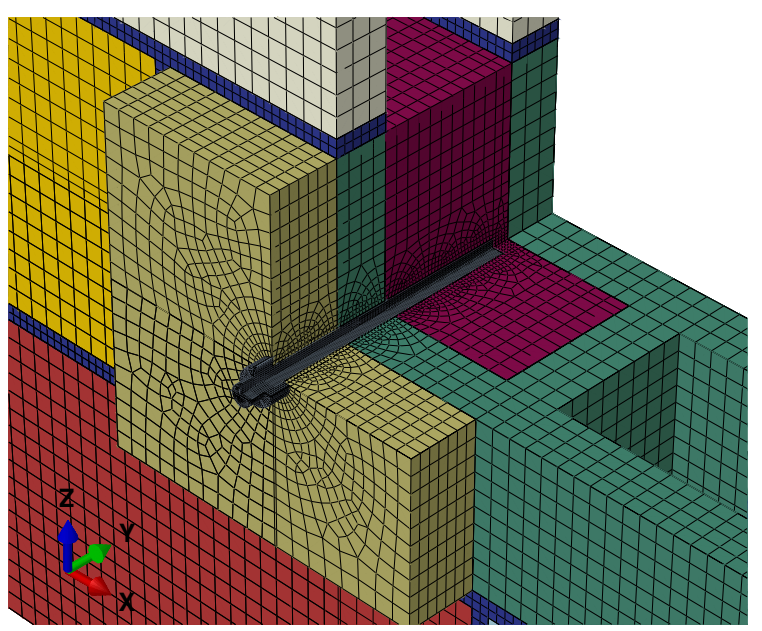

Fonte: O autor.

As propriedades térmicas do bloco, graute e argamassa foram consideradas iguais. Foram utilizadas as propriedades validadas no estudo preliminar da estratégia de simulação. Essas propriedades estão descritas na Figura 4.4. Por outro lado, a massa específica do aço pode ser considerada independente da temperatura, a qual é definida como $\rho_{a}=$ $7850 \mathrm{~kg} / \mathrm{m}^{3}$. Já a condutividade térmica e o calor específico dependem da temperatura como ilustrado na Figura 4.26.

A simulação realizada no painel de alvenaria seguiu a mesma metodologia descrita na Seção 4.1.2. Como mostrado anteriormente, a consideração do ar no interior das cavidades do bloco tem pouca influência nos resultados. Dessa forma, optou-se por desconsiderar o ar nas cavidades, considerando apenas transferência de calor por radiação com emissividade $\varepsilon=0,95$. Além disso, considerou-se a curva de elevação de temperatura da ISO 834-1:1999 apenas na face oposta ao chumbador. Ou seja, o modelo representa a condição de incêndio fora do ambiente da escada. 
Figura 4.26 - Propriedades térmicas do aço

(a) Condutividade térmica

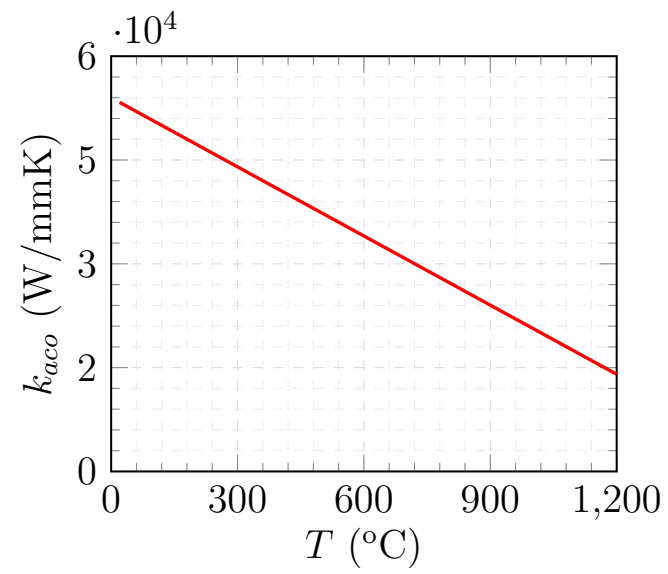

(b) Calor específico

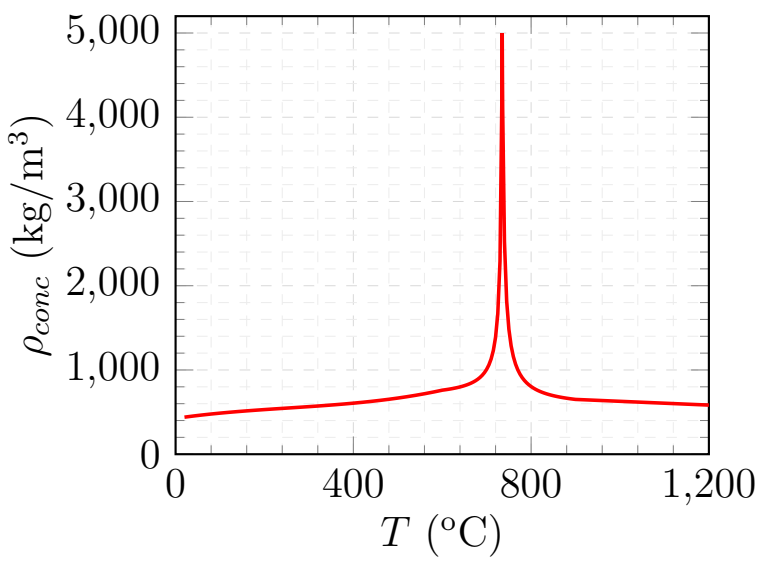

Fonte: NBR 14323:2013 (ABNT, 2013)

\subsubsection{Resultados e Análise}

Inicialmente, cabe destacar que um resumo do custo computacional demandado em todas as simulações está presente no Apêndice C. A Figura 4.27 mostra o campo de temperatura na alvenaria e chumbador para vários períodos de incêndio. É interessante notar o efeito do chumbador e das cavidades no campo de temperatura. O chumbador por ser feito de aço, o qual tem uma condutividade térmica muito maior que o concreto, influencia o campo de temperatura. Apesar de ser possível observar essa influência, ela é mais significativa perto da face do incêndio, ou seja, para maiores profundidades de embutimento do chumbador. Por outro lado, a influência da transferência de calor por radiação na cavidade é perceptível em todos os tempos analisados. Tomando pontos nos septos a mesma distância da face sob incêndio, aqueles pontos da superfície das cavidades apresentam temperaturas maiores do que os pontos internos. Além disso, o ponto de maior temperatura na face não-exposta ao fogo é aquele mais distante dos septos, alinhado ao centro da cavidade. 
Figura 4.27 - Campo de temperatura $\left({ }^{\circ} \mathrm{C}\right)$ para diferentes tempos de incêndio

(a) $t=15,1 \mathrm{~min}$

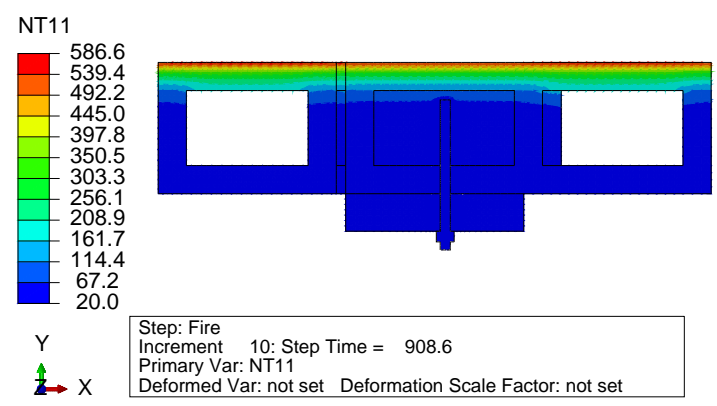

(c) $t=46,9 \mathrm{~min}$

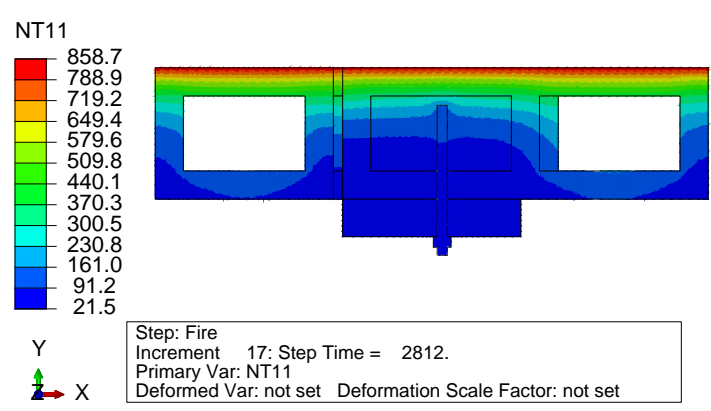

(e) $t=84,4 \mathrm{~min}$

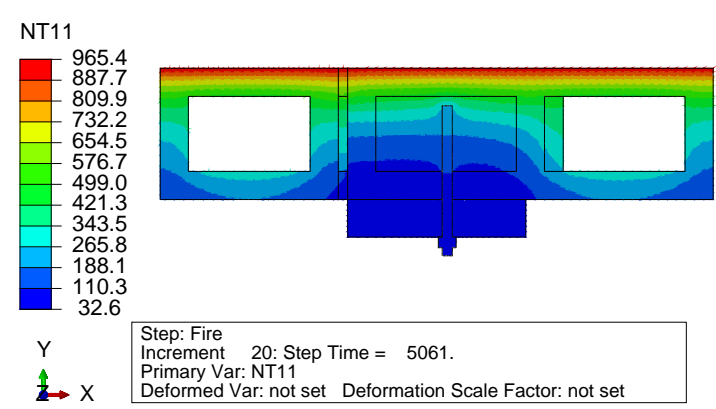

(b) $t=32,6 \mathrm{~min}$

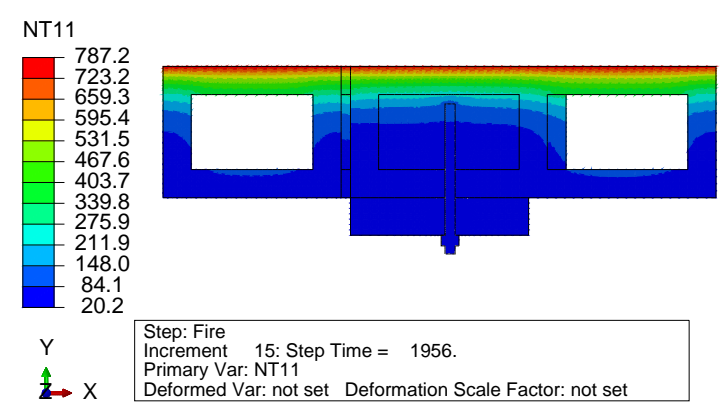

(d) $t=57,6 \min$

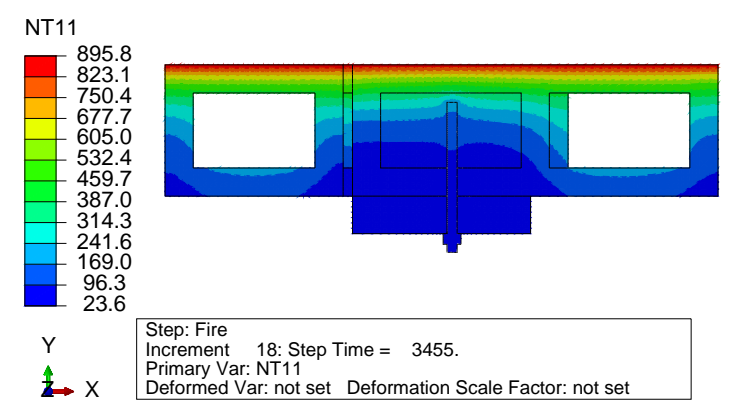

(f) $t=120 \mathrm{~min}$

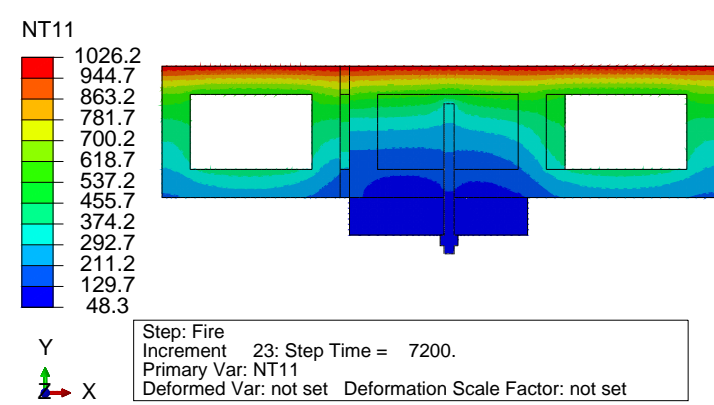

Nota: Seção transversal passando pelo chumbador. Incêndio ISO 834:1999 na face +Y. Fonte: O autor.

A Figura 4.28 mostra como se dá a evolução de temperatura ao longo do tempo em uma seção que passa pela superfície do chumbador. Percebe-se que em 120 min de incêndio a temperatura máxima no chumbador foi inferior a $350{ }^{\circ} \mathrm{C}$. Isso leva a crer que os efeitos da temperatura no aço sejam limitados, uma vez que até $300{ }^{\circ} \mathrm{C}$ considera-se que o aço mantém sua tensão de escoamento e de ruptura iguais a temperatura ambiente. Nessa temperatura o principal efeito é uma certa perda de rigidez devido a redução do módulo de elasticidade. A Seção 5 traz mais detalhes sobre as propriedades do aço em altas temperaturas. Além disso, a condutividade térmica elevada do aço faz com que a temperatura na interface aço-concreto se eleve de maneira mais rápida e uniforme ao longo do comprimento do chumbador. Tal fato é evidenciado pela brusca mudança de inclinação no gráfico. Por fim, a placa de carregamento, que representa a viga denteada, apresenta 
temperatura inferior a $120{ }^{\circ} \mathrm{C}$ aos 120 min de incêndio. Tal temperatura não é suficiente para promover mudanças de resistência significativas nesse elemento.

Figura 4.28 - Temperatura em função da distância da face sob incêndio - Seção Chumbador

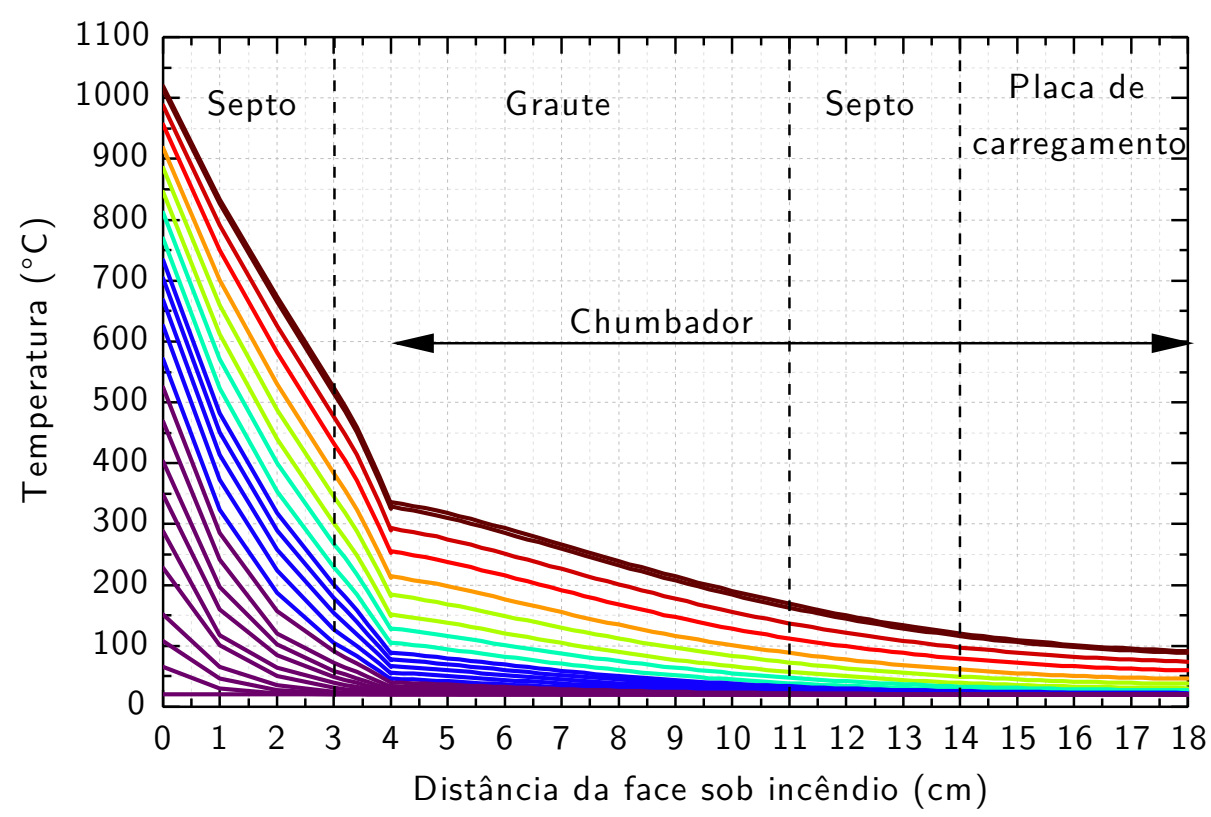
Tempo $(\min )$

Fonte: O autor.

A Figura 4.29 mostra a evolução da temperatura em uma seção transversal que passa pela cavidade do bloco. Como era esperado, a temperatura no bloco na região da cavidade é maior do que na região grauteada. A análise das curvas nos permite identificar alguns resultados importantes. Aos 45 min de incêndio, mais de 1/3 do septo exposto ao fogo apresenta temperatura superior a $600{ }^{\circ} \mathrm{C}$, temperatura que caracteriza um nível alto de deterioração do concreto. A temperatura na face não-exposta ao fogo atinge $140{ }^{\circ} \mathrm{C}$ entre 60 e $75 \mathrm{~min}$, sendo que $140{ }^{\circ} \mathrm{C}$ é a temperatura média permitida pelo critério de isolamento térmico de paredes divisórias. Além disso, é possível perceber que a diferença de temperatura entre as superfícies da cavidade inicialmente aumenta, se estabiliza e por fim começa a diminuir. Aos 120 min de incêndio a diferença de temperatura é de aproximadamente $100{ }^{\circ} \mathrm{C}$. Cabe lembrar, que o fluxo de calor por radiação é proporcional a $\left(T_{1}-T_{2}\right)^{4}$, onde $T_{1}$ e $T_{2}$ são as temperaturas das superfícies envolvidas. Assim, a diferença de temperatura é um indicativo de que há um forte aumento de transferência de calor por radiação e com isso o septo oposto tem um incremento de temperatura. Esse fato, por fim, leva a uma dimunuição da parcela de calor por radiação. 
Figura 4.29 - Temperatura em função da distância da face sob incêndio - Seção na cavidade do bloco

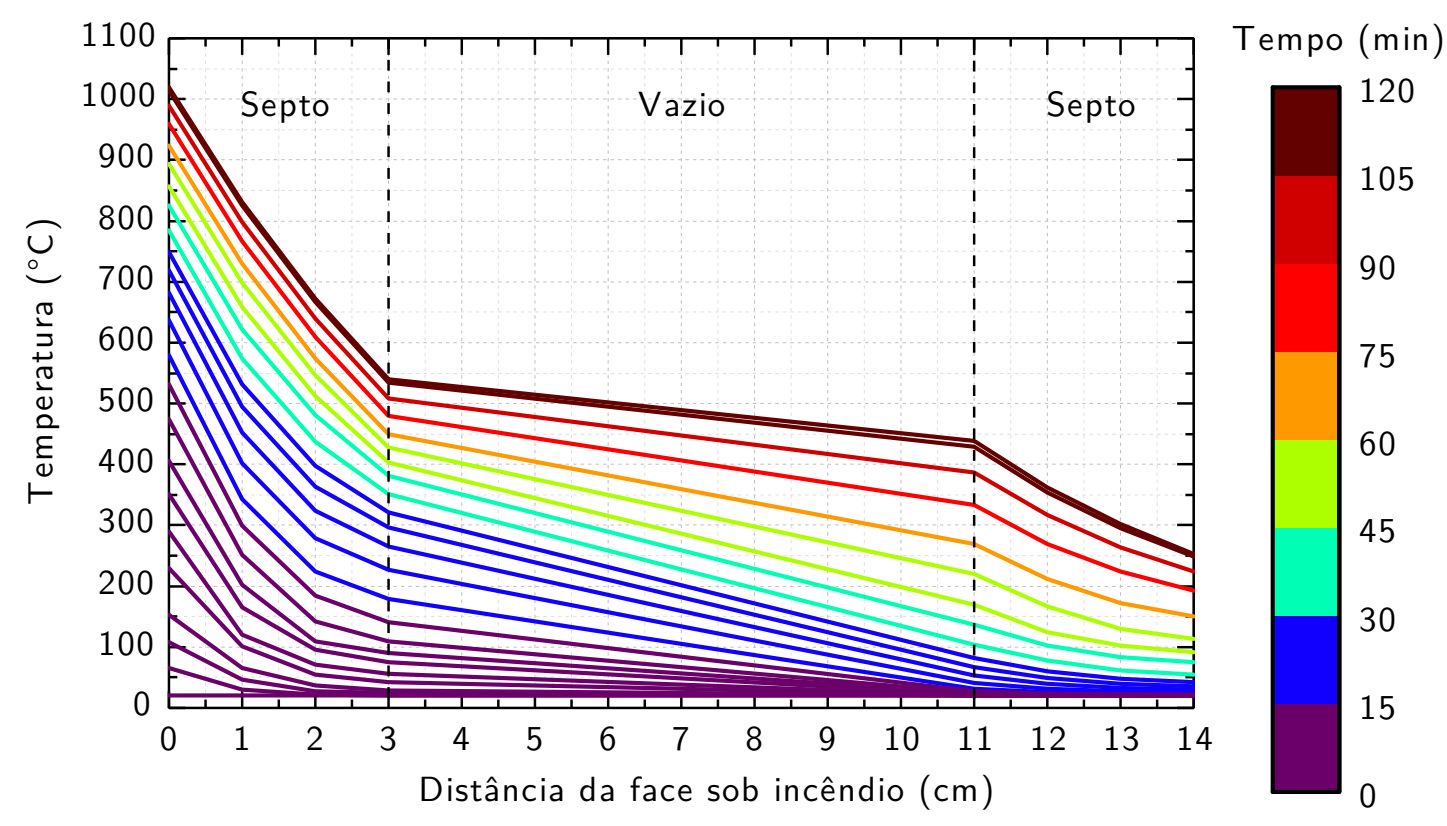

Fonte: $\mathrm{O}$ autor. 



\section{ANÁLISE TERMOESTRUTURAL}

O objetivo desse capítulo é avaliar o comportamento estrutural em situação de incêndio de um chumbador ancorado em alvenaria de concreto. Para isso, continua-se estudando o modelo de um chumbador ancorado em painel de alvenaria de blocos de concreto o qual foi estudado na Seção 3.3 e Seção 4.2. Na Seção 4.2.1 foi realizada a análise de transferência de calor e assim foi possível obter os campos de temperatura na alvenaria e chumbador ao longo do tempo de exposição ao incêndio padrão ISO 834-1:1999 . Esse campo de temperatura será utilizado para simular o comportamento mecânico do sistema durante o incêndio. Com essa abordagem, é possível avaliar se o chumbador terá perda de rigidez e resistência que comprometa a estabilidade da viga denteada da escada apresentada na Seção 3.2.

\subsection{Características geométricas e de análise}

O modelo em elementos finitos utilizado é exatamente o mesmo apresentado na Seção 3.3 o qual é reproduzido na Figura 5.1.

Figura 5.1 - Modelo de chumbador em painel de alvenaria de concreto

(a) Geometria do modelo - Caso 1

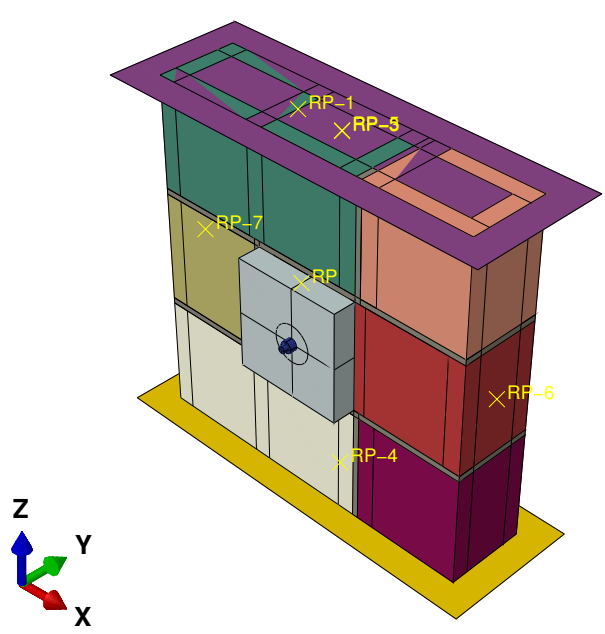

(b) Detalhe da malha

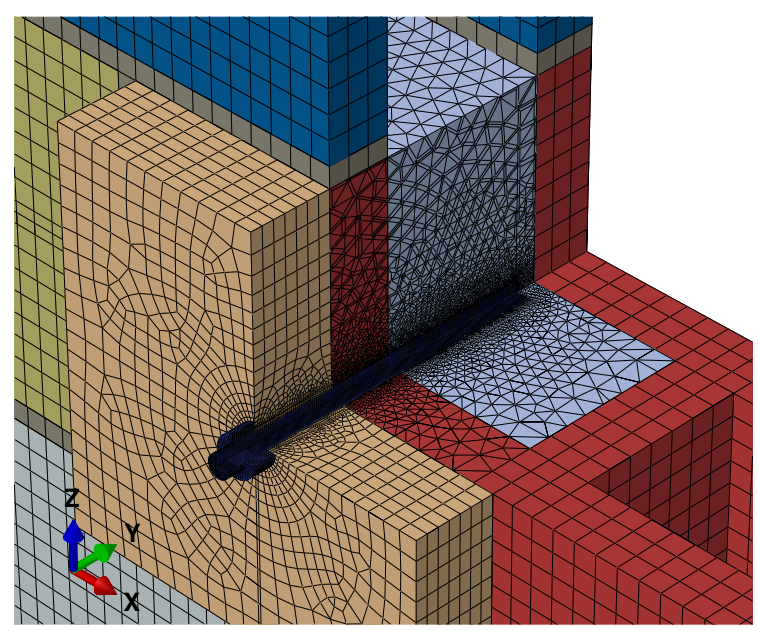

Fonte: O autor.

No entanto, as análises dessa seção se diferenciam pela consideração da temperatura e pelas diferentes condições de contorno. Enquanto na Seção 3.3 o objetivo foi obter a carga última do chumbador e do painel de alvenaria, nessa seção o objetivo é avaliar a influência do incêndio em um nível de carregamento pré-existente. Assim, todas as simulações consistem em duas etapas: a primeira consiste em carregar a alvenaria e o chumbador até um nível pré-determinado, a segunda consiste em manter o carregamento 
prévio e considerar o aumento de temperatura no tempo.

A NBR 5628:2001 (ABNT, 2001) especifica que o nível de pré-carregamento deve ter a mesma ordem de grandeza daqueles esperados em situação de serviço. Em geral, é possível considerar esse valor como algo entre $20 \%$ e $40 \%$ da carga de ruptura (CARVALHO, 2019; RODOVALHO, 2018). No presente trabalho considera-se $40 \%$ da carga de ruptura estimada através das simulações da Seção 3.3. Através da Figura 3.45 é possível estimar que a tensão de ruptura na área bruta é $\sigma_{\text {rup }}^{\text {painel }}=6,25 \mathrm{MPa}$ para o Caso 1 , onde as Faces $+\mathrm{X}$ e -X estão livres. Assim, adota-se $\sigma_{s}^{\text {painel }}=2,5 \mathrm{MPa}$ como tensão de serviço no momento do incêndio.

Por outro lado, na análise realizada consideramos que o chumbador está sendo usado para ancorar uma escada pré-moldada. É de interesse avaliar o comportamento do chumbador visto que a escada é fundamental para desocupação do edifício em situação de incêndio. Assim, é razoável considerar que no momento de incêndio a escada será solicitada com sua carga característica de dimensionamento e não apenas com a carga de serviço. Por isso, o carregamento do chumbador foi atribuído como a força de reação solicitante característica da escada, a qual é estudada na Seção 3.2 e ilustrada na Figura 3.25. Isso significa que $F_{s}^{c h u m b}=2,271 \mathrm{kN}$ o qual é $10,76 \%$ da carga de ruptura estimada na Seção 3.3.3.

Após a etapa de carregamento da alvenaria e do chumbador até o nível desejado, a carga é mantida e se inicia a etapa do incêndio. O campo de temperaturas no modelo é importado dos resultados da simulação térmica da Seção 4.2 e interpolado para os pontos de integração da malha do modelo mecânico. A temperatura inicial do modelo é assumida como $20^{\circ} \mathrm{C}$. A Tabela 5.1 mostra as principais características adotadas nas simulações realizadas.

Além das 3 diferentes condições de contorno das Faces $+\mathrm{X}$ e -X avaliadas quando do estudo da resistência da alvenaria (Tabela 3.7) optou-se também em realizar um estudo das condições na Face + Z. As 4 diferentes condições de contorno estão descritas na Tabela 5.2. Essas condições tem o objetivo de analisar diferentes combinações entre o deslocamento $u_{z}$ da chapa e o seu giro $\theta_{x}$. Essas condições são importantes na medida em que o painel sofre expansão durante a ação do incêndio e solicitações adicionais surgem caso essa expansão esteja restrita. Cabe ressaltar que as condições adotadas se tratam de casos limites e que as reais condições de uma parede de alvenaria num edifício são intermediárias às adotadas. Além disso, o estudo de várias configurações é interessante para que se possa avaliar se há situações que são benéficas ou prejudicais para o comportamento do chumbador. 
Tabela 5.1 - Características da análise termoestrutural

\begin{tabular}{ccc}
\hline & Pré-carregamento & Incêndio \\
\hline & & Incêndio na Face $+\mathrm{Y}$ \\
Carregamento & $F_{z}^{\text {Chumb }}\left(t^{*}=3600\right)=-2,271 \mathrm{kN}$ & $\sigma_{z}^{\text {Face }+\mathrm{Z}}=-2,5 \mathrm{MPa}=$ cte \\
& $\sigma_{z}^{\text {Face }+\mathrm{Z}}\left(t^{*}=3600\right)=-2,5 \mathrm{MPa}$ & $F_{z}^{\text {Chumb }}=-2,271 \mathrm{kN}=$ cte \\
& & $u_{z}^{\text {Face }+\mathrm{Z}}$ e $\theta_{x}^{\text {Face }+\mathrm{Z}}:$ Tabela 5.2 \\
Período (s) & $t^{*}=0$ a $3600 \mathrm{~s}$ & $t^{*}=3600$ a $7200 \mathrm{~s}$ \\
& & $t=t_{\text {inc }}=0$ a $3600 \mathrm{~s}$
\end{tabular}

Tipo de análise

Dinâmica explícita quasi-estática
$\Delta t_{\text {est }}(\mathrm{s})$
0,55
0,12

Escala

de massa

Variável durante análise para satisfazer $\Delta t_{\text {est }}$

Nota: O tempo $t^{*}$ não tem significado físico nessa análise, enquanto $t$ é o tempo decorrido do início do incêndio. $\Delta t_{\text {est }}$ é o incremento de tempo estável da análise explícita no tempo. Os incrementos de força necessários para $\sigma_{z}^{\text {Face }+Z}$ e $F_{z}^{\text {Chumb }}$ são aplicados através de uma curva suave em formato de $\mathrm{S}$ para minimizar efeitos inerciais.

Tabela 5.2 - Diferentes condições de contorno na chapa da Face $+\mathrm{Z}$

\begin{tabular}{ccccc}
\hline Faces $+\mathrm{X}$ e $-\mathrm{X}$ & \multicolumn{4}{c}{ Face $+\mathrm{Z}$} \\
\hline Casos 1, 2 e 3 de acordo & $u_{z} \leq u_{z}^{t=0}$ & $u_{z} \leq u_{z}^{t=0}$ & $u_{z}=$ livre & $u_{z}=$ livre \\
com a Tabela 3.7 & $\theta_{x}=0$ & $\theta_{x}=$ livre & $\theta_{x}=0$ & $\theta_{x}=$ livre \\
\hline
\end{tabular}

Nota: Considerando as combinações de Face X e Face Z foram analisadas 12 diferentes condições de contorno no painel de alvenaria

\subsection{Modelos Constitutivos}

Para a análise termoestrutural é preciso adotar métodos para estimar as propriedades dos materiais em função da temperatura. Os modelos constitutivos adotados no Abaqus podem lidar com propriedades dependentes da temperatura, logo, o que se buscou foram métodos para o seu cálculo.

As propriedades básicas do aço estão descritas na Seção 3.3.2. Já as curvas tensãodeformação para altas temperaturas foram calculada de acordo com o método da EN 1993-1-2:2005 (CEN, 2005) e são ilustradas na Figura 5.2.

A Equação 5.1 mostra as expressões do coeficiente de expansão térmica do aço $\left(\alpha_{\text {ą̧o }}\right)$, as quais foram calculadas com base na EN 1993-1-2:2005 (CEN, 2005) considerando $T_{0}=20^{\circ} \mathrm{C}$. 
Figura 5.2 - Gráfico tensão-deformação adotado para o aço do chumbador em função da temperatura

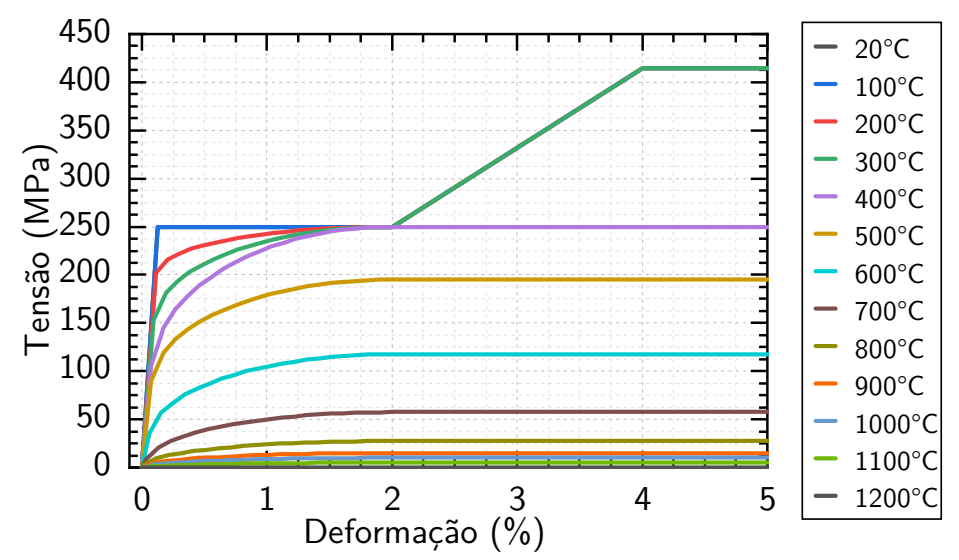

Fonte: $\mathrm{O}$ autor

$$
\begin{aligned}
& \alpha_{\text {aço }}(T)=\left(\left(1,2 \cdot 10^{-5}\right) \cdot T+\left(0,4 \cdot 10^{-8}\right) \cdot T^{2}-2,416 \cdot 10^{-4}\right) /(T-20), \quad T<750^{\circ} \mathrm{C} \\
& \alpha_{\text {aço }}(T)=\left(1,1 \cdot 10^{-2}\right) /(T-20), \quad 750^{\circ} \mathrm{C} \leq T \leq 860^{\circ} \mathrm{C} \\
& \left.\alpha_{\text {aço }}(T)=\left(\left(2 \cdot 10^{-5}\right) \cdot T-6.2 \cdot 10^{-3}\right)\right) /(T-20), \quad T>860^{\circ} \mathrm{C}
\end{aligned}
$$

As propriedades básicas do concreto estão descritas na Seção 3.3.2 bem como a descrição de como as curvas são construídas. A metodologia para as curvas em altas temperaturas é a mesma, no entanto, considera-se agora a EN 1992-1-2:2004 (CEN, 2004b) para a curva não-linear entre $\sigma_{c}=0,4 f_{c}$ e $\sigma_{c}=f_{c}$. Além disso, utiliza-se a referida norma para cálculo dos fatores de redução da resistência para o caso de agregados silicosos. Para cálculo das curvas de "tensão de tração vs abertura de fissura" também foi considerada a dependência da energia de fratura com a temperatura de acordo com Tian (2019). A Figura 5.3, Figura 5.4 e Figura 5.5 mostram as curvas calculadas para o bloco, argamassa e graute.

Figura 5.3 - Blocos - Comportamento uniaxial do concreto em altas temperaturas

(a) Compressão

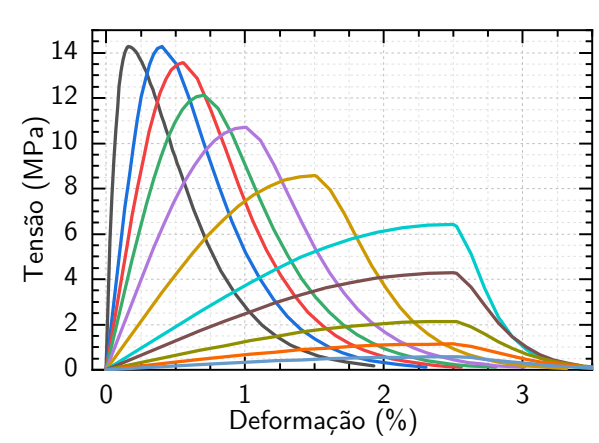

(b) Tração
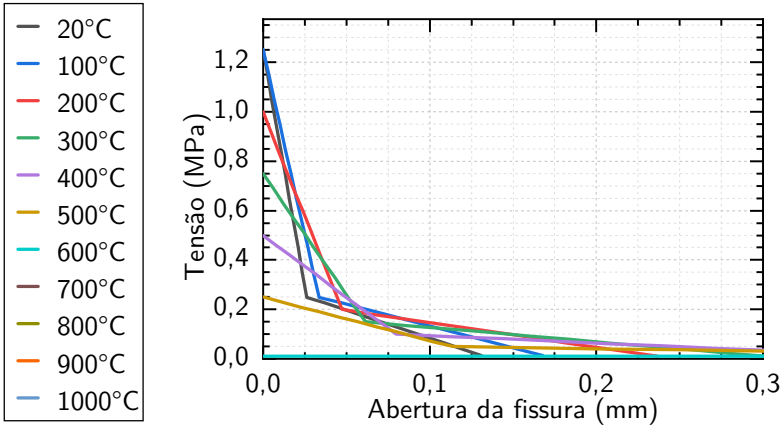

Fonte: O autor 
Figura 5.4 - Argamassa - Comportamento uniaxial do concreto em altas temperaturas

(a) Compressão

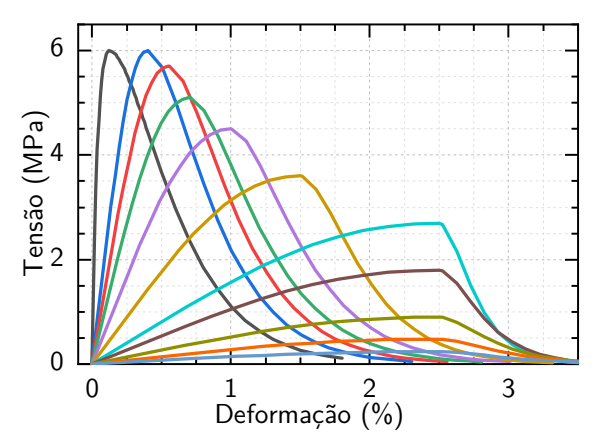

(b) Tração

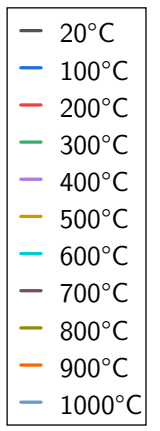

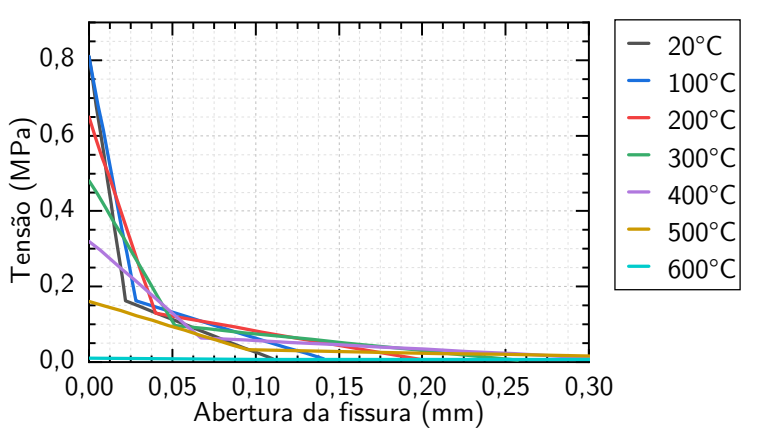

Fonte: O autor

Figura 5.5 - Graute - Comportamento uniaxial do concreto em altas temperaturas

(a) Compressão

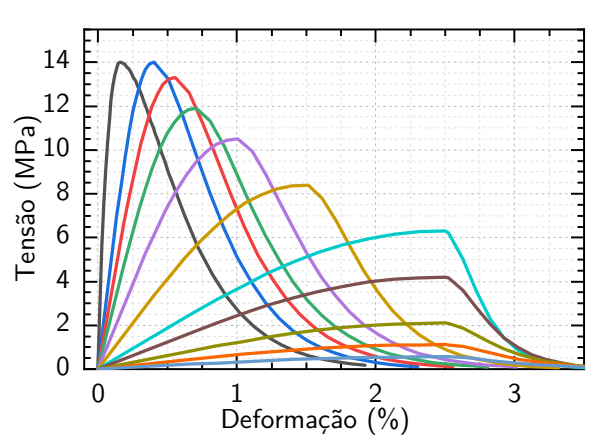

(b) Tração

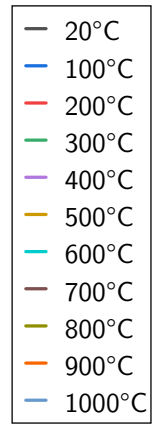

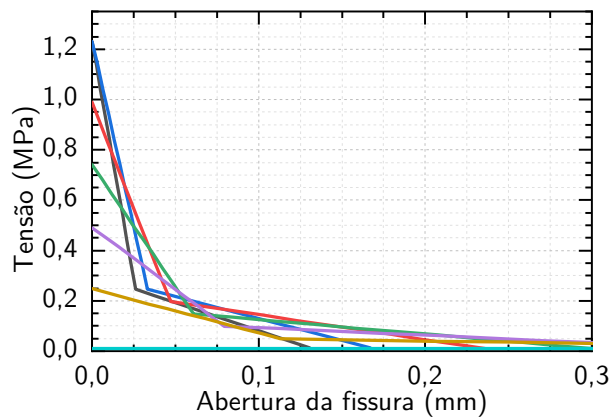

$-20^{\circ} \mathrm{C}$
$-100^{\circ} \mathrm{C}$
$-200^{\circ} \mathrm{C}$
$-300^{\circ} \mathrm{C}$
$-400^{\circ} \mathrm{C}$
$-500^{\circ} \mathrm{C}$
$-600^{\circ} \mathrm{C}$

Fonte: $\mathrm{O}$ autor

O módulo de elasticidade em função da temperatura é obtido a partir das curvas tensão-deformação do concreto para as diferentes temperaturas. Já o coeficiente de Poisson é calculado de acordo com a Equação 5.2 as quais são apresentadas por (GERNAY; MILLARD; FRANSSEN, 2013).

$$
\begin{aligned}
& \nu_{\text {conc }}(T)=\nu_{\text {conc }}\left(T=20^{\circ} C\right) \cdot(0,2+0,8 \cdot((500-T) /(500-20))), \quad T \leq 500^{\circ} \mathrm{C} \\
& \nu_{\text {conc }}(T)=0,2 \cdot \nu_{\text {conc }}\left(T=20^{\circ} C\right), \quad T>500^{\circ} \mathrm{C} \\
& \nu_{\text {conc }}\left(T=20^{\circ} C\right)=0,2
\end{aligned}
$$

Assim como na Seção 3.3, adotou-se o modelo constitutivo de plasticidade com dano (Concrete Damaged Plasticity) para simulação do concreto. Nesse caso considera-se que a razão entre resistência à compressão biaxial e compressão uniaxial $\left(f_{b 0} / f_{c 0}\right)$ varia com a temperatura de acordo com a Equação 5.3 (GERNAY; MILLARD; FRANSSEN, 2013). Os outros parâmetros do modelo são considerados independentes da temperatura (Tabela 3.3). 


$$
\begin{aligned}
& f_{b 0} / f_{c 0}=1,16, \quad T \leq 350^{\circ} \mathrm{C} \\
& f_{b 0} / f_{c 0}=1,16 \cdot(1+0.6 \cdot(T-350) /(750-350)), \quad 350^{\circ} \mathrm{C} \leq T \leq 750^{\circ} \mathrm{C} \\
& f_{b 0} / f_{c 0}=1,86, \quad T>750^{\circ} \mathrm{C}
\end{aligned}
$$

Por fim, Equação 5.4 mostra as expressões do coeficiente de expansão térmica do concreto $\left(\alpha_{\text {conc }}\right)$, as quais foram calculadas com base na EN 1992-1-2:2004 (CEN, 2004b) considerando $T_{0}=20^{\circ} \mathrm{C}$.

$$
\begin{aligned}
& \alpha_{\text {conc }}(T)=\left(1,8 \cdot 10^{-4}+\left(9 \cdot 10^{-6}\right) \cdot T+\left(2,3 \cdot 10^{-11}\right) \cdot T^{3}\right) /(T-20), \quad T \leq 700^{\circ} \mathrm{C} \\
& \alpha_{\text {conc }}(T)=\left(14 \cdot 10^{-3}\right) /(T-20), \quad T>700^{\circ} \mathrm{C}
\end{aligned}
$$

\subsection{Resultados e Análise}

Nessa seção são apresentadas as principais conclusões obtidas através das diversas análises. Em todas as simulações, para garantir que a análise é quasi-estática é preciso analisar os gráficos de energia de forma similar ao realizado na Seção 3.1. Os gráficos de energia das simulações da presente seção estão inclusos no Apêndice A.3. Já o Apêndice C traz um resumo do custo computacional demandado em todas as simulações.

Durante o incêndio em apenas uma face da alvenaria há a expansão térmica dessa face a qual pode ser restrita ou não a depender das condições de contorno. Analisando as diferentes condições de contorno para as Faces $+\mathrm{X}$ e $-\mathrm{X}$ foi possível observar que quando essa face está livre o diferencial térmico leva a um estado de solicitação que gera inúmeras trincas nos blocos em um tempo curto de incêndio. Esse estado é ilustrado na Figura 5.6a. Já a Figura 5.6b ilustra a situação quando há restrição nas Faces +X e -X, onde o confinamento gerado impede o surgimento desse mecanismo de deterioração. Esse resultado mostra que o estado de confinamento lateral é importante no modelo estudado, influenciando em seus resultados. Por isso, é importante analisar os resultados para as diferentes condições de contorno da Face $+\mathrm{X}$ e levar esse fato em consideração ao utilizar esses resultados como referência para trabalhos futuros. Cabe ressaltar que foge ao escopo do trabalho realizar uma análise do estado de confinamento de paredes em edifícios.

O objetivo principal das simulações foi analisar um chumbador utilizado para ancorar uma viga de escada pré-moldada de concreto em alvenaria estrutural de blocos de concreto. Busca-se responder se o chumbador apresenta falha mediante o evento de um incêndio na face oposta a parede da escada. Para isso, considerou-se o chumbador ancorado em um painel mínimo de alvenaria, supondo assim, que sua possível ruptura se dá por um efeito local. 
Figura 5.6 - Dano à tração em $t=4$ min de incêndio

(a) Caso 1 - Faces $+\mathrm{X}$ e -X livres

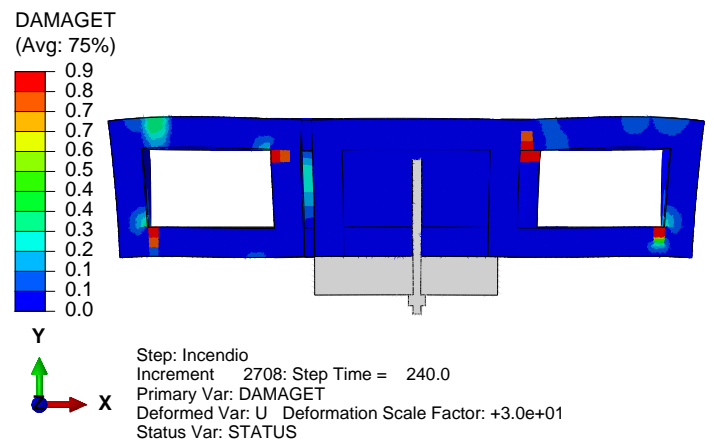

(b) Caso 2 - Faces $+\mathrm{X}$ e $-\mathrm{X}$ restritas

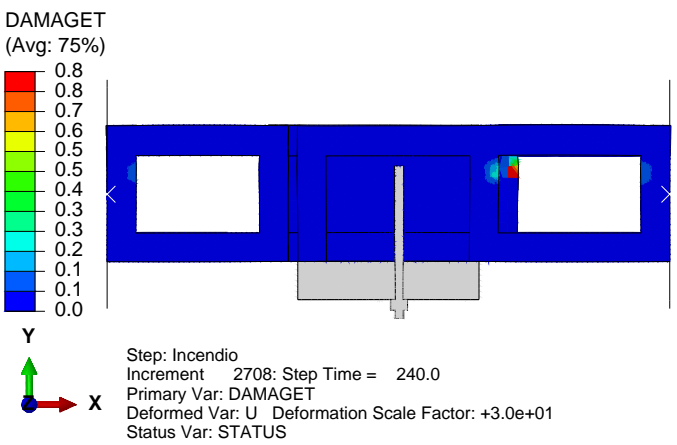

Nota: Seção transversal passando pelo chumbador. Escala de deformação $=30$. Fonte: $\mathrm{O}$ autor.

A Figura 5.7 mostra a tensão de Von Mises no chumbador para o Caso 1, no tempo $t=0$ e em $t=48$ min quando o painel de alvenaria já não resiste os $0,4 \cdot \sigma_{\text {rup }}^{\text {painel }}$. Perceba que há um aumento nas tensão do chumbador mas ela permanece abaixo da tensão de escoamento do aço $\left(f_{y}=250 \mathrm{MPa}\right)$.

Figura 5.7 - Tensão de Von Mises no chumbador de acordo com o tempo de incêndio

(a) $t=0 \mathrm{~min}$

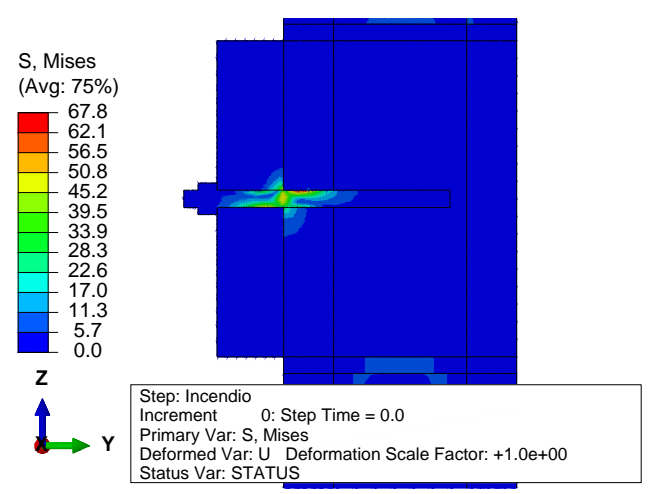

(b) $t=48 \min$

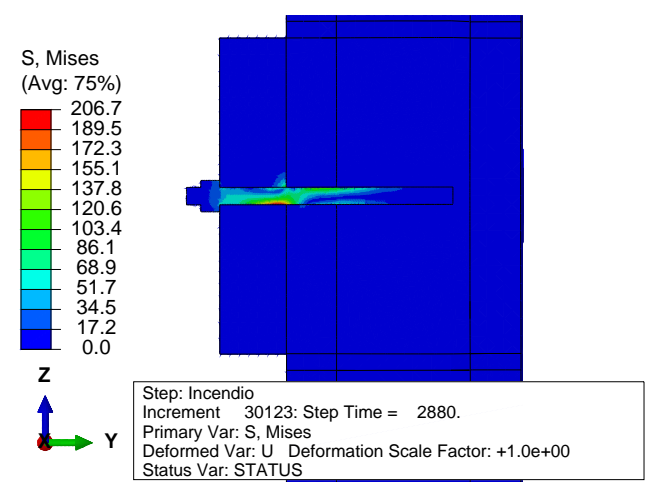

Nota: Caso 1 - Faces $+\mathrm{X}$ e -X livres. Condições de contorno da chapa no topo do painel: $u_{z} \leq u_{z}^{t=0}$ e $\theta_{x}=0$. Seção transversal passando pelo chumbador. Fonte: O autor.

Além do aço, é interessante observar se há formação de mecanismo de ruptura do chumbador por falha do concreto. A Figura 5.8 e Figura 5.9 mostram o dano à tração e à compressão no concreto. Há um aumento no dano à tração e à compressão no concreto mediante a exposição ao incêndio. No entanto, não há formação de um mecanismo que leve a falha do chumbador por meio da ruptura do concreto como, por exemplo, a ruptura de uma cunha de concreto por efeito de braço de alavanca (pry-out failure). Há um grande 
plano de fissura coincidente com o chumbador (Figura 5.8b) a qual é oriunda do mecanismo de expansão lateral observado na Figura 5.6a. Dependendo das restrições na Face+X esse dano é menos pronunciado ou inexistente.

Em todos os outros casos de condições de contorno simuladas a conclusão foi idêntica: não houve formação de um mecanismo de ruptura do chumbador antes da formação de um mecanismo de ruptura do painel de alvenaria. Em relação ao aço, em 120 min não há aumento de temperatura relevante para que a seu comportamento seja modificado a ponto de afetar a capacidade portante do chumbador, especialmente porque a região mais solicitada encontra-se longe da face do incêndio (ver Figura 4.28 e Figura 5.7). Em relação ao concreto, a princípio parece razoável assumir que danos no concreto levam à ruptura primeiramente a parede e não o chumbador. Esse fato é sustentado pelo fato de que embora se considere situações de contorno muito benéficas à resistência da alvenaria, como giros restritos e confinamento, o chumbador não apresentou falha, apenas deslocamentos que seguem aproximadamente o deslocamento da alvenaria. Cabe relembrar que todas as análises são realizadas considerando $F_{s}^{\text {chumb }}=2,271 \mathrm{kN}$ a qual é $10,76 \%$ da carga de ruptura estimada na Seção 3.3.3.

Figura 5.8 - Dano a tração próximo ao chumbador de acordo com o tempo de incêndio
(a) $t=0 \mathrm{~min}$
(b) $t=48 \mathrm{~min}$
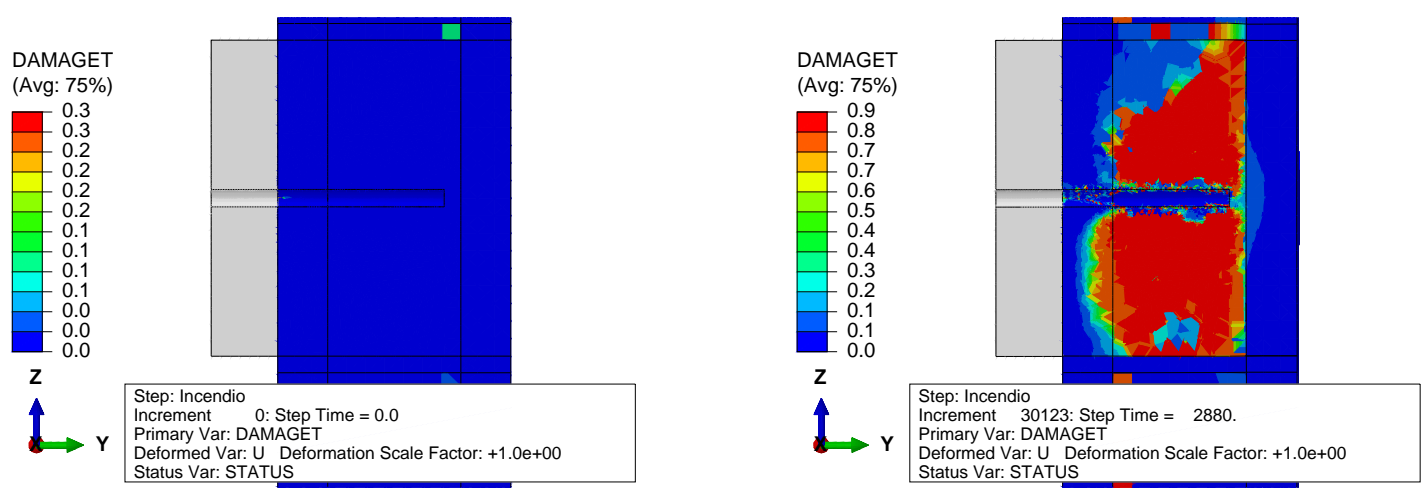

Nota: Caso 1 - Faces $+\mathrm{X}$ e -X livres. Condições de contorno da chapa no topo do painel: $u_{z} \leq u_{z}^{t=0}$ e $\theta_{x}=0$. Seção transversal passando pelo chumbador. Fonte: O autor.

Como uma análise secundária foi realizada uma estimativa do tempo de ruptura dos paineis de alvenaria simulados. No entanto, foi realizada análise dinâmica explícita quasi-estática e o carregamento não é por deslocamento controlado (como aqueles realizados na Seção 3.3). Esse fato dificulta a caracterização de um ponto de ruptura. Para isso foram elencados alguns fatos de interesse para que a partir da análise de um ou mais destes pontos fosse possível determinar um tempo estimado de ruptura. Tais situações são elencadas a seguir: 
Figura 5.9 - Dano a compressão próximo ao chumbador de acordo com o tempo de incêndio

(a) $t=0 \min$

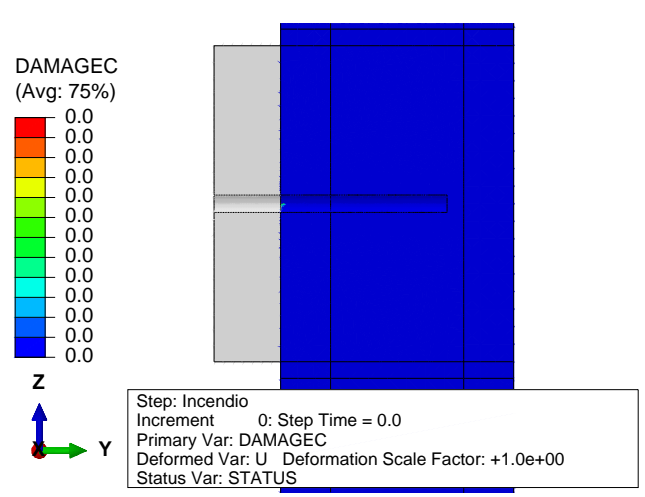

(b) $t=48 \mathrm{~min}$

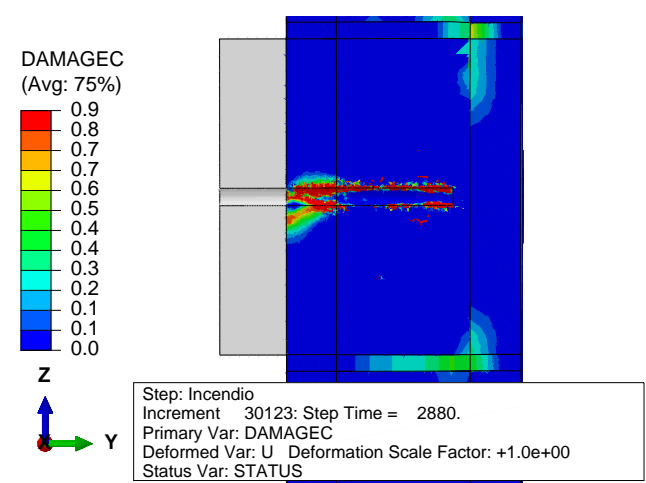

Nota: Caso 1 - Faces $+\mathrm{X}$ e -X livres. Condições de contorno da chapa no topo do painel: $u_{z} \leq u_{z}^{t=0}$ e $\theta_{x}=0$. Seção transversal passando pelo chumbador. Fonte: O autor.

- Para os casos em que $u_{z} \neq$ livre: $\left|\sigma_{z}(t)\right| \leq\left|\sigma_{z}(t=0)\right|$;

- Para os casos em que $u_{z}=$ livre: aumento excessivo de $u_{z}$;

- Para os casos em que $\theta_{x}=$ livre: aumento excessivo de $\theta_{x}$;

- Em todos os casos, aumento excessivo da razão entre energia cinética em relação a parcelas de energia de deformação e dissipação, em geral acima de 10\% (ver Apêndice A.1).

A partir da análise dos resultados das simulações, estimou-se o tempos de ruptura apresentados na Tabela 5.3. O leitor é convidado a analisar os resultados brutos apresentados no Apêndice B. Eles consistem em: deslocamentos do chumbador, deslocamentos do painel de alvenaria, tensão na área bruta, momentos nas chapas, rotações das chapas e campos de dano à tração e à compressão. O autor se reserva de análises adicionais destes resultados uma vez que a análise de resistência da alvenaria em si não é objeto de estudo desse trabalho. Destaca-se mais uma vez que esses resultados indicam que, para as condições analisadas, o chumbador não atinge sua carga de ruptura antes que o próprio painel de alvenaria rompa. 
Tabela 5.3 - Tempo de ruptura estimado do painel de alvenaria em condição de incêndio

\begin{tabular}{|c|c|c|c|c|}
\hline Condição na Face +Z: & $\begin{array}{c}u_{z} \leq u_{z}^{t=0} \\
\theta_{x}=0\end{array}$ & $\begin{array}{l}u_{z} \leq u_{z}^{t=0} \\
\theta_{x}=\text { livre }\end{array}$ & $\begin{array}{c}u_{z}=\text { livre } \\
\theta_{x}=0\end{array}$ & $\begin{array}{l}u_{z}=\text { livre } \\
\theta_{x}=\text { livre }\end{array}$ \\
\hline $\begin{array}{c}\text { Caso } 1 \text { - Face }+\mathrm{X} \\
\text { e Face -X livres }\end{array}$ & $48 \mathrm{~min}$ & $40 \mathrm{~min}$ & $88 \mathrm{~min}$ & $56 \mathrm{~min}$ \\
\hline $\begin{array}{l}\text { Caso } 2 \text { - Face }+\mathrm{X} \\
\text { e Face }-\mathrm{X} \text { restritas }\end{array}$ & $104 \min$ & $40 \mathrm{~min}$ & $120 \mathrm{~min}$ & $84 \mathrm{~min}$ \\
\hline $\begin{array}{c}\text { Caso } 3 \text { - Face }+\mathrm{X} \\
\text { restrita e Face }-\mathrm{X} \text { livre }\end{array}$ & $84 \mathrm{~min}$ & $44 \mathrm{~min}$ & $100 \mathrm{~min}$ & $60 \mathrm{~min}$ \\
\hline
\end{tabular}

Nota: Face -Z: $u_{z}=0$ e $\theta_{x}=0$ 


\section{CONSIDERAÇÕES FINAIS}

As simulações presentes neste trabalho tem características exploratórias e podem subsidiar uma possível campanha experimental acerca do desempenho de escadas prémoldadas leves de concreto e de sistemas de fixação em alvenaria estrutural. Um problema enfrentado foi o fato de não terem sido encontrados na literatura estudos de sistemas de fixação de escadas em alvenaria sob situação de incêndio. Portanto, fez-se necessário validar as estratégias de modelagem através de ensaios semelhantes que sejam representativos do problema. Isso foi realizado através do estudo de chumbador submetido a cisalhamento em peça de concreto simples e do estudo do campo de temperatura em um bloco de alvenaria em concreto sujeito ao incêndio padrão.

As simulações de cisalhamento de chumbadores em peças de concreto simples mostraram a aplicabilidade dos modelos constitutivos de plasticidade e dano para os materiais, a consideração da interação de contato entre chumbador e bloco e a estratégia de análise dinâmica quasi-estática explícita com escala de massa. Os resultados apresentaram boa concordância com os dados experimentais e as limitações do modelo puderam ser exploradas.

A escada dimensionada por Mamede (2001) foi utilizada como base para os modelos. Através da simulação da viga denteada leve pré-moldada apoiada em chumbadores foi possível estimar a sua carga e modo de ruptura. Isso foi possível utilizando as estratégias empregadas na simulação de cisalhamento dos chumbadores, tais como, o modelo constitutivo com plasticidade e dano para o concreto, o contato no apoio sobre chumbadores e a análise dinâmica quasi-estática explícita com escala de massa. Pôde-se verificar que a carga de ruptura é consideravelmente superior a carga solicitante para escadas de 1,2 m de largura. Além disso, a ruptura ocorreu na região de apoio do chumbador provocando uma ruptura de borda na viga de concreto.

Após validar a estratégia de simulação estrutural com o exemplo acima, foi proposto um modelo que tem o objetivo de ser a representação mínima de uma unidade de alvenaria englobando os blocos e juntas. Nesse painel de alvenaria considera-se um chumbador sujeito a cisalhamento por uma chapa de concreto com espessura igual ao da viga denteada pré-moldada da escada. Através de uma revisão da literatura, foram adotados valores de resistência dentro de uma faixa de valores razoáveis para os componentes da alvenaria. Através dos simulações obteve-se a resistência à compressão do painel de alvenaria e do chumbador ancorado no respectivo painel.

A tensão de ruptura na área bruta do painel foi de 78,13\% da tensão de ruptura na área bruta assumida para os blocos. Além disso, foi possível perceber que essa resistência 
pode aumentar caso haja restrições laterais na direção perpendicular a carga aplicada as quais gerem confinamento no painel. A resistência ao cisalhamento do chumbador analisado foi de $F_{r}^{\text {chumb }}=21,1 \mathrm{kN}$ caracterizada pela deformação excessiva do aço indicando sua ruptura. Por outro lado, a força solicitante cisalhante característica no apoio da viga denteada é $F_{s}=2,28 \mathrm{kN}$ (MAMEDE, 2001). Na etapa de simulação termoestrutural foi possível analisar se a resistência e rigidez do chumbador tem mudanças significativas em situação de incêndio.

A estratégia de simulação térmica foi validada através da análise de blocos de alvenaria em concreto em situação de incêndio. A consideração da transferência de calor por radiação nas cavidades do bloco bem como o acoplamento fluido-sólido permitiu a adequada consideração da influência das cavidades na simulação. As análises mostraram boa aproximação com os dados experimentais e pôde-se discutir suas limitações. Percebe-se que para valores altos de emissividade na superfície da cavidade a influência da convecção é limitada e a transferência de calor por radiação é preponderante entre as faces da cavidade. Por esse motivo, apenas a transferência de calor por radiação foi considerada nas simulações do painel de alvenaria.

Os resultados da análise de transferência de calor em situação de incêndio do painel de alvenaria com chumbador ancorado mostraram que a presença do graute na cavidade de ancoragem do chumbador limita a sua elevação de temperatura. Em 120 min de incêndio-padrão ISO 834-1:1999, a temperatura no aço permaneceu abaixo de $350{ }^{\circ} \mathrm{C}$. A presença do chumbador tem influência pouco significativa no campo de temperatura nos blocos e grautes. Por outro lado, a consideração da transferência de calor por radiação no interior das cavidades faz com que, para uma mesma distância da face sob incêndio, os pontos na superfície da cavidade apresentam temperaturas superiores aqueles no interior dos septos. Desse forma, o ponto com maior temperatura na face oposta ao incêndio é aquele mais distante dos septos, alinhado ao eixo central da cavidade do bloco. Os resultados da análise térmica também mostram que a temperatura na viga denteada após 120 min é menor do que $125^{\circ} \mathrm{C}$. Tal temperatura é insuficiente para levar a diminuições significativas de resistência na viga denteada. Assim, de acordo com as simulações, para o incêndio na face oposta a escada, pode-se considerar que a alvenaria protege a viga denteada e os degraus do efeito da temperatura.

Para a análise em situação de incêndio foram utilizadas simulações termoestruturais com acoplamento unidirecional, isto é, o campo de temperaturas transiente, produto da análise de transferência de calor, é aplicado na análise estrutural. Essa estratégia é válida assumindo a hipótese de que a resposta mecânica tem influência desprezível na distribuição de temperatura ao longo do tempo. Essa estratégia vem sendo utilizada com sucesso em trabalhos semelhantes (CARVALHO, 2019). A análise do chumbador ancorado em painel de alvenaria considerou $\sigma_{s}^{\text {painel }}=0,4 \cdot \sigma_{\text {rup }}^{\text {painel }}=2,5 \mathrm{MPa}$ e $F_{s}=2,28 \mathrm{kN}$ constantes no 
painel e chumbador respectivamente. A análise dos resultados mostrou que, para esse nível de carregamento e as demais características do modelo, não ocorre formação de mecanismo de ruptura do chumbador antes que o próprio painel perca sua capacidade resistente. No entanto, há aumento nas tensões do chumbador, aumento do dano na cavidade grauteada e aumento dos deslocamentos da chapa de carregamento do chumbador. Para o nível de carga avaliado, o aço não chega a plastificar e os aumentos de deslocamento do chumbador se devem principalmente pelo movimento do painel de alvenaria como um todo.

É importante destacar que a análise realizada considera um carregamento no chumbador sensivelmente menor que sua resistência ao cisalhamento. O resultado dessa análise pode ser diferente caso se considere níveis maiores de solicitação. No entanto, mesmo nesse caso, a análise térmica mostra que a temperatura no chumbador não é suficiente para perdas significativas de resistência do aço. Portanto, caso haja ruptura precoce do chumbador durante o incêndio, ela provavelmente terá origem na perda de resistência do concreto.

\subsection{Sugestões para trabalhos futuros}

Considerando as características e limitações dos modelos utilizados no presente trabalho, apresenta-se algumas sugestões e observações que podem orientar trabalhos futuros no tema:

- No presente trabalho foi considerado um uso de um chumbador metálico com adesivo químico. Esse chumbador é caracterizado pela ausência de cabeça de ancoragem e sua ancoragem se dá ao longo do comprimento de embutimento por meio do uso de um adesivo polimérico. Na modelagem considerou-se aderência perfeita entre chumbador e concreto, sendo esta uma idealização, que se julgou adequada visto que a adesão tem influência secundária na resistência ao cisalhamento. No entanto, sugere-se que trabalhos futuros abordagem com mais rigor o comportamento da interface entre chumbador e concreto. Esse análise pode ser importante especialmente em altas temperaturas, uma vez que os adesivos poliméricos apresentem perda de resistência.

- Em trabalhos futuros sugere-se o estudo de outros tipo de chumbadores como, por exemplo, chumbadores mecânicos com cabeça pré e pós-instalados.

- Mesmo que o grauteamento da cavidade de fixação seja uma boa prática já difundida é interessante avaliar a resposta do sistema de fixação na ausência do grauteamento da cavidade.

- Nesse trabalho buscou-se avaliar o comportamento do sistema de fixação em alvenaria oriundo de um projeto de escada pré-moldada de concreto. Assim, utilizou-se as cargas 
adequadas para esse objetivo. Sugere-se que em trabalhos futuros seja estudado o sistema de fixação de forma genérica, utilizando assim vários níveis de carregamento.

- As seguintes variáveis poderiam ser consideradas em uma análise paramétrica: resistência dos blocos, resistência do graute, resistência do chumbador, geometria dos blocos e comprimento de embutimento do chumbador.

- É de especial interesse estudos experimentais no tema para que assim as simulações possam ser validadas. Nesse sentido, trabalhos de simulação como este podem auxiliar a definir tópicos ou variáveis de interesse que valem a pena ser estudadas em laboratório. Isso abriria caminho para análise de segurança e aprimoramento de métodos de dimensionamento. 


\section{REFERÊNCIAS}

ABECE - ASSOCIAÇÃO BRASILEIRA DE ENGENHARIA E CONSULTORIA ESTRUTURAL. Recomendações ABECE 005:2019: Projeto de fixações com chumbadores químicos em elementos de concreto (revisão 1). São Paulo, 2019. 35 p.

AL-MANSOURI, O. et al. Influence of testing conditions on thermal distribution and resulting load-bearing capacity of bonded anchors under fire. Engineering Structures, v. 192, p. 190 - 204, 2019. ISSN 0141-0296. Disponível em: http://www.sciencedirect.com/science/article/pii/S0141029618328542.

AMERICAN SOCIETY FOR TESTING AND MATERIALS. ASTM A307-14:

Standard specification for carbon steel bolts, studs, and threaded rod 60000 psi tensile strength. West Conshohocken, PA, United States, 2014. 6 p.

AMERICAN SOCIETY FOR TESTING AND MATERIALS. ASTM F1554-15:

Standard specification for anchor bolts, steel, 36, 55, and 105-ksi yield strength. West Conshohocken, PA, United States, 2015. 9 p.

ANDRADE, R. C.; MAMEDE, F. C. The use of precast stairs in masonry structures. In: 15TH INTERNATIONAL BRICK AND BLOCK MASONRY CONFERENCE. Proceedings ... Florianópolis, Brasil, 2012. p. 10.

ASSIS, E. B. de; MUNAIAR NETO, J. Analysis of heat transfer mechanisms on hollow concrete masonry units under standardized fire conditions. In: XLI IBERO-LATIN-AMERICAN CONGRESS ON COMPUTATIONAL METHODS IN ENGINEERING, 41., 2020, (Online) Foz do Iguaçu/PR, Brazil. Proceedings... Associação Brasileira de Métodos Computacionais em Engenharia, 2020. p. 7. Disponível em: https://doi.org/10.5281/zenodo.4283007.

ASSOCIAÇÃO BRASILEIRA DE NORMAS TÉCNICAS. NBR 5628: Componentes construtivos estruturais - determinação da resistência ao fogo. Rio de Janeiro, 2001. 6 p.

ASSOCIAÇÃO BRASILEIRA DE NORMAS TÉCNICAS. ABNT NBR 14323: Projeto de estruturas de aço e de estruturas mistas de aço e concreto de edifícios em situação de incêndio. Rio de Janeiro, 2013. 74 p.

ASSOCIAÇÃO BRASILEIRA DE NORMAS TÉCNICAS. ABNT NBR 6136: Blocos vazados de concreto simples para alvenaria - requisitos. Rio de Janeiro, 2016. 16 p.

BRITISH STANDARDS INSTITUTION. BS 5628-3:2005: Code of practice for the use of masonry - part 3: Materials and components, design and workmanship. London, 2005. $136 \mathrm{p}$.

BROWN, R. H.; WHITLOCK, A. R. Strength of anchor bolts in grouted concrete masonry. Journal of Structural Engineering, v. 109, n. 6, p. 1362-1374, 1983. Disponível em: https://ascelibrary.org/doi/abs/10.1061/\%28ASCE\%290733-9445\%281983\%29109\% $3 \mathrm{~A} 6 \% 281362 \% 29$.

CARREIRA, D. J.; CHU, K.-H. Stress-Strain Relationship for Plain Concrete in Compression. ACI Journal Proceedings, v. 82, n. 6, jan 1985. 
CARVAlHO, P. R. de O. Análise numérica de pequenas paredes de alvenaria estrutural de blocos de concreto em situação de incêndio: ênfase no comportamento térmico e termoestrutural. 2019. 313 p. Dissertação (Mestrado em Engenharia Civil (Estruturas)) — Escola de Engenharia de São Carlos, Universidade de São Paulo, São Carlos, 2019. Disponível em: https://doi.org/10.11606/D.18.2019.tde-02082019-114958.

CEN - EUROPEAN COMMITTEE FOR STANDARDIZATION. EN 1991-1-2:2002: Eurocode 1: Actions on structures - part 1-2: General actions - actions on structures exposed to fire. Brussels, 2002.

CEN - EUROPEAN COMMITTEE FOR STANDARDIZATION. EN 1992-1-1:2004: Eurocode 2:design of concrete structures - part 1.1: General rules and rules for buildings. Brussels, 2004.

CEN - EUROPEAN COMMITTEE FOR STANDARDIZATION. EN 1992-1-2:2004: Eurocode 2:design of concrete structures - part 1.2: General rules - structural fire design. Brussels, 2004.

CEN - EUROPEAN COMMITTEE FOR STANDARDIZATION. EN 1993-1-2:2005: Eurocode 3: Design of steel structures - part 1-2: General rules - structural fire design. Brussels, 2005. 81 p.

CEN - EUROPEAN COMMITTEE FOR STANDARDIZATION. EN ISO 898-1:2013: Mechanical properties of fasteners made of carbon steel and alloy steel - part 1: Bolts, screws and studs with specified property classes - coarse thread and fine pitch thread (iso 898-1:2013). Brussels, 2013.

CEN - EUROPEAN COMMITTEE FOR STANDARDIZATION. EN 1992-4:2018:

Eurocode 2 - design of concrete structures - part 4: Design of fastenings for use in concrete. Brussels, 2018. 129 p.

Dassault Systèmes Simulia Corp. Abaqus 6.14 Analysis user's guide Volume III: Materials. [S.l.: s.n.], 2014.

DUPIM, R. H. Resistência residual de compressão de blocos, prismas e pequenas paredes de alvenaria estrutural de blocos de concreto submetidos à situação de incêndio. 2019. 252 p. Dissertação (Mestrado em Engenharia Civil (Estruturas)) - Escola de Engenharia de São Carlos, Universidade de São Paulo, São Carlos, 2019. Disponível em: https://doi.org/10.11606/D.18.2019.tde-22082019-125341.

ELIGEHAUSEN, R.; MALLÉE, R.; SILVA, J. F. Anchorage in concrete construction. [S.l.: s.n.]: John Wiley \& Sons, 2006. v. 10.

ÇENGEL, Y. Introduction to thermodynamics and heat transfer. Dubuque, IA: McGraw-Hill, 2008. ISBN 978-0071287739.

ÇENGEL, Y.; CIMBALA, J. Fluid mechanics : fundamentals and applications. New York, NY: McGraw-Hill Education, 2018. ISBN 9781259696534.

FIB - FÉDÉRATION INTERNATIONALE DU BÉTON. fib Model Code for Concrete Structures 2010. [S.l.], 2013. 
GENIKOMSOU, A. S.; POLAK, M. A. Finite element analysis of punching shear of concrete slabs using damaged plasticity model in abaqus. Engineering Structures, v. 98, p. 38 - 48, 2015. ISSN 0141-0296. Disponível em: http: //www.sciencedirect.com/science/article/pii/S0141029615002643.

GERNAY, T.; MILLARD, A.; FRANSSEN, J.-M. A multiaxial constitutive model for concrete in the fire situation: Theoretical formulation. International Journal of Solids and Structures, Elsevier BV, v. 50, n. 22-23, p. 3659-3673, oct 2013. Disponível em: https://doi.org/10.1016\%2Fj.ijsolstr.2013.07.013.

GROSSER, P. R. Load-bearing behavior and design of anchorages subjected to shear and torsion loading in uncracked concrete. 2012. 339 p. Tese (Doutorado em Engenharia) - Institut für Werkstoffe im Bauwesen der Universität Stuttgart, Stuttgart, 2012. Disponível em: http://dx.doi.org/10.18419/opus-473.

HAACH, V. G. Development of a design method for reinforced masonry subjected to in-plane loading based on experimental and numerical analysis. 2009. 367 p. Tese (Doutoramento em Engenharia Civil (ramo do conhecimento Estruturas)) — Escola de Engenharia - Universidade do Minho, Minho, 2009. Disponível em: http://hdl.handle.net/1822/9596.

HOFMANN, J. E. Tragverhalten und Bemessung von Befestigungen unter beliebiger Querbelastung in ungerissenem Beton. 2004. 282 p. Tese (Doutorado em Engenharia) - Institut für Werkstoffe im Bauwesen der Universität Stuttgart, Stuttgart, 2004.

ISO - INTERNATIONAL ORGANIZATION FOR STANDARDIZATION. ISO

834-1:1999: Fire-resistance tests — elements of building construction — part 1: General requirements. Geneve, Switzerland, 1999.

IZQUIERDO, O. S. Estudo da interface bloco/graute em elementos de alvenaria estrutural. 2015. 290 p. Tese (Doutorado em Engenharia de Estruturas) — Escola de Engenharia de São Carlos, Universidade de São Paulo, São Carlos, 2015.

IZQUIERDO, O. S.; CORRÊA, M. R. S.; SOTO, I. I. Study of the block/grout interface in concrete and clay block masonry structures. Revista IBRACON de Estruturas e Materiais, scielo, v. 10, p. 924 - 936, 08 2017. ISSN 1983-4195. Disponível em: https://doi.org/10.1590/s1983-41952017000400009.

KIRANE, K.; BAŽANT, Z. P.; ZI, G. Fracture and size effect on strength of plain concrete disks under biaxial flexure analyzed by microplane model m7. Journal of Engineering Mechanics, American Society of Civil Engineers (ASCE), v. 140, n. 3, p. 604-613, mar 2014. Disponível em: https://doi.org/10.1061\%2F\%28asce\%29em.1943-7889.0000683.

LAHOUAR, M. A. et al. Fire design of post-installed bonded rebars: Full-scale validation test on a $2.94 \times 2 \times 0.15 \mathrm{~m} 3$ concrete slab subjected to iso 834-1 fire. Engineering Structures, v. 174, p. 81 - 94, 2018. ISSN 0141-0296. Disponível em: http://www.sciencedirect.com/science/article/pii/S0141029617325294.

LEE, J.; FENVES, G. L. Plastic-damage model for cyclic loading of concrete structures. Journal of Engineering Mechanics, v. 124, n. 8, p. 892-900, 1998. Disponível em: https://ascelibrary.org/doi/abs/10.1061/\%28ASCE\%290733-9399\%281998\%29124\% $3 \mathrm{~A} 8 \% 28892 \% 29$. 
LEITE, H. A. L.; MORENO Jr., A. L.; TORRES, D. L. Dimensionamento da alvenaria estrutural em situação de incêndio: contribuição à futura normatização nacional.

Ambiente Construído, scielo, v. 16, p. 89 - 107, 06 2016. ISSN 1678-8621. Disponível em: https://doi.org/10.1590/s1678-86212016000200081.

LOPES, R. F. R. Comportamento ao fogo de paredes de alvenaria estrutural de blocos de betão com alvéolos verticais. 2017. 81 p. Dissertação (Mestrado em Segurança aos Incêndios Urbanos) - Faculdade de Ciências e Tecnologia, Universidade de Coimbra, Coimbra, 2017. Disponível em: http://hdl.handle.net/10316/83259.

LUBLINER, J. et al. A plastic-damage model for concrete. International Journal of Solids and Structure, v. 25, n. 3, p. 299 - 326, 1989. ISSN 0020-7683. Disponível em: http://www.sciencedirect.com/science/article/pii/0020768389900504.

MAMEDE, F. C. Utilização de pré-moldados em edifícios de alvenaria estrutural. 2001. 187 p. Dissertação (Mestrado em Engenharia Civil (Estruturas)) — Escola de Engenharia de São Carlos, Universidade de São Paulo, São Carlos, 2001. Disponível em: https://doi.org/10.11606/D.18.2001.tde-06062006-162432.

MAMEDE, F. C.; CORRÊA, M. R. S.; RAMALHO e M. A. Pré-moldados leves em edifícios de alvenaria estrutural. Caderno Técnico Alvenaria Estrutural - Revista Prisma, Mandarim, v. 18, p. 40 - 45, 03 2006. ISSN 1809-4708.

MCGINLEY, W. M. Design of anchor bolts in masonry. Progress in Structural Engineering and Materials, v. 8, n. 4, p. 155-164, 2006. Disponível em: https://onlinelibrary.wiley.com/doi/abs/10.1002/pse.222.

MCGINLEY, W. M. et al. Capacity of anchor bolts in concrete masonry. In: INTERNATIONAL BRICK AND BLOCK MASONRY CONFERENCE, 13., 2004, Amsterdam. Proceedings... Amsterdam, 2004. p. 10. Disponível em: http://www.hms.civil.uminho.pt/ibmac/2004/022.pdf.

NATIONAL CONCRETE MASONRY ASSOCIATION. TEK 12-3c: Design of anchor bolts embedded in concrete masonry. Herndon, Virginia, 2013. 6 p.

NETTO, R. M. Práticas racionalizadas de execução de alvenaria estrutural de blocos de concreto. 2016. 281 p. Dissertação (Mestrado em Habitação: Planejamento e Tecnologia) - Instituto de Pesquisas Tecnológicas do Estado de São Paulo, São Paulo, 2016.

OLIVEIRA, C. R. M.; BERTO, A. F. Determinação da resistência ao fogo em parede sem função estrutural: Relatório de ensaio nº 1072 608-203. São Paulo: IPT, 2015. 12 p.

OLIVEIRA, L. M. F. de. Estudo teórico e experimental do comportamento das interfaces verticais de paredes interconectadas de alvenaria estrutural. 2014. 272 p. Tese (Doutorado em Engenharia de Estruturas) — Escola de Engenharia de São Carlos, Universidade de São Paulo, São Carlos, 2014.

PARSEKIAN, G. A.; MEDEIROS, W. A.; SIPP, G. High-rise concrete and clay block masonry building in brazil. Mauerwerk, v. 22, n. 4, p. 260-272, 2018. Disponível em: https://onlinelibrary.wiley.com/doi/abs/10.1002/dama.201800010. 
PAVLOVIČ, M.; VELJKOVIČ, M. Fe validation of push-out tests. Steel Construction, v. 10, n. 2, p. 135-144, 2017. Disponível em: https://onlinelibrary.wiley.com/doi/abs/10. $1002 /$ stco. 201710017 .

PORTO FERRAZ CONSTRUTORA. Pré-Fabricação Em Obras De Alvenaria Estrutural. 2012. Palestra no $3^{\mathrm{O}}$ Fórum Mineiro de Alvenaria Estrutural (2012). Disponível em: http://www.comunidadedaconstrucao.com.br/upload/ativos/320/anexo/ portoferra.pdf. Acesso em: 04 fev. 2020.

PURKISS, J. A.; LI, L.-Y. Fire safety engineering design of structures. [S.l.: s.n.]: CRC press, 2013.

RAMALHO, M. A.; CORRÊA, M. R. S. Projeto de edifícios de alvenaria estrutural. São Paulo: Pini, 2003. ISBN 85-7266-147-6.

RODOVALHO, F. d. S. Simulação numérica de blocos e prismas de alvenaria em situação de incêndio. 2018. 158 p. Dissertação (Mestrado em Engenharia Civil (Estruturas) ) - Escola de Engenharia de São Carlos, Universidade de São Paulo, São Carlos, 2018. Disponível em: https://doi.org/10.11606/D.18.2018.tde-27082018-123952.

RODOVAlHO, F. d. S.; CORRÊA, M. R. S.; MUNAIAR NETO, J. Simulação termomecânica de prismas com blocos de concreto em situação de incêndio. Matéria (Rio de Janeiro), scielo, v. 25, 04 2020. ISSN 1517-7076. Disponível em: https://doi.org/10.1590/s1517-707620200001.0886.

RODOVALHO, F. S.; CORRÊA, M. R. S. Thermal simulation of prisms with concrete blocks in a fire situation. Revista IBRACON de Estruturas e Materiais, scielo, v. 12, p. 638 - 657, 06 2019. ISSN 1983-4195. Disponível em: https://doi.org/10.1590/s1983-41952019000300011.

RUSSO, S.; SCIARRETTA, F. Numeric research on the mechanical properties of different masonry units during and after fire. In: Brick and Block Masonry. CRC Press, 2016. p. 999-1006. Disponível em: https://doi.org/10.1201\%2Fb21889-125.

SEITO, A. I. et al. (ed.). A Segurança contra incêndio no Brasil. São Paulo: Projeto Editora, 2008. 496 p.

SILVA, V. P. et al. Segurança das estruturas em situação e incêndio. In: A Segurança contra incêndio no Brasil. São Paulo: Projeto Editora, 2008. p. 496.

SOCIETY FOR AUTOMOTIVE ENGINEERING. SAE J429: Mechanical and quality requirements for externally threaded fasteners. Washington, 1971. 6 p.

THAI, H.-T. et al. Explicit simulation of bolted endplate composite beam-to-cfst column connections. Thin-Walled Structures, v. 119, p. 749 - 759, 2017. ISSN 0263-8231. Disponível em: http://www.sciencedirect.com/science/article/pii/S0263823117303798.

THE MASONRY SOCIETY. TMS 402/602-16: Building code requirements and specification for masonry structures. Boulder, 2016. 382 p.

TIAN, K. Concrete failure of headed stud fasteners exposed to fire and loaded in shear: experimental and numerical study. 2019. 221 p. Tese (Doutorado em Engenharia) - Institut für Werkstoffe im Bauwesen der Universität Stuttgart, Stuttgart, 2019. Disponível em: http://dx.doi.org/10.18419/opus-10616. 
TIAN, K. et al. Concrete edge failure of single headed stud anchors exposed to fire and loaded in shear: Experimental and numerical study. Fire Safety Journal, v. 100, p. 32 - 44, 2018. ISSN 0379-7112. Disponível em: http: //www.sciencedirect.com/science/article/pii/S0379711218300663.

TIAN, K. et al. Experimental study on concrete edge failure of single headed stud anchors after fire exposure. Fire Safety Journal, v. 96, p. 176 - 188, 2018. ISSN 0379-7112. Disponível em: http://www.sciencedirect.com/science/article/pii/S0379711217305799.

VASSART, O. et al. Membrane action in fire design of composite slab with solid and cellular steel beams - valorisation (MACS+) final report. Luxembourg: Publications Office of the European Union, 2014. ISBN 978-92-79-38540-7. Disponível em: https://doi.org/10.2777/76136.

WICKSTRÖM, U. Temperature Calculation in Fire Safety Engineering. Springer International Publishing, 2016. Disponível em: https://doi.org/10.1007\% 2F978-3-319-30172-3.

WOSATKO, A. et al. Role of dilatancy angle in plasticity-based models of concrete. Archives of Civil and Mechanical Engineering, v. 19, n. 4, p. 1268 - 1283, 2019. ISSN 1644-9665. Disponível em: http://www.sciencedirect.com/science/article/pii/ S1644966519300767. 


\section{APÊNDICES}





\section{APÊNDICE A - GRÁFICOS DE ENERGIA}

\section{A.1 Balanço de energia}

O balanço de energia no Abaqus é definido pela Equação A.1 (Dassault Systèmes Simulia Corp., 2014).

$$
E_{i}+E_{v}+E_{a t r}+E_{c i n}+E_{I H E}-W_{e x t}-E_{P W}-E_{C W}-E_{M W}-E_{H F}=E_{\text {total }} \cong \text { constante }
$$

Onde se define:

$E_{i}$ - Energia interna

$E_{v}$ - Energia dissipada devido a viscosidade

$E_{a t r}$ - Energia dissipada devido ao atrito

$E_{\text {cin }}$ - Energia cinética

$E_{I H E}$ - Energia na forma de calor interno

$W_{\text {ext }}$ - Trabalho das forças externas

$E_{P W}$ - Trabalho realizado pelas penalizações de contato

$E_{C W}$ - Trabalho realizado pelas penalizações de acoplamento cinemático

$E_{M W}$ - Trabalho realizado para impulsionar massa adicionada

$E_{H F}$ - Calor externo calculado através dos fluxo de calor externo

Além disso, $E_{i}=E_{S E}+E_{P D}+E_{C D}+E_{A E}+E_{D M D}+E_{D C}+E_{F C}$, onde:

$E_{S E}$ - Energia de deformação recuperável

$E_{P D}$ - Energia dissipada por deformação plástica

$E_{C D}$ - Energia dissipada por viscoelasticidade

$E_{A E}$ - Energia de deformação "artificial" para remover modos de deformação singulares da malha (hourglass control)

$E_{D M D}$ - Energia dissipada por meio de dano

$E_{D C}$ - Energia dissipada pelo controle de distorção da malha 
$E_{F C}$ - Energia do fluido em cavidades, definida como o negativo do trabalho realizado em todas as cavidades

Cabe destacar que a existência das parcelas depende do tipo de simulação a ser realizada, por exemplo, a dissipação plástica será nula se os modelos constitutivos utilizados não envolverem plasticidade. A análise das parcelas de energia após a simulação permite avaliar a importância de determinadas características do modelo. Além disso, é possível verificar se há alguma parcela de energia com valores inesperados, ajudando na detecção de erros de modelagem. No contexto de análise quasi-estática é de interesse que a energia cinética do modelo seja pequena quando compara a energia interna, ou seja, deseja-se que o trabalho das forças externas seja quase que totalmente convertido em parcelas de energia com significado físico. Como uma regra geral, a energia cinética do material deformável não deve exceder uma pequena fração (tipicamente entre $5 \%$ e 10\%) da sua energia interna durante a maior parte do processo de análise (Dassault Systèmes Simulia Corp., 2014).

\section{A.2 Análise Estrutural}

Figura A.1 - Porcentagem do trabalho das forças externas que não se torna energia interna

(a) Resistência do painel de alvenaria

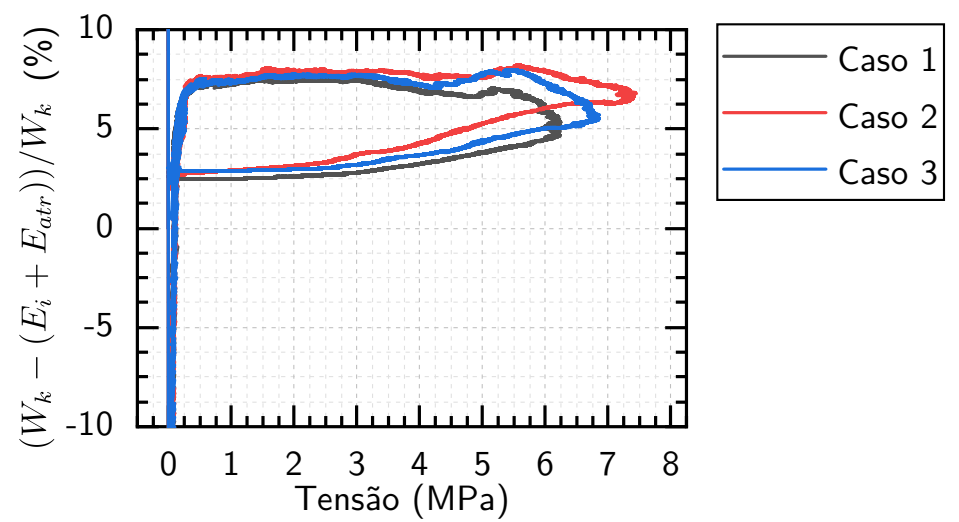

(b) Resistência do Chumbador

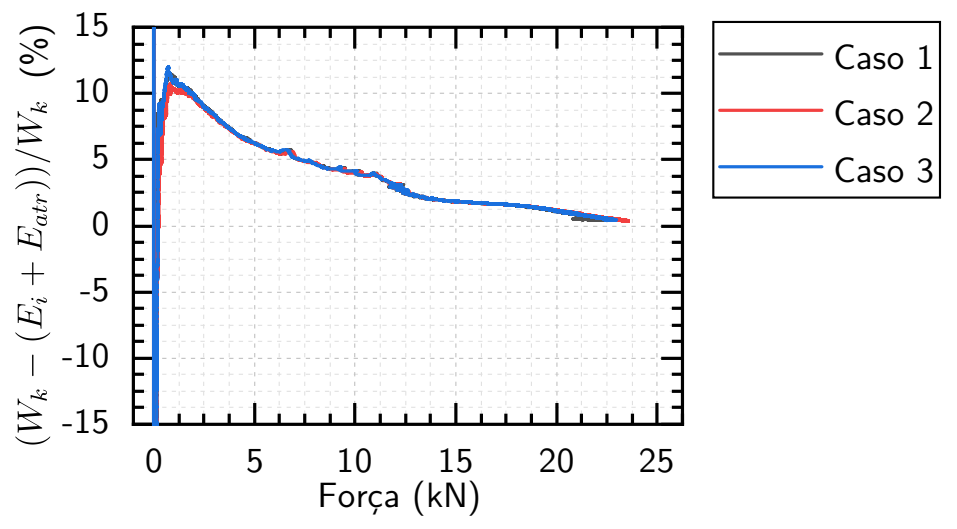

Fonte: $\mathrm{O}$ autor 


\section{A.3 Análise Termoestrutural}

Figura A.2 - Porcentagem de energia cinética em relação à energia interna e dissipação por atrito

(a) Caso 1 - Face $+\mathrm{X}$ e -X livres

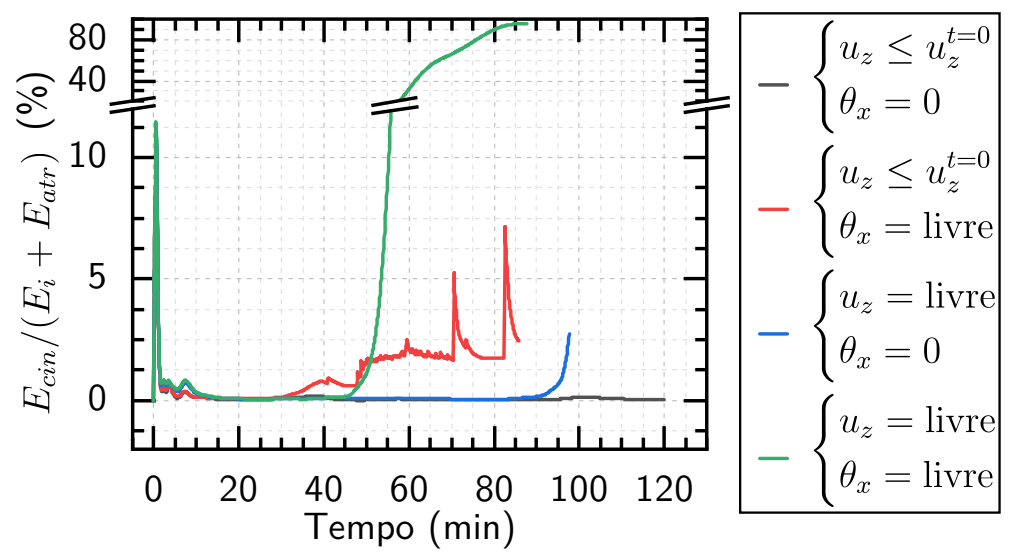

(b) Caso 2 - Face $+\mathrm{X}$ e -X restritas

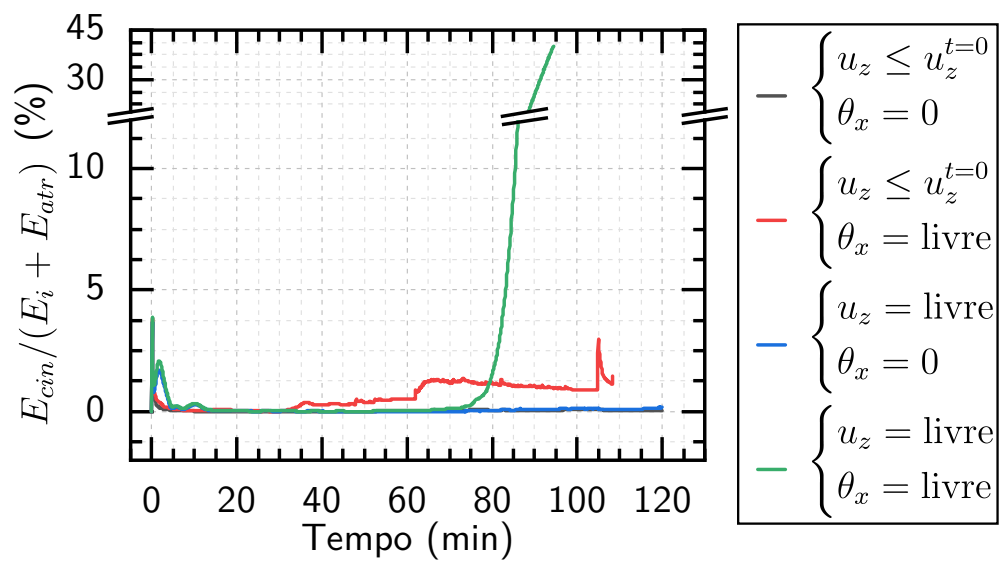

(c) Caso 3 - Face $+\mathrm{X}$ restrita e Face $-\mathrm{X}$ livre

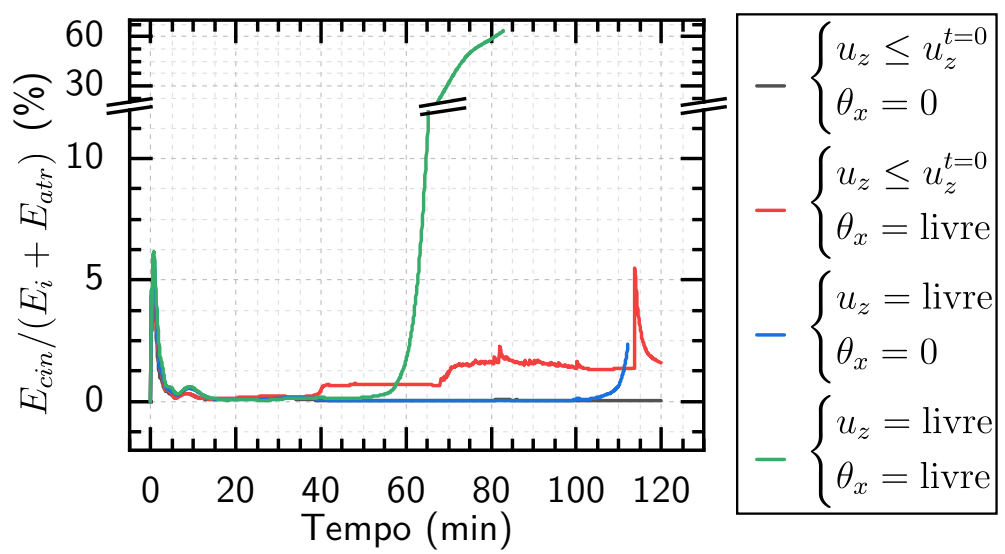

Fonte: $\mathrm{O}$ autor 



\section{APÊNDICE B - BANCO DE RESULTADOS - ANÁLISE TERMOESTRUTURAL}

\section{B.1 Caso 1 - Faces $+\mathrm{X}$ e - $\mathrm{X}$ livres}

Figura B.1 - Deslocamento $u_{z}$ da chapa do chumbador - Caso 1

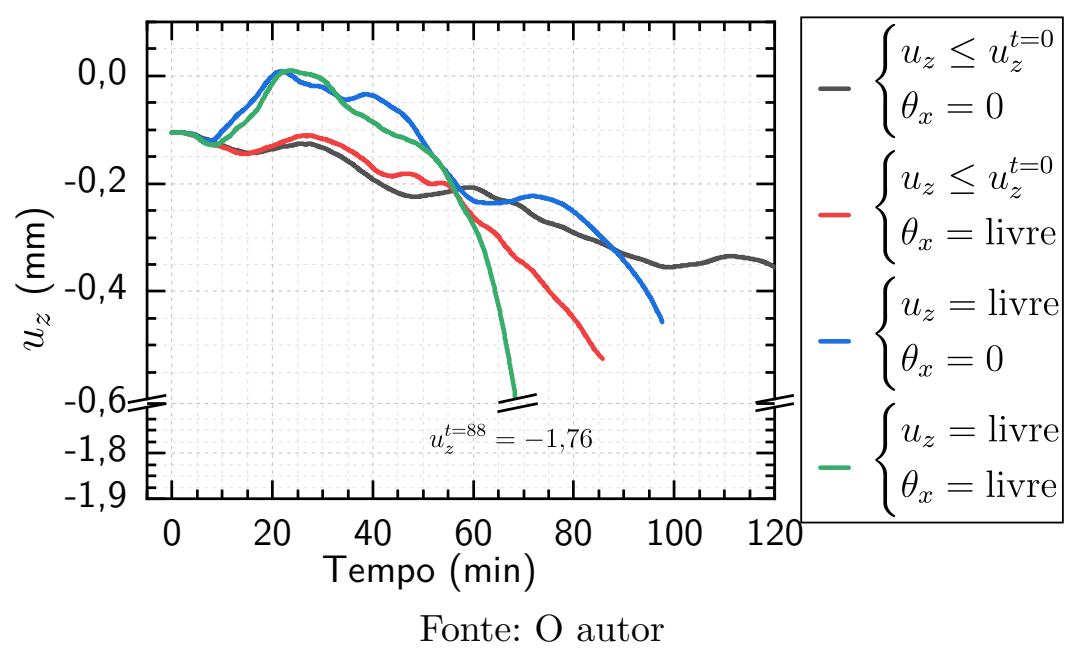

Figura B.2 - Tensão $\sigma_{z}$ na área bruta da Face -Z - Caso 1

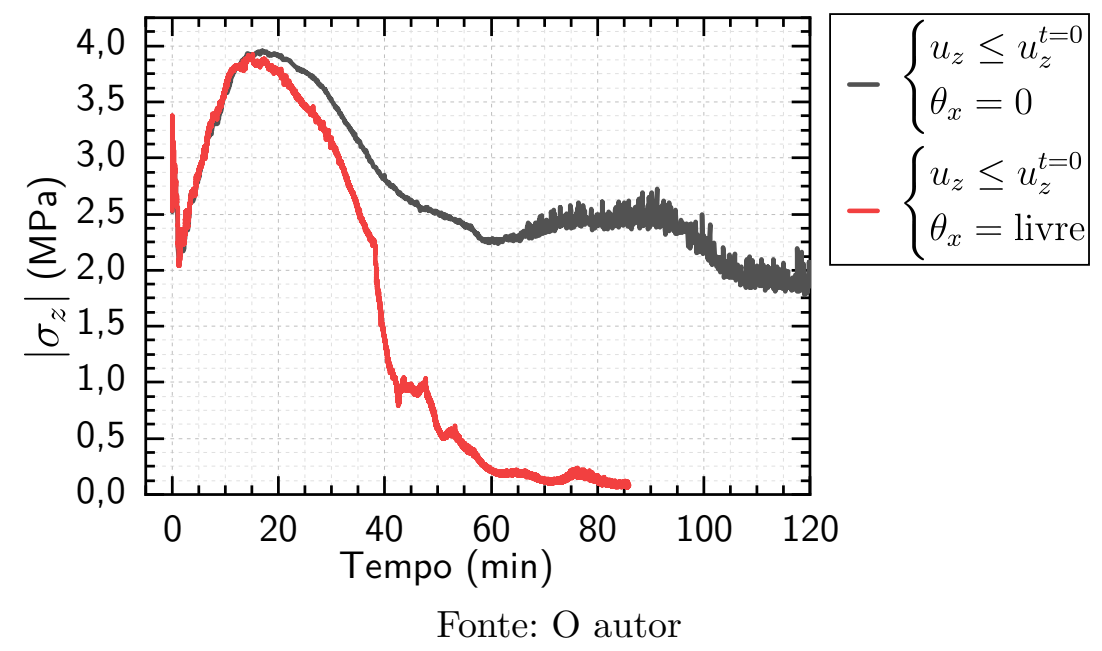


Figura B.3 - Deslocamento $u_{z}$ na chapa da Face $+\mathrm{Z}$ - Caso 1

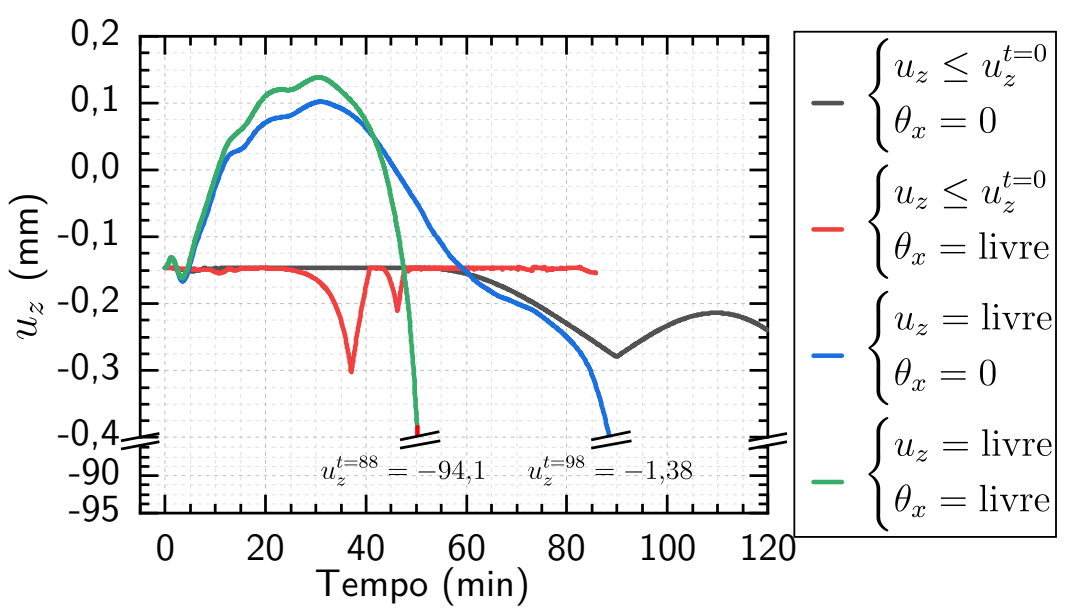

Fonte: $\mathrm{O}$ autor

Figura B.4 - Momento $M_{x}$ na chapa da Face $+\mathrm{Z}$ - Caso 1

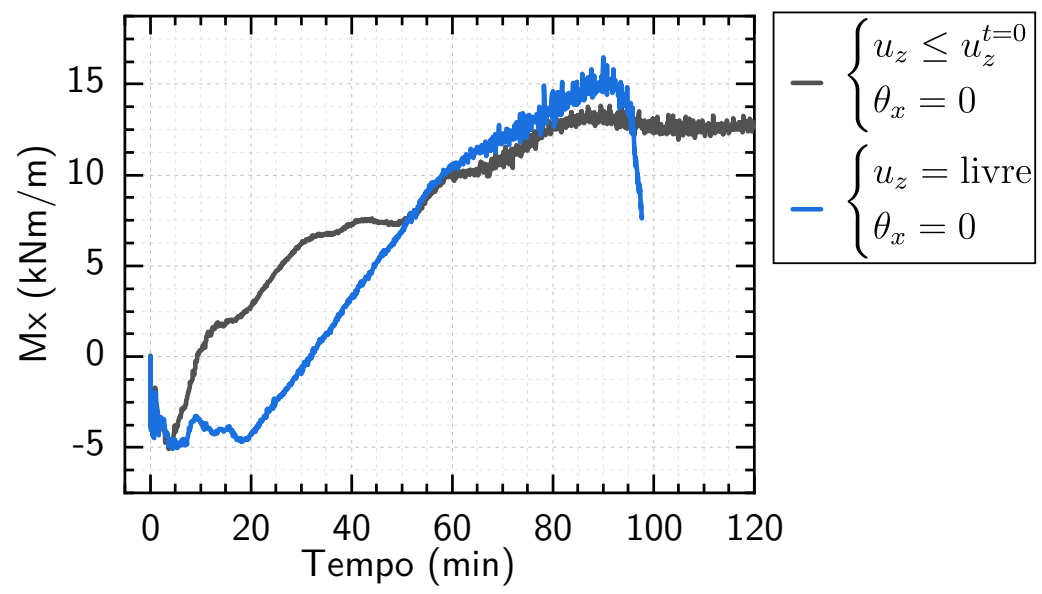

Fonte: $\mathrm{O}$ autor

Figura B.5 - Rotação $\theta_{x}$ na chapa da Face $+\mathrm{Z}$ - Caso 1

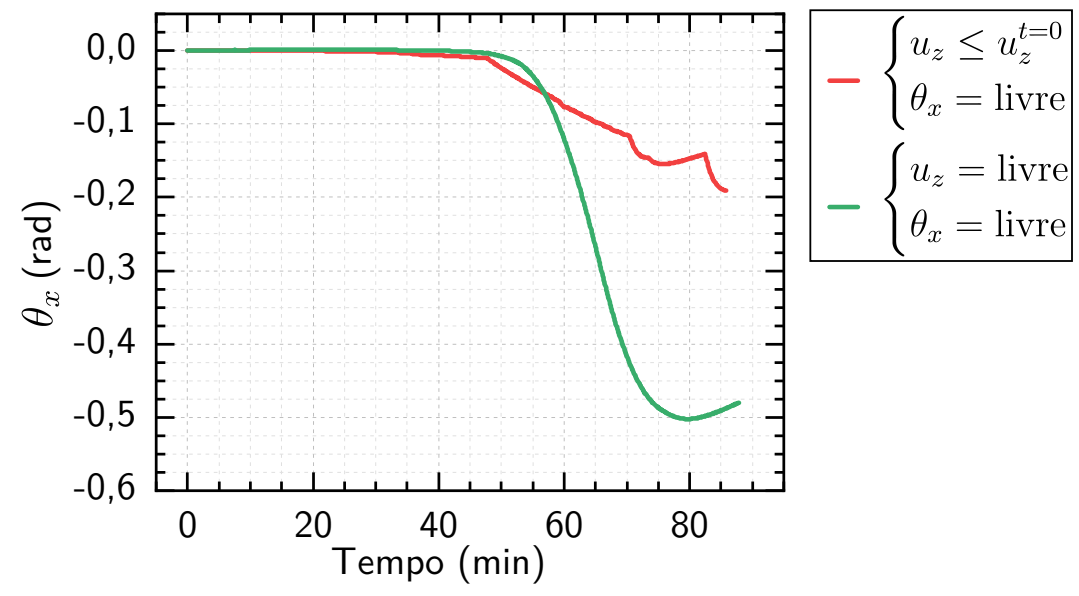

Fonte: $\mathrm{O}$ autor 
Figura B.6 - Dano no painel de alvenaria submetido a incêndio para diferentes condições de contorno na chapa de carregamento $($ Face $+\mathrm{Z})$. Caso $1-$ Faces $+\mathrm{X}$ e $-\mathrm{X}$ livres

(a) Dano a tração. Face $+\mathrm{Z}: u_{z} \leq u_{z}^{t=0} \mathrm{e}$ $\theta_{x}=0 . t=48 \mathrm{~min}$

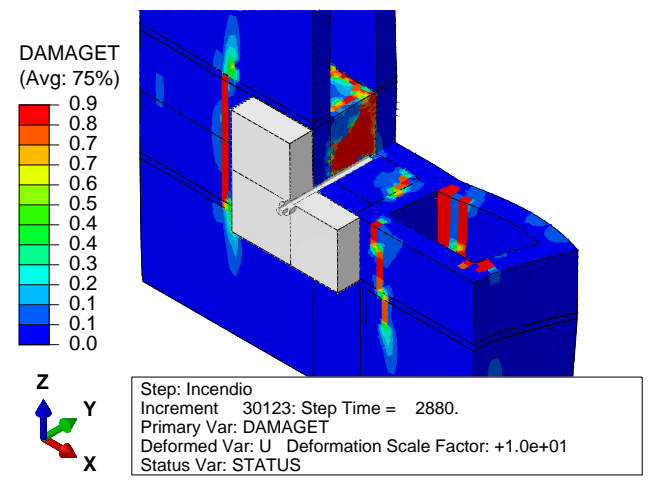

(c) Dano a tração. Face $+\mathrm{Z}: u_{z} \leq u_{z}^{t=0} \mathrm{e}$ $\theta_{x}=$ livre. $t=40 \mathrm{~min}$

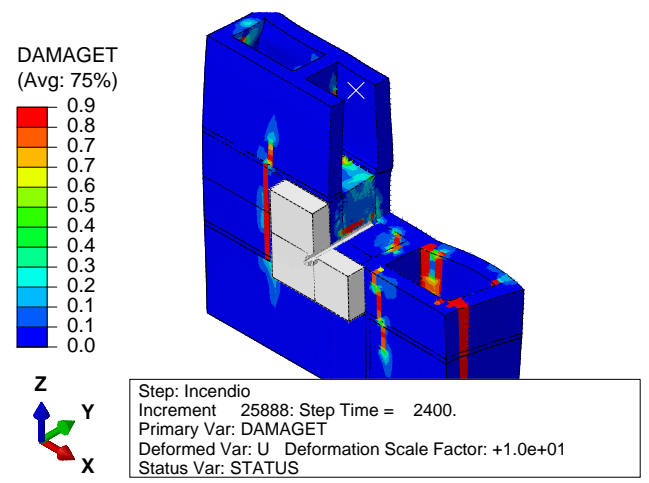

(e) Dano a tração. Face $+\mathrm{Z}: u_{z}=$ livre e $\theta_{x}=0 . t=88 \mathrm{~min}$

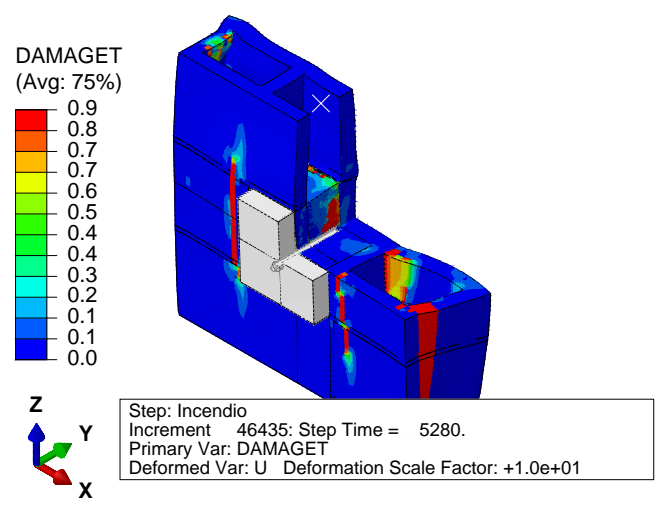

(b) Dano a compressão. Face +Z: $u_{z} \leq u_{z}^{t=0} \mathrm{e}$ $\theta_{x}=0 . t=48 \mathrm{~min}$

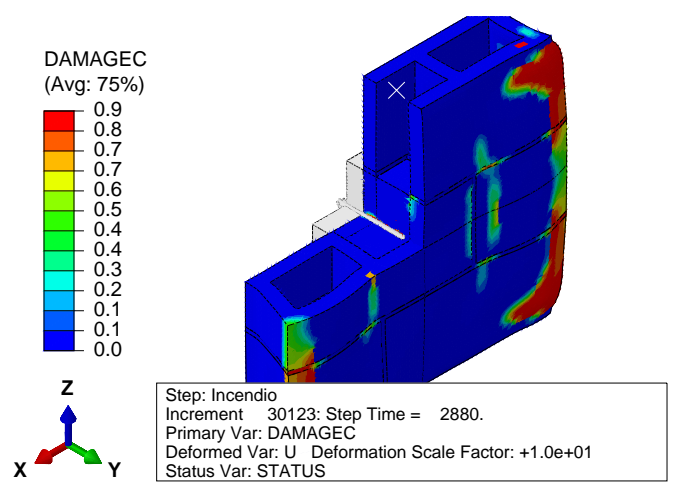

(d) Dano a compressão. Face $+\mathrm{Z}: u_{z} \leq u_{z}^{t=0} \mathrm{e}$ $\theta_{x}=$ livre. $t=40 \mathrm{~min}$

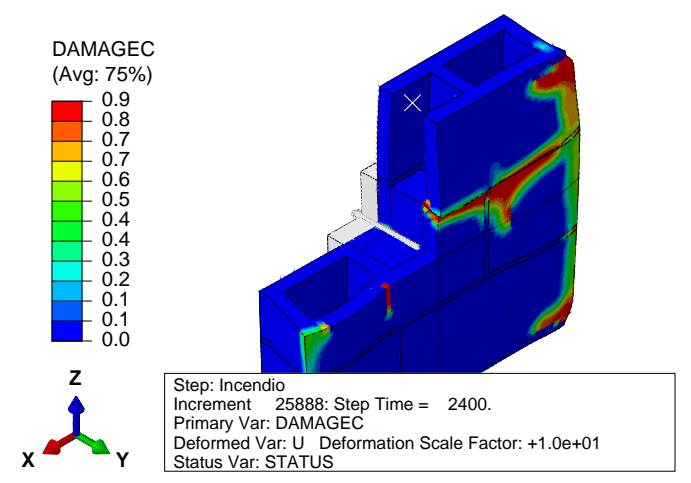

(f) Dano a compressão. Face $+\mathrm{Z}: u_{z}=$ livre e $\theta_{x}=0 . t=88 \mathrm{~min}$

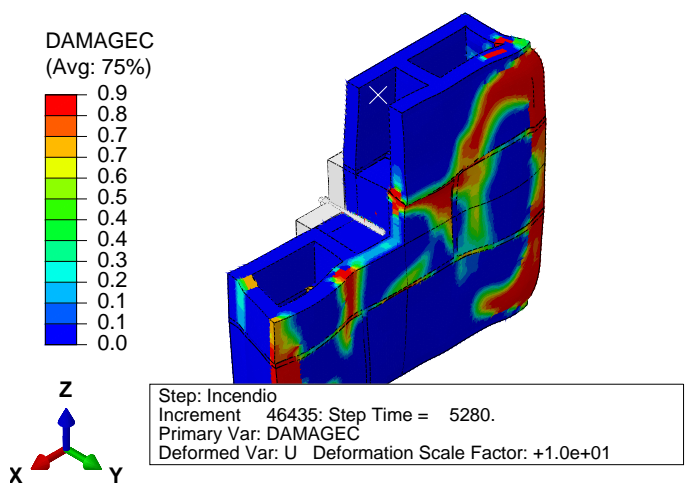

Continua... 
Figura B.6 - Dano no painel de alvenaria submetido a incêndio para diferentes condições de contorno na chapa de carregamento $($ Face $+\mathrm{Z})$. Caso $1-$ Faces $+\mathrm{X}$ e $-\mathrm{X}$ livres (Continuação)

(g) Dano a tração. Face $+\mathrm{Z}: u_{z}=$ livre e $\theta_{x}=$ livre. $t=56 \mathrm{~min}$

(h) Dano a compressão. Face $+\mathrm{Z}: u_{z}=$ livre e

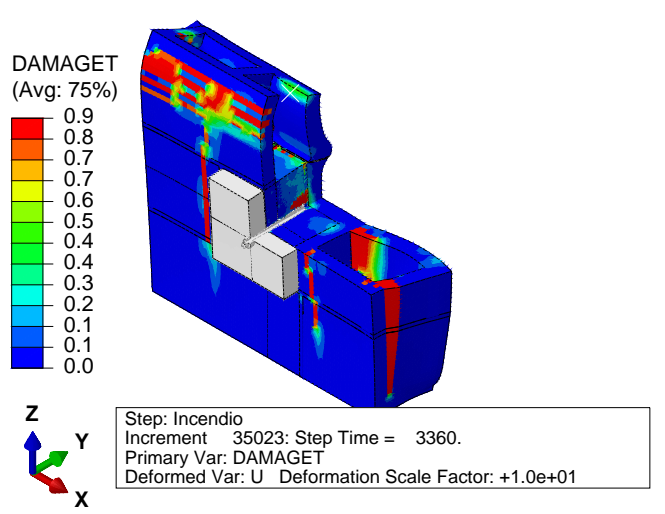
$\theta_{x}=$ livre. $t=56 \mathrm{~min}$

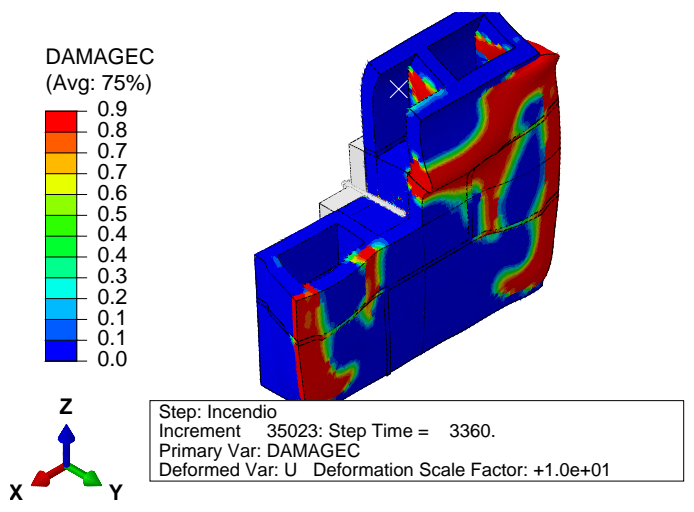

Nota: Seção transversal passando pelo chumbador. Deslocamentos exagerados para permitir sua vizualização. Fonte: O autor.

\section{B.2 Caso 2 - Faces $+\mathrm{X}$ e $-\mathrm{X}$ restritas}

Figura B.7 - Deslocamento $u_{z}$ da chapa do chumbador - Caso 2

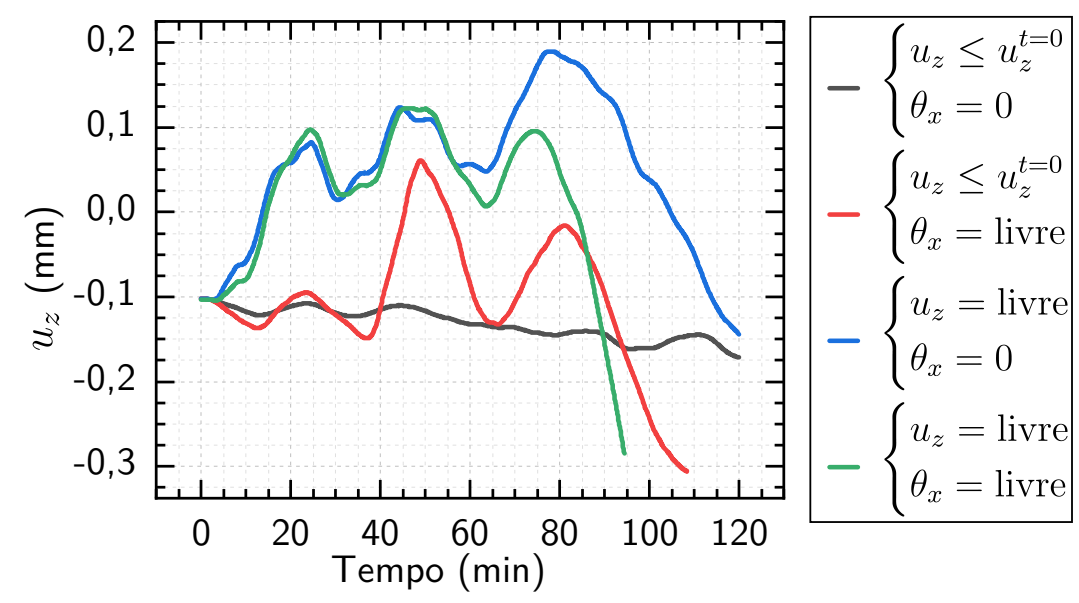

Fonte: $\mathrm{O}$ autor 
Figura B.8 - Tensão $\sigma_{z}$ na área bruta da Face -Z - Caso 2

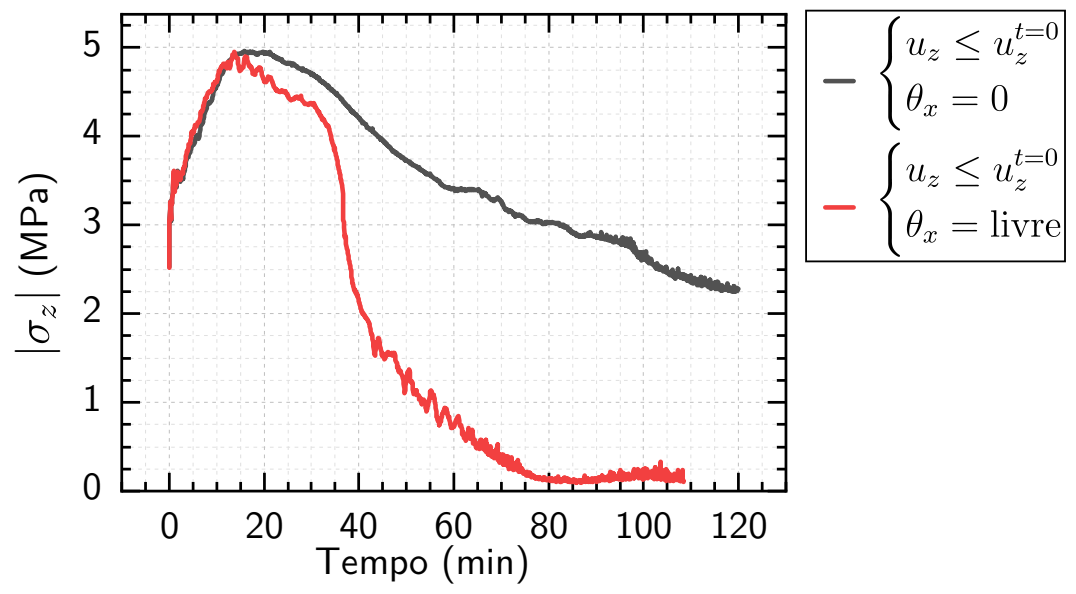

Fonte: $\mathrm{O}$ autor

Figura B.9 - Deslocamento $u_{z}$ na chapa da Face $+\mathrm{Z}$ - Caso 2

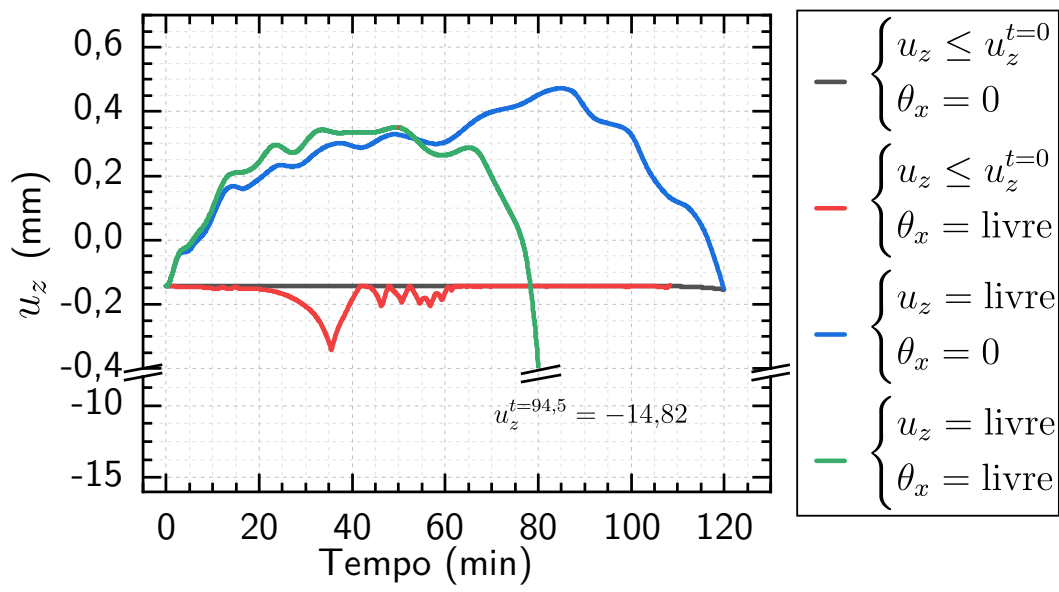

Fonte: $\mathrm{O}$ autor

Figura B.10 - Momento $M_{x}$ na chapa da Face $+\mathrm{Z}$ - Caso 2

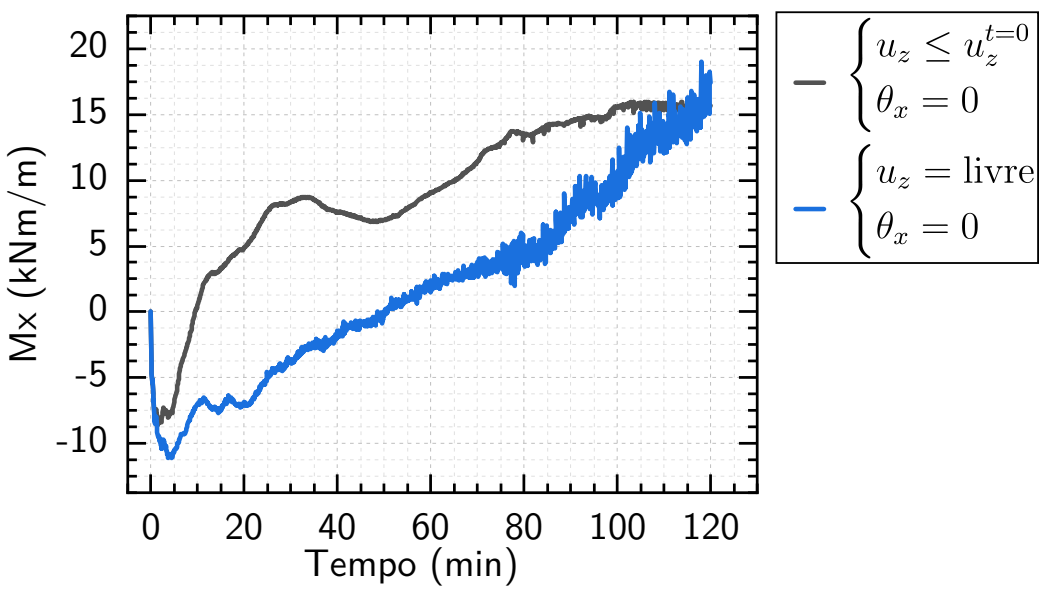

Fonte: O autor 
Figura B.11 - Rotação $\theta_{x}$ na chapa da Face +Z - Caso 2

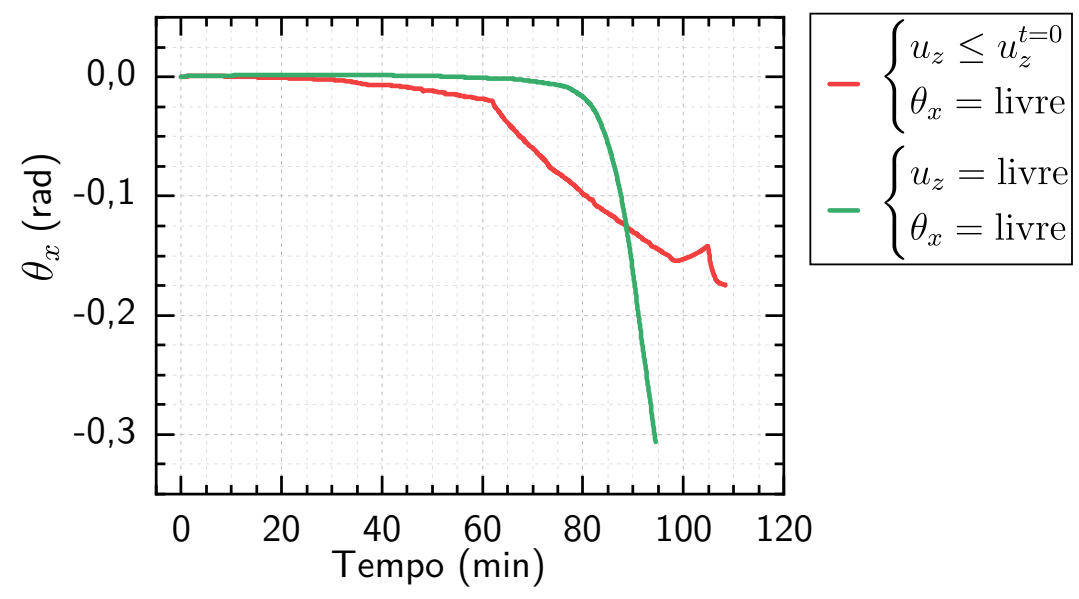

Fonte: $\mathrm{O}$ autor

Figura B.12 - Tensão $\sigma_{x}$ na área bruta da Face $+\mathrm{X}$ - Caso 2

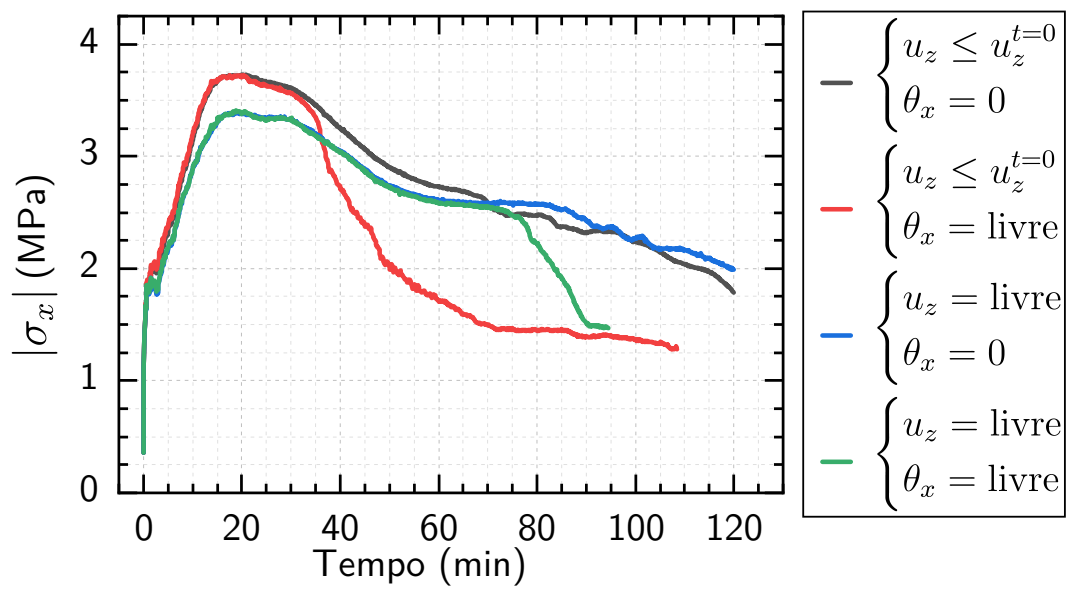

Fonte: $\mathrm{O}$ autor

Figura B.13 - Momento $M_{z}$ na chapa da Face $+\mathrm{X}$ - Caso 2

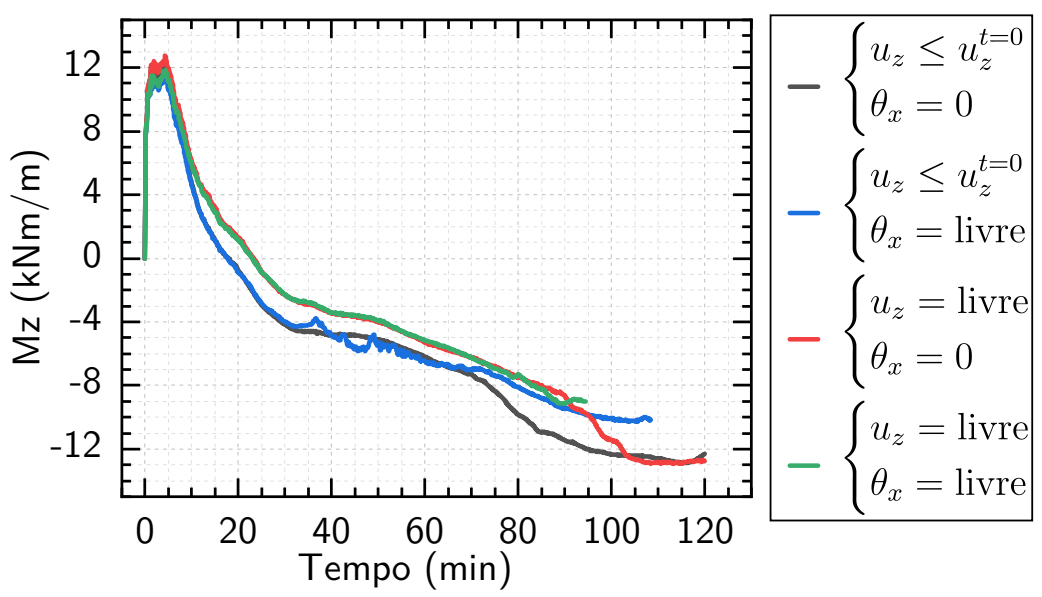

Fonte: $\mathrm{O}$ autor 
Figura B.14 - Dano no painel de alvenaria submetido a incêndio para diferentes condições de contorno na chapa de carregamento $($ Face $+\mathrm{Z})$. Caso 2 - Faces $+\mathrm{X}$ e $-\mathrm{X}$ restritas

(a) Dano a tração. Face $+\mathrm{Z}: u_{z} \leq u_{z}^{t=0} \mathrm{e}$ $\theta_{x}=0 . t=104 \mathrm{~min}$

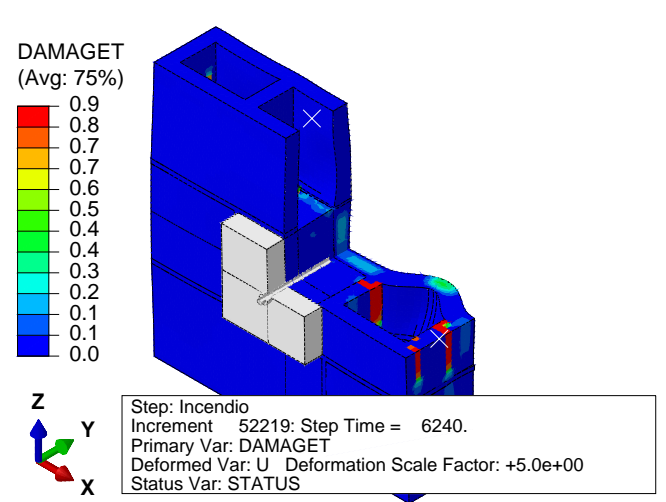

(c) Dano a tração. Face $+\mathrm{Z}: u_{z} \leq u_{z}^{t=0} \mathrm{e}$ $\theta_{x}=$ livre. $t=40 \mathrm{~min}$

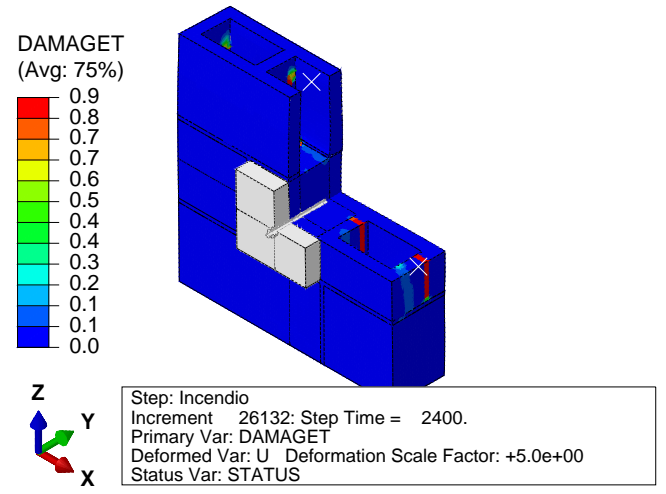

(e) Dano a tração. Face $+\mathrm{Z}: u_{z}=$ livre e $\theta_{x}=0 . t=120 \mathrm{~min}$

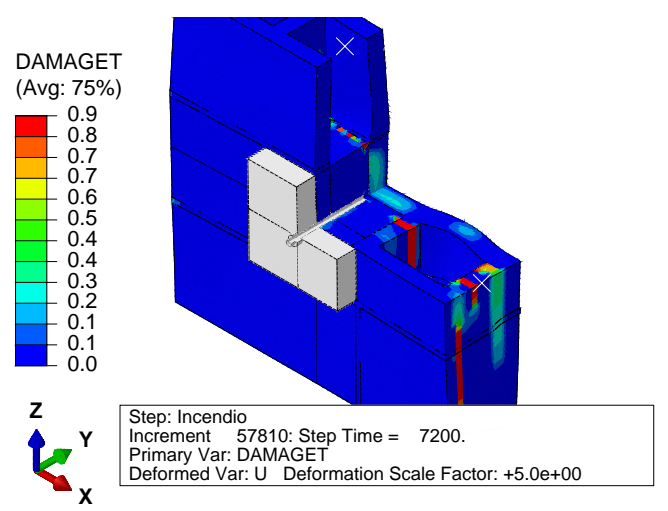

(b) Dano a compressão. Face $+\mathrm{Z}: u_{z} \leq u_{z}^{t=0} \mathrm{e}$ $\theta_{x}=0 . t=104 \mathrm{~min}$

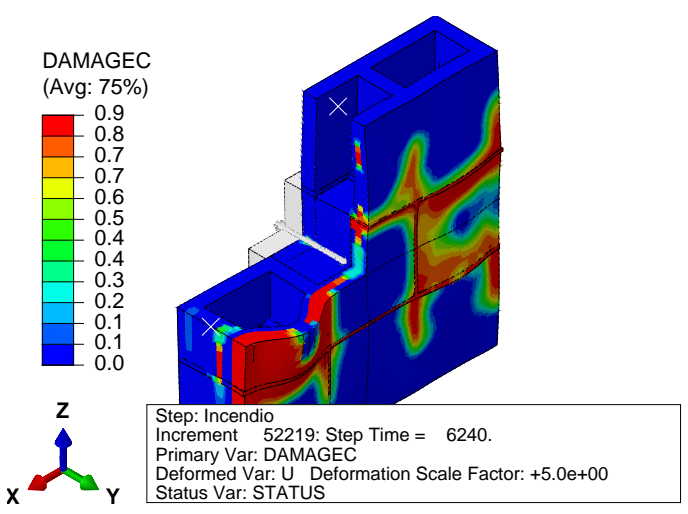

(d) Dano a compressão. Face $+\mathrm{Z}: u_{z} \leq u_{z}^{t=0} \mathrm{e}$ $\theta_{x}=$ livre. $t=40 \mathrm{~min}$

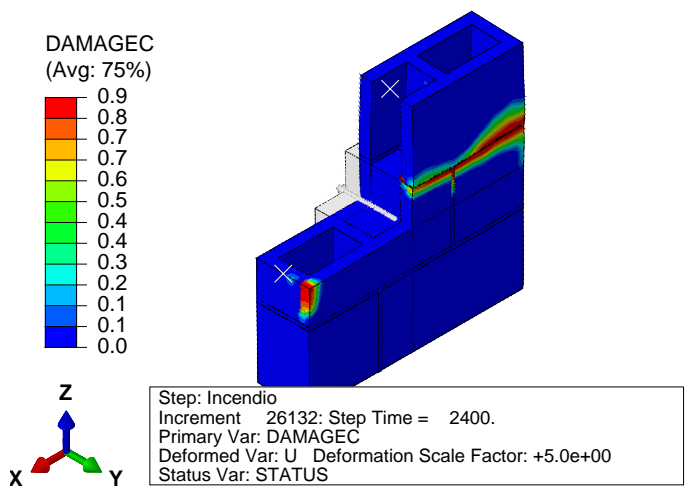

(f) Dano a compressão. Face $+\mathrm{Z}: u_{z}=$ livre e $\theta_{x}=0 . t=120 \mathrm{~min}$

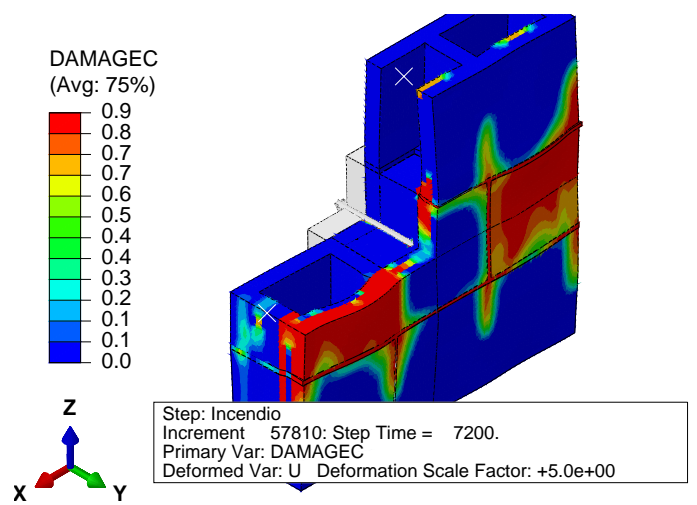

Continua... 
Figura B.14 - Dano no painel de alvenaria submetido a incêndio para diferentes condições de contorno na chapa de carregamento $($ Face $+\mathrm{Z})$. Caso 2 - Faces $+\mathrm{X}$ e $-\mathrm{X}$ restritas (Continuação)

(g) Dano a tração. Face + Z: $u_{z}=$ livre e $\theta_{x}=$ livre. $t=84 \mathrm{~min}$

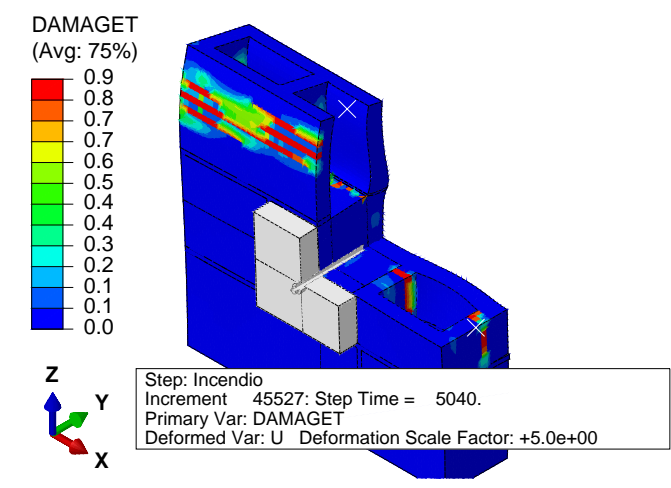

(h) Dano a compressão. Face + Z: $u_{z}=$ livre e $\theta_{x}=$ livre. $t=84 \mathrm{~min}$

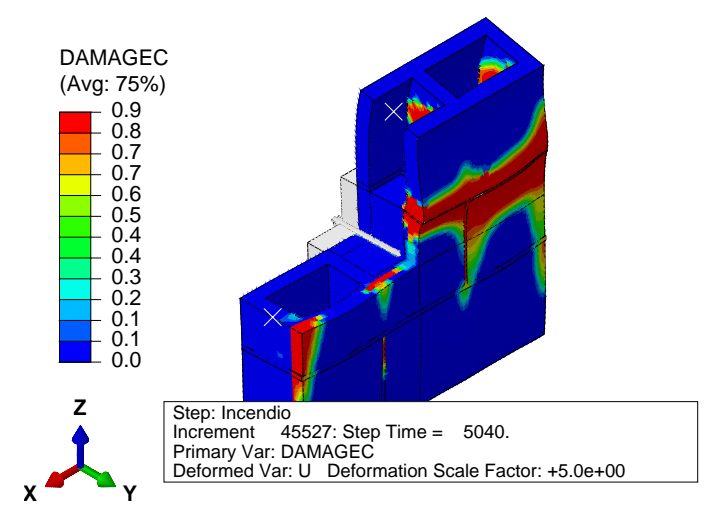

Nota: Seção transversal passando pelo chumbador. Deslocamentos exagerados para permitir sua vizualização. Fonte: O autor.

\section{B.3 Caso 3 - Face $+\mathrm{X}$ restrita e Face $-\mathrm{X}$ livre}

Figura B.15 - Deslocamento $u_{z}$ da chapa do chumbador - Caso 3

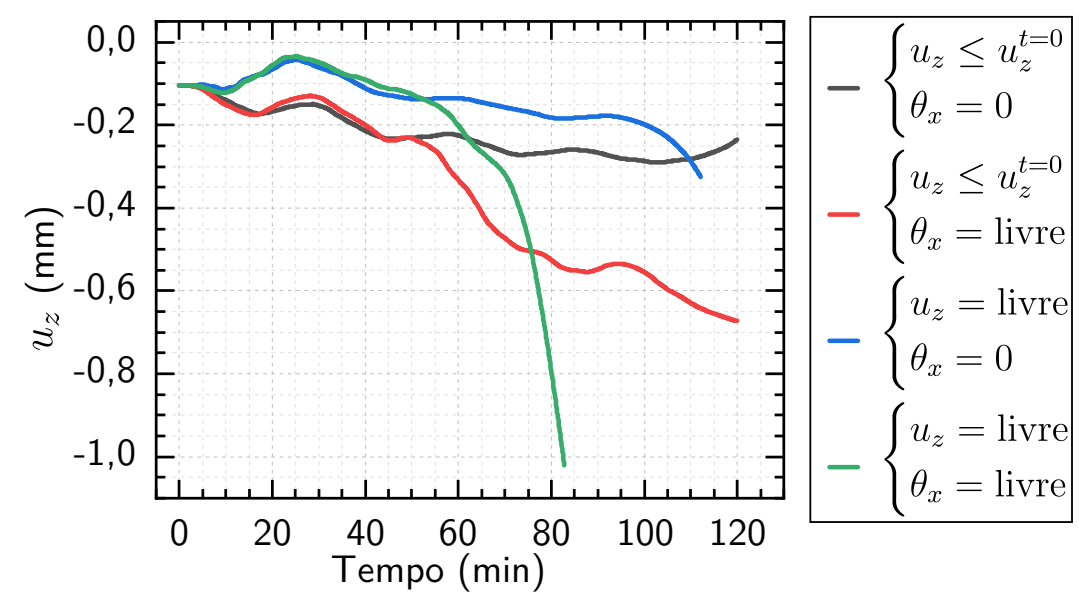

Fonte: $\mathrm{O}$ autor 
Figura B.16 - Tensão $\sigma_{z}$ na área bruta da Face -Z - Caso 3

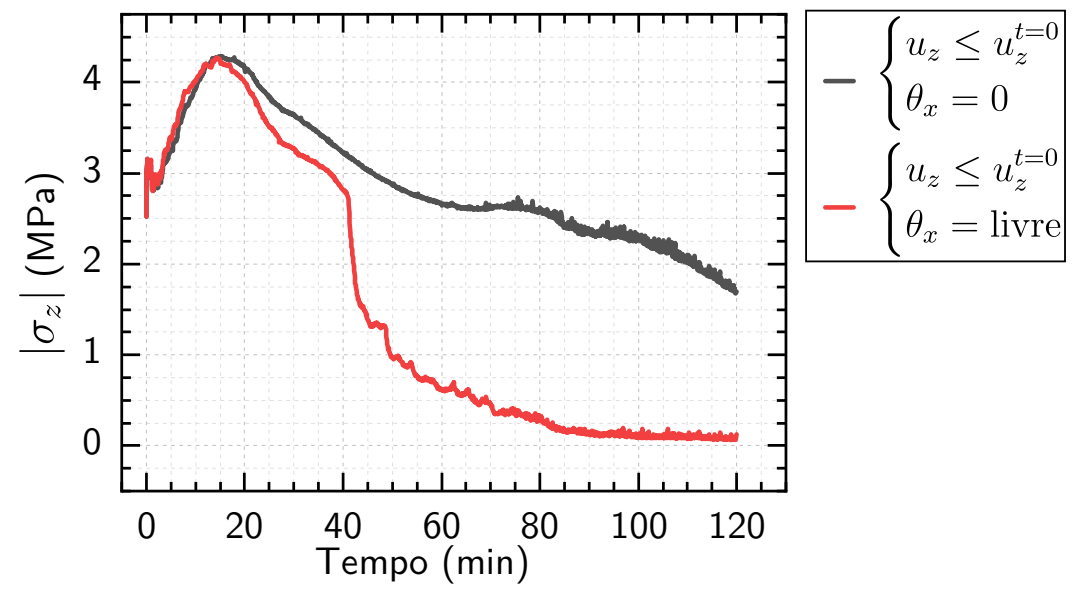

Fonte: $\mathrm{O}$ autor

Figura B.17 - Deslocamento $u_{z}$ na chapa da Face $+\mathrm{Z}$ - Caso 3

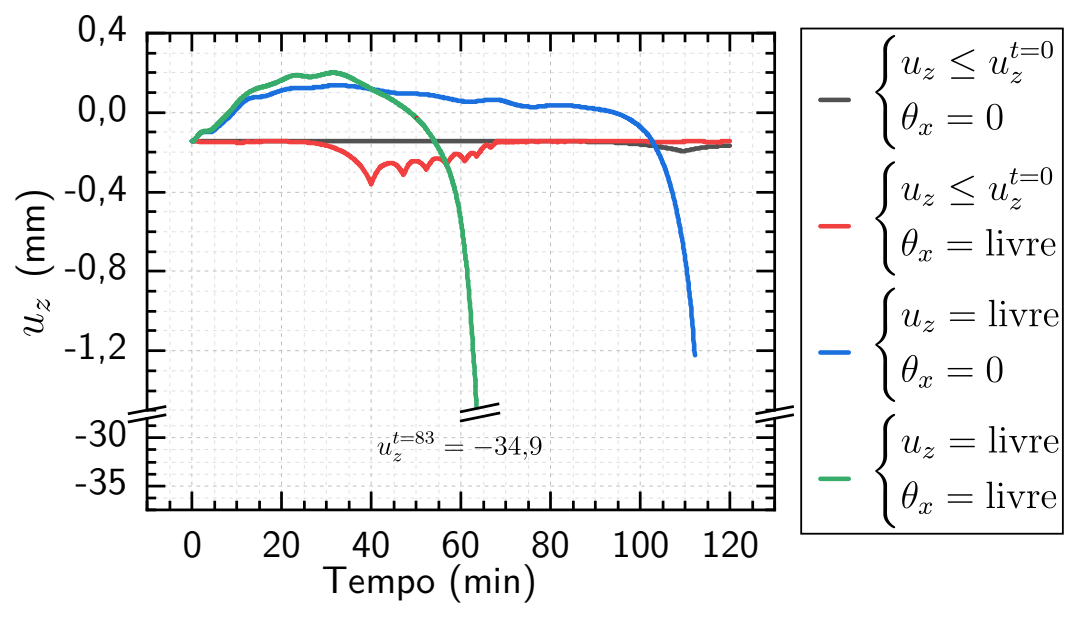

Fonte: $\mathrm{O}$ autor

Figura B.18 - Momento $M_{x}$ na chapa da Face $+\mathrm{Z}$ - Caso 3

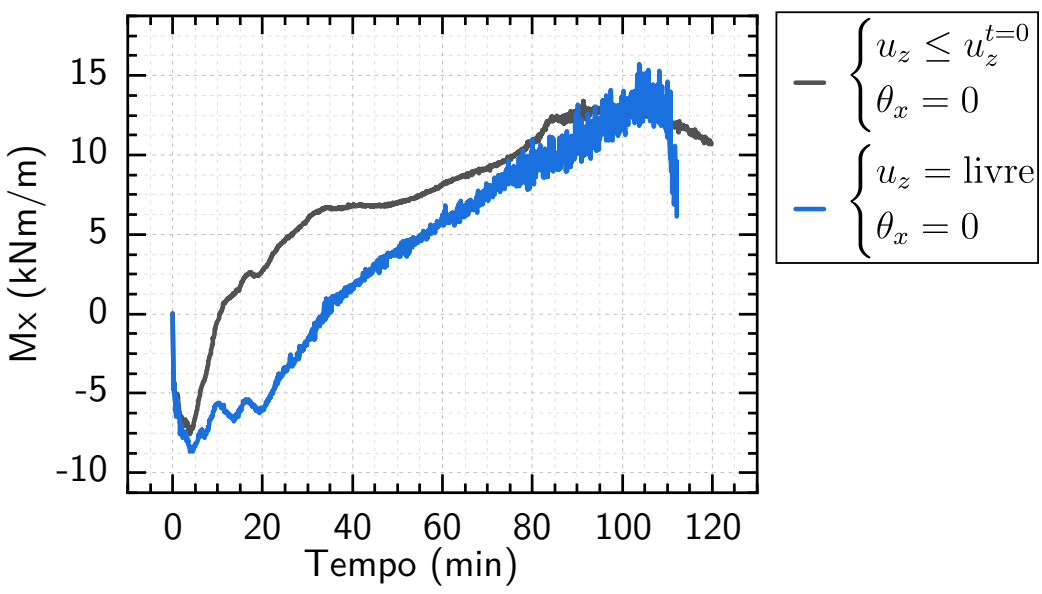

Fonte: O autor 
Figura B.19 - Rotação $\theta_{x}$ na chapa da Face + Z - Caso 3

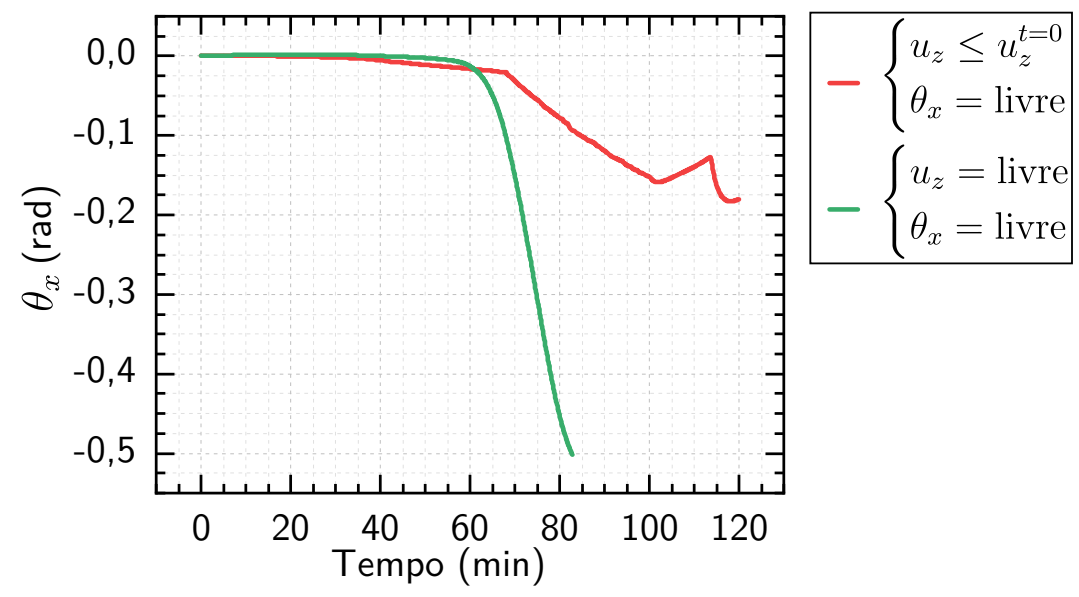

Fonte: $\mathrm{O}$ autor

Figura B.20 - Tensão $\sigma_{x}$ na área bruta da Face $+\mathrm{X}$ - Caso 3

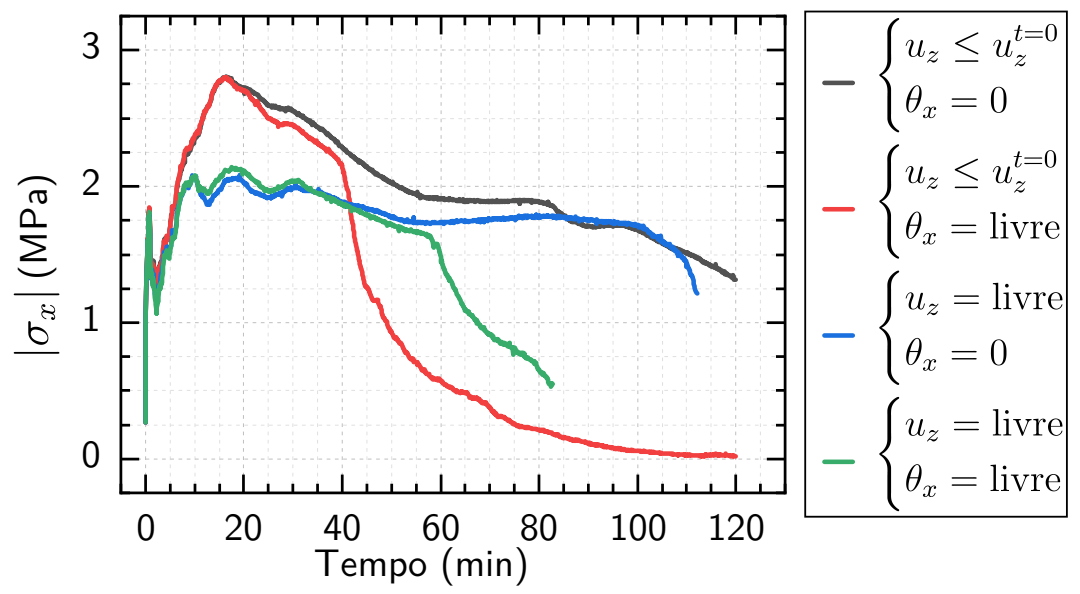

Fonte: $\mathrm{O}$ autor

Figura B.21 - Momento $M_{z}$ na chapa da Face $+\mathrm{X}$ - Caso 3

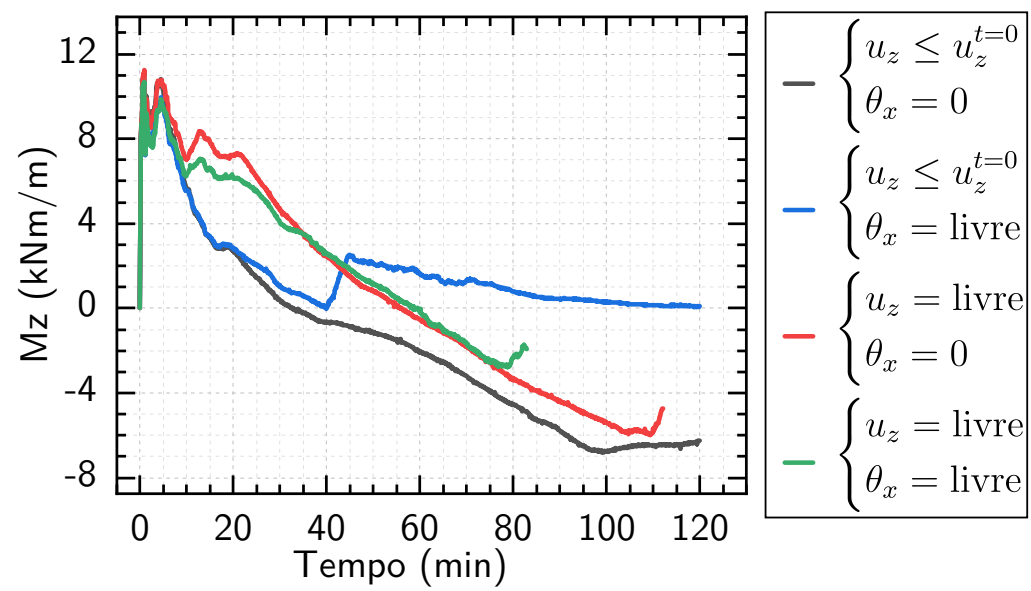

Fonte: $\mathrm{O}$ autor 
Figura B.22 - Dano no painel de alvenaria submetido a incêndio para diferentes condições de contorno na chapa de carregamento $($ Face $+\mathrm{Z})$. Caso 3 - Face $+\mathrm{X}$ restrita e Face -X livre

(a) Dano a tração. Face $+\mathrm{Z}: u_{z} \leq u_{z}^{t=0} \mathrm{e}$ $\theta_{x}=0 . t=84 \mathrm{~min}$

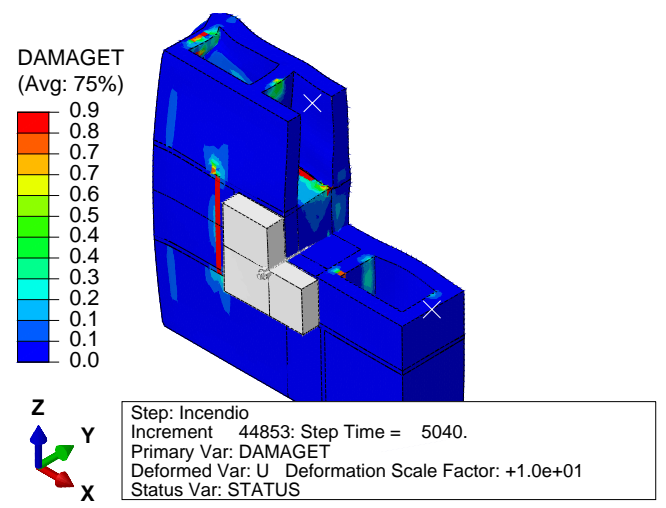

(c) Dano a tração. Face $+\mathrm{Z}: u_{z} \leq u_{z}^{t=0} \mathrm{e}$ $\theta_{x}=$ livre. $t=44 \mathrm{~min}$

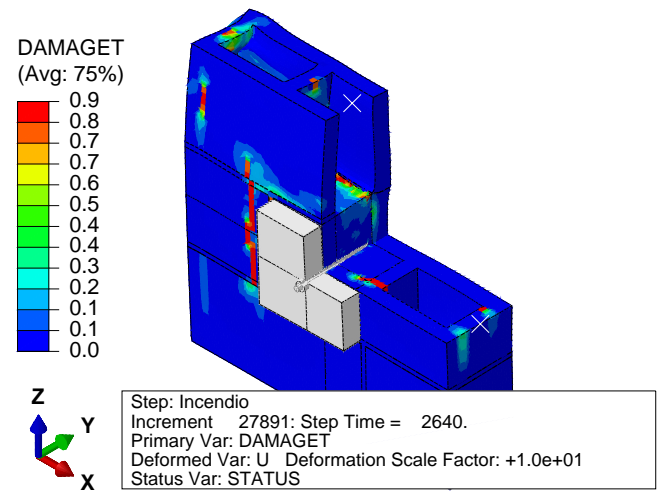

(e) Dano a tração. Face $+\mathrm{Z}: u_{z}=$ livre e $\theta_{x}=0 . t=100 \mathrm{~min}$

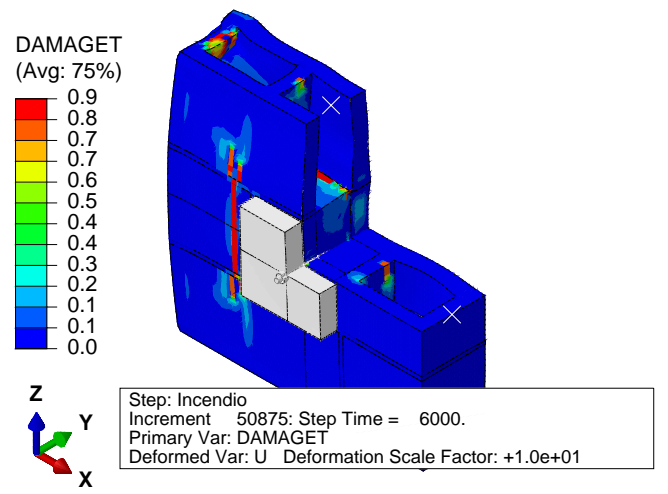

(b) Dano a compressão. Face +Z: $u_{z} \leq u_{z}^{t=0} \mathrm{e}$ $\theta_{x}=0 . t=84 \mathrm{~min}$

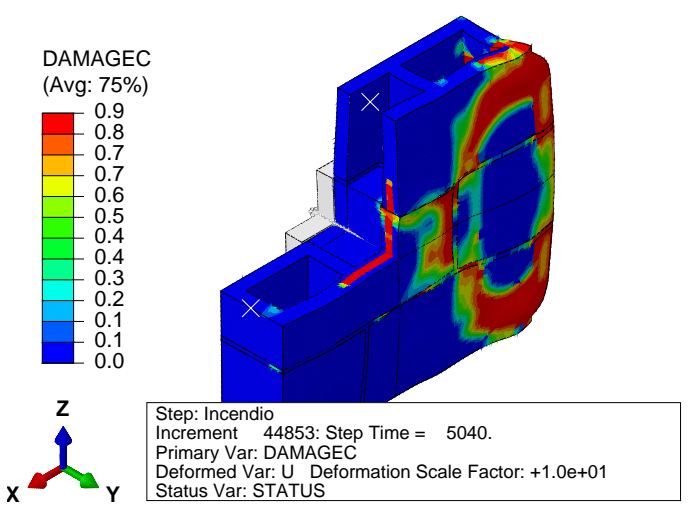

(d) Dano a compressão. Face $+\mathrm{Z}: u_{z} \leq u_{z}^{t=0} \mathrm{e}$ $\theta_{x}=$ livre. $t=44 \mathrm{~min}$

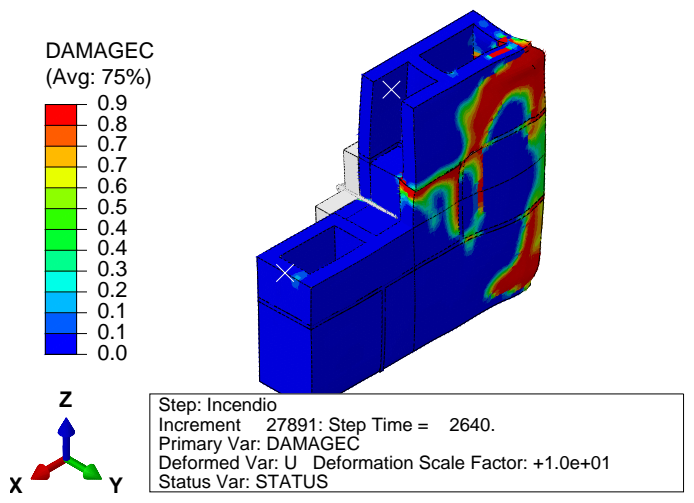

(f) Dano a compressão. Face $+\mathrm{Z}: u_{z}=$ livre e $\theta_{x}=0 . t=100 \mathrm{~min}$

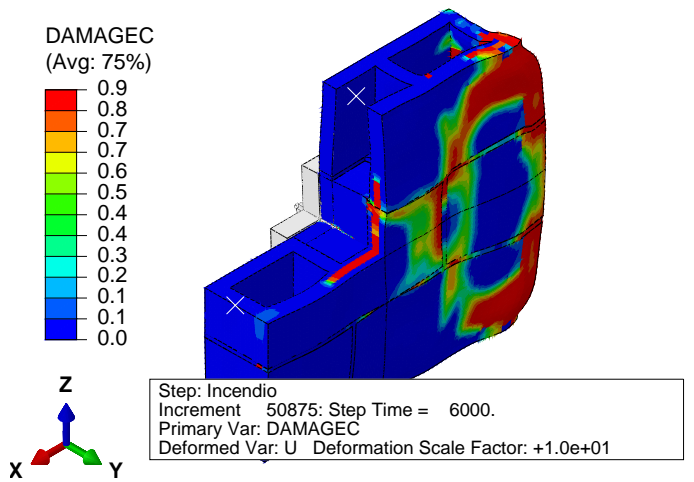

Continua... 
Figura B.22 - Dano no painel de alvenaria submetido a incêndio para diferentes condições de contorno na chapa de carregamento $($ Face $+\mathrm{Z})$. Caso $3-$ Face $+\mathrm{X}$ restrita e Face -X livre (Continuação)

(g) Dano a tração. Face + Z: $u_{z}=$ livre e $\theta_{x}=$ livre. $t=60 \mathrm{~min}$

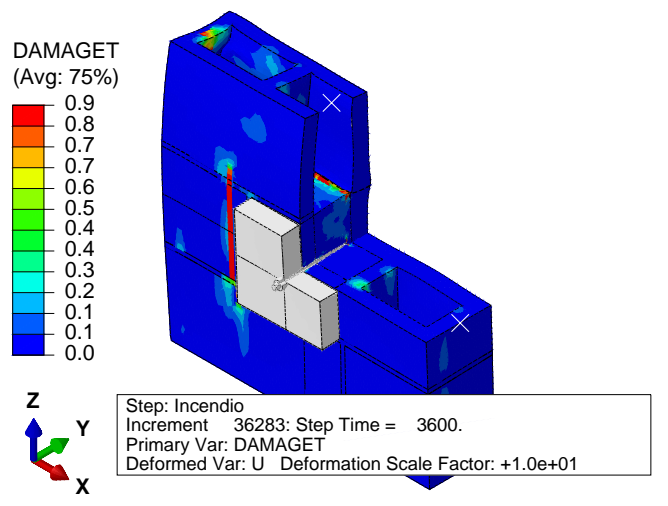

(h) Dano a compressão. Face + Z: $u_{z}=$ livre e $\theta_{x}=$ livre. $t=60 \mathrm{~min}$

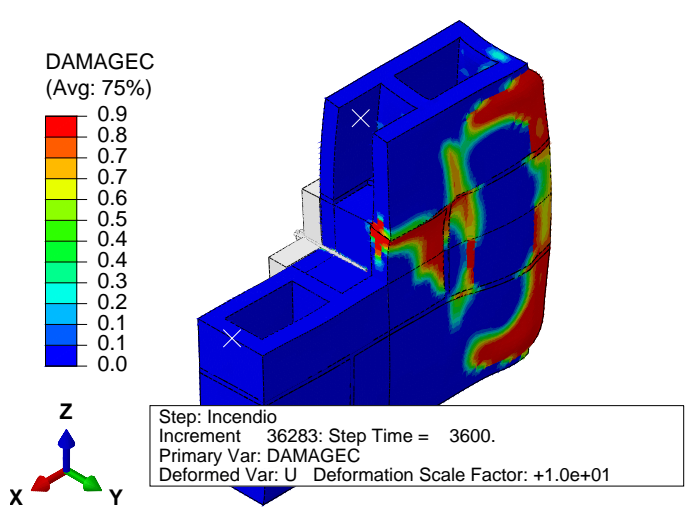

Nota: Seção transversal passando pelo chumbador. Deslocamentos exagerados para permitir sua vizualização. Fonte: O autor. 


\section{APÊNDICE C - CUSTO COMPUTACIONAL DAS SIMULAÇÕES}

Abaixo segue uma tabela com uma descrição básica das simulações. Foi utilizado PC equipado com processador Intel(R) Core(TM) i7-7700 CPU @ 3,60GHz, 4 Núcleo(s), 8 Processador(es) Lógico(s) e Memória RAM DDR4 16 GB. Cada linha da tabela representa uma simulação realizada onde foram consideradas diferentes propriedades dos materiais ou condições de contorno. Detalhes dos modelos podem ser encontrados no corpo da dissertação.

Tabela C.1 - Tempo computacional das simulações realizadas

\begin{tabular}{|c|c|c|c|}
\hline Breve descrição & № de variáveis & $\begin{array}{l}\text { Memória RAM } \\
\text { necessária para } \\
\text { minimizar E/S }\end{array}$ & $\begin{array}{c}\text { Tempo } \\
\text { computacional }\end{array}$ \\
\hline \multirow{9}{*}{$\begin{array}{c}\text { Estrutural - Chumbador } 12 \text { mm } \\
\text { (Seção 3.1) }\end{array}$} & 117422 & 266,6 & $00: 18: 35$ \\
\hline & 117422 & 266,6 & $00: 18: 27$ \\
\hline & 117422 & 266,6 & $00: 18: 27$ \\
\hline & 117422 & 266,6 & 00:18:29 \\
\hline & 117423 & 266,6 & 00:18:22 \\
\hline & 117424 & 266,6 & $00: 37: 24$ \\
\hline & 117425 & 260,4 & $00: 15: 54$ \\
\hline & 117426 & 260,4 & 00:16:08 \\
\hline & 117427 & 260,4 & $00: 16: 25$ \\
\hline \multirow{9}{*}{$\begin{array}{c}\text { Estrutural - Chumbador } 16 \text { mm } \\
\text { (Seção 3.1) }\end{array}$} & 137414 & 237,1 & $00: 13: 33$ \\
\hline & 137415 & 237,1 & $00: 13: 51$ \\
\hline & 137416 & 237,1 & $00: 13: 47$ \\
\hline & 137417 & 234,3 & 00:13:31 \\
\hline & 137418 & 234,3 & $00: 26: 54$ \\
\hline & 137419 & 234,3 & $00: 13: 47$ \\
\hline & 137420 & 234,3 & $00: 13: 45$ \\
\hline & 137421 & 234,3 & $00: 27: 45$ \\
\hline & 137422 & 234,3 & $00: 27: 41$ \\
\hline $\begin{array}{l}\text { Estrutural - Viga denteada } \\
\text { (Seção 3.2) }\end{array}$ & 281972 & 634,3 & $02: 22: 11$ \\
\hline
\end{tabular}


Tabela C.1 - Tempo computacional das simulações realizadas

\begin{tabular}{|c|c|c|c|}
\hline Breve descrição & № de variáveis & $\begin{array}{l}\text { Memória RAM } \\
\text { necessária para } \\
\text { minimizar E/S }\end{array}$ & $\begin{array}{c}\text { Tempo } \\
\text { computacional }\end{array}$ \\
\hline \multirow{6}{*}{$\begin{array}{l}\text { Estrutural - Painel de Alvenaria } \\
\text { (Seção 3.3) }\end{array}$} & 306618 & 673,7 & $01: 48: 34$ \\
\hline & 306618 & 673,7 & $02: 16: 14$ \\
\hline & 307410 & 681,6 & 01:48:07 \\
\hline & 307410 & 681,6 & 02:08:26 \\
\hline & 307014 & 706,5 & 01:48:04 \\
\hline & 307014 & 706,5 & $02: 13: 27$ \\
\hline $\begin{array}{l}\text { Térmico - Bloco, dupla simetria } \\
\text { acoplado sólido-fluido (Seção 4.1) }\end{array}$ & 8988 + fluido & 171 & $00: 36: 42$ \\
\hline \multirow{4}{*}{$\begin{array}{l}\text { Térmico - Bloco, dupla simetria } \\
\text { apenas sólido (Seção 4.1) }\end{array}$} & 8988 & 171 & 00:01:40 \\
\hline & 8988 & 171 & 00:01:41 \\
\hline & 8988 & 171 & 00:01:41 \\
\hline & 8988 & 48 & 00:00:41 \\
\hline $\begin{array}{l}\text { Térmico - Bloco, simetria simples } \\
\text { acoplado sólido-fluido (Seção 4.1) }\end{array}$ & 17443 + fluido & 496 & $06: 47: 34$ \\
\hline \multirow{2}{*}{$\begin{array}{l}\text { Térmico - Bloco, simetria simples } \\
\text { apenas sólido (Seção 4.1) }\end{array}$} & 17443 & 496 & 00:07:29 \\
\hline & 20721 & 549 & 00:08:05 \\
\hline $\begin{array}{l}\text { Térmico - Painel de alvenaria } \\
\text { (Seção 4.2) }\end{array}$ & 105656 & 2229 & $00: 14: 48$ \\
\hline $\begin{array}{l}\text { Térmico - Painel de alvenaria } \\
\text { malha refinada }\end{array}$ & 338429 & 15241 & $02: 56: 15$ \\
\hline \multirow{11}{*}{$\begin{array}{l}\text { Termoestrutural - Painel de alvenaria } \\
\text { (Seção 5) }\end{array}$} & 306629 & 674,3 & 01:14:06 \\
\hline & 306629 & 674,3 & 01:03:16 \\
\hline & 306618 & 673,8 & 01:07:48 \\
\hline & 306618 & 673,8 & 01:04:54 \\
\hline & 307421 & 684 & 01:09:26 \\
\hline & 307421 & 684 & 01:05:07 \\
\hline & 307410 & 681,7 & 01:07:20 \\
\hline & 307410 & 681,7 & 01:00:12 \\
\hline & 307025 & 708,7 & $01: 17: 34$ \\
\hline & 307025 & 708,7 & $01: 17: 56$ \\
\hline & 307014 & 706,6 & 01:14:30 \\
\hline
\end{tabular}


Tabela C.1 - Tempo computacional das simulações realizadas

\begin{tabular}{cccc}
\hline Breve descrição & & $\begin{array}{c}\text { Memória RAM } \\
\text { No de variáveis } \\
\text { minimizar E/S }\end{array}$ & $\begin{array}{c}\text { Tempo } \\
\text { computacional }\end{array}$ \\
\hline 307014 & 706,6 & $01: 03: 27$ \\
\hline
\end{tabular}

